\title{
JOB SATISFACTION OF SAUDI NURSES WORKING IN SAUDI ARABIAN PUBLIC HOSPITALS
}

\author{
Submitted in Total Fulfilment for the Degree of \\ Doctor of Philosophy $(\mathrm{PhD})$ \\ by \\ Mohammed Saleh Alshmemri \\ BSN, Jordan University \\ MSN, Royal Melbourne Institute of Technology University
}

March 2014

SCHOOL OF HEALTH SCIENCES

DISCIPLINE OF NURSING AND MIDWIFERY

Royal Melbourne Institute of Technology University

Melbourne, Australia 


\begin{abstract}
This research study explored the job satisfaction levels of Saudi national nurses working in three main public hospitals in the Makkah region of Saudi Arabia in order to identify the factors that positively influence levels of job satisfaction among Saudi nurses.

This descriptive, exploratory cross-sectional study used a mixed-method design to capture the job satisfaction levels of Saudi nurses to inform the decisions of Saudi policymakers and assist them in developing long-term sustainable strategies to recruit and retain national nurses to service the Saudi healthcare delivery system. Quantitative and qualitative data were collected and analysed to explore and determine the factors that influence job satisfaction in Saudi nurses working in three public hospitals in the Makkah region of Saudi Arabia. Data were collected in two phases. In the first phase 272 nurses were surveyed to identify which factors they believed led to job satisfaction in public hospitals. The second phase consisted of face-to-face interviews with 17 female and male Saudi nurses; to explore and identify in greater depth the factors they perceived as most important in providing them with positive feelings and leading to job satisfaction in their nursing field. Quantitative data were analysed through the Statistical Package for the Social Sciences (SPSS, V18.0); descriptive and inferential statistical tests were utilised. Qualitative data were analysed with a thematic approach, using NVivo 9® qualitative analysis software.
\end{abstract}

Saudi nurses must be satisfied with their jobs in order to maintain and retain the national nursing workforce in Saudi Arabia. The Ministry of Health and Healthcare agencies must strategies ways to help reduce the potential for job stress and maintain a level of job satisfaction by decreasing the variables such as work overload, lack of 
control and improving leadership style, that are antecedents to job dissatisfaction. The findings of this study indicate that in general Saudi nurses working in public hospitals were not satisfied with their jobs. The female Saudi nurses were more dissatisfied with their jobs than the male nurses. Nurses who were responsible for dependent adults and who had worked in public hospitals for a period of 5-10 years were dissatisfied with their jobs. Nursing staff with 4-10 years of experience were also not satisfied with their jobs.

It is hoped that these findings will provide insights for Ministry of Health policymakers indicating that nurses' dissatisfaction may influence the recruitment and retention of nurses, and that increasing the number of Saudi nationals who study nursing will alleviate the shortage of nurses and help to bring stability to the nursing workforce in Saudi Arabia, maintaining the efficient functioning of its healthcare system, especially in the public hospitals.

Keywords: nursing job satisfaction; shortage of nurses; turnover; nurses in Saudi Arabia. 


\section{Declaration}

I certify that:

a) Except where due acknowledgement has been made, the work is that of the author alone;

b) The work has not been previously submitted, in whole or in part, to qualify for any other academic award;

c) The content of the thesis is the result of work that has been carried out since the official commencement date of the approved research programme;

d) Any edited work, paid or unpaid, carried out by a third party is acknowledged; and,

e) Ethics procedures and guidelines have been followed.

Mohammed Saleh Alshmemri 


\section{Dedication}

I firstly honour and am eternally grateful to the inspiration of Allah for enabling me to complete this work.

I gratefully dedicate all my achievements including this thesis:

- To my great father, Saleh Alshmemri, and my lovely mother, Jamila Alnameri, who both wished me to have the best of everything, and I thank them for their unconditional love, unlimited care, support and prayers throughout my research and indeed during all my studies.

- To my loving wife, Nuha, for her devotion, endless support and encouragement of my accomplishment during my study towards this thesis.

- To my lovely children, Joud, Abdulmalk, Nawaf and my new baby, Abdullah.

- To all my brothers and sisters, who encouraged me at all times.

- To all my family back home in Saudi Arabia, who encouraged me throughout my studies.

May Allah bless you all. 


\section{Acknowledgements}

I would like first to thank Allah (my God), the Most Gracious, the Most Merciful. All praise be to Allah for helping, guiding, supporting and giving me this chance to study at a higher level of education, and the inspiration, patience, time and strength to accomplish this thesis. Then, Prophet Mohammed (peace be upon him) said 'He who would not be thankful to people, he will not be thankful to Allah' (reported by Ahmed).

I wish to express my sincere and heartfelt thanks to my principal supervisor, Associate Professor Lina Shahwan-Akl, for her guidance, consistent support and encouragement over the past few years. She has always been a 'big sister' and a good communicator and she has been friendly, warm and patient with me as a student. I have not only learned research writing from her, but I have also learned from her organisation, critical thinking, research skills, sincerity, smiling manner and enthusiasm. My mind will keep these qualities forever. I further extend my thanks and gratitude to Associate Professor Phillip Maude, who helped, supported and directed me through the study write-up and did a great deal to help me accomplish this thesis. I have appreciated my supervisors' positive criticism and constructive comments throughout the development of my skills, knowledge and the course of my study. Thank you both for all your hard work with me, and I am so sorry if I cannot thank you as much as you deserve. Further, I thank the RMIT research members, International Office, library staff, all nursing faculty members and administrative staff and the Statistical Consultancy Department at RMIT, especially Dr. Adrian Schembri, for his assistance with the quantitative data analysis.

My greatest appreciation goes to the Ministry of Health in Saudi Arabia, my sponsor, for its financial support, especially the Ministry's Nursing Department. 
Moreover, I am grateful to the Cultural Mission of Saudi Arabia in Australia for their support.

I am thankful to all the nurses working in public hospitals in the Makkah region who gave their valuable time and much effort to participate in this study. I am also grateful to all my colleagues and friends who made helpful suggestions and comments during my $\mathrm{PhD}$ journey in Australia and in Saudi Arabia.

Finally, my special thanks go to all my family members, who have always provided endless encouragement, support and patience, throughout my study and as I worked towards my goals. 


\section{Table of Contents}

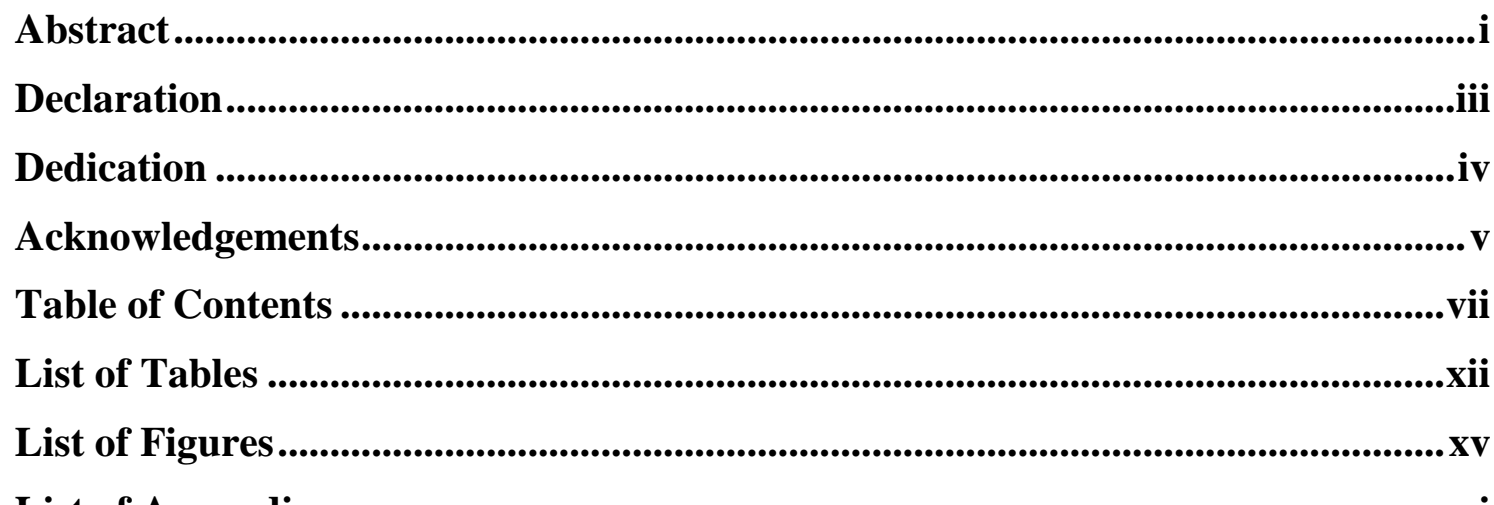

List of Appendices .....................................................................................................................

List of Abbreviations ....................................................................................................xvii

Chapter 1: Introduction and Overview .........................................................................1

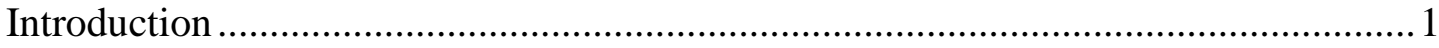

The Nursing Workforce in Saudi Arabia ..................................................................

The History of Nursing in Saudi Arabia ..................................................................

Context and Background of the Study ....................................................................

History of Saudi Arabia. .......................................................................................

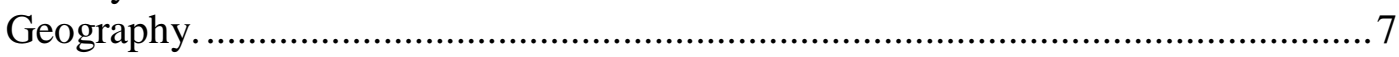

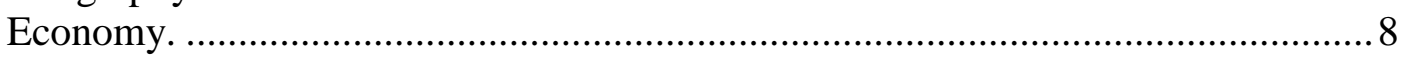

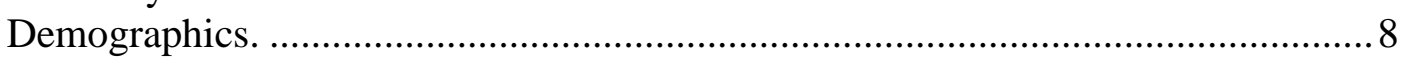

Society and culture ……………………………………………………...

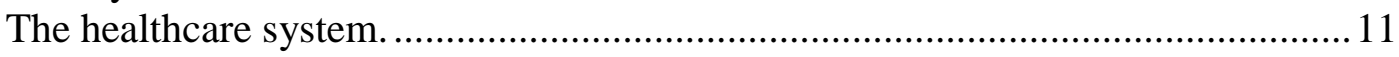

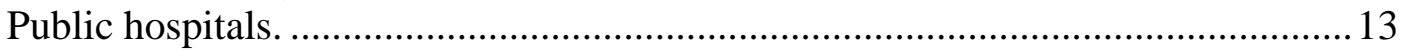

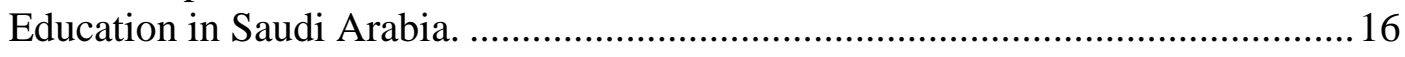

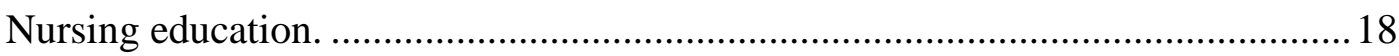

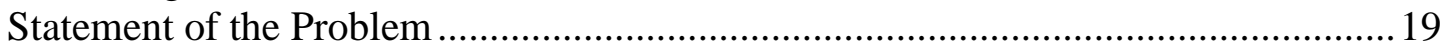

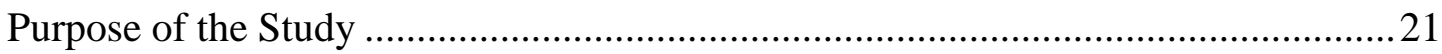

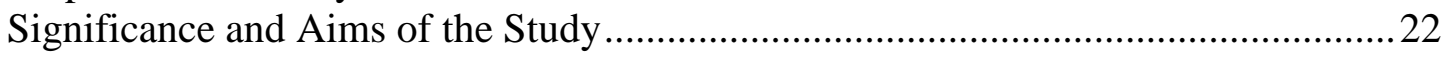

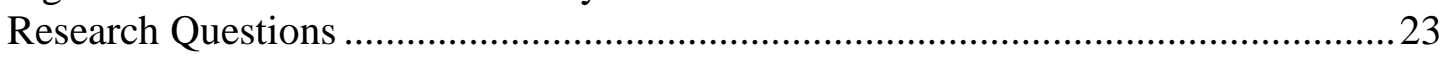

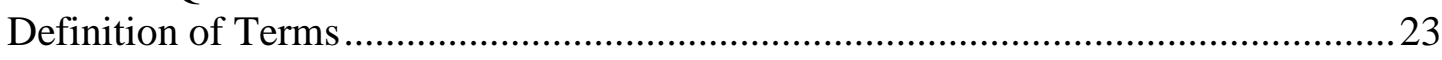

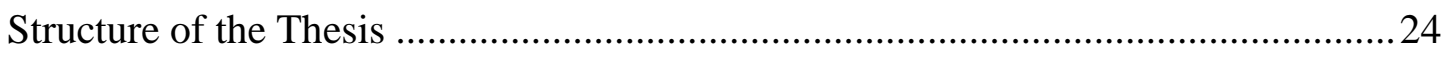

Chapter 2: Review of the Literature …............................................................27

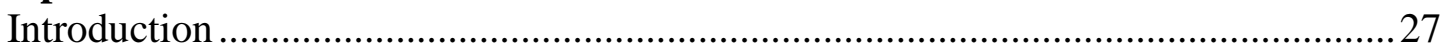

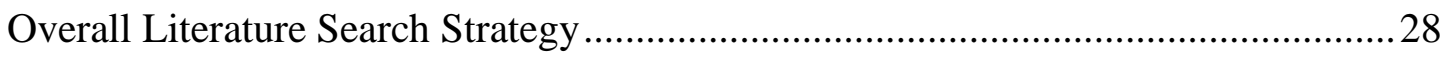

Job Satisfaction in Nursing ..................................................................................... 30

Job satisfaction defined................................................................................. 30

Job satisfaction among nurses globally............................................................... 31

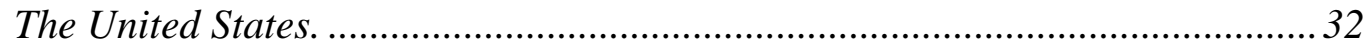

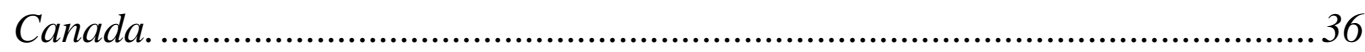

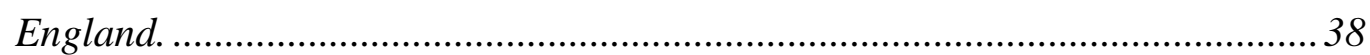

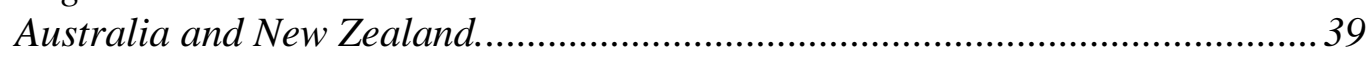

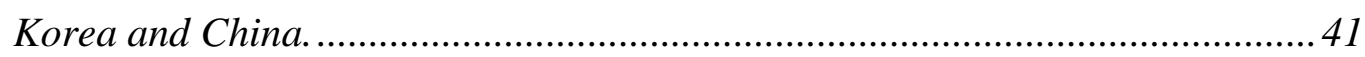

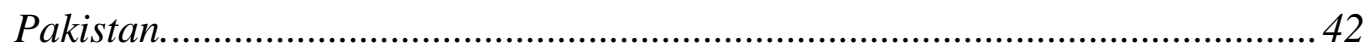

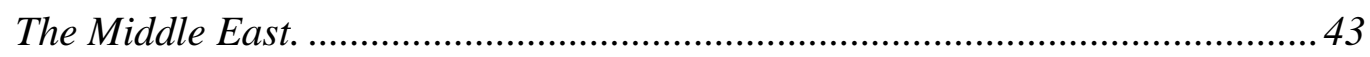

Job satisfaction among nurses in Saudi Arabia......................................................... 44 
Factors affecting job satisfaction and dissatisfaction in Saudi Arabia. ............. 45

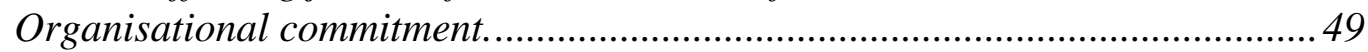

Strategies for improved satisfaction and nurse retention...............................51

Key Factors Influencing Nurses' Job Satisfaction and Staff Turnover.......................55

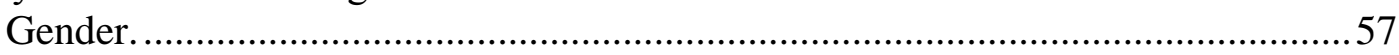

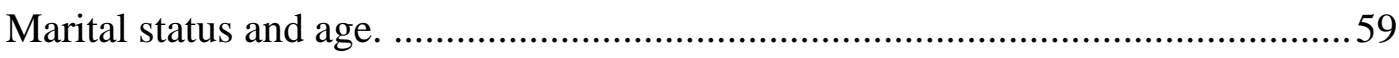

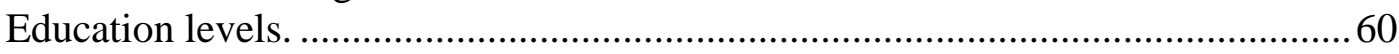

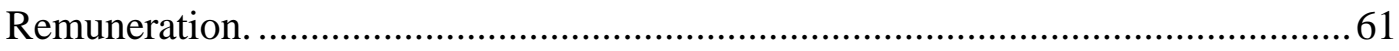

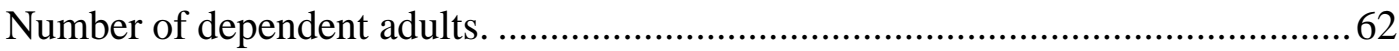

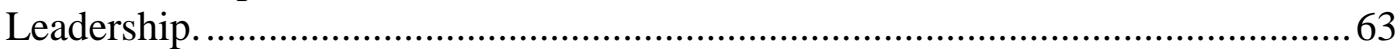

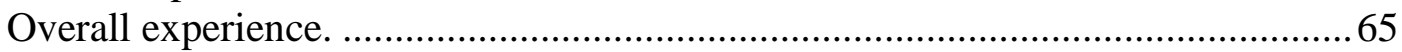

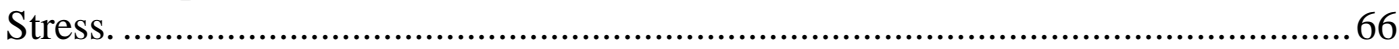

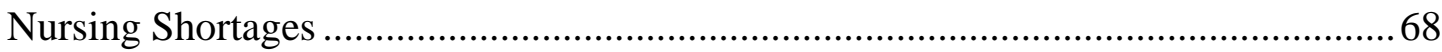

Factors Influencing the Shortage of Saudi Nurses .............................................. 70

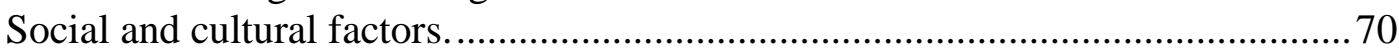

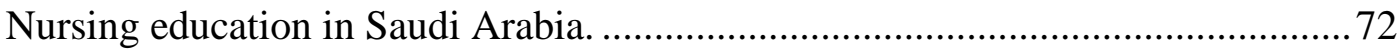

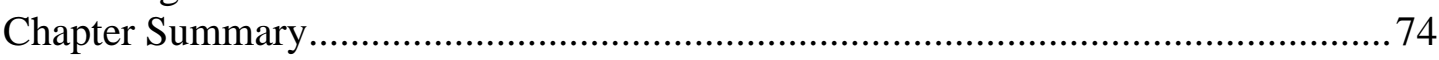

Chapter 3: Herzberg's Two-Factor Theory ........................................................76

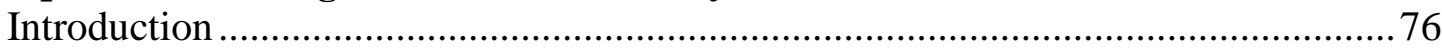

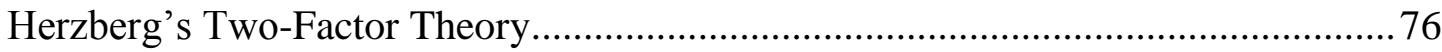

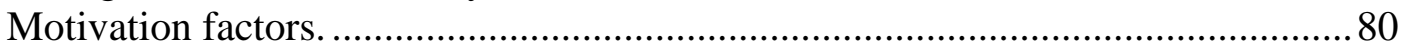

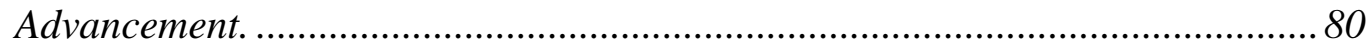

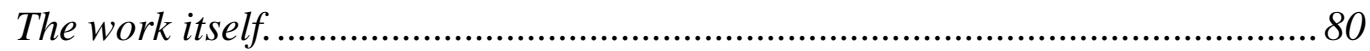

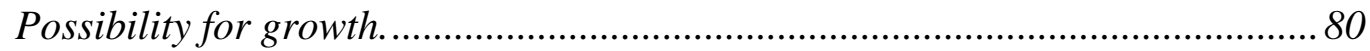

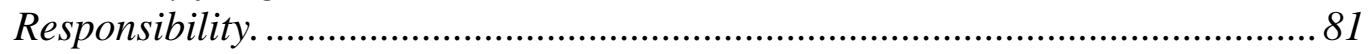

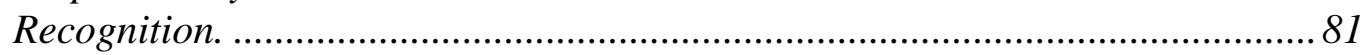

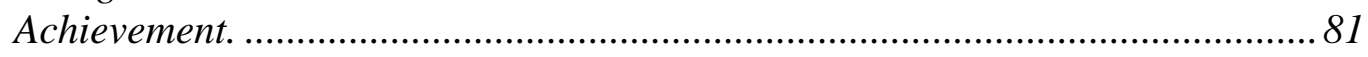

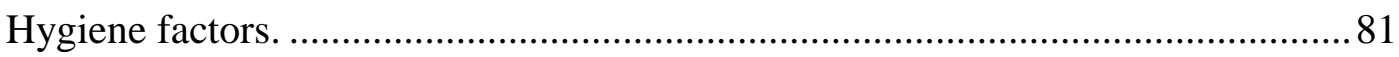

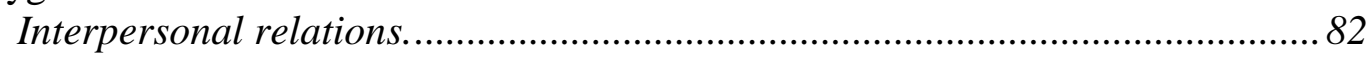

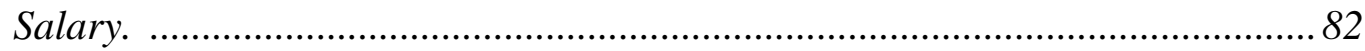

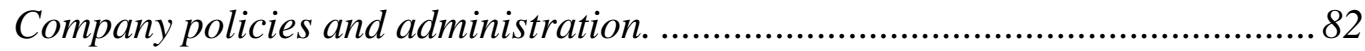

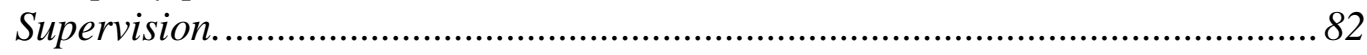

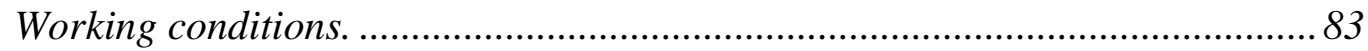

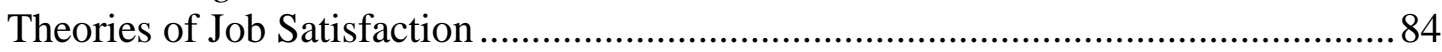

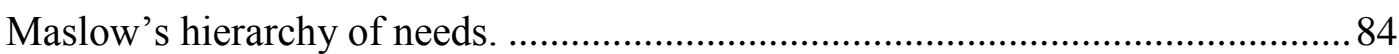

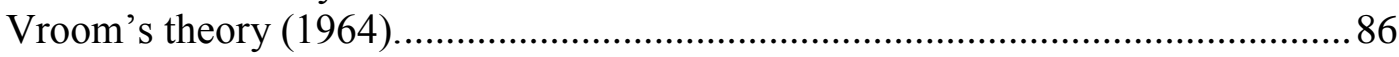

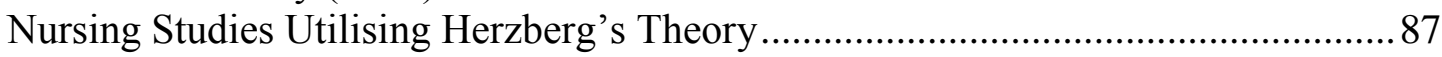

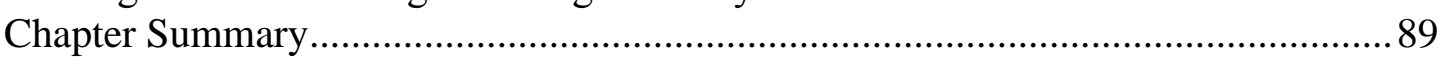

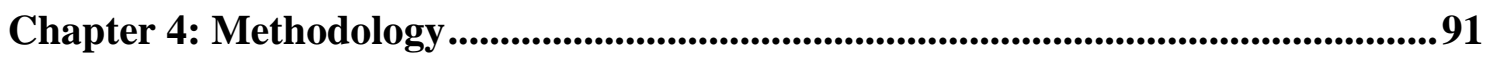

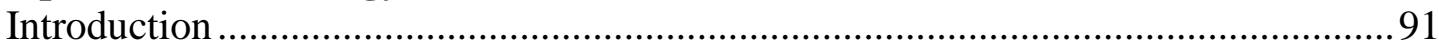

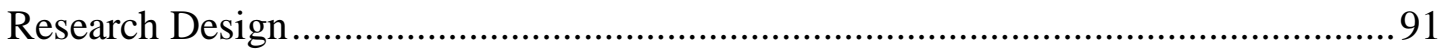

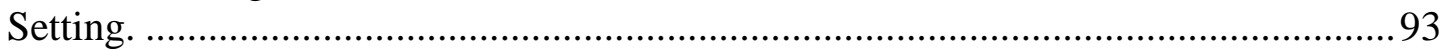

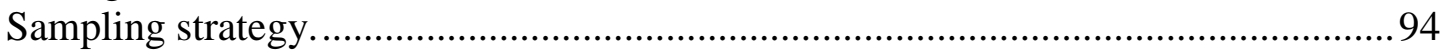

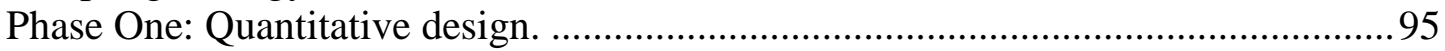

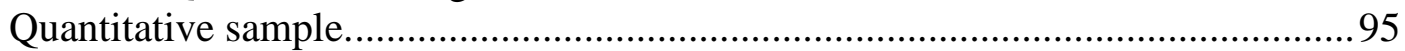

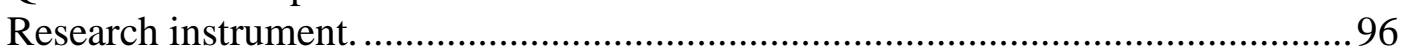

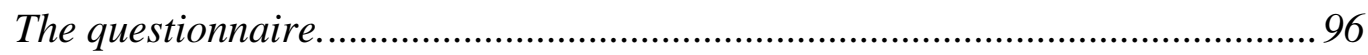

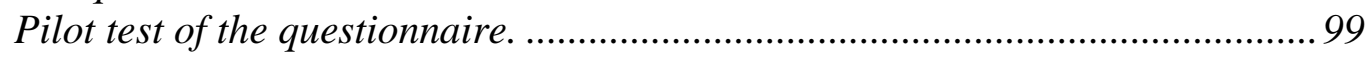

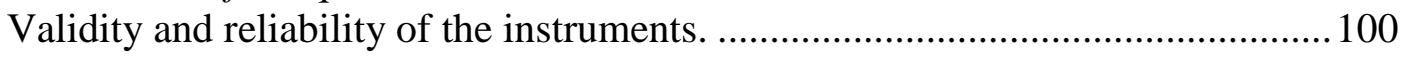




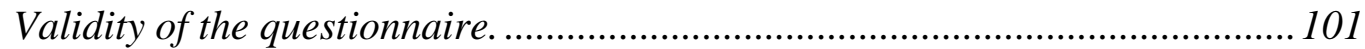

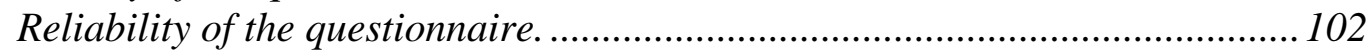

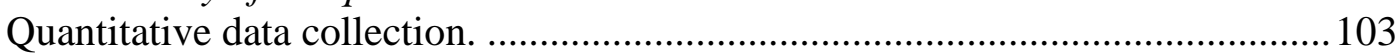

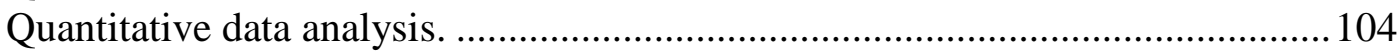

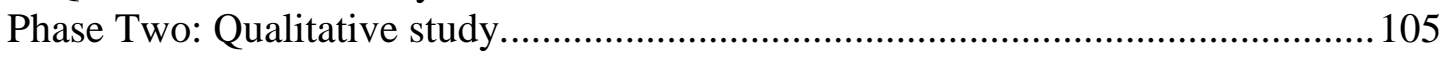

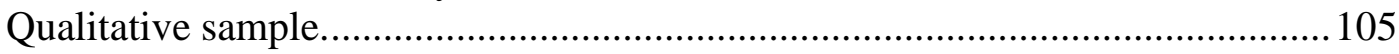

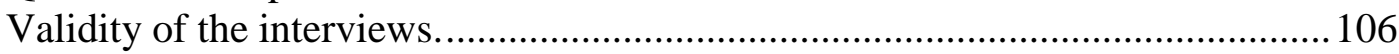

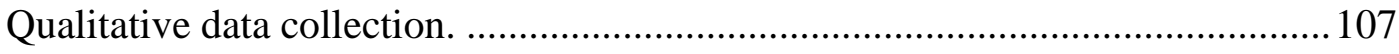

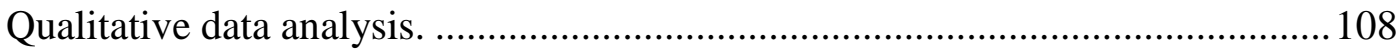

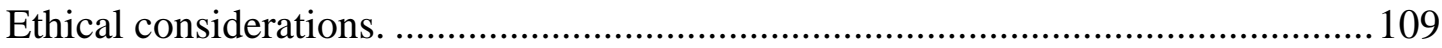

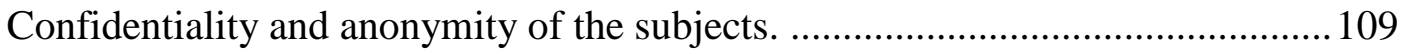

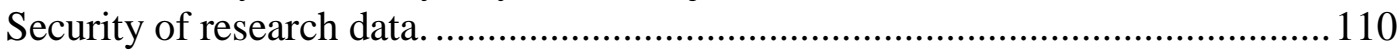

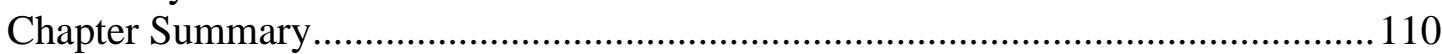

Chapter 5: Descriptive and Inferential Analyses ..............................................112

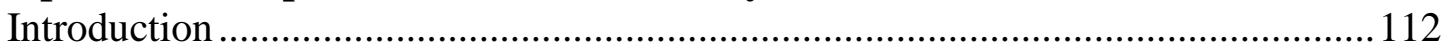

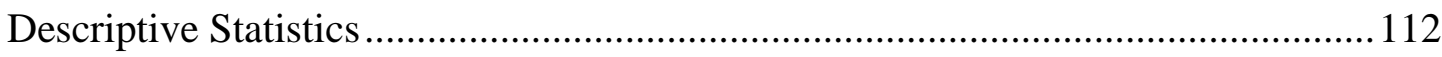

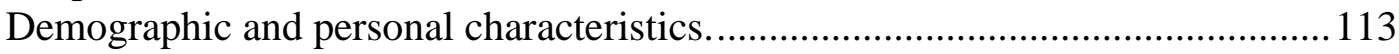

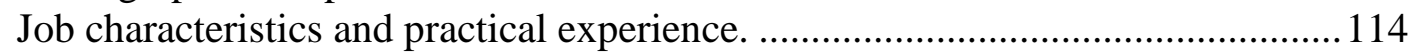

Responses Reflecting Level of Job Satisfaction ................................................. 116

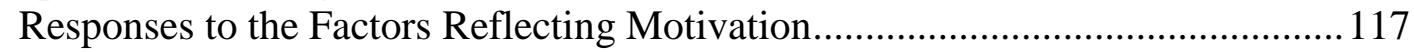

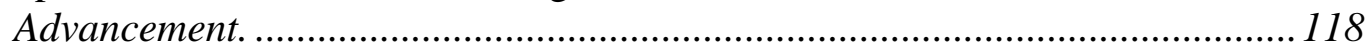

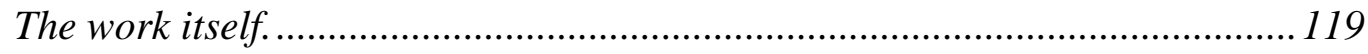

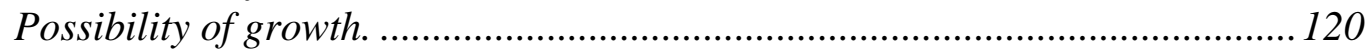

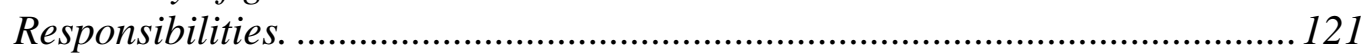

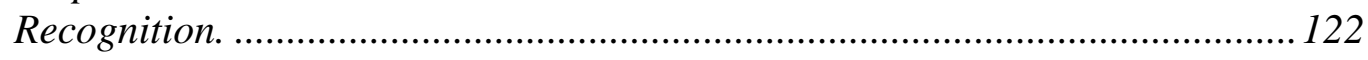

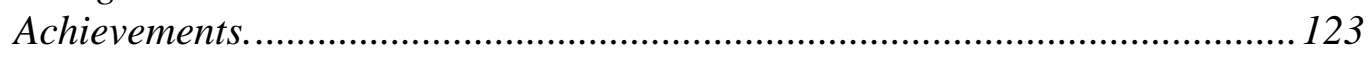

Responses to the Factors Reflecting Hygiene ................................................... 124

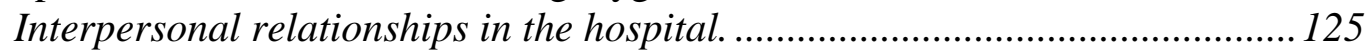

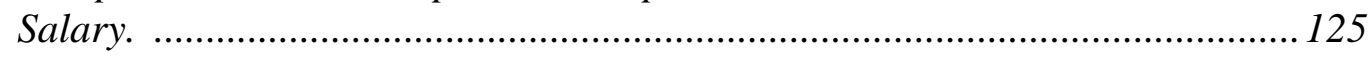

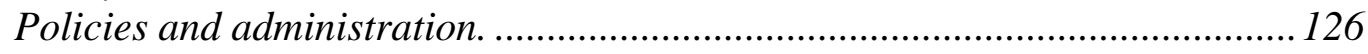

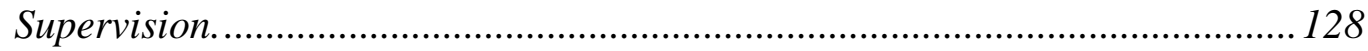

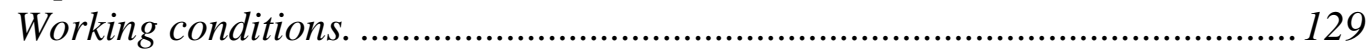

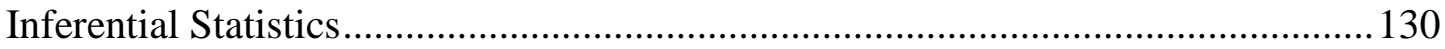

Research Question 1: Motivation factors affecting job satisfaction. ....................130

Research Question 2: Hygiene factors affecting job satisfaction. ........................ 133

Research Question 3: Factors that predict job satisfaction. ................................. 136

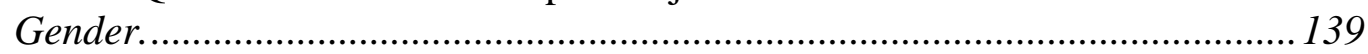

Age group ........................................................................................ 144

Research Question 4: Factors that predict job satisfaction in each hospital. ........ 153

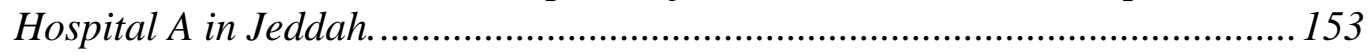

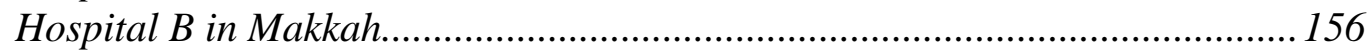

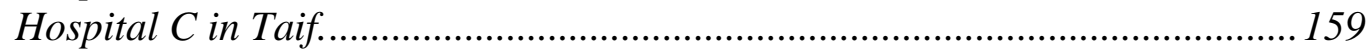

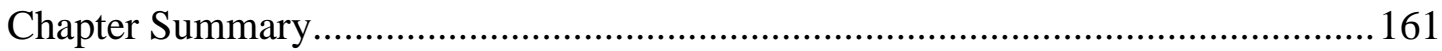

Chapter 6: Qualitative Data Findings ..............................................................164

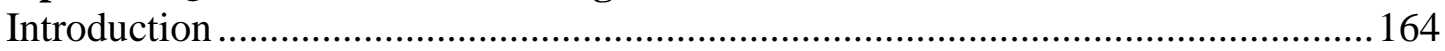

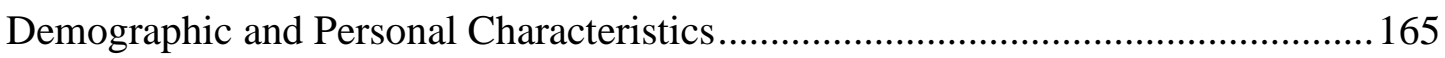

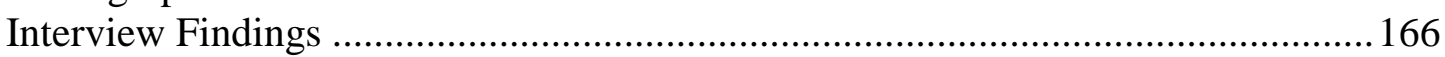

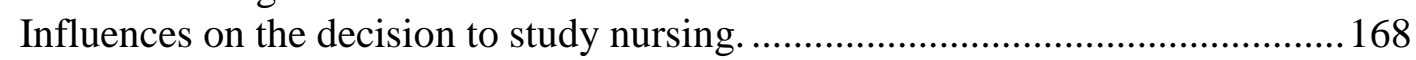

Role of the family in making educational decisions........................................ 168 
Role of friends in making educational decisions............................................ 169

Personal educational decision-making....................................................... 170

Factors that motivate nurses to continue working as nurses............................... 171

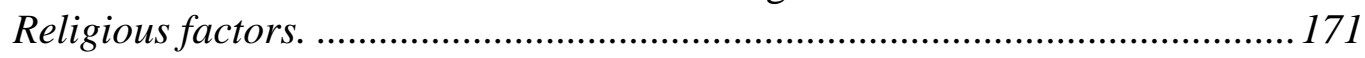

Moral and financial factors. ................................................................... 172

Social and community service factors...................................................... 173

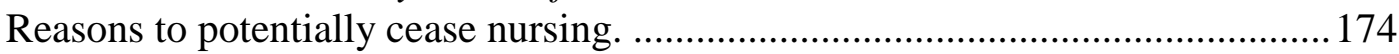

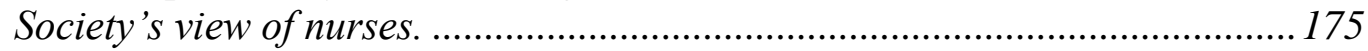

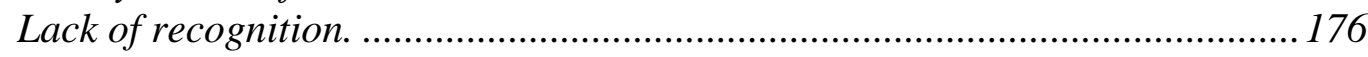

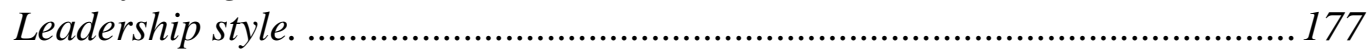

Shortage of nurses and the associated long working hours.......................... 179

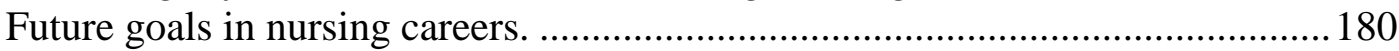

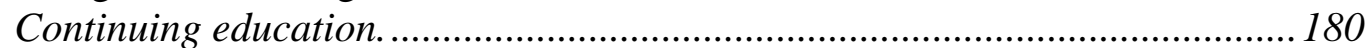

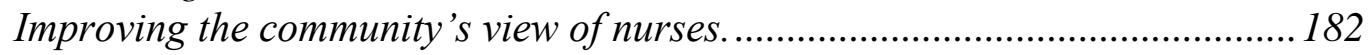

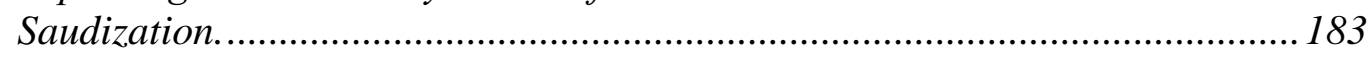

Factors perceived to improve the public image of nurses in Saudi Arabia........... 184

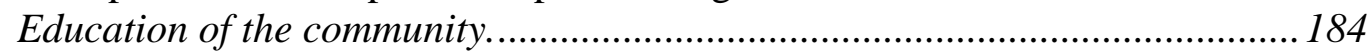

Increasing the numbers of Saudi nurses. ..................................................... 187

Suggestions to increase the recruitment and retention of Saudi Arabian nurses. . 188

Developing nursing colleges. ........................................................................ 188

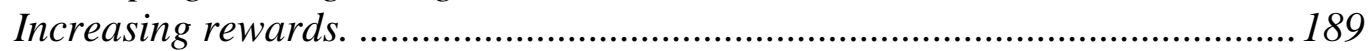

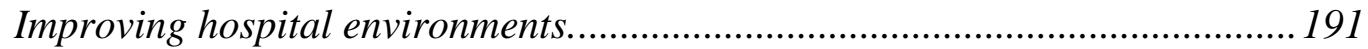

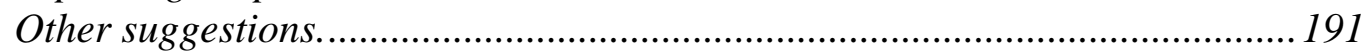

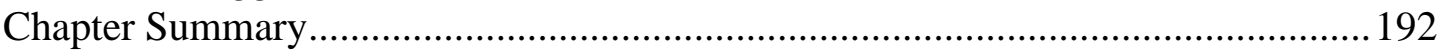

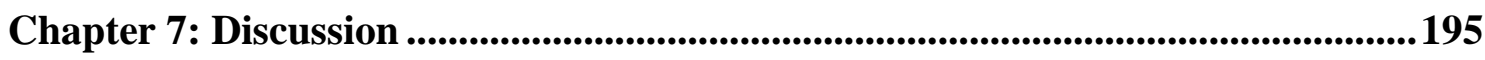

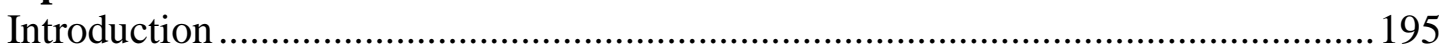

Demographic Factors Affecting Motivation Job Satisfaction................................. 195

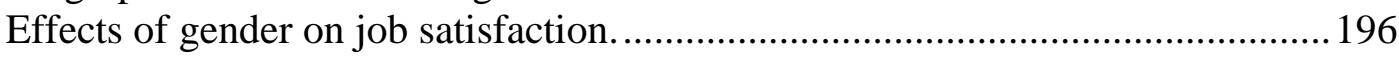

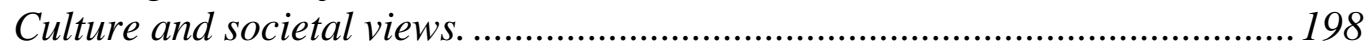

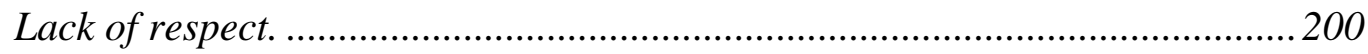

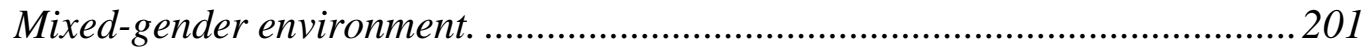

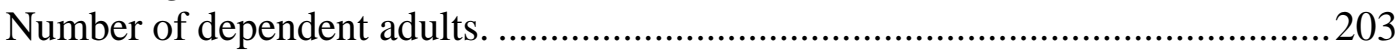

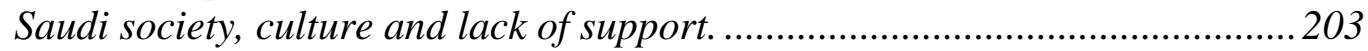

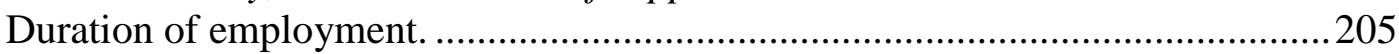

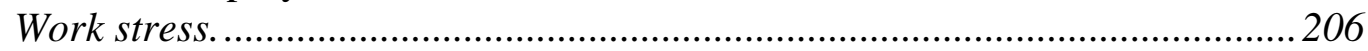

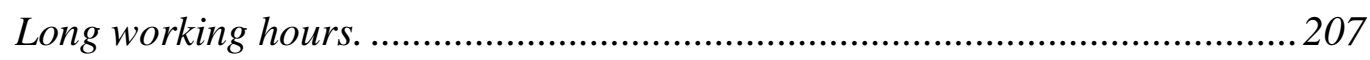

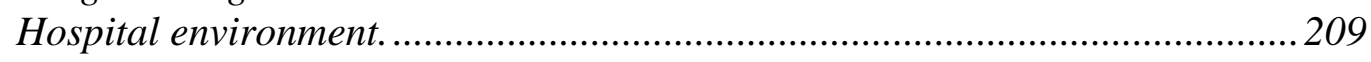

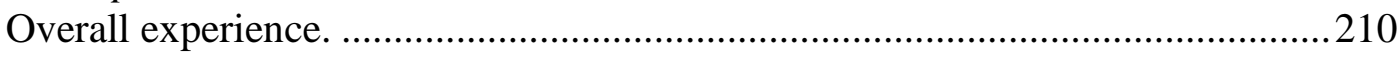

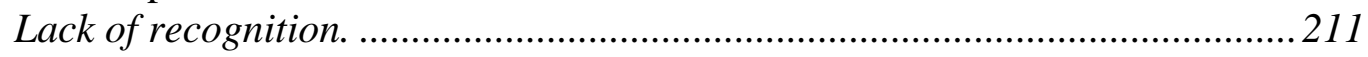

Demographic Factors Affecting Hygiene Job Satisfaction ......................................214

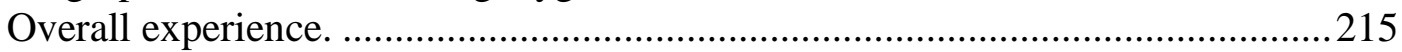

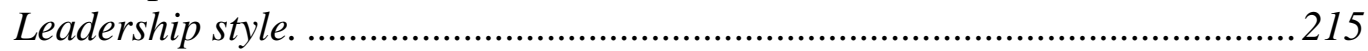

Factors That Most Predict Job Satisfaction Among Saudi Nurses .........................2 217

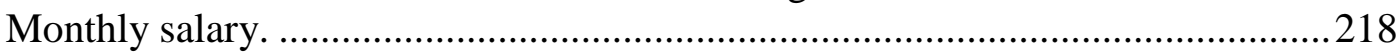

Factors That Predict Job Satisfaction Among Saudi Nurses in Each of the

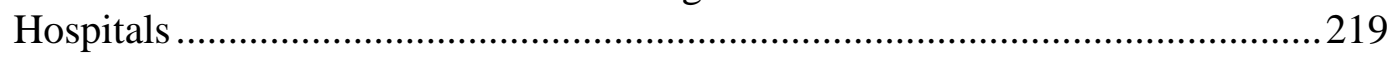

Hospital A in Jeddah. ................................................................................. 219

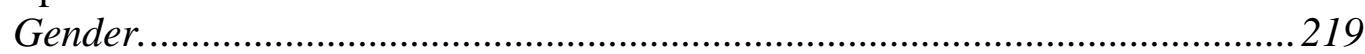

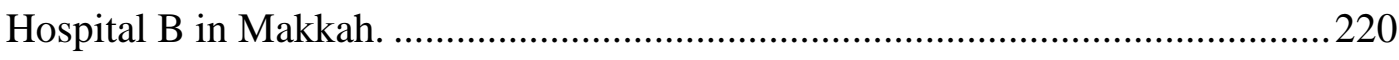

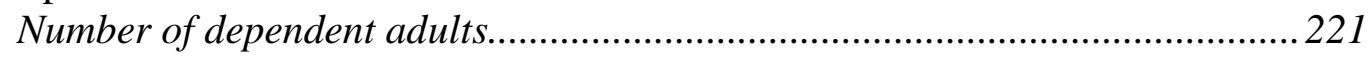




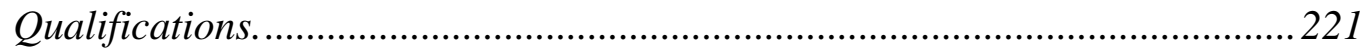

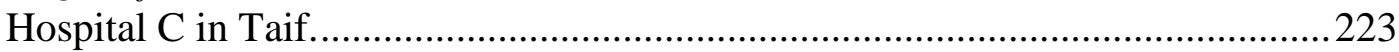

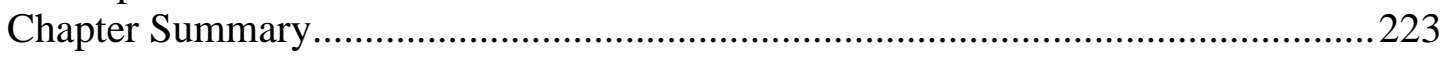

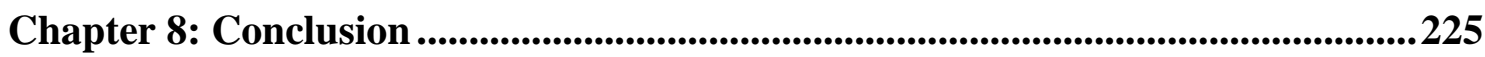

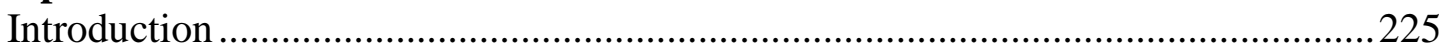

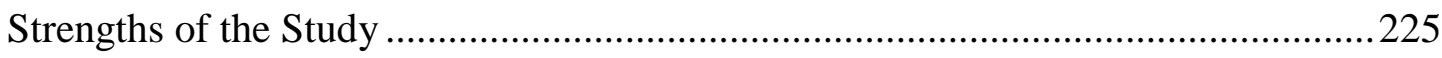

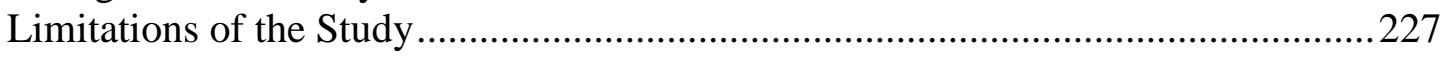

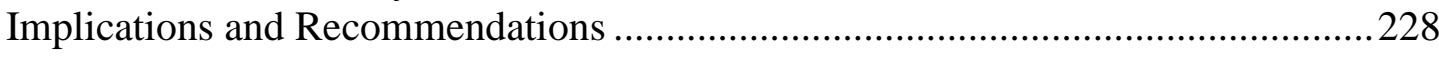

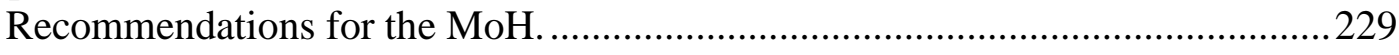

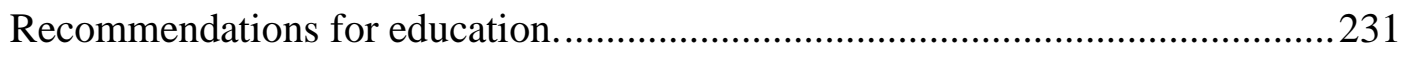

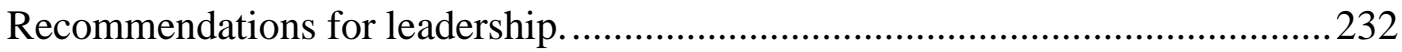

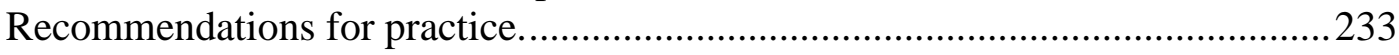

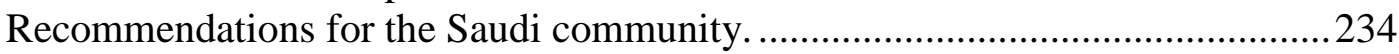

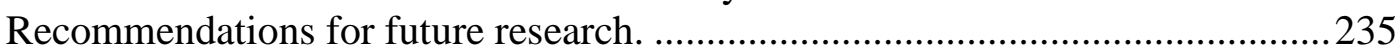

Implications of the conceptual framework...................................................236

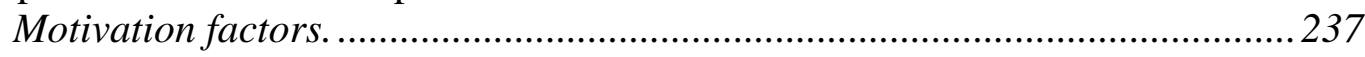

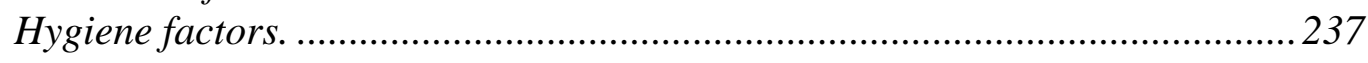

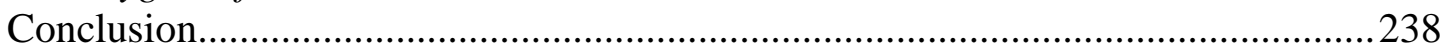

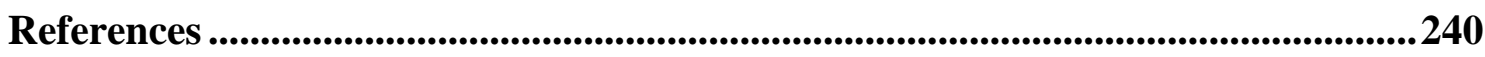




\section{List of Tables}

Table 1.1 The Saudi Arabian Government Budget and the MoH Budget 20062011

Table 1.2 Number of Nurses Working in Saudi Public Hospitals From 20052011 15

Table 1.3 Gender of Nurses Working in Saudi Public Hospitals 15

Table 1.4 The Number of MoH Public Hospitals and their Bed Capacity 20052011 16

Table 2.1 International Search Summary from1999 to 2013 .29

Table 2.2 Saudi Search Summary from1999 to 2013. 30

Table 2.3 Summary of Nursing Job Satisfaction Studies in Saudi Arabia .53

Table 3.1 Summary of the Factors in Herzberg's Theory 79

Table 3.2 Comparisons Between the Two Factors of Herzberg's Theory 79

Table 3.3 The Relationship Between Herzberg's and Maslow's Theories. .86

Table 4.1 The Total Number of Nurses, and the Number of Saudi Nurses, by each Hospital. 94

Table 4.2 Distribution of the NWI-R Questions in Relation to Herzberg's Motivation and Hygiene Theory 98

Table 4.3 Distribution of the NWI-R Questions in Relation to Herzberg's Motivation Factors 99

Table 4.4 Distribution of the NWI-R Questions in Relation to Herzberg's Hygiene Factors

Table 4.5 Reliability Statistics

Table 5.1 Demographic and Personal Characteristics of the Study Group $(N=272)$

Table 5.2 Job Characteristics and Practical Experience of the Study Group $(N=272)$

Table 5.3 Distribution of the NWI-R Questions .

Table 5.4 Summary of Motivating Factors

Table 5.6 Responses of Nurses to the Work Itself .

Table 5.7 Responses Reflecting Nurses' Opinions of the Possibility of Growth

Table 5.8 Responses of the Nurses to Items Reflecting Responsibilities 122

Table 5.9 Responses of the Nurses to Items Reflecting Recognition. 123

Table 5.10 Responses of the Nurses Reflecting Feelings of Achievement. 124

Table 5.11 Summary of All Hygiene Factors 124

Table 5.12 Responses to Items Reflecting Interpersonal Relationships in the Hospital. 
Table 5.13 Response to Item Reflection Nurses' Opinions on Salary.

Table 5.14 Responses to Items Reflecting Nurses' Opinion of Policies and

Administration.

Table 5.15 Responses to Items Reflecting Nurses' Opinions on Supervision

Table 5.16 Nurses' Responses to the Items Reflecting Hospital Working

Conditions.

Table 5.17 Satisfaction with Motivating Factors According to the Demographic

Characteristics of the Study Group ( $N=272)$

Table 5.18 Satisfaction with Motivating Factors According to the Job

Characteristics and Practical Experience of the Study Group (N=272)

Table 5.19 Satisfaction with Hygiene Factors According to the Demographic

Characteristics of the Study Group $(N=272)$

Table 5.20 Satisfaction with Hygiene Factors According to Job Characteristics and Practical Experience of the Study Group $(N=272)$...................................................136

Table 5.21 Predictors for Level of Satisfaction Reflecting Motivating Factors ........ 137

Table 5.22 Model Summary...................................................................................137

Table 5.23 Predictors for Level of Satisfaction Reflecting Hygiene Factors ............138

Table 5.24 Model Summary......................................................................................... 139

Table 5.25 Predictors for Female Level of Satisfaction Reflecting Motivating

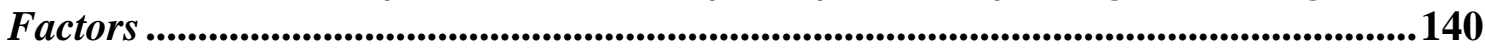

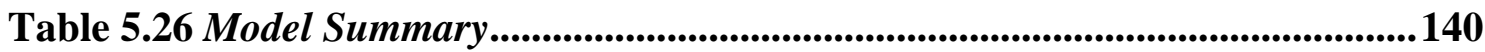

Table 5.27 Predictors for Female Level of Satisfaction Reflecting Hygiene

Factors

Table 5.28 Model Summary.

Table 5.29 Predictors for Male Level of Satisfaction Reflecting Motivating

Factors

Table 5.30 Model Summary.

Table 5.31 Predictors for Male Level of Satisfaction Reflecting Hygiene Factors... 144

Table 5.32 Model Summary.

Table 5.33 Predictors for Level of Satisfaction in the First Age Group Reflecting

Motivating Factors

Table 5.34 Model Summary

Table 5.35 Predictors for Level of Satisfaction of the First Age Group Reflecting

Hygiene Factors

Table 5.36 Model Summary

Table 5.37 Predictors for Level of Satisfaction of the Second Age Group

Reflecting Motivating Factors

Table 5.38 Model Summary 
Table 5.39 Predictors for Level of Satisfaction of the Second Age Group

Reflecting Hygiene Factors

Table 5.40 Model Summary

Table 5.41 Predictors for Level of Satisfaction of the Third Age Group Reflecting

Motivating Factors

Table 5.42 Model Summary

Table 5.43 Predictors for Level of Satisfaction of the Third Age Group Reflecting Hygiene Factors

Table 5.44 Model Summary

Table 5.45 Predictors for Level of Satisfaction at Hospital A in Jeddah Reflecting

Motivating Factors ...............................................................................................154

Table 5.46 Model Summary...........................................................................154

Table 5.47 Predictors for Level of Satisfaction at Hospital A in Jeddah Reflecting Hygiene Factors .............................................................................................................155

Table 5.48 Model Summary..........................................................................156

Table 5.49 Predictors for Level of Satisfaction at Hospital B in Makkah

Reflecting Motivating Factors ......................................................................................157

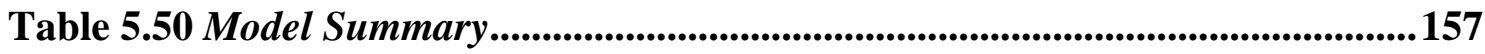

Table 5.51 Predictors for Level of Satisfaction at Hospital B in Makkah Reflecting Hygiene Factors .........................................................................................158

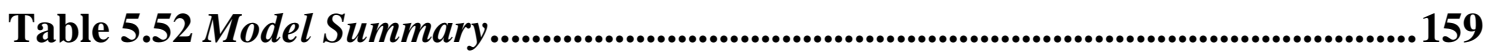

Table 5.53 Correlation between the Independent Variables for Saudi Nurses Working at Hospital C Reflecting Motivating and Hygiene Factors .........................160

Table 6.1 Demographics Information for the Interviewees ............................................166

Table 6.2 Overview of Job Satisfaction by the Participants in Face-to-Face Interviews 


\section{List of Figures}

Figure 1.1: A map of Saudi Arabian provinces and major cities. .............................7

Figure 1.2: Levels of the MoH healthcare system in Saudi Arabia......................... 13

Figure 3.1: Herzberg's two-factor theory as a conceptual framework of the

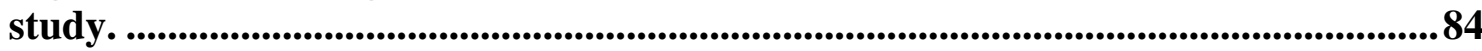

Figure 3.2: Maslow's hierarchy of needs. ..........................................................85

Figure 3.3: Expectancy theory by Victor Vroom (1964). .......................................87

Figure 4.1: The mixed methods approach used in this study................................93 


\section{List of Appendices}

Appendix A: The Study Advertisement Letters ....................................................258

Appendix B: Plain Language Statement ....................................................................259

Appendix C: Semi-Structured Interview Invitation Letter ...................................261

Appendix D: Demographic Survey.................................................................262

Appendix E: NWI Revised Questionnaire (English and Arabic) ..........................264

Appendix F: Questions for Semi-structured Interviews ......................................266

Appendix G: Qualitative Data Translation .........................................................267

Appendix H: Ethics Approval Letter (RMIT University)........................................268

Appendix I: Permission letter from MoH and Medical Research Committee,

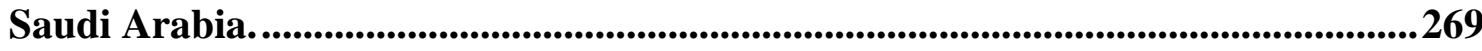

Appendix J: Translation of the MoH and Medical Research Committee Letter..270 Appendix K: Consent Form for Interviews 


\section{List of Abbreviations}

\begin{tabular}{|c|c|}
\hline ANOVA & Analysis of Variance \\
\hline BSN & Bachelor of Science in Nursing \\
\hline CDSI & Central Department of Statistics and Information \\
\hline CHEAN & College Human Ethics Advisory Network \\
\hline EIA & Energy Information Administration \\
\hline ITNS & International Transplant Nurses Society \\
\hline KRA & Key Result Area \\
\hline MMSS & McCloskey/Mueller Satisfaction Scale \\
\hline $\mathrm{MoE}$ & Ministry of Education \\
\hline $\mathrm{MoH}$ & Ministry of Health \\
\hline MoHE & Ministry of Higher Education \\
\hline MoPM & Ministry of Petroleum and Minerals \\
\hline MSN & Master of Science in Nursing \\
\hline NHMRC & National Health and Medical Research Council \\
\hline NUMs & Nurse Unit Managers \\
\hline NWI-R & Nursing Work Index Revised \\
\hline RMIT & Royal Melbourne Institute of Technology \\
\hline WHO & World Health Organization \\
\hline
\end{tabular}




\section{Chapter 1: Introduction and Overview}

\section{Introduction}

Nurses' job satisfaction has been studied for over four decades. Nurses make up the largest group of healthcare providers working within healthcare services and they contribute significantly to the quality and delivery of patient care (Al-Aameri, 2000; Chan, Tam, Lung, Wong, \& Chau, 2013). Nurse shortages and high nurse turnover continue to be among the most vexing problems for healthcare systems worldwide. These two issues have become of great concern in many countries, including Saudi Arabia. Many factors affect the worldwide shortage of nurses; these include a decrease in the number of students wishing to study nursing, a shortage of nurses entering the profession following graduation and job dissatisfaction among practicing nurses, which results in many nurses leaving the profession (Longo, 2007; Miller, 2007). According to Aiken et al. (2001), work overload is the main cause for job dissatisfaction among nursing staff in many countries. The United States of America has the highest rate of job dissatisfaction, at 41 per cent, followed by Scotland, at 38 per cent, the United Kingdom, at 36 per cent, Canada, at 33 per cent and Germany, at 17 per cent (Aiken et al., 2001; Lu, While, \& Barriball, 2005). In Saudi Arabia, several research studies that have been conducted in various geographical regions have examined job satisfaction among combined cohorts of Saudi and non-Saudi nurses working in both the private and public healthcare sectors. These studies included a variety of related variables, such as job satisfaction and organisational commitment, leadership style, hospital performance and job satisfaction, as well as burnout and intention to stay (Al-Aameri, 2000; AlAhmadi 2009; Al-Dossary, Vail, \& Macfarlane, 2012; El-Gilany \& Al-Wehady, 2001; Mitchell, 2009; Omer, 2005; Zaghloul, Al-Hussaini, \& Al-Bassam, 2008). According to these studies, job dissatisfaction was mainly attributed to organisational commitments, 
payment, rewards and operating conditions, social views, company policy, administration, hospital policies and recognition.

There is a paucity of literature relating to job satisfaction and rates of job dissatisfaction among national Saudi nurses. This study identifies and explores the level of job satisfaction among female and male Saudi nurses working in public hospitals in the Makkah region, one of the largest regions of the Kingdom of Saudi Arabia. The main aim of this study is to investigate the job satisfaction of Saudi nurses employed in Saudi public hospitals in the Makkah region. This chapter will provide an introduction to, and background information on, the context of this study, the history and development of nursing and nursing education in Saudi Arabia and the Saudi Arabian healthcare system. This will be followed by an outline of the research statement of this study and the aims and the structure of this thesis.

\section{The Nursing Workforce in Saudi Arabia}

Since the 1950s Saudi Arabia has been a destination for expatriate nurses. Saudi Arabia's healthcare system has relied exclusively on recruiting expatriate-registered nurses from various countries, such as the United States, the United Kingdom, Ireland, Sweden, Australia, India, Philippines, Malaysia and the Middle East (Al-Dossary, While, \& Barriball, 2008). It has been one of the most popular destinations for Western foreign nurses, since they were offered many benefits, such as free accommodation, high tax-free salaries, long annual vacations, rewards and bonuses and yearly round trip airfare tickets to their homeland.

However, the 1991 Gulf War created a crisis in hospitals in the Gulf region. At this time Saudi Arabian hospitals became severely short-staffed when expatriate nurses left to return home (Tumulty, 2001). The loss of the expatriate workforce was one of the most important reasons for the decision by the Saudi government to create the 
'Saudization' programme. Saudization refers to 'A policy that promotes Saudi nationals to be educated and/or trained in all areas of employment to replace expatriate workers' (Miller-Rosser, Chapman, \& Francis, 2006, p. 4). According to Omer (2005), under the Saudization programme the Saudi Arabian government gave high priority to the recruitment and education of Saudi nationals in nursing programmes to satisfy the healthcare system's needs. The Ministry of Health's (MoH) Saudization plan for the nursing workforce was to reach a target of 50 per cent Saudi nurses by 2025 . In implementing this plan, many strategies have been put in place, such as increasing the number of nursing colleges in various geographical regions in Saudi Arabia, improving the quality of education and training, improving the salaries of national nurses and providing specialty training (Mufti, 2000). As a result of this programme, the number of Saudi nurses has increased dramatically over the past decade. The proportion of Saudi nurses was nine per cent in 1996, and in 2011 proportion of Saudi nurses had increased to around 45 per cent $(\mathrm{MoH}, 2011)$.

The healthcare delivery system in Saudi Arabia has improved and expanded dramatically during the past few years due to the country's growth and development, an increase in the population and increased improvements in the national health budget (Almalki, FitzGerald, \& Clark, 2011a). Hence, Saudi Arabia has advanced and developed in all healthcare disciplines, particularly in the field of nursing (Al-Dossary et al., 2012). Nevertheless, the shortage of Saudi nurses is a major concern, as it greatly affects the efficiency and productivity of the Saudi healthcare system (Almalki et al., 2011b; Al-Aameri, 2000). The nurse shortage in Saudi Arabia is mainly attributed to various social, cultural and educational factors (Abu-Zinadah, 2006; Miller-Rosser, Chapman, \& Francis, 2009). Saudi Arabia has relied exclusively on recruiting expatriate-registered nurses to service its healthcare system, especially the public 
hospitals, because of the national shortage of Saudi female and male nurses. There is limited information relating to Saudi nurses' job satisfaction to guide the $\mathrm{MoH}$ in addressing these issues.

The shortage of national nurses is of great concern in the Saudi Arabian healthcare system, and the $\mathrm{MoH}$ has identified that this issue requires immediate attention. One of the most important actions for the $\mathrm{MoH}$ is to recruit and retain Saudi national nurses to service the Saudi public healthcare system. Saudi nurses share the Arabic language with their patients and are able to offer high quality nursing care for their patients. Job satisfaction is a key issue for the maintenance and stability of the nursing workforce worldwide (Hansen, 2007; Hegney, Plank, \& Parker, 2006; Mitchell, 2009; Peterson, 2009; Ruggiero, 2005), and in Saudi Arabia. Nursing job satisfaction has not only been linked to a decrease in turnover, but is also linked to positive patient care and outcomes (Aiken et al., 2002; Hayes, Bonner \& Pryor, 2010).

\section{The History of Nursing in Saudi Arabia}

Nursing has had a long history in Saudi Arabia. It began 14 centuries ago, during the time of the Prophet Mohammed (peace be upon him). At this time, Koaiba Bint Said Al-Asalmiya, who became known as Rufaidah Al-Asalmiya, was the first female Muslim nurse, who worked with the Muslim armies through the Jihad (holy Islamic wars). She became known as Rufaidah (رفيدة), which means in the Arabic language 'the female who delivers help and provides for others' (Almalki et al., 2011b). Before becoming a Muslim she had learned and developed her nursing skills from her father, who was a folk healer. Rufaidah was the manager and teacher of the oldest school of nursing in the Islamic world (Al-Osaimi, 2004; Jradi, Zaidan, \& Shehri, 2013). She trained many Muslim women volunteers as nurses to deliver nursing care, community social support and community education. Rufaidah and her volunteer nurses 
started the first clinic in Islam in Al Madina Al Mnoura (Al-Osaimi, 2004; Kasule, 2003; Lovering, 2008; Mebrouk, 2008; Mitchell, 2009). The Prophet Mohammed (peace be upon him) gave her permission to attend, provide help and treat Muslim war casualties by providing them with water, caring for their wounds and offering them medicines (Miller, 2007). She provided care for both female and male patients alike and her history illustrates all the attributes expected of a good nurse. As a public health nurse and social worker, she was kind and empathetic and did not confine her nursing to clinical situations; she also tried to solve social problems in the community (Al-Dossary et al., 2008; Kasule, 2003).

She participated in many invasions, such as the invasion of Badr in January of 624G and she was the first of the holy Prophets (including Uhud, Khandaq and Khaibar) to provide basic nursing care to Muslim soldiers. This included first aid, wound protection and dressing, bleeding prevention and emotional support. In appreciation of her efforts, the Prophet assigned her a share of the treasure that was equivalent to that of the soldiers (Al-Osaimi, 2004). Her practice of nursing was not limited to the care of the soldiers at war, but also extended to patients experiencing illnesses. She also cared for pregnant women and assisted in the delivery of their babies (Al-Osaimi, 2004).

\section{Context and Background of the Study}

This study was conducted in the Kingdom of Saudi Arabia, an Arab Islamic country that differs drastically in lifestyle, culture and religion from other countries. Thus, it is important to provide an overview of Saudi Arabia prior to addressing the research questions of this thesis. The following section will present a general overview of the history of Saudi Arabia, as well as its geography, economics, demography, social customs and cultural practices. A general description of the healthcare system will also be presented. 


\section{History of Saudi Arabia.}

Saudi Arabia is a young country; however the Arabian Peninsula has much history and tradition. It is the birthplace of Islam, and the centre of the holy lands of Islam is the cities of Makkah al Mukarrama and Al Madina Al Mnoura. The Prophet Mohammed (peace be upon him) founded Islam more than 1,400 years ago in Arabia and the holy Qu'ran (the holy book of Islam) is written in Arabic, the language that the Prophet Mohammed (peace be upon him) spoke. Islam has a prominent role and influence over the lifestyle in Saudi Arabia (Ramady, 2010). The Kingdom of Saudi Arabia is the official name of the country (in Arabic, al-Mamlaka al-Arabiya asSaudiya) and it is also called 'The Land of the Two Holy Mosques'.

The Kingdom of Saudi Arabia was established in 1902 when King Abd Alaziz bin Abd al-Rahman Al Saud (Ibn Saud) reunited most parts of the Arabian Peninsula from various leaders. The Kingdom of Saudi Arabia was established and declared an Islamic monarchy in 1932 by King Abd Alaziz bin Abd al-Rahman. Islam is the official religion and it guides the moral law of the country (Al-Sadan, 2000).

Saudi Arabia contains vast tracts of desert. This has affected and influenced people's lifestyles. Most people lived a poor Bedouin lifestyle, living in tents in the desert, taking care of animals (such as sheep, cows and camels) and moving from area to area as the presence of rain and water dictated (Mitchell, 2009). After the discovery of oil, many people abandoned the nomad Bedouin lifestyle and moved to the main cities of Riyadh (the Kingdom's capital), Dammam in the east and Jeddah in the west. Jeddah has the largest port in the Kingdom and is located between the two holy cities of Makkah al Mukarrama and Al Madina Al Mnoura. 


\section{Geography.}

Saudi Arabia is located in the Middle East within the Asian continent. Saudi Arabia is the largest country in the Middle East and the fourteenth largest country in the world, covering approximately 2.25 million square kilometres (Al-Dossary et al., 2012; Central Department of Statistics, 2012). The climate of the Kingdom of Saudi Arabia varies from region to region, depending on the location. However, the general climate is hot and dry. The main cities of Saudi Arabia, including the capital city of Riyadh, are shown in Figure 1.1 (Royal Embassy of Saudi Arabia [USA], 2013).

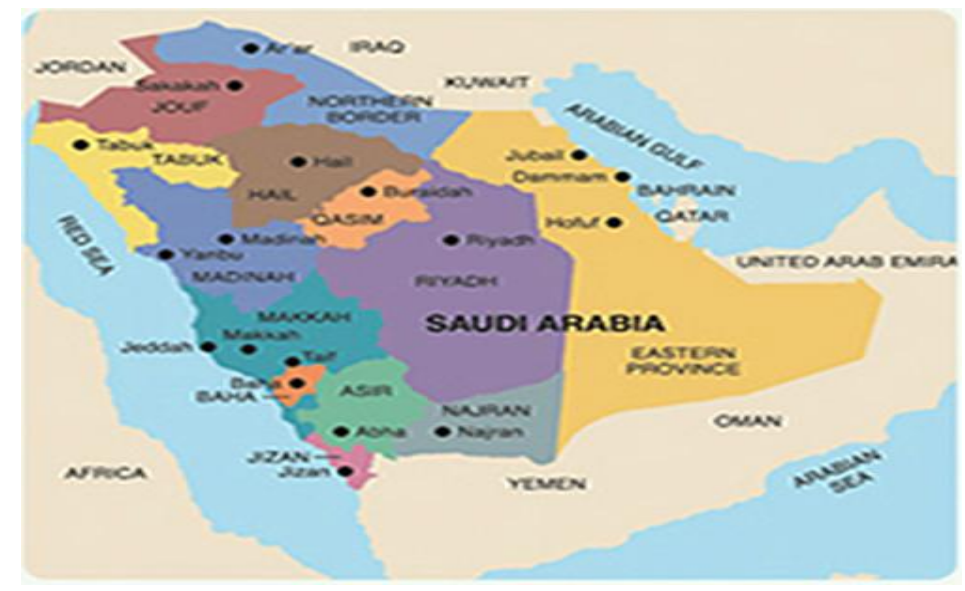

Figure 1.1: A map of Saudi Arabian provinces and major cities.

Source: Royal Embassy of Saudi Arabia (2013).

As shown on the map, the Kingdom of Saudi Arabia is divided into 13 regions, each of which has local administration responsibilities. These are Riyadh, Makkah, Madinah, Qasim, the Eastern Province, Asir, Tabouk, Hail, the Northern Border, Jizan, Najran, Baha and Al-Jouf (Central Department of Statistics, 2012). These regions include more than 6,000 cities, towns and villages (Al-Sadan, 2000). Saudi Arabia is bordered by the Red Sea on the west; Yemen and the Sultanate of Oman in the south; the Arabian Gulf, the United Arab Emirates, Qatar and the Kingdom of Bahrain on the 
east; and Jordan, Iraq and Kuwait in the north (Royal Embassy of Saudi Arabia [USA], 2013).

\section{Economy.}

Prior to the discovery of oil, the economy of Saudi Arabia was limited, relying on trading, fishing, farming and religious tourists travelling to Makkah al Mukarrama and Al Madina Al Mnoura for events such as the Pilgrimage. In 1933, the Saudi Arabian government granted concessions to American geologists and engineers to begin prospecting and exploring for oil in the eastern parts of the country (MOPM, 2006). Today, oil plays a major role in the country's economy and industry. It has led to dramatic increases in wealth and growth, aiding in the development and planning of infrastructure, education and healthcare. Additionally, economic, military, public and social services have increased. After beginning to export oil to the world, the status of Saudi's wealth changed from poor to rich and the quality of life changed from complicated to easy. Today, Saudi Arabia is the world's leading oil producer and exporter. In 2010, Saudi Arabia produced approximately 11-12 million barrels of oil per day. Saudi Arabia contains a quarter of the world's oil reserves, the equivalent of approximately 263 billion barrels (EIA, 2011).

Other sources have also been used to improve the national budget and income of Saudi Arabia, such as religious tourism. Millions of Muslims come from more than 140 countries each year to visit the Holy Mosque, perform the Hajj (the Pilgrimage; the fifth pillar of Islam) to Makkah al Mukarrama and to visit the city of Al Madina Al Mnoura, the home of the Prophet Mohammed (peace be upon him).

\section{Demographics.}

According to the Central Department of Statistics and Information of Saudi Arabia, the latest population figures show that in 2012 Saudi Arabia had reached a 
population of 29.1 million, including 9.3 million non-nationals. Saudi nationals comprised 68 per cent of the population, and non-Saudis the remaining 32 per cent. With respect to composition, 90 per cent of the native population were Arab and 10 per cent were from a different descent (CDSI, 2013).

The following statistics summarise the demographic information of the Saudi Arabia population. The currency of Saudi Arabia is the riyal, with a present exchange rate of US $1 \$=3.75$ SR. Saudi Arabia's population growth rate in 2012 was 2.90 per cent (CDSI, 2013). According to the MoH, in 2011 the life expectancy was 73.87 years. The male life expectancy was 71.93 years and the female life expectancy was 75.9 . The birth rate was 22.9 births $/ 1,000$ of the population. The death rate was $3.9 / 1,000$ of the population and the infant mortality rate was 16.5 deaths per 1,000 live births. In 2011, the estimated GDP for Saudi Arabia was \$154,666,666 (MoH, 2011).

\section{Society and culture.}

The social culture of Saudi Arabia expresses the principles and ethics of Islam and the Arab way of life. In addition, like other Muslim people, Saudi people believe that death, illness and health all come from God (Allah). Islam affects and influences most aspects of Saudi society, including politics, economy, education, health and lifestyle. For example, Islam influences Saudi dietary and drinking habits as Muslims must follow the Halal dietary code, which requires all beef, lamb, camel and birds to be slaughtered in the Islamic Sharia manner. Other meat, such as fish, can be eaten freely. However, pork, pork products, the blood of dead animals and the consumption of all intoxicants (including alcohol) are forbidden (Lawrence \& Rozmus, 2001). Islam and the Prophet Mohammed (peace be upon him) advised people that when they eat, they must use their right hand and when they drink, they should sit and also use their right hand. 
Ramadan, the month of Muslim fasting, affects the eating habits, health and lifestyle of all Saudi people. The fast is from sunrise until sunset. During this time, no one is allowed to drink, eat, or smoke. Most Saudi family and friends meet in the evening to break the fast together. Some patients with chronic illnesses or who are admitted to hospital for treatment are exempt from fasting. After Ramadan, all Muslims people have a large celebration, called Aid Al-fater.

Families are very important units in Saudi life. Islamic ethical principles, such as honesty, loyalty, mercy, sympathy, respect, obedience, decency and kindness include standards of behaviour that manage the relationships between family members (Mebrouk, 2008). Family members are required to visit the elder members of their extended family, such as grandfathers or grandmothers, at least once a week (usually on Fridays). Younger family members respect and care for older family members.

In the past, most Saudi women stayed at home and performed the essential roles of homemakers and caregivers (Brown, 2005). However, Saudi women now play a vital role in the wider Saudi community. Most are now professionals and work in various sectors (e.g., hospitals, schools, universities, the media and banks). They have the same rights as men at work.

Although the education system segregates males and females in schools and universities, women are able to apply and compete with men for scholarships to study in other countries, including Australia, the United Kingdom, Canada and the United States. Traditionally, men have possessed more rights than women; however, this situation has changed in the past few years. For example, in September 2011, Saudi women became able to vote, stand in as candidates in municipal elections in the city and become members of the Shoura Council (Arab News, 2011). However, women are still not 
allowed to drive. Thus, they must depend on male family members for their transportation to work and school.

\section{The healthcare system.}

The healthcare system in Saudi Arabia is developing rapidly due to rapid advancements in technology, infrastructure and the country's economy. Further, the health services in the Kingdom of Saudi Arabia are viewed as having undergone remarkable development and significant progress over the past few decades. Today, they are viewed as among some of the best in the world.

The Saudi government has given high priority to developing and supporting healthcare services. It has been very generous in spending to improve the healthcare system and monitoring of quality of care has increased the number of healthcare organisations. The healthcare agencies in Saudi Arabia consist of government hospitals, the National Guard of Health Affairs, the Army Forces Medical Services, Saudi ARAMCO hospitals, the Security Forces Medical Services, the Royal Commission for Jubail and Yanbu Health Services, the Ministry of Higher Education hospitals and private hospitals, most of which are under the umbrella of the MoH.

The government contributed to the development of the health services via the $\mathrm{MoH}$ to raise the level and quality of health services by ensuring healthcare was at international levels and by upgrading the skills of medical workers. Additionally, equipment was upgraded to improve medical support. Recently, the $\mathrm{MoH}$ started a longterm plan to educate and improve the quality and number of healthcare workers by funding scholarships and training programme placements for medical staff, such as in pharmacy, medicine and nursing, in developed countries, including Australia, Canada, the United States and the United Kingdom. 
The Saudi MoH is responsible for health strategic planning, health policies for Saudi and non-Saudi residents and for all the heath programmes in the country (AlDossary et al., 2008). The MoH was established in 1950 and is the government agency responsible for the supervision of healthcare in all public and private hospitals, private dispensaries, private polyclinics, primary health care clinics, first aid centres and ambulance services (Almalki et al., 2011a). It developed the healthcare system by creating new strategies, as well as by planning and supervising. This has resulted in a high standard of healthcare service.

Healthcare services in Saudi Arabia have developed gradually with strong support from the Saudi government, as a high priority for the development of the country. According to the World Health Organization's (WHO) international rankings reported in 2000 (WHO, 2002a), Saudi Arabia's healthcare service was ranked as twenty-sixth of 190 international healthcare systems. Further, the ranking showed that the Saudi Arabian healthcare system is better than that of many other developed countries, including Canada (30), Australia (32) and the United States (37). According to Gallagher (2002):

Saudi Arabia offers a picture of spectacular progress in healthcare over the past three decades. Although many nations have seen sizeable growth in their healthcare system, probably no other nation of large geographic expanse and population has, in comparable time, achieved so much on a broad national scale with a relatively high level of care made available to virtually all segments of the population (p. 182).

The MoH provides three levels of healthcare services, including primary, secondary and tertiary care. The primary level provides healthcare services through 2,094 centres, which are distributed all over the country. The secondary level is the 
public hospitals, and the tertiary level is the specialised hospitals and medical centres, such as the mental health hospitals, maternity and children's hospital, eye specialist hospitals, kidney diseases centres, cardiac centres and diabetes care centres $(\mathrm{MoH}$, 2011). It is expected that health services in the country will continue to grow over the next few years with the steady growth of the country. The development of e-health services are also expected to continue.

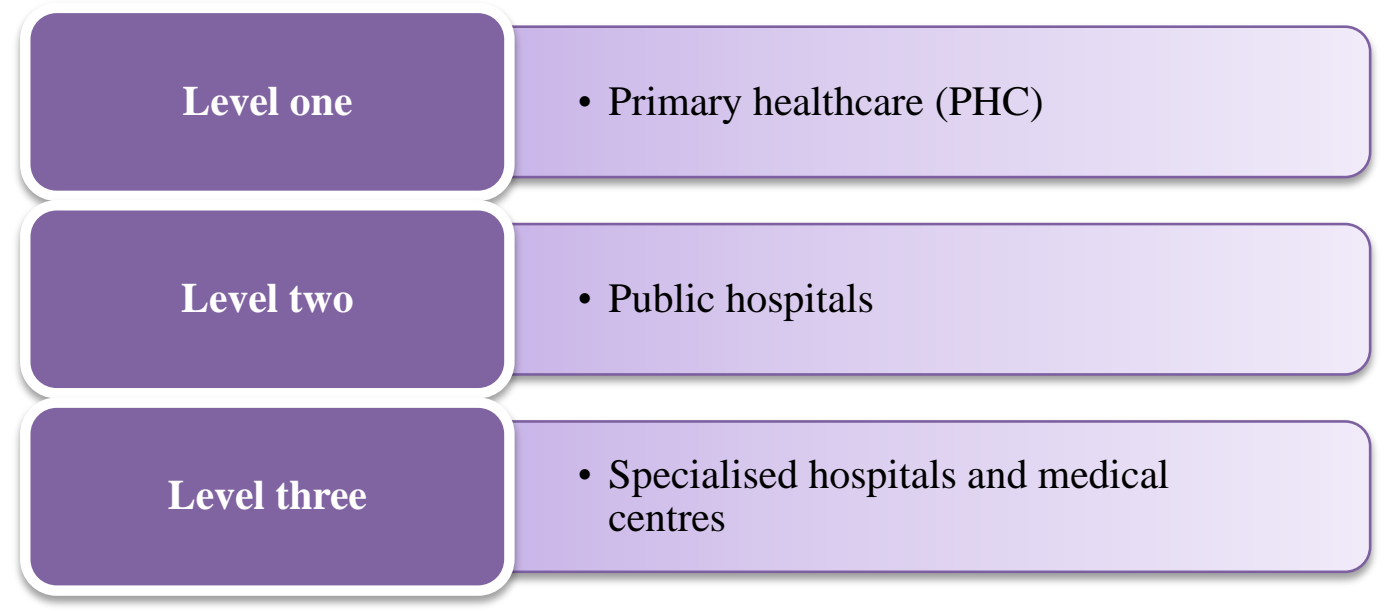

Figure 1.2: Levels of the MoH healthcare system in Saudi Arabia.

\section{Public hospitals.}

As shown in Figure 1.2, the public hospitals are the second level of the $\mathrm{MoH}$ healthcare system in Saudi Arabia. The early public health department in Saudi Arabia was established by King Abdulaziz ibn Saud at Makkah al Mukarrama in 1925 to help provide healthcare services to Muslim people during the Hajj (Almalki et al., 2011a). The first public hospitals in Saudi Arabia opened in 1950 (Mitchell, 2009; Tumulty, 2001). According to a MoH report, in 2011 there were 251 government-operated hospitals, with a capacity of more than 34,450 beds (MoH, 2011). 
The nursing workforce in Saudi Arabia relies mainly on expatriates, who are recruited from 40 different countries, including the United Kingdom, Ireland, the United States, India, the Philippines, South Africa, Malaysia and other Middle Eastern countries (Al-Dossary et al., 2008). However, the number of Saudi nurses has gradually increased over the past few years as a result of Saudization, the national policy designed to encourage employment of Saudi nationals. In 1996 the proportion of Saudi nurses was 9 per cent of the total nursing workforce, and this increased gradually to 17 per cent in 1999. In 2003, the proportion of Saudi nurses had increased to 18 per cent. According to the $\mathrm{MoH}$ (2011), the total number of nurses was 60,671 , with 44.6 per cent $(27,040)$ being Saudi nationals. Moreover, the MoH has attempted to maintain the stability of the nursing workforce by raising the salaries of Saudi nurses by 20 per cent in 2009 .

The Saudi Arabian government has committed significant resources to the healthcare system, allocating more than 39,860,200 SR (US\$ 10,629,386.60) (6.9 per cent) from the government budget. There was a gradual increase in the MoH budget with respect to the total government budget from 5.9 per cent in 2006 to 6.9 per cent in 2011. Its annual budget for developing and improving the medical care system, health organisation and structures is given in Table 1.1, with the ultimate goal of providing free medical care and treatment for 28.3 million individuals, including 8.9 million nonnationals (MoH, 2011). Table 1.1 below presents the Saudi Arabian government budget and the MoH budget from 2006 to 2011. This table indicates the strong support from the Saudi Arabian government to improving the national healthcare system by increasing the MoH budget from 5.9 per cent in 2006 to 6.9 per cent in 2011. 
Table 1.1

The Saudi Arabian Government Budget and the MoH Budget 2006-2011

\begin{tabular}{cccc}
\hline Year & Government Budget (US\$) & MoH Budget (US\$) & Per Cent \\
\hline 2006 & $89,333,333$ & $5,248,986.6$ & 5.9 \\
2007 & $101,333,333$ & $6,082,186$ & 6.0 \\
2008 & $120,000,000$ & $6,725,333.3$ & 5.6 \\
2009 & $126,666,666$ & $7,871,653.3$ & 6.2 \\
2010 & $144,000,000$ & $9,350,186.6$ & 6.5 \\
2011 & $154,666,666$ & $10,629,386.6$ & 6.9 \\
\hline
\end{tabular}

Tables 1.2 and 1.3 present the number, nationality and gender of nurses working in Saudi Arabian MoH public hospitals from 2005 to 2011. These tables do not include nurses working within the private medical sector or in primary healthcare.

Table 1.2

Number of Nurses Working in Saudi Public Hospitals From 2005-2011

\begin{tabular}{lccccccc}
\hline \multicolumn{1}{c}{ Nationality } & 2005 & 2006 & 2007 & 2008 & 2009 & 2010 & 2011 \\
\hline Saudi & 9,669 & 10,417 & 13,542 & 14,737 & 20,977 & 26,307 & 27,040 \\
Non-Saudi & 20,910 & 21,495 & 24,110 & 26,195 & 23,742 & 33,291 & 33,631 \\
Total & 30,579 & 31,912 & 37,652 & 40,932 & 44,719 & 59,598 & 60,671 \\
$\begin{array}{l}\text { Percentage of } \\
\text { Saudi nurses }\end{array}$ & 31.1 & 32.6 & 35.9 & 36 & 46.9 & 44.1 & 44.6 \\
\hline
\end{tabular}

Table 1.3

Gender of Nurses Working in Saudi Public Hospitals

\begin{tabular}{lcccl}
\hline \multicolumn{1}{c}{ Nationality } & Saudi & Non-Saudi & Total & $\begin{array}{c}\text { Percentage of Saudi } \\
\text { Nurses }\end{array}$ \\
\hline Male & 11,564 & 1,541 & 13,105 & 42.8 Saudi male \\
Female & 15,476 & 32,090 & 47,566 & 57.2 Saudi female \\
Total & 27,040 & 33,631 & 60,671 & \\
Percentage of total & 44.6 & 55.4 & 100 & \\
\hline
\end{tabular}

Source: $\mathrm{MoH}$ (2011). 
Table 1.4 gives the number of the MoH public hospitals and their bed capacity. The percentage of Saudi nurses working in public hospitals increased slowly from 31.1 per cent in 2005 to 44.6 per cent in 2011. Further, in the past few years the number of public hospitals in the Kingdom of Saudi Arabia has also increased dramatically, from 213 in 2005 to 251 in 2011.

Table 1.4

The Number of MoH Public Hospitals and their Bed Capacity 2005-2011

\begin{tabular}{lccccccc}
\hline MoH & 2005 & 2006 & 2007 & 2008 & 2009 & 2010 & 2011 \\
\hline Hospitals & 213 & 218 & 225 & 231 & 244 & 249 & 251 \\
Beds & 30,489 & 30,617 & 31,420 & 31,720 & 33,277 & 34,370 & 34,450 \\
\hline
\end{tabular}

The Saudi Arabian MoH is responsible for all public hospitals and they all share similar goals, policies, planning strategies and funding arrangements, although they differ in their management and their geographic locations. However, the nursing workforce in some of these hospitals has not been stable, and some hospitals have a 'revolving door' workforce, mainly attributed to job dissatisfaction among the nursing staff. Job dissatisfaction leads to shortage of nurses and increased recruitment efforts. The MoH must address the factors related to job dissatisfaction in order to stabilise the nursing workforce in Saudi Arabian public hospitals.

\section{Education in Saudi Arabia.}

In general, education in Saudi Arabia is compulsory for all children between the ages of 6 and 17 years. The government of Saudi Arabia has given significant attention to education under the global slogan 'Education for all', and it has allocated more than 25 per cent of the Saudi annual national budget for education, including higher education (Ministry of Higher Education, 2010). The Ministry of Education (MoE), 
which was established in 1954, controls the administration of general education and provides education services through all government and private schools. Further, it is responsible for the education budget and managing infrastructure, equipment and curricula (MoE, 2002). The MoE in Saudi Arabia is responsible for providing a free general education to Saudi students at all levels of education. Tertiary education is also free for all students, but this is under the responsibility of the Ministry of Higher Education (MoHE).

The education system in Saudi Arabia is designed for Saudi and non-Saudi students and there are three general education levels: primary (Grades 1-6), intermediate (Grades 7-9) and secondary (Grades 10-12). Education in Saudi Arabia is gender-segregated at all levels, and boys and girls are educated at separate locations. Further, schools for girls are operated by women and schools for boys are operated by men.

Tertiary education (or higher education) in Saudi Arabia is the responsibility of the MoHE, which was established in 1975 to supervise all aspects of higher education in Saudi Arabia. Much encouragement is given to Saudi students to further their education. Higher education students can receive monthly remuneration ranging from SR 700 to SR 1,000 (average \$AU 200 to 250).

The MoHE (2010) produces comparative statistics that have shown that there were 31 public and private universities in 2009. The MoHE also supervises scholarships and international academic relations. Higher education in Saudi Arabia has grown comprehensively over the past decade, expanding to include 25 government universities and 27 private universities and colleges located in different cities in Saudi Arabia (Saudi Arabia MoHE, 2010) 


\section{Nursing education.}

Nursing education is vital to increasing the number of qualified Saudi nurses to remedy the current shortages. Nursing education in Saudi Arabia started as a basic and limited programme for males only through cooperation between the $\mathrm{MoH}$ and the WHO in 1958 in Riyadh. Fifteen Saudi male students enrolled in this programme for one year. In 1961, two health institutes were established for women, one in Riyadh (the capital) and the other in Jeddah. These institutes educated and trained both women and men to become nurses' aides in hospitals (Miller-Rosser et al., 2006).

In 1967, the MoH created a special Department of Health Education and Training to develop health education, including a nursing department. This department supervises and is responsible for health institutes, including nursing schools (Almalki et al., 2011b). Health institutes and nursing schools were also being developed at that time. A total of 46 health institutes were operating by 1992, with 27 for females and 19 for males. Further, the $\mathrm{MoH}$ is developing 25 of these institutes into junior colleges, 10 for females and 15 for males (Alhusaini, 2006). By 2005 there were 109 health institutions covering the 13 regions of Saudi Arabia, with most of them operated by the MoH (AlMahmoud, 2013).

In 2008, all these health institutes and health junior colleges were transferred from the MoH to the MoHE. The purpose of this transfer was to upgrade these institutes and junior colleges to enable them to offer a bachelor's degree under the university system. Further, the MoHE has the financial resources, education facilities and academic experience that is crucial to developing healthcare education and this was thought to be a potential way to improve the quality of health education and training for all health departments, including nursing (Almalki et al., 2011b). 
The majority of nurses in Saudi Arabia hold a Diploma in Nursing. However, to improve and upgrade this level of education, there are few programmes in universities that provide a bridging Bachelor of Science degree in nursing programmes. Additionally, most of these programmes only have a limited number of places. The MoHE initiated the first female Bachelor of Science in Nursing (BSN) programmes in 1976 at King Saud University in Riyadh and King Abdulaziz University at Jeddah in 1977 and at King Faisal University in Dammam in 1987. Further, a Master of Science in nursing (MSN) programme was started in 1987 at King Saud University in Riyadh (Mebrouk, 2008; Tumulty, 2001). A PhD programme was established as a limited programme through cooperation between King Abdulaziz University and certain British universities in 1994 (Abu-Zinadah, 2004; Almalki et al., 2011b). All of these postgraduate programmes were established for female students only. The nursing education system in Saudi Arabia is totally segregated by gender, as is the general education system; however, there is interaction between males and females in the work environment.

A scholarship programme was established in 1996; this programme provides for Saudi students who wish to study nursing abroad, including in Australia, the UK, Canada and the United States. For example, King Faisal Specialist Hospital and the Research Centre (KFSH\&RC), in collaboration with Monash University in Australia, offer in-country scholarship programmes for Saudi nurses to obtain their Master's and $\mathrm{PhD}$ degrees when they are unable to leave Saudi Arabia (due to family commitments or otherwise) to study abroad (Al-Dossary et al., 2008; Miller-Rosser et al., 2006).

\section{Statement of the Problem}

The healthcare system and the health infrastructure in Saudi Arabia are improving and developing gradually. Nevertheless, the shortage of nurses and the 
instability in numbers of Saudi national nurses have become critical issues for health policymakers. Most nurses working in the healthcare system come from other countries and if they leave their jobs for any reason, then the Saudi healthcare system and public hospitals will be faced with a crisis situation. According to Abu-Zinadah (2004), the national shortage of nurses arises from the small number of Saudi graduates from nursing school institutes and colleges.

Nursing job satisfaction is important in order for the healthcare system to maintain a stable workforce and reduce the shortage of nurses (Al-Dossary et al., 2012). Researchers have found that there are many variables, such as work environment, age, level of education and experience that can influence nursing job satisfaction (Apostlidis \& Polifroni, 2006; Borkowski, Amann, Song, \& Weiss 2007; Jones, 2011). According to Hansen (2007), job dissatisfaction has been identified as the major cause of nurse turnover and nursing instability and it contributes to the shortage of nurses (Hayes et al., 2010). Job satisfaction also affects the productivity of nurses and is linked to positive patient outcomes (Hayes et al., 2010; Kovner, Brewer, Wu, Cheng, \& Suzuki, 2006; Lynn and Redman, 2005).

Saudi Arabia is currently facing a significant shortage of, and high turnover among, Saudi nurses. Hence, the country is faced with the need to recruit and retain Saudi national nurses. Identifying and exploring the level of job satisfaction of Saudi nurses could help health managers to support the $\mathrm{MoH}$ and policymakers with clear information about the factors that influence job satisfaction regarding Saudi nurses working in public hospitals. This information could potentially promote the stability of Saudi nurses working in the Saudi healthcare system.

Globally, there is a lack of nursing research, especially with regard to the shortage of nurses in Saudi Arabia and job satisfaction of Saudi nurses. This study will 
help remedy this problem by identifying factors influencing the job satisfaction levels of Saudi nurses working in Saudi public hospitals. Further, the research data will provide policymakers with information regarding the factors contributing to Saudi nurses' job satisfaction.

\section{Purpose of the Study}

The purpose of this study is to explore the level of job satisfaction of Saudi nurses working in Saudi public hospitals. In particular, this study will identify and explore the factors that influence the level of job satisfaction of Saudi nurses working in three of the largest public hospitals in three cities in the Makkah region. It will evaluate Herzberg's motivation-hygiene theory and explore which motivating and hygiene factors are instrumental in contributing to the job satisfaction/dissatisfaction of Saudi nurses. Exploring and describing job satisfaction in Saudi nurses working in public hospitals may assist in developing strategies to improve job satisfaction, which will lead to improved productivity and patient care. Based on the lack of studies of Saudi nurses working in public hospitals and due to the paucity of studies conducted in the area of job satisfaction of Saudi nurses, the purpose of this study was to address this gap in the literature.

The first phase of the study involved the use of a quantitative research method using the Nursing Work Index-Revised (NWI-R) survey by Aiken and Patrician (2000). In determining job satisfaction, the NWI-R questionnaire elicits information on the intrinsic factors (such as advancement, the work itself, possibility of growth, responsibility, recognition and achievement) and extrinsic factors (such as interpersonal relationships, salary, workplace policies and administration, supervision and working conditions) that might contribute to job satisfaction of Saudi nurses in public hospitals in the Makkah region. It was preceded by demographic information which included 
gender, age, marital status, number of dependent children, number of dependent adults, educational qualifications, monthly salary, employing hospital, position, duration of employment at the hospital, number of weekly hours worked and overall experience in nursing. In the second phase semi-structured face to face interviews were conducted. These nurse interviews provided indepth information in relation to job satisfaction, recruitment of these nurses into the profession and the general public image of the profession of nursing in Saudi Arabia.

\section{Significance and Aims of the Study}

This research aims to describe and explore the level of job satisfaction of Saudi nurses working in public hospitals, as well as nurses' perceptions of the causes of rapid turnover in the nursing workforce. Globally, many researchers have studied job satisfaction, including the factors that influence nursing job satisfaction in various countries (Aiken et al., 2001; Apostlidis \& Polifroni, 2006; Best \& Thurston, 2004; Hayes et al., 2010; Hegney et al., 2006; Kovner, Brewer, Wu, Cheng, \& Suzuki, 2006; Ma, 2002; Price, 2002; Seo, Ko \& Price, 2004; Zangaro \& Johantgen, 2009). This study will specifically identify the factors that affect job satisfaction for Saudi nurses. Further, it offers recommendations and possible solutions for the shortage of Saudi nurses in public hospitals.

The significance of this research is its attempt to identify and assess factors that influence job satisfaction in order to prevent the collapse of the Saudi public healthcare system. As the maintenance of public hospitals and the provision of quality healthcare to the Saudi public are at stake, this issue is of utmost interest to policymakers in the $\mathrm{MoH}$, nurse managers, directors and nurse educators. This study could also help the $\mathrm{MoH}$ to provide and encourage the stability of Saudi nurses and to increase the supply of nursing staff in public hospitals. 
The $\mathrm{MoH}$ has devoted considerable attention to this issue. For example, in March 2011, the MoH commissioned a high-level committee to draft a new strategic plan to increase the number of Saudi nurses, address the nursing shortage and increase the retention of nursing staff by examining and discussing the level of job satisfaction and turnover of nursing staff (Maaet, 2011). This study will contribute by providing information and strategies to remedy the shortage of Saudi nurses and to promote a better public image of nursing. As such, this study will inform policymakers and provide valuable information for workforce planning.

\section{Research Questions}

The major research question posed by this research reflects the concepts integral to Herzberg's two-factor theory, and is: What are the factors that affect job satisfaction among Saudi nurses working in three public hospitals: (A) King Fahd General Hospital in Jeddah, (B) King Abdul Aziz General Hospital in Makkah and (C) King Faisal General Hospital in Taif, in the Makkah region of Saudi Arabia, with respect to the two levels of motivation and hygiene of Herzberg's theory?

This larger research question is subdivided into the following four questions:

Q1: How do demographic factors affect motivation and job satisfaction?

Q2: How do demographic factors affect the hygiene factors and job satisfaction?

Q3: What are the factors that predict job satisfaction among Saudi nurses in public hospitals?

Q4: What are the factors that predict job satisfaction among Saudi nurses in each of the three hospitals?

\section{Definition of Terms}

According to Robbins, Judge, Millett and Waters-Marsh (2008), the term job satisfaction is defined as 'a positive feeling about one's job resulting from an evaluation 
of its characteristics'( p. 79), and turnover is defined as 'the voluntary and involuntary permanent withdrawal from an organisation'( p. 25).

Saudization refers to 'a policy that promote Saudi nationals to be educated and/or trained in all areas of employment to replace current expatriate workers' (MillerRosser et al., 2006, p. 2).

Shortage of nurses refers to 'an imbalance between demand for employment and the available supply' (Oulton, 2006, p. 34S).

Motivator factors are intrinsic factors that refer to internal factors, such as growth, achievement, the work itself and responsibility. They are generated inside the individual to create motivation towards the job and influence job satisfaction (Herzberg et al., 1959). In contrast, hygiene factors are extrinsic and external factors, such as salary, benefits, status, security and working conditions that are generated outside of the individual to create motivation towards the job and influence satisfaction (Herzberg et al., 1959).

Registered Saudi nurse refers to a nurse licensed by the Saudi Commission for Health Specialties (SCFHS) as a registered nurse.

Job stress refers to 'the extent to which employees feel a tension or anxiety caused by their jobs' (Gill, Flaschner \& Shachar, 2006, p. 472).

\section{Structure of the Thesis}

Structurally, the current thesis consists of eight chapters, as described below.

Chapter 1. This chapter has provided an introduction to the study and an overview of the thesis, including the study location, and also provided a comprehensive picture of the study context, including the history, geography, economy, demographics, social practices, culture, healthcare system and education in Saudi Arabia. Further, it 
describes a statement of the problem, the purpose of the study, the significance and aim of the study, the research questions and definitions of terms used in the study.

Chapter 2. This chapter reviews the literature related to the research questions. This includes a discussion concerning job satisfaction globally and in Saudi Arabia, identifying the factors that influence nurses' job satisfaction and the shortage of nurses both locally and globally, as well as identifying the factors that influence shortage of Saudi national nurses.

Chapter 3. This chapter describes the conceptual framework of the study. The conceptual framework used in this study is the 'motivation-hygiene theory', also known as Herzberg's two-factor theory or Herzberg's dual-factor theory. The main concept of this theory is the difference between two factors: motivation and hygiene (Herzberg et al., 1959).

Chapter 4. This chapter describes the research design and methodology utilised for this study. The research design, settings and sampling strategy used are presented. The chapter is divided into two phases: the first phase is quantitative and the second phase employs qualitative methods. It also describes the instruments used for data collection, the assessment of validity and reliability, the methods of data analysis and ethical considerations.

Chapter 5. This chapter presents the analysis of the quantitative data. It uses the NWI-R survey instrument and a demographic survey to measure the variables in the current study. It is divided into two phases: the first phase is a descriptive analysis, while the second phase is an inferential analysis.

Chapter 6. This chapter presents the analysis of qualitative data. It incorporates a qualitative method of semi-structured interviews with Saudi nurses. In addition, it focuses on answering the current study's research questions. The interviews were 
intended to permit a deeper understanding of the concept of job satisfaction among Saudi nurses.

Chapter 7. This chapter discusses the major research results of the quantitative and qualitative analyses in relation to the research questions.

Chapter 8. The final chapter begins by examining the strengths and limitations of this study. This is followed by a discussion of the implications of the research findings and recommendations for the $\mathrm{MoH}$, nursing education, leadership, practice and for the Saudi community. The chapter also provides implication of the conceptual framework and suggestions for further research. The last section in this chapter presents the study conclusion.

The next chapter, Chapter 2, reviews the literature related to job satisfaction and will explore the factors that influence nurses' job satisfaction. 


\section{Chapter 2: Review of the Literature}

\section{Introduction}

Job satisfaction has been frequently studied within many disciplines, including nursing, sociology, psychology, engineering, accounting, health work and management. The study of job satisfaction has a long history in the discipline of nursing as one of the most investigated topics in nursing management globally (Jackson-Malik, 2005). Job satisfaction research started with the famous Hawthorn studies in 1924, conducted by Elton Mayo and his team at the Western Electronic Company in Massachusetts. The purpose of the Hawthorn studies was to explore the effects of observation on workers' productivity (Hansen, 2007). Job satisfaction is a topic of great interest for many health organisations. Research supports the importance of examining job satisfaction when developing work policies to determine and assess the attitudes and perceptions of staff, as well as the various elements that can affect job productivity and quality of care, such as environment, pay, workload, leadership style, shortages of nursing staff and nursing staff turnover (Hayes et al., 2010; Lu, Lin, Wu, Hsieh, \& Chang, 2002; Lu et al., 2005).

The widespread shortage and the high turnover rates of nurses have become persistent problems in most healthcare organisations around the globe. Poor job satisfaction has been linked to high levels of nurse turnover and intentions to leave nursing as a profession (Abu Raddaha et al., 2012; Choong, Lau, Kuek, \& Lee, 2012). However, with increased job satisfaction overall employee turnover has been shown to decrease and the stability and retention of nursing staff to increase (Miller, 2007). Thus, job satisfaction can positively affect the overall work of the organisation, whereas job dissatisfaction can negatively impact the work of the organisation (McGlynn, Griffin, Donahue, \& Fitzpatrick, 2012). The literature identifies key areas of concern relevant to this thesis. Therefore, the literature was considered both geographically and 
thematically. A focus on individual country-based research identified the factors that could affect nursing job satisfaction and turnover. The thematic analysis provided an overview of common factors that influence nursing satisfaction, irrespective of the geographic location.

The primary goal of this chapter is to present the literature related to nurses' job satisfaction. This chapter is presented in three main sections. The first section offers a discussion of job satisfaction, both globally and locally in Saudi Arabia. This provides a comparative context for research into Saudi nurses' job satisfaction. In the second section, the discussion identifies the factors that influence nurses' job satisfaction. This provides a counterpoint to the findings derived from geographic factors. The third section consists of a review of literature focused on the global nursing shortage as well as the local nurse shortage in Saudi Arabia. This section also identifies the specific factors that influence the shortage of Saudi nursing staff.

\section{Overall Literature Search Strategy}

A comprehensive review of the literature on nurses' job satisfaction, both internationally and within Saudi Arabia, was conducted in order to gain a better understanding of the factors that affect nursing job satisfaction and retention. This review provided the background for this study and identified the need for continued research in this area. The researcher conducted a series of literature searches utilising electronic databases to gather relevant articles. These databases included CINHAL, PUBMED, SCOPUS, PROQUEST and Nursing and Allied Health Science. The search included research studies conducted within the past 15 years (the articles selected are dated from 1999 to 2013). The search strategy utilised various combinations of terms, such as ‘nursing job satisfaction’ AND ‘shortage of nurses’ AND ‘turnover' AND 'public hospitals' (refer to Table 2.1 below). Another secondary search using the terms 
'Saudi nurses’ AND ‘job satisfaction’ AND ‘shortage of nurses' (refer to Table 2.2 below) was utilised to locate Saudi Arabian literature on nursing job satisfaction. A total of 61 studies were identified and reviewed, comprising 45 international studies and 16 Saudi studies. In addition, a number of relevant internet sites were utilised, such as the American Council of Nurses and WHO sites as well as the Saudi Arabian MoH website.

Table 2.1 presents a summary of the terms used in the international literature search, the databases and the number of articles found to be related to this study. All duplicate and unrelated articles were excluded.

Table 2.1

International Search Summary from1999 to 2013

\begin{tabular}{lcccccc}
\hline Database & \multicolumn{5}{c}{ Search Terms/Process } \\
\hline & $\begin{array}{c}\text { Nursing job } \\
\text { satisfaction }\end{array}$ & $\begin{array}{c}\text { AND } \\
\text { shortage } \\
\text { of nurses }\end{array}$ & $\begin{array}{c}\text { AND } \\
\text { turnover }\end{array}$ & $\begin{array}{c}\text { AND } \\
\text { public } \\
\text { hospitals }\end{array}$ & $\begin{array}{c}\text { Found to } \\
\text { be } \\
\text { relevant to } \\
\text { the study }\end{array}$ & $\begin{array}{c}\text { After } \\
\text { removal } \\
\text { of } \\
\text { duplicates }\end{array}$ \\
\hline IINHAL & 320 & 15 & 8 & 1 & 1 & 1 \\
PUBMED & 5,230 & 313 & 139 & 7 & 3 & 2 \\
$\begin{array}{l}\text { SCOPUS } \\
\text { PROQUEST }\end{array}$ & 5,666 & 1,001 & 581 & 272 & 32 & 8 \\
Nursing) & 19,241 & 5,354 & 2,282 & 1,640 & 91 & 34 \\
\hline
\end{tabular}

The table below presents a summary of the terms used in the Saudi literature search, the databases and the number of articles found to be related to this study. Duplicate and unrelated articles were excluded. 
Table 2.2

Saudi Search Summary from1999 to 2013

\begin{tabular}{lccccc}
\hline Database & \multicolumn{5}{c}{ Search Terms/Process } \\
\hline Saudi nurses & $\begin{array}{c}\text { AND job } \\
\text { satisfaction }\end{array}$ & $\begin{array}{c}\text { AND shortage } \\
\text { of nurses }\end{array}$ & $\begin{array}{c}\text { Found to be } \\
\text { relevant to the } \\
\text { study }\end{array}$ & $\begin{array}{c}\text { After } \\
\text { removal } \\
\text { of } \\
\text { duplicates }\end{array}$ \\
\hline IINHAL & 38 & 7 & 1 & 1 & 1 \\
PUBMED & 203 & 15 & 1 & 1 & 0 \\
SCOPUS & 234 & 34 & 9 & 6 & 3 \\
PROQUEST & 1,582 & 244 & 105 & 35 & 12 \\
Nursing) & & & & &
\end{tabular}

\section{Job Satisfaction in Nursing}

It is essential for healthcare managers and policymakers of private and public healthcare organisations to identify the level of job satisfaction among nurses to plan recruitment and staff retention strategies. Positive job satisfaction is vital, especially for nurses, to enhance nursing care, improve daily practice, increase productivity and enable the delivery of high quality healthcare, as well as to maintain a stable nursing work force (Al-Enezi, Chowdhury, Shah, \& Al-Otabi, 2009; Sullivan-Havens \& Johnston, 2004). However, negative job satisfaction can lead to nurses having negative attitudes towards their jobs and poor patient care outcomes, which can increase the length of patients' hospital stays, thus increasing treatment costs, as well as resulting in an increase in staff turnover and hence creating shortage of nursing staff (Choong et al., 2012).

\section{Job satisfaction defined.}

Job satisfaction is difficult to define as it differs from study to study and from researcher to researcher. Nevertheless, job satisfaction has been generally described as a positive effective attitude towards one's job (Miller, 2007). Smith, Kendall and Hulin 
(1969) stated that the definition of job satisfaction is the general feeling an employee has towards their job. When exploring the phenomenon of job satisfaction, many of the aspects of the job must be considered, such as work satisfaction, supervision, pay, promotion opportunities, as well as the practices of the organisation. Adams and Bond (2000) define job satisfaction as the degree of positive affect that a job offers. Brooks and Anderson (2004) defined job satisfaction as worker's 'likes' and 'dislikes.' More recently, Wilson (2006) defined job satisfaction as the extent to which needs are currently being met. In contrast, Tourangeau, McGillis Hall, Doran and Petch (2006) defined job satisfaction as the positive and negative attitudes and feelings a worker holds towards their job. Finally, according to Robbins and colleagues (2008), the term job satisfaction is defined as 'a positive feeling about one's job resulting from an evaluation of its characteristics' (p. 79). Thus, the literature utilises many terms to describe job satisfaction; some of these terms are job attitudes, work satisfaction and job morale (Hansen, 2007). This can result in a lack of clarity in the literature study results.

\section{Job satisfaction among nurses globally.}

It is of interest to refer to one of the first studies in the literature relating to nursing job satisfaction by Nahm (1940) from the University of Minnesota. The study results showed that supervisory relations, income, promotional opportunities, hours of work, interest in work, and family and social relationships were determinants of job satisfaction. Since that initial study, many studies on nursing job satisfaction have been conducted in various countries, including the United States (Cahill, 2011; Kovner et al., 2006; Ma, 2002; McGlynn et al., 2012; Zangaro \& Johantgen, 2009), Canada (Best \& Thurston, 2004; Hansen, 2007), England (Price, 2002), Australia and New Zealand (Hayes, Bonner, \& Douglas, 2013; Hegney et al., 2006; Skinner, Madison, \& Humphries, 2012), Korea and China (Seo et al., 2004; Hwang et al., 2009), Pakistan 
(Bahalkani et al., 2011), Kuwait (Al-Enezi et al., 2009) and Jordan (Mrayyan, 2005). These studies sought to identify and explore the factors that could contribute to nursing job satisfaction around the world. They demonstrated strong similarities in their results, regardless of where they were conducted.

Aiken et al. (2001) conducted a study on nurses' job satisfaction via questionnaires that were posted to 43,329 registered nurses working in 711 adult acute care hospitals in five countries during 1998 and 1999. The sample of this study was recruited from the United States (13,471), Canada (17,450), England (5,006), Scotland $(4,721)$ and Germany $(2,681)$. Response rates for this study ranged from 42 per cent to 53 per cent. The findings showed that job dissatisfaction was highest among nurses working in the United States. Nurses working in Germany were more satisfied with their opportunities for advancement (61 per cent) than other groups of nurses, while Canadian nurses were more satisfied with their salaries than others (69 per cent) (Aiken et al., 2002; Hayes et al., 2010).

Aiken et al. (2002) described commonalities across countries in terms of the shortcomings of the work environment and quality of care, highlighting the universality of nursing shortages and nurse dissatisfaction. The authors called for the need for new personnel policies to address the needs of front-line nurses. Given the nuances in language and culture, this could have been a limitation of the study, but was not noted as such.

\section{The United States.}

Studies conducted in the United States demonstrated the lowest level of nursing job satisfaction (Aiken et al., 2002; McGlynn et al., 2012) and revealed that many factors are related to job dissatisfaction, including individual demographic characteristics, job-specific issues and geographic factors (Cahill, 2011; Kovner et al., 
2006; Ma, 2002; Zangaro \& Johantgen, 2009). Although Ma (2002) found a significant relationship between years of experience and job satisfaction, the most significant factors related to job satisfaction in the studies from the United States focused on the job, workplace environment and organisational factors. These factors include health and retirement plans and job position (Ma, 2002); group cohesion, variety of work experiences, organisational support, low work-family conflict (Kovner et al., 2006); promotional opportunities, supervisor support and co-worker support (Kovner et al., 2006; Zangaro \& Johantgen, 2009) and autonomy (Cahill, 2011; Kovner et al., 2006). To understand the methods, data collection and analysis, as well as the results, each study, starting with Ma's (2002) study is discussed and detailed at length.

Ma (2002) conducted a study sampling nurses from hospitals in South Carolina to identify the individual, work and geographic factors that influence nurses' job satisfaction. A questionnaire was administered to 4,000 registered nurses and the results showed that there is a significant difference in job satisfaction and years of experience, health retirement plans, job position and geographic area, which all affect overall job satisfaction. The study was limited by a low response rate of approximately 20 per cent.

Kovner et al. (2006) also studied the factors that influence work satisfaction, using a national survey sample of registered nurses in the United States. A sample of 1,538 registered nurses was randomly selected from 40 metropolitan areas in 29 states. The response rate in this study was 48 per cent. The findings indicated that high autonomy, high group cohesion, good promotional opportunities, high distributive justice, strong supervisor support, high variety of work, low organisational support and low work-to-family conflict were significantly correlated with satisfaction. Adding to the literature on nurse satisfaction, it was found that registered nurses who worked in nursing education and nurses who provided direct care were more satisfied than 
registered nurses who worked as managers. The cross-sectional study design utilised a large and diverse sample that was demographically reflective of the United States national population of registered nurses (Kovner et al., 2006), supporting the validity of the findings. Although the study defined relationships between satisfaction and independent variables, it failed to provide insight into meaningful change, as in the amount of change needed to produce a significant change in satisfaction; this was beyond the scope of the study. Additional research into meaningful change stemming from these variables is needed.

A third study in the United States by Zangaro and Johantgen (2009) was a crosssectional study of nurses working in navy and military hospitals. This study identified the factors that influence the job satisfaction of navy and civilian registered nurses. The response rate in the study was 42 per cent of the 496 nurses that were surveyed. The findings revealed that there was a strong negative correlation between job satisfaction and staff rotations through various clinical areas. Promotional opportunity was a significant indicator of job satisfaction for both civilian and military nurses, and has a high influence on military nurses. Co-workers' support had a significantly positive correlation with job satisfaction for civilian nurses, although supervisor support was a significant positive factor for navy nurses. Further, the results showed that a higher level of clinical rotations and increased amount of role ambiguity predicted lower levels of satisfaction. The regression model explained roughly 50 per cent of the variation in satisfaction; although this was significant, there may be other compounding factors that were not considered in this study. In addition, given the unique setting of the military hospitals in this study, the results may not be generalisable to the larger non-military nursing population. 
Using a descriptive correlational research design, Cahill (2011) sought to identify the link in the state practice environments between nurse practitioners in Iowa and Illinois. Survey Monkey was used for this study, with a convenience sample of 289 nurse practitioners. Herzberg's two-factor theory provided the conceptual framework for Cahill's study. The findings revealed that hours worked and practice locations were the only significant demographic factors. Further, the nurse practitioners were most satisfied with intrinsic factors, such as autonomy. Although the study provided insight into nursing satisfaction related to the environment, the online-only format of the survey instrument may have limited response types, particularly with regard to age. The author reported that the 'typical respondent' was 49 years old, but there were no other reports of the age distribution of the sample. With the online-only survey format, it is questionable as to whether certain age groups would readily participate and therefore, an age gap could be present, particularly among older, more experienced nurses.

Finally, McGlynn et al. (2012) studied a model of registered nurse job satisfaction and satisfaction with professional practice in an academic medical centre in the northeast of the United States. A descriptive cross-sectional method was used. Questionnaires were administered to 182 full-time and part-time registered nurses. The response rate for this study was 53 per cent. The conceptual framework of this study was also Herzberg's two-factor theory. The findings revealed that overall the level of job satisfaction was low. However, the nurses were moderately satisfied with the professional practice environment. Further, the results indicated that there was no statistically significant relationship between job satisfaction and variables such as age and work experience. The significant negative relationship between overall nurse satisfaction and satisfaction with the work environment was a result that was 
contradictory to previous research in this field. Perhaps this result highlights the multidimensional nature of nurse satisfaction.

\section{Canada.}

Two studies were identified from Canada. These studies found that the factors that affect job satisfaction among Canadian nurses mirrored those in the American studies (Best \& Thurston, 2004), with a focus on autonomy, pay, interactions (coworker and supervisory support), task requirements, professional status and organisational policies. However, where the United States studies failed to show a definite influence of age and years of experience (McGlynn et al., 2012), the Canadian studies supported an increase in job satisfaction with age (Best \& Thurston, 2004; Hanson, 2007) and a decrease in job satisfaction with number of years in the position (Hanson, 2007). The study by Best and Thurston (2004) focused on a children's hospital and three adult acute care hospitals in Canada. The sample included 20 per cent of approximately 4,000 full-time and part-time registered nurses who were randomly selected from nine clinical departments, including operating and recovery rooms, psychiatry, surgical inpatients, renal, medical, ambulatory care and inpatients, women's health, child health, heart health, emergency, neuroscience and rehabilitation. Questionnaires were administered to 800 registered nurses and 387 were returned, representing an overall 48 per cent response rate. Best and Thurston explored the relationship among selected variables related to work life and job satisfaction. Calculating significance scores to define the level of job satisfaction of registered staff nurses from these hospitals resulted in the following order of job satisfaction components: autonomy, pay, interaction, task requirements, professional status and organisational policies. 
Best and Thurston (2004) indicated that these six job satisfaction components were the same in this study as in many studies conducted in United States hospitals, reflecting a similarity in clinical care. The findings of this study showed that job satisfaction increases and improves with age. Further, age is a more significant predictor of satisfaction with being a nurse. Older registered nurses expressed higher satisfaction with their jobs and with nursing as a profession. However, the study did not offer insight into the mechanisms for explaining the differences in satisfaction according to age.

Hansen (2007) studied nurses' job satisfaction in a large urban care hospital in Ontario, Canada; this study focused on four clinical areas, including mental health, surgery, medical and intensive care. Surveys were administered to 240 registered nurses; the response rate for this study was 55 per cent. Hansen's study used a quantitative descriptive design to identify the factors that influence the job satisfaction of registered nurses working in an acute care hospital. Further, this study determined the level of job satisfaction and investigated the relationship between job satisfaction and demographic variables, including the total years of experience as a nurse, clinical area and nature of employment, age and total number of years spent in the current position. The conceptual framework of the Hansen's study was Maslow's hierarchy of needs. The findings of this study showed that job satisfaction increases and improves with age. The results also demonstrated that if the number of years in a position increased, job satisfaction decreased. Although increased age supported satisfaction, a longer time in one's position decreased satisfaction, suggesting the need for diversity in work roles. Investigating this was beyond the scope of the study, but this finding highlights the need to look beyond direct relationships with satisfaction and into the reasons behind these relationships, perhaps using a qualitative method. 


\section{England.}

A single study was reviewed from England. The majority of the nurses in this study demonstrated positive levels of satisfaction, highlighting similar factors as both the Canadian and United States studies, which focused on organisational factors and age. Price (2002) studied the job satisfaction of registered nurses working in an acute hospital, using a quantitative study design. Surveys were administered to 175 registered nurses working in the medical and surgical wards in a large teaching hospital, with a response rate of 87 per cent. The results revealed that over half of the participants ( $\mathrm{n}=82 ; 58$ per cent) were generally satisfied with working in nursing. Co-worker support showed the highest significant correlation with job satisfaction and the strongest dissatisfaction was with a lack of professional opportunities and the amount of control the nurses had. Further, the results showed that most satisfied nurses were aged between 51 and 60 years and the most dissatisfied nurses were identified as being aged between 31 and 40. Price's study used a quantitative approach to identify the job satisfaction of nurses working in adult medical and surgical specialties; the instrument used was the McCloskey/Mueller Satisfaction Scale (MMSS) (1990).

The high response rate and diversity of the sample for the study by Price (2002) strengthens the validity of the study. The results are consistent with research from the United States and Canada, as discussed previously. In addition, the results are consistent within the study, as dissatisfaction with a lack of control/responsibility and satisfaction with more control would seem to coincide with age in that more experienced nurses may be likely to be in positions of greater control and/or responsibility. Price (2002) acknowledged the likelihood of impact of compounding variables not considered in the analysis, again highlighting the multidimensional nature of nurse satisfaction. 


\section{Australia and New Zealand.}

As with the British study by Price (2004), studies of nurses' job satisfaction in Australia tended to demonstrate moderate to high levels of job satisfaction (Skinner et al., 2012). The studies conducted in this region showed both intrinsic and extrinsic factors to be relevant to levels of job satisfaction (Hegney et al., 2006). Similar to the previous studies, task requirements, morale and level of autonomy were significant intrinsic factors affecting job satisfaction (Hayes et al., 2013; Hegney et al., 2006). In addition, extrinsic and organisational factors were also reported to be significantly related to job satisfaction, including working environment, organisational policies, pay and professional status (Hayes et al., 2013; Hegney et al., 2006).

In Australia, Hegney and colleagues (2006) performed a study to identify the extrinsic and intrinsic work values that influenced job satisfaction for nurses belonging to the Queensland Nurses Union (QNU) in Queensland, Australia. Questionnaires were posted to 2,800 registered nurses and nursing assistants working in three sectors; public, private and aged care. The response rate for this study was 53 per cent. The extrinsic work values included remuneration, working conditions, rewards for skills and experience and perceptions of nursing as a career. The intrinsic work values included the physical demands of nursing work, morale, work stress, emotional challenges of nursing work and the level of autonomy. The results revealed that intrinsic and extrinsic work values impact on job satisfaction and the nurses' intentions to leave their profession. It was further indicated that morale was either low or decreasing and work stress was high. The sample in this study included registered nurses, enrolled nurses, and nursing assistants. The authors accounted for limitations and potential biases by estimating the potential effects of these limitations on the results of the study, which helped to support the validity of the findings. 
Skinner et al. (2012) studied job satisfaction of Australian nurses and midwives. A descriptive survey method research study was used with a convenience sample of 562 registered nurse and midwives from aged care facilities, public hospitals and community health centres. The response rate in this study was 41.4 per cent. The researcher used three theories as conceptual framework for this research and these included: the effort-reward imbalance theory (Vroom, 1979), Karasek's (1979) demandcontrol model and the person-fit theory (Mansfield et al., 1989). The results of this study showed that only 4 per cent of the participants' were dissatisfied with their jobs. The vast majority of the participants (96 per cent) were moderately to highly satisfied with their jobs. The results of Skinner's study (2012) demonstrated regular instances of experiences of moderate to high stress. The study found that participants were satisfied with their work, which suggested that the nurses in the study were able to work with moderate effects of stress without this contributing to job dissatisfaction (Skinner et al., 2012). The results seemed to indicate stress is related to the workplace environment, personal characteristics or responses to stress. The relationship between stress and dissatisfaction seems to be an area in need of additional research. In addition, this study supported other research from many countries suggesting that older nurses were more satisfied. The authors provided a full factor analysis of the survey instrument, contributing to the credibility and validity of the survey results.

In Australia and New Zealand, Hayes et al. (2013) conducted a cross-sectional study to identify the levels of job satisfaction, stress and burnout among Australian and New Zealand haemodialysis nurses. A sample of 417 registered nurses responded to an online survey, with 396 nurses working in Australian and 21nurses from New Zealand haemodialysis units participating in this study. The results revealed that overall job satisfaction for haemodialysis nurses was comparable between Australia and New 
Zealand on a six-point scale. Australian nurses rated autonomy, organisational policies, pay and professional status components higher than their New Zealand counterparts. The authors related stress and burnout to younger nurses, who were also found to have lower job satisfaction levels. Burnout was found to be related to lack of support, heavy workloads, and interpersonal conflicts. The relationship between stress and burnout or turnover remained somewhat ambiguous. Given the previous results from Skinner et al. (2012), identifying the mechanisms and interactions of stress and dissatisfaction and the factors that contribute to each may reveal insights into the multidimensional nature of satisfaction and how it can be supported.

\section{Korea and China.}

Two studies were conducted on nurses' job satisfaction in the Asian regions of Korea and China. The study results focused on professionalism, job position and age (Hwang et al., 2009), as well as organisational factors related to job opportunities, supervisory support and workload, pay and routinisation of tasks (Seo et al., 2004).

In Korea, Seo et al. (2004) conducted a study to determine job satisfaction among hospital nurses. A descriptive study design was used, and questionnaires were administered to 540 nurses from two general acute care hospitals in the cities of Seoul and Taegu. All nurses participating in this study were female, and the response rate of the study was 65.4 per cent. The results of this study showed that there are many variables that can impact significantly upon hospital nurses' job satisfaction, such as structural variables, including workload, supervisory support, routinisation and pay; psychological variables included positive and negative affect, and environmental variables job opportunity and promotion. Despite a large sample with nearly 400 usable surveys, the sample was exclusively female, which was a limitation of the study on a global level, but perhaps representative of the Korean population of nurses. Whether 
male nurses were a cultural anomaly in this country was not discussed. In addition, the sample was limited to two hospitals in Korea. Lastly, the cross-sectional design limited the results of the model formulation, preventing inferences being made on cause and effect.

Hwang and colleagues (2009) studied the major factors that influence job satisfaction among Korean and Chinese nurses. A descriptive cross-sectional study was used. Questionnaires were administered to 1,311 nurses who worked in five hospitals in two countries, including 693 nurses from three general hospitals in China and 593 nurses from two general hospitals in Korea. The response rates for this study were very high, at 97.1 per cent for the Korean nurses and 99 per cent for the Chinese nurses. The findings of this study revealed that there was a positive relationship between professionalism and job satisfaction, with professionalism as the most important factor impacting nurses' satisfaction in both countries. Further, other factors demonstrated a significant influence the job satisfaction of the Korean nurses; these factors included their clinical specialty area, their job position and age. A key weakness of the study, which was not directly addressed, was the differences in cultural understanding of professionalism between Korean and Chinese nurses. The authors discussed these differences in terms of self-concept and social awareness as these relate to the nursing field and suggested that the individual nurse's perceptions of professionalism are uniquely shaped by their cultural backgrounds. The results of the study did not take this factor into account.

\section{Pakistan.}

A single study conducted in Pakistan was reviewed. Bahalkani et al. (2011) conducted a study of job satisfaction in nurses working in tertiary-level healthcare settings in Islamabad. A descriptive cross-sectional design was used, with a sample of 
56 qualified nurses working a tertiary hospital. The findings revealed that 26 per cent of those who participated were highly dissatisfied, and 86 per cent of them were dissatisfied with their jobs. The factors that caused dissatisfaction included poor work environment, poor fringe benefits, lack of education and training opportunities, lack of proper leadership and supervision, time pressures and very poor financial rewards. Again, the cross-sectional design limits the cause and effect generalisability of the study. In addition, the social aspects of the Pakistan healthcare system, in which the disparity between private and public healthcare is significant (Bahalkani et al., 2011), may contribute negatively to the social image and therefore self-concept of nurses working in the public healthcare system. These types of cultural perspective differences, as seen in the study by Hwang et al. (2009) in Korea and China, may be critical to deciphering certain socially linked aspects of satisfaction.

\section{The Middle East.}

In this region, the research revealed nurses to be moderately satisfied in general, with differences in satisfaction levels among nurses in public versus private hospital environments, and with factors associated with satisfaction and dissatisfaction similar to other global studies (Al Enenzi et al., 2009; Mrayyan, 2005). As with the studies from Canada and England, demographic characteristics were found to be significant to job satisfaction among nurses in the Middle East region (Al Enenzi et al., 2009). In addition, almost universally significant factors related to organisational policies and opportunities were also found to be significant, such as professional opportunities, pay, control and responsibilities.

Al-Enezi et al. (2009) explored factors that influence job satisfaction and identified the relationship between certain selected background characteristics, including age group, gender, nationality, qualification, marital status, monthly salary, 
experience in other countries, years of experience and the overall score on job satisfaction of nurses from 35 different countries working in five public hospitals in Kuwait. The response rate in this study was 87.2 per cent out of 500 nurses surveyed. They identified five factors influencing satisfaction: (a) professional opportunities, (b) praise and recognition, (c) extrinsic payments, (d) control and responsibility and (e) scheduling of duties. They found that nurses were dissatisfied with two factors: professional opportunities and extrinsic payments. Further, the level of job satisfaction among expatriate nurses was not very high.

The second study of nurses in the Middle East was that of Mrayyan (2005), who performed a study of nurses working in three public and two private hospitals in Jordan. The purpose of this study was to describe and identify variables influencing Jordanian nurses' job satisfaction and retention. A descriptive design used a convenience sample of 438 nurses, with 124 nurses from public hospitals and 314 nurses from private hospitals. The response rate of this study was 79.6 per cent. Mrayyan's study showed that nurses reported that they were moderately satisfied with their jobs and had a neutral opinion about their retention. Nurses who worked in public hospitals reported lower levels of job satisfaction and fewer of them had the intention to stay at their jobs than nurses in private hospitals. However, it was noted that the study was limited by a small sample of evening and night shift nurses, which may have skewed the results and might not be an accurate assessment of all nurses' satisfaction in these hospitals. This limitation suggests the need for a more varied sample for the current study in order to include various shift nurses.

\section{Job satisfaction among nurses in Saudi Arabia.}

Due to the shortage of both female and male Saudi registered nurses, more than half of the nurses working in public hospitals in Saudi Arabia come from overseas; 
approximately 55.4 per cent of all nurses working in 251 public hospitals were expatriates $(\mathrm{MoH}, 2011)$. A lack of job satisfaction in the nursing profession may cause an increase in job turnover, exacerbating Saudi Arabia's problems with a shortage of nursing staff. Identifying job dissatisfaction will help develop new policies and to provide more support for nurses and the opportunity for workforce improvement plans. Job satisfaction among nurses has long been documented as an important indicator of how nurses can improve their performance and the quality of patient care. In Saudi Arabia, several research studies have investigated job satisfaction in nursing from the perspective of expatriate nurses of different nationalities as well as Saudi nurses in public hospitals, private hospitals, tertiary care hospitals and military hospitals. These studies included a variety of related variables, such as quality of life, organisational commitment, recruitment and retention barriers, leadership style, hospital performance, intention to stay and the work environment (Abo-Znadh, 1999; Al-Aameri, 2000; AlAhmadi 2009; Al-Dossary et al., 2012; Al-Zayyer, 2003; El-Gilany \& Al-Wehady, 2001; Mitchell, 2009; Omer, 2005; Zaghloul et al., 2008).

\section{Factors affecting job satisfaction and dissatisfaction in Saudi Arabia.}

Several studies have been conducted in Saudi Arabia on the factors affecting nurse job satisfaction and dissatisfaction. Given the unique situation in Saudi Arabia, with a predominance of expatriate nurses, studies have examined nationality as a potential factor affecting satisfaction; however, this research has demonstrated inconsistent results with regard to the relationship between nationality and job satisfaction among these nurses (Abo-Znadh, 1999; Al-Ahmadi, 2009), with more recent research failing to show any relationship between these variables (Al-Ahmadi, 2009). 
To investigate the multi-national population of nurses in Saudi Arabia and factors related to this population, Abo-Znadh (1999) conducted a study focused on nurses' job satisfaction and turnover in two tertiary care hospitals under the MoHE in Riyadh. Surveys were administered to 334 nurses, both Saudi and non-Saudi, from medical and surgical units; the response rate for this study was 92 per cent. This study used an exploratory design to identify the relationship between job characteristics and quality of work life. The findings revealed that six predictor variables (out of 13) were significantly correlated with satisfaction. The predictor variables included nationality, availability of a family member, total years of Saudi Arabian nursing experience, growth needs, critical psychological states and motivating potential. Only two variables (growth needs and critical psychological states) were significantly correlated with internal motivation.

Three studies addressed factors related to job satisfaction and dissatisfaction separately to identify potential differences and ways to contribute to supporting satisfaction, while reducing dissatisfaction (Al-Dossary et al., 2012; Mitchell, 2009; Zaghloul et al., 2008). Satisfaction tended to be related to intrinsic factors such as salary, motivation, effect of leadership style, achievement, relationships with peers and supervisors and challenging career opportunities (Al-Dossary et al., 2012; Mitchell, 2009; Zaghloul et al., 2008); whereas dissatisfaction was related to hospital policies, work conditions, pay, fringe benefits, lack of recognition for achievement, as well as personal and relationship factors (Al-Dossary et al., 2012; Mitchell, 2009; Zaghloul et al., 2008). In general, research has revealed a general satisfaction among nurses in Saudi Arabia with regard to the nature of the work (Al-Dossary et al., 2012; Mitchell, 2009). Zaghloul et al. (2008) conducted a cross-sectional descriptive study of nurses at King Fahd Hospital of the University (KFHU) in Al-Khobar, Saudi Arabia. This study 
examined nurses' intentions to stay in their jobs, as well as the dimensions of job satisfaction. The response rate in the study was 55.3 per cent of the 499 nurses that were surveyed. The findings revealed job satisfaction dimensions other than salary and motivation, including leadership styles in the organisation and challenging career opportunities at work. Further, the findings showed that nurses were dissatisfied with the benefits the hospital offered, the hospital policies implemented and recognition of their achievements. The authors developed a self-administered survey for the study, but failed to report any details supporting the validity and reliability of the survey instrument, reducing the credibility of the study and highlighting the importance of the discussion of validity and reliability in research.

Mitchell (2009) performed a mixed methods study on expatriate registered nurses who worked in 25 different public and private hospitals in two cities, Jeddah and Makkah, in the Makkah region of Saudi Arabia. A survey was administered to 944 foreign-trained nurses, and 25 participated in interviews; the response rate for this study was 48 per cent. The study was conducted in two different phases: the qualitative phase of the study used focus group interviews, while the quantitative phase of the study involved data being collected through surveys. There were significant correlations between work environment and job satisfaction.

The results of Mitchell's (2009) study showed that job satisfaction increased when the work environment improved. The study also demonstrated that participants gained job satisfaction via recognition, work itself, salary, work conditions, achievement, hospital policies and administration, relationships with supervisors and relationships with peers. In addition, job dissatisfaction was reported with hospital policies and administration, work conditions, status, relationships with supervisors, security and personal life. The nurses working in the public hospitals were highly 
satisfied with their recognition and the work itself; however, they were dissatisfied with hospital policies and administration and work conditions. The nurses working in the private hospitals were highly satisfied with the recognition and salaries they received; however, they were dissatisfied with hospital policy and administration and status. However, it was noted in this study that nurse managers reported that foreign-trained nurses were sceptical and afraid of repercussions despite assurances that the hospital administration supported the study. This may have had a significant impact on the results of the study. The study was methodologically rigorous, incorporating both qualitative and quantitative techniques in an attempt to provide both inferential data and depth of detail. Despite these efforts, the participants' scepticism was a likely source of bias in the results.

Al-Dossary and colleagues (2012) conducted a quantitative cross-sectional study of nurses in a Saudi Arabian university teaching hospital. The aim of the study was to measure nurses' job satisfaction and to determine the factors that influence job satisfaction. The response rate in the study was 87.5 per cent of 217 nurses, including Saudis and non-Saudis, who were surveyed. The findings revealed that the participants were satisfied with certain factors, such as the nature of work, their co-workers, leadership and supervisors. However, they were dissatisfied with other factors, such as pay, operational conditions, fringe benefits and contingent rewards. The cross-sectional design limited cause and effect inferences, in addition to the small sample size obtained despite the high response rate. In addition, the study was limited to a single university teaching hospital, thus limiting the generalisability of the results.

The study by Zaghloul et al. (2008) related to the influence of leadership style on satisfaction and dissatisfaction among nurses in Saudi Arabia. The results provided support to the findings reported by Omer (2005), who had previously identified the 
effects of leadership on nursing job satisfaction; specifically, the influence of transformational and transactional leadership styles. Omer used a mixed-method design on nurses from two National Guard Health Affairs hospitals in two cities, Jeddah and Riyadh. He obtained a response rate of 65.3 per cent from among 415 Saudi and nonSaudis nursing staff and managers. Staff nurses and nursing managers participated in two separate stages: quantitative data collection through a questionnaire and qualitative data collection through interviews.

Although Omer's (2005) study showed no significant differences between demographic characteristics and perceived leadership style, there was a significant difference among staff nurses and nurse managers' perceptions. The results of this study demonstrated that there was a significant correlation between perceived leadership style and job satisfaction. Further, there was a positive correlation between job satisfaction and transactional leadership characteristics. Also, the result indicated that transformational leadership factors can predict job satisfaction. However, the convenience sample used in this study may not have been representative of the population, and even more so given the low response rate. The results demonstrated correlations, but fell short of demonstrating a causative relationship. Finally, with a single male nurse manager, the study was unable to evaluate the impact of gender on leadership, which may be a critical factor.

\section{Organisational commitment.}

Organisational commitment has been shown to correlate strongly with job satisfaction among nurses in Saudi Arabia (Al-Aameri, 2000; Al-Ahmadi, 2009). With a focus on the relationship between job satisfaction and organisational commitment, AlAameri (2000) used a sample of nurses from public hospitals in Riyadh, Saudi Arabia. Four hundred nurses from different nationalities, such as Arabs, Filipinos, Indians, 
Americans and Saudis completed the surveys, with a response rate of 72.5 per cent. A strong positive correlation was found between organisational commitment and job satisfaction. Further, the study also found that age and experience are significantly correlated with satisfaction and commitment. The findings showed that older nurses and those with more experience were more satisfied with, and more committed to, their jobs than the younger nurses and those with less experience.

Organisational commitment also has been found to be positively correlated with job performance as well as with job satisfaction (Al-Ahmadi, 2009). In the study by AlAhmadi (2009), the author examined the factors that affect the performance of hospital nurses in the Riyadh region of Saudi Arabia, with a focus on job satisfaction and organisational commitment. A survey was administered to 1,834 nurses of different nationalities, including Saudis, in 15 randomly selected MoH hospitals in the Riyadh region; the response rate for this study was 50.3 per cent. The findings showed a positive correlation between job performance, organisational commitment and job satisfaction; personal variables including years of experience, nationality, gender and marital status. However, there was a negative correlation with level of education. The highest satisfaction indicated was related to work; the lowest satisfaction indication was related to pay. These findings showed a higher correlation between job satisfaction and males and married nurses. There were no significant differences between nationalities. The large sample size and use of 15 different hospitals were the strengths of the study. Cultural aspects may have a significant role in the results of the study, though this was not specifically discussed, as the sample was 94 per cent non-Saudi. Although mentioned by the authors, cultural aspects and perspectives can have a critical impact on variables related to job satisfaction and should have been considered as an important 
aspect of the discussion in Saudi Arabia, where the majority of the nursing population is foreign.

\section{Strategies for improved satisfaction and nurse retention.}

Moving from investigating the factors that support job satisfaction and retention towards strategies for addressing the issues, this review now focuses on research examining strategies for improvement in terms of supporting the recruitment and retention of nursing staff in Saudi Arabia and the barriers to promoting job satisfaction and retention. From the research, strategies focused on improving teamwork and interdepartmental and peer relationships, offering competitive wages, support for nursing personnel and a positive work environment may be successful at achieving higher job satisfaction and retention of nursing staff (Al-Zayyer, 2003). In addition, changes in the social view of nursing as a career would support greater recruitment and retention in the field (El-Gilany \& Al-Wehady, 2001).

Al-Zayyer's (2003) descriptive study of nurses who worked in nine different tertiary hospitals had a response rate of 46 per cent of 259 nursing administrators. AlZayyer examined their recruitment and retention strategies, as well as the barriers to these strategies, over a three-year period. He discovered that 40.3 per cent of the nursing administrators reported that the numbers of vacancies remained the same during this three-year period; 34.5 per cent of the respondents reported increased vacancies; 21.8 per cent reported a decrease in vacancies. Nursing administrators provided the following reasons for an increase in vacancies: salaries, competitive job markets, increased workload, expansion of services, the political situation in Saudi Arabia, financial instability, lack of support for nursing personnel, the living conditions in Saudi Arabia and personal reasons. However, Al-Zayyer found that hospitals that worked on the job satisfaction plan reported a decrease in vacancies. Further, the job satisfaction efforts in 
the hospitals included teamwork and improved working relationships between departments, competitive wages, a happy work environment and adequate support for nursing personnel.

El-Gilany and Al-Wehady (2001) studied job satisfaction in female Saudi nurses in a descriptive study of 243 female Saudi nurses working in government healthcare facilities at Al-Hassa in the northern region of Saudi Arabia. The response rate for this study was 95.9 per cent. This study assessed the degree of job satisfaction of Saudi female nurses and identified the factors that could positively influence their satisfaction. The findings revealed that most nurses were satisfied with their job, and that the main factor that could increase their satisfaction was to improve the public image of nursing as a profession and to provide a comfortable working environment. The authors did not identify a validated and standardised measure of job satisfaction for nurses in Arabic and therefore this was measured as 'a subjective feeling of the nurse' on a self-rated scale. The relatively small sample in this study revealed the need for a larger-scale study using a standardised, validated and culturally appropriate instrument for assessing job satisfaction among the diverse nursing population in Saudi Arabia.

The table below summarises all the above studies of Saudi Arabian nurses by Saudi and non-Saudi researchers. The studies investigated a variety of Saudi geographical areas and healthcare sectors, and employed a range of methods, samples, aims and data analysis techniques (Abo-Znadh, 1999; Al-Aameri, 2000; Al-Ahmadi 2009; Al-Dossary et al., 2012; Al-Zayyer, 2003; El-Gilany \& Al-Wehady, 2001; Mitchell, 2009; Omer, 2005; Zaghloul et al., 2008). 
Table 2.3

Summary of Nursing Job Satisfaction Studies in Saudi Arabia

\begin{tabular}{|c|c|c|c|c|}
\hline $\begin{array}{c}\text { Job Satisfaction } \\
\text { Studies } \\
\end{array}$ & Methods & Sample & $\begin{array}{l}\text { Statistical } \\
\text { Approach }\end{array}$ & Key Findings \\
\hline $\begin{array}{l}\text { Abo-Znadh (1999): } \\
\text { An exploration of } \\
\text { selected staff and } \\
\text { job characteristics } \\
\text { and their } \\
\text { relationship to } \\
\text { quality of work life } \\
\text { among staff nurses } \\
\text { in medical/surgical } \\
\text { units in two tertiary } \\
\text { care hospitals in } \\
\text { Saudi Arabia }\end{array}$ & $\begin{array}{l}\text { Mixed } \\
\text { methods } \\
\text { non- } \\
\text { experimental } \\
\text { and } \\
\text { exploratory } \\
\text { design }\end{array}$ & $\begin{array}{l}329 \text { Saudi and } \\
\text { non-Saudi } \\
\text { nurses } \\
\text { participated } \\
\text { from two } \\
\text { tertiary care } \\
\text { hospitals } \\
\text { under the } \\
\text { MoHE in } \\
\text { Riyadh }\end{array}$ & $\begin{array}{l}\text { Descriptive, } \\
\text { comparison, } \\
\text { correlational } \\
\text { and } \\
\text { regression } \\
\text { analysis }\end{array}$ & $\begin{array}{l}\text { Six predictor variables } \\
\text { (nationality, } \\
\text { availability of a family } \\
\text { member, total years of } \\
\text { Saudi Arabian } \\
\text { experience, growth } \\
\text { needs, critical } \\
\text { psychological states } \\
\text { and motivating } \\
\text { potential) were } \\
\text { significantly correlated } \\
\text { with the prediction of } \\
\text { satisfaction }\end{array}$ \\
\hline $\begin{array}{l}\text { Al-Aameri (2000): } \\
\text { Job satisfaction } \\
\text { and organisational } \\
\text { commitment for } \\
\text { nurses }\end{array}$ & $\begin{array}{l}\text { Descriptive } \\
\text { quantitative } \\
\text { design }\end{array}$ & $\begin{array}{l}290 \text { Saudi and } \\
\text { non-Saudi } \\
\text { nurses from } \\
\text { public } \\
\text { hospitals in } \\
\text { Riyadh region }\end{array}$ & $\begin{array}{l}\text { Descriptive, } \\
\text { Scheffee test } \\
\text { and one-way } \\
\text { ANOVA }\end{array}$ & $\begin{array}{l}\text { A strong positive } \\
\text { correlation was found } \\
\text { between organisational } \\
\text { commitment and job } \\
\text { satisfaction. Older } \\
\text { nurses were more } \\
\text { satisfied and more } \\
\text { committed to their jobs } \\
\text { than younger ones. It } \\
\text { also revealed that } \\
\text { nurses with more } \\
\text { experience tended to } \\
\text { be more committed to } \\
\text { their organisations } \\
\text { than those with less } \\
\text { experience }\end{array}$ \\
\hline $\begin{array}{l}\text { Al-Zayyer (2003): } \\
\text { The effectiveness } \\
\text { of recruitment and } \\
\text { retention strategies } \\
\text { and the severity of } \\
\text { recruitment and } \\
\text { retention barriers } \\
\text { in a group of staff } \\
\text { nurses in selected } \\
\text { tertiary care } \\
\text { hospitals in Saudi } \\
\text { Arabia }\end{array}$ & $\begin{array}{l}\text { Mixed } \\
\text { methods } \\
\text { descriptive } \\
\text { design }\end{array}$ & $\begin{array}{l}119 \text { Saudi and } \\
\text { non-Saudi } \\
\text { administration } \\
\text { nurses } \\
\text { participated } \\
\text { from nine } \\
\text { tertiary care } \\
\text { hospitals in } \\
\text { Saudi Arabia }\end{array}$ & $\begin{array}{l}\text { Descriptive } \\
\text { analysis and } \\
\text { Correlational } \\
\text { coefficient }\end{array}$ & $\begin{array}{l}\text { Hospitals that worked } \\
\text { on the job satisfaction } \\
\text { plan reported a } \\
\text { decrease in vacancies. } \\
\text { The job satisfaction } \\
\text { efforts in hospitals } \\
\text { included teamwork } \\
\text { and improved working } \\
\text { relationships between } \\
\text { departments, } \\
\text { competitive wages, a } \\
\text { happy work } \\
\text { environment and } \\
\text { adequate support for } \\
\text { nursing personnel }\end{array}$ \\
\hline $\begin{array}{l}\text { El-Gilany and Al- } \\
\text { Wehady (2001): } \\
\text { Job satisfaction of } \\
\text { female Saudi }\end{array}$ & $\begin{array}{l}\text { Descriptive } \\
\text { quantitative } \\
\text { design }\end{array}$ & $\begin{array}{l}233 \text { female } \\
\text { Saudi nurses } \\
\text { participated } \\
\text { from }\end{array}$ & $\begin{array}{l}\text { Descriptive } \\
\text { analysis and } \\
\text { Fisher's } \\
\text { exact test }\end{array}$ & $\begin{array}{l}\text { The female Saudi } \\
\text { nurses were satisfied } \\
\text { with their jobs and the } \\
\text { main factor that could }\end{array}$ \\
\hline
\end{tabular}




\begin{tabular}{|c|c|c|c|c|}
\hline nurses & & $\begin{array}{l}\text { government } \\
\text { healthcare } \\
\text { facilities in } \\
\text { the Al-Hassa } \\
\text { region }\end{array}$ & & $\begin{array}{l}\text { increase their } \\
\text { satisfaction was to } \\
\text { improve the social } \\
\text { view of the nursing as } \\
\text { a profession and to } \\
\text { provide a comfortable } \\
\text { working environment }\end{array}$ \\
\hline $\begin{array}{l}\text { Omer (2005): } \\
\text { Leadership style of } \\
\text { nurse managers at } \\
\text { the Saudi National } \\
\text { Guard hospitals }\end{array}$ & $\begin{array}{l}\text { Mixed } \\
\text { methods } \\
\text { descriptive, } \\
\text { non- } \\
\text { experimental } \\
\text { and } \\
\text { comparative } \\
\text { design }\end{array}$ & $\begin{array}{l}271 \text { Saudi and } \\
\text { non-Saudi } \\
\text { nurses and } \\
\text { managers } \\
\text { from two } \\
\text { National } \\
\text { Guard } \\
\text { hospitals in } \\
\text { Riyadh and } \\
\text { Jeddah }\end{array}$ & $\begin{array}{l}\text { Descriptive } \\
\text { analysis, } \\
\text { correlation, } \\
\text { one-way } \\
\text { ANOVA and } \\
\text { multiple } \\
\text { regression } \\
\text { analysis }\end{array}$ & $\begin{array}{l}\text { There was a significant } \\
\text { correlation between } \\
\text { perceived leadership } \\
\text { style and three } \\
\text { organisational } \\
\text { outcomes: job } \\
\text { satisfaction, } \\
\text { effectiveness and extra } \\
\text { effort }\end{array}$ \\
\hline $\begin{array}{l}\text { Al-Ahmadi (2009): } \\
\text { Factors that affect } \\
\text { the performance of } \\
\text { hospital nurses in } \\
\text { the Riyadh region } \\
\text { of Saudi Arabia }\end{array}$ & $\begin{array}{l}\text { Descriptive } \\
\text { quantitative } \\
\text { design }\end{array}$ & $\begin{array}{l}923 \text { Saudi and } \\
\text { non-Saudi } \\
\text { nurses from } \\
15 \text { randomly } \\
\text { selected MoH } \\
\text { hospitals in } \\
\text { the Riyadh } \\
\text { region }\end{array}$ & $\begin{array}{l}\text { Descriptive } \\
\text { analysis, } \\
\text { correlation, } \\
\text { t-test and } \\
\text { regression } \\
\text { analysis }\end{array}$ & $\begin{array}{l}\text { The highest } \\
\text { satisfaction indicated } \\
\text { was related to work; } \\
\text { the lowest satisfaction } \\
\text { indication was related } \\
\text { to pay. There was a } \\
\text { higher correlation } \\
\text { between job } \\
\text { satisfaction and male } \\
\text { and married nurses }\end{array}$ \\
\hline $\begin{array}{l}\text { Zaghloul et al. } \\
\text { (2008): Intention to } \\
\text { stay and nurses' } \\
\text { satisfaction } \\
\text { dimensions }\end{array}$ & $\begin{array}{l}\text { A cross- } \\
\text { sectional } \\
\text { descriptive } \\
\text { quantitative } \\
\text { design }\end{array}$ & $\begin{array}{l}276 \text { Saudi and } \\
\text { non-Saudi } \\
\text { nurses } \\
\text { participated } \\
\text { from KFHU } \\
\text { in Al-Khobar }\end{array}$ & $\begin{array}{l}\text { Descriptive } \\
\text { analysis and } \\
\text { ordinal } \\
\text { regression } \\
\text { analysis }\end{array}$ & $\begin{array}{l}\text { Nurses were } \\
\text { dissatisfied with the } \\
\text { hospital benefits } \\
\text { offered, implemented } \\
\text { hospital policies and } \\
\text { recognition of their } \\
\text { achievements }\end{array}$ \\
\hline $\begin{array}{l}\text { Mitchell (2009): } \\
\text { Job satisfaction } \\
\text { and burnout among } \\
\text { foreign-trained } \\
\text { nurses in Saudi } \\
\text { Arabia }\end{array}$ & $\begin{array}{l}\text { Triangulated } \\
\text { mixed } \\
\text { methods }\end{array}$ & $\begin{array}{l}453 \text { foreign- } \\
\text { trained nurses } \\
\text { from } 25 \\
\text { different } \\
\text { public and } \\
\text { private } \\
\text { hospitals in } \\
\text { two cities in } \\
\text { the Makkah } \\
\text { region }\end{array}$ & $\begin{array}{l}\text { Descriptive } \\
\text { analysis, } \\
\text { one-way } \\
\text { ANOVA, } \\
\text { Pearson's } \\
\text { correlation, } \\
\text { t-test and } \\
\text { multiple } \\
\text { regression } \\
\text { analysis }\end{array}$ & $\begin{array}{l}\text { Job satisfaction via } \\
\text { recognition, work } \\
\text { itself, salary, work } \\
\text { conditions, } \\
\text { achievements, } \\
\text { company policy and } \\
\text { administration, } \\
\text { relationships with } \\
\text { supervisors and } \\
\text { relationships with } \\
\text { peers. Job } \\
\text { dissatisfaction via } \\
\text { company policy and } \\
\text { administration, work } \\
\text { conditions, status, } \\
\text { relationships with } \\
\text { supervisors, security } \\
\text { and personal life }\end{array}$ \\
\hline $\begin{array}{l}\text { Al-Dossary et al. } \\
\text { (2012): Job }\end{array}$ & $\begin{array}{l}\text { A } \\
\text { quantitative }\end{array}$ & $\begin{array}{l}189 \text { Saudi and } \\
\text { non-Saudi }\end{array}$ & $\begin{array}{l}\text { Descriptive } \\
\text { analysis, }\end{array}$ & $\begin{array}{l}\text { Nurses were satisfied } \\
\text { with supervision, co- }\end{array}$ \\
\hline
\end{tabular}




\begin{tabular}{|c|c|c|c|c|}
\hline $\begin{array}{l}\text { satisfaction of } \\
\text { nurses in a Saudi } \\
\text { Arabian university } \\
\text { teaching hospital }\end{array}$ & $\begin{array}{l}\text { cross- } \\
\text { sectional } \\
\text { method }\end{array}$ & $\begin{array}{l}\text { nurses } \\
\text { participated } \\
\text { from a } \\
\text { university } \\
\text { teaching } \\
\text { hospital in the } \\
\text { Eastern } \\
\text { Province of } \\
\text { Saudi Arabia }\end{array}$ & $\begin{array}{l}\text { one-way } \\
\text { ANOVA, } \\
\text { Pearson's } \\
\text { correlation } \\
\text { and t-test }\end{array}$ & $\begin{array}{l}\text { workers and the nature } \\
\text { of their work. } \\
\text { However, they were } \\
\text { dissatisfied with pay, } \\
\text { fringe benefits, } \\
\text { contingent rewards and } \\
\text { operating conditions }\end{array}$ \\
\hline
\end{tabular}

\section{Key Factors Influencing Nurses' Job Satisfaction and Staff Turnover}

There is evidence in the literature supporting the relationship between job satisfaction and factors including demographic, personal and job characteristics (gender, marital status and age, education or qualifications levels, Remuneration, number of dependent adults, leadership, experience and stress). The relationship between job satisfaction and these factors has been well identified in the nursing literature. For example, Lu and colleagues (2005) studied the impact of job satisfaction components on intent to leave and turnover in hospital-based nurses in the United Kingdom. The findings of this study revealed that stress and leadership issues continue to have an influence on the job satisfaction of nurses. Further, it found that there is a correlation between job satisfaction, level of education achieved and salary. Job satisfaction (or dissatisfaction) has been linked to nurse turnover. Wagner and Huber (2003) conducted a study entitled 'Catastrophe and Nursing Turnover', wherein they suggested two key influences that cause nurses to leave their jobs: organisational commitment and job tension. Larrabee et al. (2003) deduced that the most important predictor of leaving was job dissatisfaction and the main predictor of job satisfaction was psychological empowerment. In addition, Shader, Broome, Broome, West and Nash (2001) studied the relationship between work satisfaction, stress, age, cohesion, work schedule and anticipated turnover in an academic medical centre. A cross-sectional survey design was used. The findings indicated that higher levels of job stress resulted in lower levels of 
group cohesion and work satisfaction, and therefore a higher anticipated turnover rate. Further, the authors mention that the more stable work schedules correlated with less work-related stress, higher group cohesion, lower anticipated turnover and thus higher work satisfaction.

Al-Hussami (2008) studied the following factors in nurses' job satisfaction: the relationship to job and organisational commitment, perceived organisational support, transactional leadership, transformational leadership and level of education. The study found that there is a significant link between job satisfaction and organisational commitment. The findings showed a positive correlation between the dependent variable, including job satisfaction, and the independent variables, including organisational commitment, organisational support, level of education and transformational leadership. Examining nurse retention in Jordanian public hospitals, Al-Momani (2008) identified ten key factors that influenced the respondents' intention to leave their positions: payment, workload, autonomy in decision-making, environment, motivation, job description, nurses' welfare, growth opportunities, perception of fair leadership and recognition. The study sample was randomised, giving additional strengths to the results.

Demographic variables are important for evaluating and determining the level of employees' job satisfaction; they are frequently measured to identify the factors that influence nurses' job satisfaction (Miller, 2007). Moreover, demographic factors, such as gender, marital status and age, education, pay and number of dependent adults, are often used to represent some of the convincing predictors in the employee job satisfaction and turnover literature (Michal, Jan, \& Amy, 2001). Further, demographic factors have been used in many studies to identify the relationship between nursing staff, job satisfaction and turnover. One of these studies, regarding public welfare 
workers, found that the intention to leave was predicted by the demographic factors age and education (Nissly, 2004). Job characteristics, practical experience and organisational factors are vital avenues to explore, as they have been found to have a significant influence on employee job satisfaction. Organisational factors, such as leadership style, overall experience and stress have more influence on job satisfaction than individual factors. Further, recent findings show that those factors have the strongest relationships to job satisfaction (Coomber \& Barriball, 2007). The following section will identify the relationship between job satisfaction and other factors, including demographic, personal and job characteristics (gender, marital status and age, education or qualifications and levels, pay, number of dependent adults, leadership style, experience and stress).

\section{Gender.}

Gender factors might influence job satisfaction, especially in mixed environments such as hospitals. Generally, nursing staff are mainly female. However, the proportion of male nurses is increasing gradually (Jones, 2011). According to the Saudi Arabian MoH (2011), the majority of nursing staff in the Saudi healthcare system are female: 47,566 of 60,671 nurses. Further, the total number of Saudi nurses working in public hospitals is 27,040 and the percentage of female nurses is 57.2 per cent (see Table 1.3). Recently, the number of male registered nurses has been gradually increasing in Saudi Arabia. Other researchers have found no significant difference regarding job satisfaction and gender (Cahill, 2011; Curtis, 2008).

Research conducted in the Republic of Ireland by Curtis (2008) studied the effects of biographical variables such as gender, age and education on job satisfaction among nurses. The purpose of the study was to determine the effect of biographical variables on job satisfaction among nurses. Curtis found that there was no significant 
difference between female and male nurses in the levels of job satisfaction. Despite this clear finding, the low response rate of male participants (8.7 per cent) was noted, suggesting that the findings may not be an accurate estimation of the male responses.

Cahill (2011) studied the impact of the state practice environment on nurse practitioners' job satisfaction in the United States healthcare system. The purpose of this study was to report and compare the job satisfaction of nursing practitioners in selected regulatory state practice environments. The majority of the Cahill's study participants were female nurses (96 per cent). The findings revealed that gender (although the male representation was very small) did not influence job satisfaction, and that males and females had different views on job satisfaction.

In contrast, several studies have shown that there is a significant difference in the level of job satisfaction between female and male nurses (Al-Ahmadi, 2009; Ragapaksa \& Rothsteim, 2009; Sochalski, 2002). According to Sochalski (2002), the level of job satisfaction was lower for female nurses than for male nurses and experienced female nurses' job satisfaction level was lower than that of male nurses; for female nurses it is 8 per cent and for male nurses 9.2 per cent. Further, Sochalski mentioned that 4.1 per cent of new female nurses leave the profession within the first 4 years, compared with 7.5 per cent of new male nurses.

Similarly, Al-Ahmadi (2009) explored the factors affecting the performance of hospital nurses in 15 hospitals in the Riyadh region of Saudi Arabia. The result showed that the job satisfaction was significantly lower among female nurses than male nurses, including Saudi and non-Saudi nurses. However, Ragapaksa and Rothsteim (2009) examined the factors that affect the decisions of male and female nurses to leave their jobs in the United States and found that male nurses leave at a higher rate than female nurses. 
These differences in the roles of female and male nurses may be significant factors for Saudi Arabian society and for the sample in this study. In Saudi Arabia female nurses have family roles beyond their work as nursing professionals, such as caring for their homes and their children. Further, in Saudi culture and Islamic society women play an important role in the family system. According to Mebrouk (2008), Saudi women have vital role at home as caregivers and homemakers.

\section{Marital status and age.}

Two other demographic and personal factors that impact nursing job satisfaction are marital status and age, especially in a community such as Saudi Arabia. Saudi people are usually sociable and the relationship between family members and family lifestyle stability is very important to them. Previous studies have found that marital status influences nursing job satisfaction and turnover (Ma, Yang, Lee, \& Chang, 2009; Rambur, Palumbo, McIntosh, \& Mongeon, 2003). Nurses who are older and married may be more satisfied with their jobs, leading to a lower turnover rate. In a study conducted by Ma et al. (2009), the predictive factors of job satisfaction in acute care hospitals in Taiwan related to nurses' intention to leave. The result of this study showed that 71.5 per cent of single nurses wished to leave their nursing jobs and 65.8 per cent were under the age of 30 .

Another study identified the relationship between personal variables, such as age and marital status, and dissatisfaction and turnover (Rambur et al., 2003). This study suggested that young single nurses are more likely to consider quitting their jobs than older nurses (Rambur et al., 2003). Further, young nurses have better chances of finding other opportunities and jobs with more benefits, especially if they have good qualifications. In addition, research has found that older nurses are more satisfied and 
have lower turnover rates in their jobs, and that fewer of them have the intention to leave their organisations than younger nurses (Miller, 2007).

The previously mentioned research by Curtis (2008) examined job satisfaction related to both age and gender. The findings related to age suggested that younger nurses aged 18-35 years were less satisfied, with an emphasis on student-aged nurses. Older nurses demonstrated a higher job satisfaction level. The findings related to low satisfaction among the student nurse population were troublesome. Solutions to the nursing shortages are not likely to stem from a generation of students lacking satisfaction in nursing before they even start working.

Al-Aameri (2000) conducted a study entitled 'Job Satisfaction and Organisational Commitment for Nurses', and found that there is a strong link between job satisfaction and organisational commitment and that older nurses are more satisfied with, and more committed to, their jobs than are younger ones. It also revealed that older nurses with considerable experience tended to be more committed to their organisations and have greater job satisfaction and stability in their work than those who were younger and with less experience. At the same time, young nurses have greater opportunities to find other jobs with higher wages and more benefits, especially if they have high qualification and work in hospitals at a lower salary than other nurses.

\section{Education levels.}

Nurses working in Saudi Arabia have different qualifications and levels of education. Although most have a Diploma in Nursing, more recently, most nurses are graduating with a BSN. In addition, the number of those with an MSN is increasing and the government is investing money in supporting deserving nurses with scholarships abroad to obtain higher degrees in nursing. Education levels are related to job satisfaction worldwide, and there are numerous studies that have identified this 
relationship. One of these was a study conducted in United States nurses by Rambur et al. (2003), which had a response rate of 85 per cent from a population of 4,418 . The findings of this study showed that job satisfaction was higher for nurses with lower levels of education. Moreover, Yin and Yang's (2002) work in Taiwan confirmed this finding, suggesting that nurses who have lower educational levels are more satisfied with their jobs. According to Betkus and MacLeod (2004), nurses with higher levels of education are more likely to quit their jobs, especially if they find greater benefits in other organisations and have limited opportunities in their current organisation.

Higher education and training levels often equate to higher pay, but this is not always the case. In Kuwait, graduate nurses and nurses with nursing diplomas receive the same salary because the nurses' salary structure in Kuwait does not discriminate between the two groups (Al-Enezi et al., 2009). However, the healthcare system salaries are not standardised by the MoH of Saudi Arabia and are sometimes based more on nationality than on qualifications and experience. For example, nurses from Malaysia with low qualifications receive higher salaries than nurses from India and the Philippines, who have high qualifications.

\section{Remuneration.}

Remuneration is defined as either salary, salary and fringe benefits, or the money that employees receive for their services and work in an organisation (Chen et al., 2008). Globally, the migration of nurses has increased due to the pursuit of better jobs and opportunities for increased income (Lu et al., 2005). Remuneration might be the first priority among nurses when they start searching for a new job or migration; it is therefore important to staff nurses who come from poor countries such as India, Pakistan and the Philippines. 
In Saudi Arabia, there are not clear standards for nurses' salaries; they depend on the recruitment contract of each nurse. For example, nurses who work in the $\mathrm{MoH}$ organisations, such as public hospitals, may receive lower payments than nurses who work in another health organisation, such as a military hospital. These nurses have higher salaries than nurses who have personal contracts with a private health contract management company (Mitchell, 2009). Further, Saudi nurses who work in public hospitals receive lower salaries than some Saudi and non-Saudi nurses who work in military or other hospitals, including nurses from Australia, the United Kingdom and Sweden. For these reasons, nurses try to move from the public hospitals to find other opportunities in private hospitals outside of the MoH's control.

Researchers have found that payment affects job satisfaction and turnover (Yin \& Yang, 2002). For example, Yin and Yang (2002) studied nursing turnover in Taiwan and the result indicated that monthly salary and payments were the important factors influencing nursing turnover in Taiwan. However, other studies have concluded that payment was not a primary problem, nor was it a significant factor in nurse turnover when their enjoyment of some other factor in their work was high (Cowin, 2002).

Saudi Arabia is an environment in which nurses can earn high salaries, because nurses who come from abroad receive free housing, free healthcare, a yearly return ticket to their country of origin and tax-free salaries in Saudi Arabia. However, according to Herzberg's theory (1959), salary or payment represents a hygiene factor and does not necessarily result in job satisfaction.

\section{Number of dependent adults.}

The number of dependent adults is a demographic variable that may affect nurses' job satisfaction, especially in a community like Saudi Arabia, which has an Islamic context and is rooted in Arabic culture and society. Family is very important in 
the Saudi community and Islam and other religions support the idea that young people have clear obligations towards their parents and must take care of them (Mebrouk, 2008). Nurses who have a large family may be unable to strike a balance between their family responsibilities and their work. Several previous nursing studies show that the numbers of dependent adults affects employees' job satisfaction (Almalki, FitzGerald, \& Clarke, 2012; Brooks \& Anderson, 2004; Khani, Jaafarpour, \& Dyrekvandmogadam, 2008).

Almalki and colleauges (2012) performed a study on the quality of work life among primary healthcare nurses in the Jazan region of Saudi Arabia. They found a significant difference between nurses with dependent adults and those without dependent adults with regard to job satisfaction. Nurses who have dependent adults have lower job satisfaction on the job; this is due to a lack of support for nurses who have dependent adults (Almalki et al., 2012). According to the Muslim book, the holy Qu'ran, Allah said that:

Your Lord has commanded that you worship none but Him and that you be kind to your parents. Whether one or both of them attain old age in your life, say not to them a word of contempt (Fie), nor shout at them, but address them in terms of fine, correct and honourable words (the holy Qu'ran: l-isrāa, verses 17-23). All Muslims must care for, and treat the direct and extended elderly parent members of the family kindly, and provide them with the required support and care necessary for them to maintain as healthy a lifestyle as possible. This is the same recommendation that is made to all young people in all religions, not only in Islam.

\section{Leadership.}

Leadership, or management, is important in any organisation, particularly in a healthcare organisation, and it can play an essential role in maintaining job satisfaction 
and decreasing staff turnover. Leadership in Saudi Arabian hospitals is similar to other hospitals in other countries in that it follows the policy and organisation of the hospital and the country. The link between leadership style and job satisfaction has been studied extensively and it has been found that a nurse manager's leadership style is the factor that is most likely to improve nursing job satisfaction in the health organisation (Miller, 2007).

Leadership styles may improve the environment and lead to an increase in the level of job satisfaction and nurse retention rates (Mrayyan, 2005). Further, leadership style can be improved to support job satisfaction and thereby reduce the turnover rate more than other factors, such as salary and motivation (Kleinman, 2004; Zaghloul et al., 2008). In a study of nurses at a community hospital in the northeastern United States, Kleinman (2004) found a positive relationship between effective leadership behaviours and reduced staff turnover. The response rate of the sample in this study was 25 per cent of 315 staff nurses and 62 per cent of 16 nurse managers. In Saudi Arabia, Abualrub and Alghamdi (2012) studied the impact of leadership styles on nurses' satisfaction and intention to stay among Saudi nurses to examine the impact of leadership style on nurse job satisfaction and intention to stay among a convenience sample of 308 Saudi nurses. The findings revealed that Saudi nurses were moderately satisfied in their jobs and supervisor support moderated Saudi nurses' intention to leave. Al-Hussami (2008) studied job satisfaction among nurses and the relationship to organisational commitment, perceived organisational support, transactional leadership, transformational leadership and level of education in private and nursing. The findings of this study revealed that there was a positive correlation between the dependent variable, job satisfaction, and the independent variables, organisational commitment, organisational support, level of education and transformational leadership. Further, there 
was a strong relationship between nurses' attitudes towards organisational commitment and nursing job satisfaction.

\section{Overall experience.}

Experience is important for all employees working in any organisation, especially for nurses working in the health sector. Experience can play an essential role in maintaining the stability of work, the job satisfaction of nurses and decreasing the turnover rate among nursing staff. Many researchers have shown a positive effect of years of experience on job satisfaction (Al-Ahmadi, 2002; Almalki et al., 2012; Kacel, Miller, \& Norris, 2005; Kavanaugh, Duffy, \& Lilly, 2006).

Kavanaugh et al. (2006) studied the relationship between job satisfaction and demographic variables for healthcare professionals working in a rehabilitation hospital in the United States. The purpose of this study was to examine the link between demographic variables, such as overall experience in the profession, and job satisfaction. The findings of this study showed that the number of years of professional experience was commonly linked to healthcare professionals' job satisfaction.

Kacel and colleagues (2005) conducted a descriptive correlation study to measure nurse practitioners' job satisfaction in a Midwestern state with the purpose of identifying and describing the level of job satisfaction of nurse practitioners. Results of the study related to nurse experience showed that nurses who were new graduates and had less practical experience were more satisfied with nursing than other nurses. Overall, the nurse practitioners in the study were minimally satisfied, but they were most satisfied with intrinsic factors such as challenges at work, autonomy, sense of accomplishment and ability to deliver quality care. The findings were explained well in terms of the theoretical framework of Herzberg's dual theory. The recommendations 
highlighted a need for an organisational focus on external factors to support nurse satisfaction and retention (Kacel et al., 2005).

In the Saudi Arabian context, nurse experience has been linked to job satisfaction (Al-Ahmadi, 2002; Almalki et al., 2012). Al-Ahmadi (2002) conducted a descriptive study of nurses working in nine $\mathrm{MoH}$ hospitals in the Riyadh region. The study examined the level of job satisfaction among Saudi and non-Saudi nurses. The findings revealed that job satisfaction is affected positively by nurses' years of experiences. In a study on quality of work life among primary healthcare nurses in the Jazan region of Saudi Arabia, Almalki et al. (2012) found that nurses who had more years of experience were more satisfied than nurses with fewer years of experience in the profession. Furthermore, nurses with more years of experience had better problem solving skills and better self-management skills for most personal and professional issues. Further, their experience as nursing professionals contributed to an enhanced knowledge of how to develop professional issues at work and achieve job satisfaction.

\section{Stress.}

The stress related to one's work was broken down into four dimensions by James (2001). These dimensions are conflict, which refers to inconsistent job obligations; ambiguity, which refers to unclear job obligations; workload, which is the degree of work role demand and resource inadequacy, which refers to the lack of means with which to perform one's job. Stress at work is one of the most serious factors that can reduce employees' job satisfaction and productivity and can also contribute to increased turnover and job dissatisfaction in staff (Al-Omar, 2003).

Research has found a strong connection between the job satisfaction of hospital workers and stress (Hayes et al., 2006). According to Lu et al. (2005), in a study performed in the United Kingdom, stress continues to have an influence on the 
dissatisfaction and turnover rates of nurses. Further, there are many studies in different countries, such as Australia, Singapore, the United States and Taiwan that report similar results regarding stress in health organisations as a major predictive factor of anticipated nurse turnover (Coomber \& Barriball, 2007).

In Saudi Arabia stress also affects job satisfaction and the increase in nurse turnover. There are many factors that can affect stress levels, such as workload, family demands, communication, management, organisational structure and climate (AlAameri, 2003; Al-Omar, 2003). A study conducted by Al-Aameri (2003) focused on sources of job stress for nurses in public hospitals. The study explored factors that influence job stress for nurses in a number of public hospitals in Riyadh City. The findings of Al-Aameri's study showed that there are many factors that influence job stress for nurses in public hospitals. The highest stressors found were (a) climate; (b) organisational structure; (c) the nursing job itself and (d) the managerial role.

Similarly, Al-Omar (2003) conducted a study on source of work stress among hospitals staff at the MoH of Saudi Arabia. A descriptive study was used; the purpose of this study was to determine the sources of work stress among staff at five $\mathrm{MoH}$ hospitals in Riyadh City, including doctors, nurses, technicians, therapists and administration staff. The conclusion of this study revealed that the level of stress among staff at MoH hospitals is high, especially in Saudi staff, and that this high level of stress was due to many factors, such as absence of appreciation, long working hours, inadequate technical facilities at hospitals and short break times for hospital staff. Further, relating back to staff experience, Al-Omar's study found that staff with more experience report less work stress. 


\section{Nursing Shortages}

Shortages in nursing staff continue to be a challenge and have become a global issue of great concern to many developed countries such as Australia, the United Kingdom, Canada and the United States. The definition of a nursing shortage is that there is an insufficient quantity of nurses available to take care of patients (Erlin, 2004). Oulton (2006) defined a shortage of nurses as 'generally considered to be an imbalance between demand for employment and the available supply' (p. 34S). There are many factors that affect the shortage of nurses worldwide. These include the ageing of the nursing workforce, a decreased number of nurses entering the profession, the shortage of nursing faculties, increased population, other professional choices, low income and job dissatisfaction (Longo, 2007; Miller, 2007; Mitchell, 2009). Barney’s (2002) study entitled 'The Nursing Shortage: Why is it Happening?' mentioned many factors that can affect the shortage of nurses, including lack of respect, unwelcoming hospital culture, too much paperwork, alternative settings and limited funds.

Lack of respect towards nurses has been reported as another contributing factor to nurse shortages in the developed and developing countries. According to Barney (2002), 'a career in nursing, historically, was not respected' (p. 154). Most young people, especially females, report having entered the nursing profession because limited career options were available to them (Barney, 2002). It has been asserted that women in the United States who have chosen nursing as a career often steer their daughters away from becoming nurses and encourage them to pursue careers in other areas of medicine or in biotechnology (Barney, 2002).

A nursing shortage can influence stress levels and increased workloads so that the level of job satisfaction will be decreased. According to the United States Health Resources and Services Administration (2002), the shortage in the United States is 
expected to reach 20 per cent by 2015 , and it will grow to 29 per cent by 2020 . Further, a 2004 report predicted a shortage of 40,000 nurses in Australia by 2010 and a shortage of 78,000 in Canada by 2011 (International Council of Nurses, 2004). The issue of nursing shortages is one of the serious problems in the global health sector and systems. The shortage of qualified nurses could affect the vision and mission of every health sector and the quality of healthcare. The WHO (2002b) identified five key result areas (KRAs) as strategic directions to strengthen nursing and midwifery services globally. The strategic directions included: (KRA1) health planning, advocacy and political commitment; (KRA2) management of health personnel and midwifery services; (KRA3) practice and health system improvement; (KRA4) education of health personnel for nursing and midwifery services and (KRA5) stewardship and governance. The shortage of nurses in Saudi Arabia is a major concern, as it significantly affects the efficiency and productivity of the healthcare system (Al-Aameri, 2000). This problem has only been briefly documented in the literature in the Kingdom of Saudi Arabia yet, according to Abu-Zinadah (2006), it will take 25 years to train enough Saudi nurses to cover 30 per cent of the Kingdom's nursing personnel requirements. In the Kingdom of Saudi Arabia, the shortage of nurses can be attributed to various social, cultural and educational factors. There are several factors that prevent Saudi students from attending nursing programmes, some of which include the five-year length of the programme at universities, long working hours after graduation, the unwillingness of Saudi families to allow their daughters to work night shifts and the poor public image of nursing, a profession that is not considered to be respectable (Al-Zayyer, 2003). This negative public image of nursing has prevented Saudis from encouraging their children to consider enrolling at universities and health institutes to study nursing. 


\section{Factors Influencing the Shortage of Saudi Nurses}

The shortage of nurses, having become a worldwide problem, is of great concern to many countries. The Saudi Arabian MoH has focused on the need to address the lack of Saudi Arabian and non-Saudi nurses in public hospitals. There are many factors that affect the shortages of nursing worldwide. The literature reviewed suggests that within the Kingdom of Saudi Arabia, the shortage of nurses is a major problem due to various social, cultural and educational factors.

\section{Social and cultural factors.}

Saudi Arabian people are usually kind, sociable and empathetic (Mebrouk, 2008). The Saudis tend to be very conservative and are greatly affected by certain ideas surrounding certain professions. This is especially apparent on the subject of mixedgender environments, such as hospitals. Traditionally, and largely due to cultural values, it is not acceptable for Saudi women to work in environments with men, such as in the nursing profession (Al-Omar, 2004; El-Gilany \& Al-Wehady, 2001; Mebrouk, 2008). Further, nursing has a poor public image and is not considered a respectable job in Saudi society (Al-Omar, 2004; Mebrouk, 2008). This negative view of nursing has prevented people from studying or working in the profession. People who choose the nursing profession face disapproval from their families, friends and community. For example, one male Saudi nurse was quoted by a researcher as having said, 'My mother refused to tell her friends [that] I am a nurse. If they see me in the hospital, she tells them I am a doctor, as doctors are better than nurses' (Miller-Rosser et al., 2006, p. 2).

Like most Arab societies, Saudi Arabia has a negative view of nursing, especially of female nurses (Al-Omar, 2004; El-Gilany \& Al-Wehady, 2001). In her study, Mebrouk (2008) mentioned that TV programmes play an essential role in negatively affecting the general Saudi society's view of nursing. Some old Egyptian 
movies portray female nurses with antisocial attitudes and immoral behaviour. In a study involving high schools, Al-Omar (2004) explored the factors that influence Saudi females not to choose nursing as a profession. Al-Omar identified six factors: (a) family disagreement; (b) community image; (c) cultural and communal values; (d) long working hours; (e) mixed genders in the work environment and (f) the worry of not being 'marriageable.' In a 2001 study, 69 per cent of boys' secondary school students said that they could not marry a nurse (El-Gilany \& Al-Wehady, 2001).

Further, in another study that examined the oral testimonies of 17 contemporary Saudi Arabian nurses, results indicated that their overall impression of nursing was that it is a job for those who are poor and uneducated, that it is largely a profession for foreign women whose moral behaviour is questionable and that it is an unworthy profession for Saudi Arabian people (Miller-Rosser et al., 2009). This negative view of nursing has affected the number of Saudis who study and engage in the nursing profession. It may also have an impact on their level of job satisfaction, thereby increasing the turnover rate. However, in the last few years, these images have changed; people have slowly gained a better understanding of the role nursing provides in the improvement of public health and in the prevention of disease, in both the healthcare system and in health education. The latest statistics show that the total number of Saudi nurses working in public hospitals has improved from 9 per cent in 1996 to 36 per cent in 2007. Moreover, the $\mathrm{MoH}$, in its attempt to change the image of nursing, has managed to increase the number of nurses nationwide under the Saudization programme by raising their salaries by approximately 20 per cent in 2010 and providing more job benefits to national nurses, especially those who have higher qualifications. 


\section{Nursing education in Saudi Arabia.}

Nursing education is vital to increasing the number of qualified Saudi nurses in terms of both theory and practice. Nursing education for males started out as a basic and limited programme in Riyadh, through a cooperation between the MoH and the WHO in 1958. Fifteen Saudi male students were enrolled in this programme for 2 years. In 1961, two health schools were established for females, one in Riyadh and the other in Jeddah. These institutes educated and trained both women and men to become nurses' aides in hospitals (Miller-Rosser et al., 2006). These diploma programmes have existed for male and female students. They fell under the MoH umbrella, which meant that all of the graduates were only allowed to work in the MoH organisations (Mitchell, 2009). Developing the health institutes and nursing schools existing at that time was one of the goals of the Saudization programme in order to increase the numbers of female and male Saudi nurses to replace expatriate nurses (Al-Mahmoud, 2013). A total of 46 health institutes were in operation by 1992; 27 for females and 19 for males (Alhusaini, 2006).

Later, all of these institutes were transferred to the university sector and became nursing colleges under the MoHE. This step was important for developing nursing education programmes. The MoHE initiated the first female BSN programmes in 1976 and introduced postgraduate studies, such as the MSN, in 1987 at King Saud University in Riyadh. All of these programmes were established for female students only, with no existing university level programmes for males at that time. The first male BSN programmes were established in 2006 (Mebrouk, 2008).

Further, a scholarship programme was established in 1996; this programme was provided for Saudi students who wished to study nursing abroad in developed countries such as Australia, the United Kingdom, Canada, Sweden and the United States. In 
Australia, Monash University started collaborations with Saudi health organisations, such as the King Faisal Specialist Hospital and Research Centre, to offer in-country scholarship programmes for Saudi nurses working in hospitals to obtain and upgrade their level of education by studying for a BSN, or Master's and Doctorate (PhD) degrees, if they were unable to study overseas (Miller-Rosser et al., 2009). However, the latest statistics for nursing qualifications show that two-thirds (67 per cent) of the Saudi nurses graduated from the health institutes with diploma certificates, 30 per cent from junior colleges with high diploma certificates and 3 per cent from BSN programmes. There were 35 graduates holding a postgraduate certificate (Al-Dossary et al., 2008). The nursing education system in Saudi Arabia is totally separated by gender; however, there is interaction between males and females in the work environment (AlZayyer, 2003). This interaction may be a negative influence on many female students, who may not consider nursing as a profession and area of education due to cultural factors, as mentioned earlier (Al-Zayyer, 2003). Moreover, the English language is essential for studying nursing in Saudi colleges and universities. In the Saudi Arabian education system, study of the English language previously started in secondary school, but since 2012, it has been taught from Grade 4 in primary schools. In nursing schools, all the classes are taught in English. Unfortunately, most of the students who attend these schools have poor English language skills, although students are asked to have a good command of English as a condition for attending. Thus, the English language becomes a barrier for many students who are interested in nursing, but lack a command of the language. 


\section{Chapter Summary}

The main goal of the current study is to build on the prior research described in this review of the literature and identify and explore the factors that influence job satisfaction among Saudi nurses working in public hospitals in the Makah region of Saudi Arabia. This chapter has discussed the literature relevant to the current study with a specific interest in literature relevant to job satisfaction. The chapter began by offering a definition of job satisfaction and presenting the research history and contextual background of the job satisfaction. This review provided a discussion of job satisfaction and identified job satisfaction, both globally and locally in Saudi Arabia. This section also reviewed and identified nursing job satisfaction and the factors that influence nurses' job satisfaction in many countries worldwide, including the United States, Canada, England, Australia ans NewZealand, Korea and Chian, Pakistan and the Middlel East.

Further, the literature review focused on not only identifying job satisfaction in nursing, but also the factors that influence Saudi and non-Saudi nurses' job satisfaction in many areas in Saudi Arabia. The second section of the literature review focused on the main factors influencing nurses' job satisfaction, including demographic, personal and job characteristics. The relationship between job satisfaction and the demographic factors, personal characteristics and job characteristics of nurses was discussed. The demographic and personal characteristics (such as gender, marital status, age, education level, pay and number of dependent adults) are often used to determine and represent some of the convincing predictors in employee job satisfaction (Michal et al., 2001). Further, job characteristics (including leadership or management style, experience in nursing and stress) have more influence on job satisfaction than individual factors (AlOmar, 2003; Kavanaugh et al., 2006; Zaghloul et al., 2008). The literature review 
discussed the global and local shortage of nursing. This section of the review identified the factors that influence the shortage of nurses in Saudi Arabia, which included social and cultural factors, as well as nursing education in Saudi Arabia.

Chapter 3 will describe Herzberg's two-factor theory, which formulates the conceptual framework for this study and on which the questionnaire utilised in this study was based. 


\section{Chapter 3: Herzberg's Two-Factor Theory}

\section{Introduction}

A conceptual framework helps guide research and can assist researchers in observing phenomena. Burns and Grove (2005) define conceptual framework models as 'a set of highly abstract, related constructs that broadly explain phenomena of interest, express assumptions and reflect a philosophic stance' (p. 128).The conceptual framework used in this study is based on the 'motivation-hygiene theory,' also known as Herzberg's two-factor theory or dual-factor theory, and named after its creator, Frederick Herzberg.

This chapter provides an introduction of the conceptual framework used in this study, and will also discuss theories of job satisfaction and nursing studies that have used Herzberg's theory.

\section{Herzberg's Two-Factor Theory}

In 1959, Herzberg, Mausner and Snyderman published the two-factor model of work motivation and developed the motivation-hygiene theory, which was influenced by Maslow's hierarchy of needs (Jones, 2011). Maslow's theory will be discussed and compared with Herzberg's theory later in this chapter. Herzberg created a twodimensional paradigm of factors influencing people's attitudes towards work. Initially Herzberg and his colleagues developed a hypothesis that satisfaction and dissatisfaction with a job were affected by two different sets of factors and thus satisfaction and dissatisfaction could not be reliably measured on the same continuum (Herzberg et al., 1959; Stello, 2011). Herzberg and colleagues then conducted studies on job satisfaction to decide which factors in an employee's work environment caused satisfaction or dissatisfaction. After two pilot studies, the first involving 13 labourers, clerical workers, foremen, plant engineers and accountants, and the second involving 39 middle- 
managers, his theory was further developed and expanded (Herzberg, 1966; Herzberg et al., 1959). Subsequently, Herzberg et al. (1959) studied more than 203 accountants and engineers working in nine factories in the Pittsburgh area of the United States to determine which factors influence the worker's work environment and cause satisfaction or dissatisfaction (Herzberg et al., 1959). The main hypothesis of Herzberg's theory was that certain factors lead to positive attitudes towards work, and others lead to negative attitudes. The other hypothesis stated that the factors and effects involving long-range sequences of events and short-range sequences of events, respectively, were distinct (Herzberg et al., 1959; Stello, 2011). According to their research data, the original hypothesis of the Herzberg study was restated and then changed to the two-factor theory of job satisfaction. The two factors that have an effect on job satisfaction are divided into two sets of categories. The first category is associated with 'the need for growth or self-actualisation', and became known as the motivation factors. Motivation factors include achievement, recognition, the work itself, responsibility, advancement and the possibility for growth (Herzberg, 1966; Herzberg, 2003). The other category of factors is related to 'the need to avoid unpleasantness', and is known as hygiene factors. Hygiene factors include company policies and administration, relationship with supervisors, interpersonal relations, working conditions and salary (Herzberg, 1966; Herzberg, 2003). Motivation factors thus lead to positive job attitudes and hygiene factors surround the 'doing' of the job (Herzberg et al., 1959; Stello, 2011).

At the heart of the two-factor theory developed by Herzberg and his colleagues is the difference between motivation and hygiene factors, or intrinsic and extrinsic factors. Herzberg described motivation factors as intrinsic to the job and hygiene factors as extrinsic to the job. Thus, motivation factors operate to only increase and improve 
job satisfaction; whereas hygiene factors work to reduce job dissatisfaction. According to Herzberg et al. (1959):

Among the factors of hygiene, when the factors deteriorate to a level below that which the employee considers acceptable, then job dissatisfaction ensues. However, the reverse does not hold true. When job context can be characterised as optimal, we will not get dissatisfaction but neither will we get much in the way of positive attitudes. It is primarily the 'motivators' that serve to bring about that kind of job satisfaction (pp. 113-114).

Motivating events lead to job satisfaction because of a need for growth or selfactualisation. Hygiene factors are less important to job satisfaction than are motivational factors (Herzberg, 1966; Herzberg, 2003). The presence of motivational factors can produce job satisfaction, but their absence leads to no job satisfaction. Therefore, poor hygiene factors can cause job dissatisfaction, while better hygiene factors can reduce dissatisfaction but cannot cause job satisfaction (Herzberg et al., 1959). Further, Herzberg mentioned that the opposite of job dissatisfaction is no job dissatisfaction. Likewise, the opposite of job satisfaction is no job satisfaction (Herzberg, 1966; Herzberg, 2003).

Herzberg's theory is one of the most significant content theories in job satisfaction (Dion, 2006). Further, Herzberg's two-factor theory was noted by many researchers to be the most effective needs satisfaction model used in healthcare organisations (Cahill, 2011; Timmreck, 2001). Herzberg's two-factor theory has also been used widely by researchers evaluating nursing job satisfaction (i.e., Best \& Thurston, 2004; McGlynn et al., 2012; Hegney et al., 2006; Jones, 2011; Kacel et al., 2005; Lephalala, 2006; Mitchell, 2009; Rambur, Mclntosh, Palumbo, \& Reinier, 2005; Russell \& Gelder, 2008). 
The following tables are summaries of Herzberg's two-factor theory. Table 3.1 displays the motivation and hygiene factors. Motivation factors include advancement, the work itself, the possibility of growth, responsibility, recognition and achievement. Hygiene factors include interpersonal relations, salary, company policies and administration, relationship with supervision and working conditions (Herzberg, 1966). Table 3.2 provides comparisons between the motivation and hygiene factors.

Table 3.1

Summary of the Factors in Herzberg's Theory

\begin{tabular}{ll}
\hline \multicolumn{1}{c}{ Motivation Factors } & \multicolumn{1}{c}{ Hygiene Factors } \\
\hline Advancement & Interpersonal relationship \\
Work itself & Salary \\
Possibility of growth & Policies and administration \\
Responsibility & Supervision \\
Recognition & Working conditions \\
Achievement & \\
\hline
\end{tabular}

Table 3.2

Comparisons Between the Two Factors of Herzberg's Theory

\begin{tabular}{lll}
\hline & Motivation Factors & Hygiene Factors \\
\hline Absent & $\begin{array}{l}\text { The outcome is no } \\
\text { satisfaction }\end{array}$ & $\begin{array}{l}\text { The outcome is } \\
\text { dissatisfaction } \\
\text { Present }\end{array}$ \\
The outcome is satisfaction & $\begin{array}{l}\text { The outcome is no } \\
\text { dissatisfaction }\end{array}$ \\
Herzberg described & Intrinsic to the job & Extrinsic to the job \\
Important to job satisfaction & Strong & Poor \\
\hline
\end{tabular}

The main concepts behind the two-factor theory are the difference between the motivation and hygiene factors. 


\section{Motivation factors.}

The word 'motivation' comes from the Latin word movere or 'to move'. The definition of motivation is 'how to provide something to a person to drive him/her to do something' (Ruthankoon \& Ogunlana, 2003, p. 333). In the two-factor theory, motivation is the variable most strongly correlated with job satisfaction and Herzberg and his colleagues argued that to increase employees' job satisfaction the motivation factors must be improved (see Table 3.2). According to Herzberg's theory, motivation factors, or motivators, are intrinsic to the job and lead to positive attitudes towards the job because they satisfy the 'need for growth or self-actualisation' (Herzberg, 1966, p. 75). Motivation factors are related to a person's job satisfaction and include advancement, the work itself, possibility of growth, responsibility, recognition and achievement (Herzberg, 1966). The following is a brief explanation of each of the motivation factors (Adair, 2006; Herzberg, 1966):

\section{Advancement.}

Advancement is defined as the upward and positive status or position of the person or employee in the workplace. A negative, or neutral status at work is considered negative advancement.

\section{The work itself.}

The actual content of job tasks and assignments has a positive or negative effect upon employees. Whether the job is too easy or too difficult, and interesting or boring, can impact satisfaction or dissatisfaction in the workplace.

\section{Possibility for growth.}

Possibilities for growth are the actual opportunities for a person to experience personal growth and be promoted in the workplace. This allows for professional growth, 
increased chances to learn new skills, undergo training in new techniques and gaining new professional knowledge.

\section{Responsibility.}

This factor includes both responsibility and authority in relation to the job.

Responsibility is related to gaining satisfaction from being given the responsibility and freedom to make decisions. Gaps between responsibility and authority greatly impact on job satisfaction or dissatisfaction.

\section{Recognition.}

Any act of recognition happens when employees receive praise or rewards for reaching specific goals at their job, or when they are produce high quality work. On the contrary, negative recognition at work includes criticism and blame for the job done.

\section{Achievement.}

Positive achievement includes achieving a specific success, such as completing a difficult task on time, solving a job-related problem, or seeing positive results of one's work. Negative achievement involves failure to make progress at work or poor decisionmaking on the job.

\section{Hygiene factors.}

The term hygiene comes from the Latin word 'hygiena'. According to Herzberg and colleagues, this term is used in reference to 'medical hygiene...[which] operates to remove health hazards from the environment' (1959, p. 113). Disease from health hazards or hygiene is preventable; similarly, employee dissatisfaction from hygiene issues at work is preventable. Hygiene factors are the variables correlated with reducing the level of job dissatisfaction, as opposed to motivation factors, which directly influence an employee's motivation and satisfaction. Hygiene factors are related to the conditions that surround the 'doing' of the job or the workplace. Herzberg states that the 
hygiene factors are extrinsic to the job, and if present, lead to preventing job dissatisfaction because hygiene factors react to the environment and workplace for 'the need to avoid unpleasantness' (Herzberg, 1966, p. 75). Hygiene factors operate to decrease the job dissatisfaction of the employees (see Table 3.2). Hygiene factors are related to the context of the work itself, and include interpersonal relations, salary, company policies and administration, relationship with supervisors and working conditions (Herzberg, 1966). The following is a brief summary of the hygiene factors (Adair, 2006; Herzberg, 1966):

\section{Interpersonal relations.}

These relationships are limited to the personal and working relationships between the worker and her/his superiors, subordinates and peers. This includes jobrelated interactions and social discussions in the work environment and during break times.

\section{Salary.}

This includes all forms of compensation at one's place of work, such as wage or salary increases, or unfulfilled expectations of wage or salary increases or decrease. Hospital policies should be clear regarding salary increases and bonuses in the workplace.

\section{Company policies and administration.}

This includes descriptions of adequate or inadequate company organisation and management policies and guidelines. This factor involves good or poor organisational policies that affect the employee. For example, they may include a lack of delegation of authority, poor policies and procedures and poor communication.

\section{Supervision.}


Supervision is associated with the competence or incompetence, and fairness or unfairness of the supervisor or supervision. This includes the supervisor's willingness to delegate responsibility or to teach, fairness and job knowledge. A good supervisor, or access to supervision, is important to enhance the employee's level of job satisfaction. Poor leadership or management may decrease the level of job satisfaction in the workplace.

\section{Working conditions.}

These factors involve the physical surroundings of the job, and whether there are good or poor facilities. Working conditions may include the amount of work, space, ventilation, tools, temperature and safety. A good environment, as opposed to a poor environment, makes employees satisfied and proud.

Herzberg's dual-factor theory is used in most job satisfaction studies, which typically also incorporate single research method (Jones, 2011; Kacel et al., 2005; Lephalala, 2006) and mixed research methods (Mitchell, 2009). This is because the motivating and hygiene factors are correlated with the instruments used in the quantitative phase to explore and identify the factors that affect job satisfaction. This study will fill a gap in Saudi nursing research and identify the factors that can affect the job satisfaction of Saudi nurses working in public hospitals in the Makkah region.

Figure 3.1 is the conceptual framework that guided this study. 

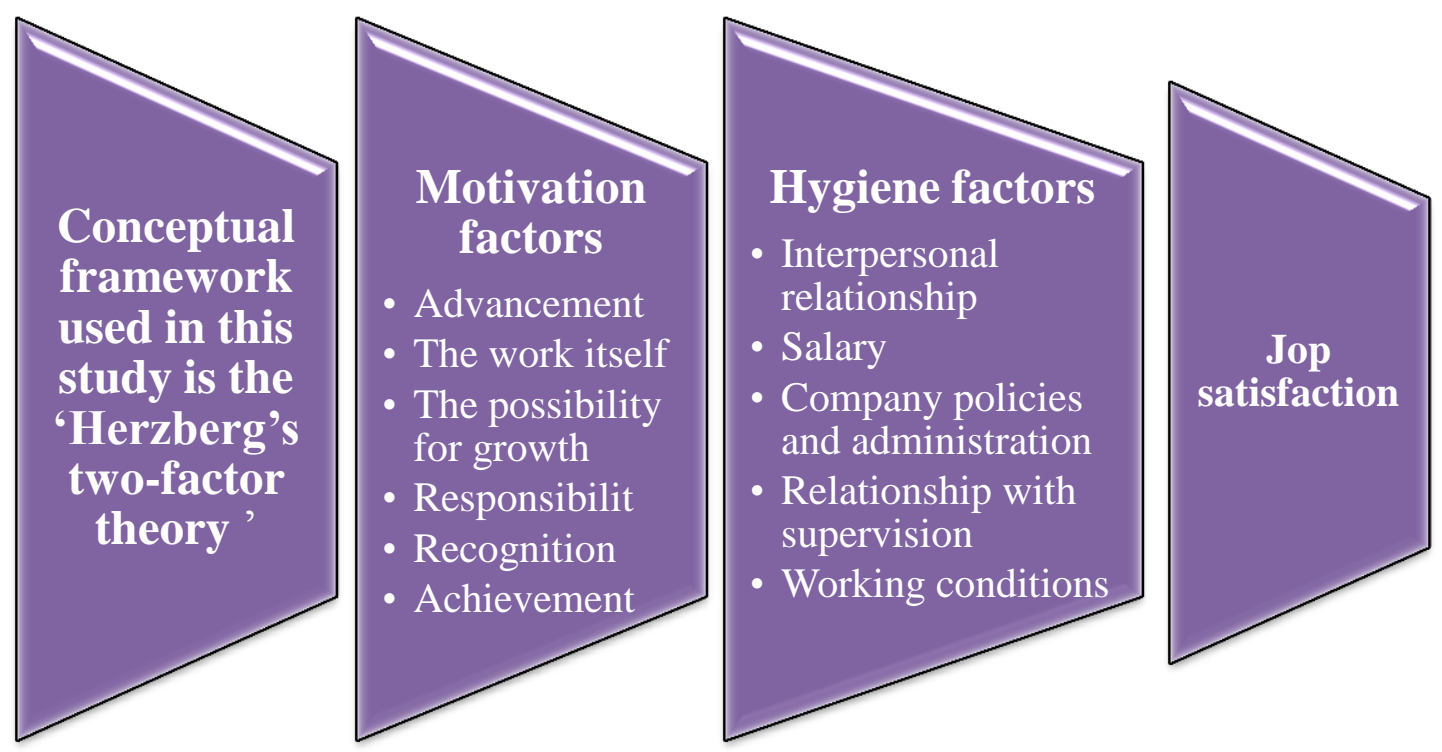

Figure 3.1: Herzberg's two-factor theory as a conceptual framework of the study.

\section{Theories of Job Satisfaction}

Source: Herzberg (1966)

The study of job satisfaction has a long history. Nursing job satisfaction can be traced back to a 1940 study by Nahm (Ma, 2002). This first major study was conducted at the University of Minnesota. To obtain a clearer perception and gain a better understanding of employees' motivation, job features and their relationship to job satisfaction, numerous psychological and management theories have emerged that are now used in nursing job satisfaction research. The following section will discuss these theories, as well as Herzberg's two-factor theory (1959) and Abraham Maslow's hierarchy of needs theory (1954).

\section{Maslow's hierarchy of needs.}

Abraham Maslow (1954) tried to identify and understand the factors could motivate people. He suggested the 'hierarchy of needs', which ranks human needs. Maslow's theory categorised human needs into five levels. The most basic are physiological (food, water, sex, shelter and other bodily needs); the second level is safety (security against physical and emotional harm); the third level is social (affection, 
belonging, acceptance and friendship), the fourth level is self-esteem (autonomy, achievement, recognition and attention); and the last level, which is the top of the hierarchy of needs pyramid, is self-actualisation (self-fulfilment and growth) (Robbins et al., 2008). Figure 3.2 illustrates Maslow's (1954) hierarchy of needs.

\section{Maslow's Hierarchy of Needs}

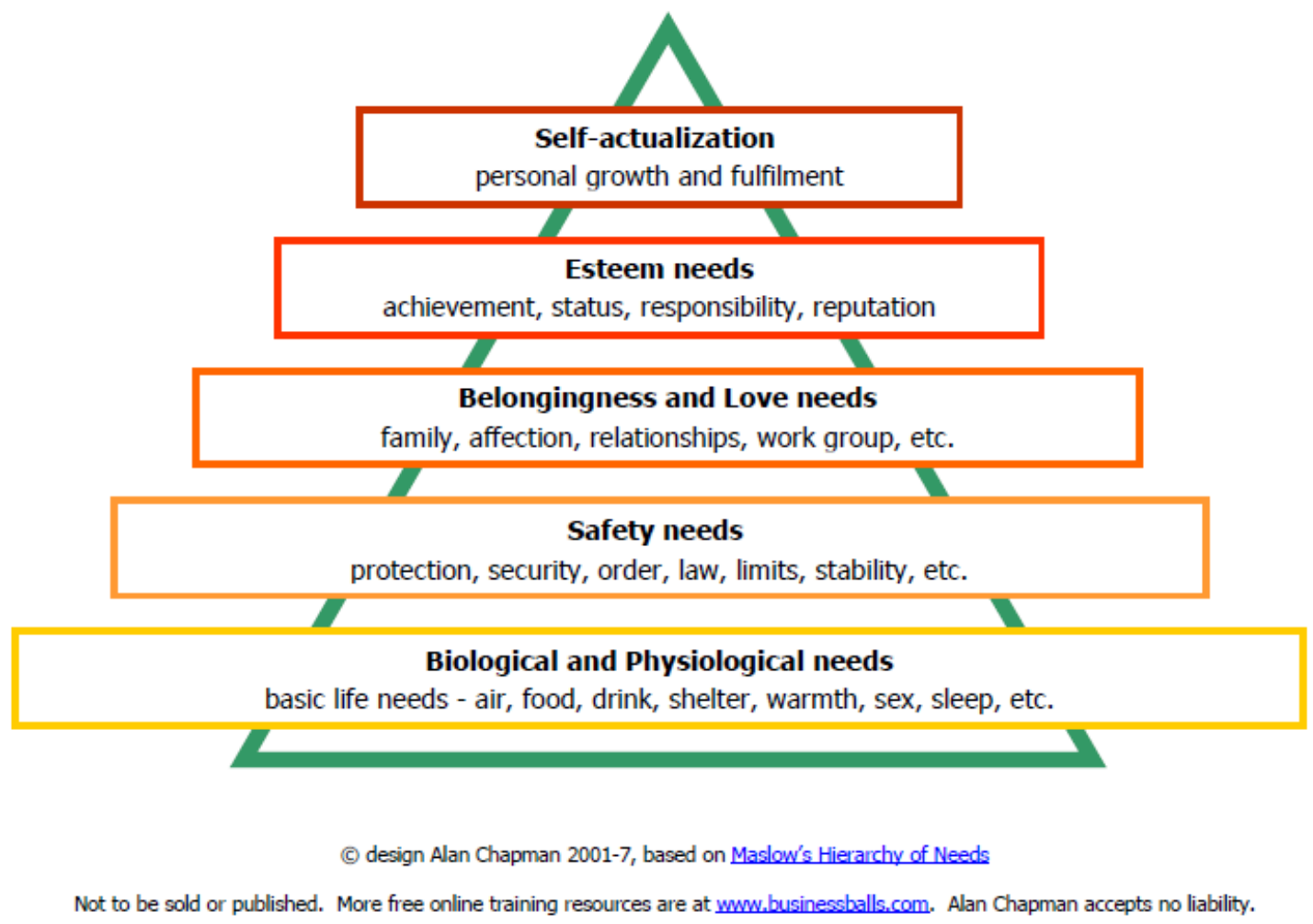

Figure 3.2: Maslow's hierarchy of needs.

Source: Chapman (2001). Retrieved from http://www.newcentre.org/programs/basicneeds/

The relationship between Herzberg's two-factor theory and Maslow's hierarchy of needs is that the motivational factors in Herzberg's theory are associated with the self-actualisation and self-esteem needs in Maslow's theory. These factors provide for a positive sense of satisfaction. The hygiene factors are associated with lower-order needs, which include the social, safety and security and physiological needs in Maslow's theory. The absence of these factors leads to dissatisfaction. Table 3.3 
summarises the relationship between Herzberg's two-factor theory and Maslow's needs hierarchy (Adair, 2006).

Table 3.3

The Relationship Between Herzberg's and Maslow's Theories

\begin{tabular}{ll}
\hline Herzberg's Two-Factor Theory & Maslow's Hierarchy of Needs \\
\hline \multicolumn{1}{c}{ Hygiene Factors } & \\
$\begin{array}{l}\text { Interpersonal relationships } \\
\text { Salary }\end{array}$ & $\begin{array}{l}\text { Social needs } \\
\text { Safety and security needs } \\
\text { Policies and administration } \\
\begin{array}{l}\text { Supervision } \\
\text { Working conditions }\end{array}\end{array}$ \\
\hline \multicolumn{1}{c}{ Motivation Factors } & \\
Advancement & \\
Work itself & \\
Possibility of growth & Self-actualisation needs \\
Responsibility & Esteem needs \\
Recognition & \\
Achievement & \\
\hline
\end{tabular}

\section{Vroom's theory (1964).}

Another theory of job satisfaction is the expectancy theory proposed by Victor Vroom (1964). The expectancy theory of job satisfaction has also been significant and when studying job satisfaction. Moreover, a theory known as the valence, instrumentality and expectancy theory resulted from Vroom's initial theory (1964). This theory proposed that an individual's job satisfaction was a function of the employee's feelings towards certain outcomes and the possibility that those outcomes would be realised. More specifically, if employees obtain less than they expect, or if they feel they have been treated unfairly, then they will be dissatisfied. However, motivation is enhanced if there is a link between performance or effort at work and valued rewards (Hansen, 2007; Miller, 2007; Vroom, 1964). The three primary concepts in this theory include: instrumentality, which refers to the employees' notion of whether or not they 
will actually receive what they desire; expectancy, which refers to employees' perception of different expectations and levels of confidence. For example, employees believe that if they complete their work or if they work harder, they will obtain more payment or more benefits at work. The third concept is valence, which refers to emotional orientations and the value of expected outcomes or rewards to the employee (Hansen, 2007; Vroom, 1964). Figure 3.3 illustrates Vroom's initial theory (1964).

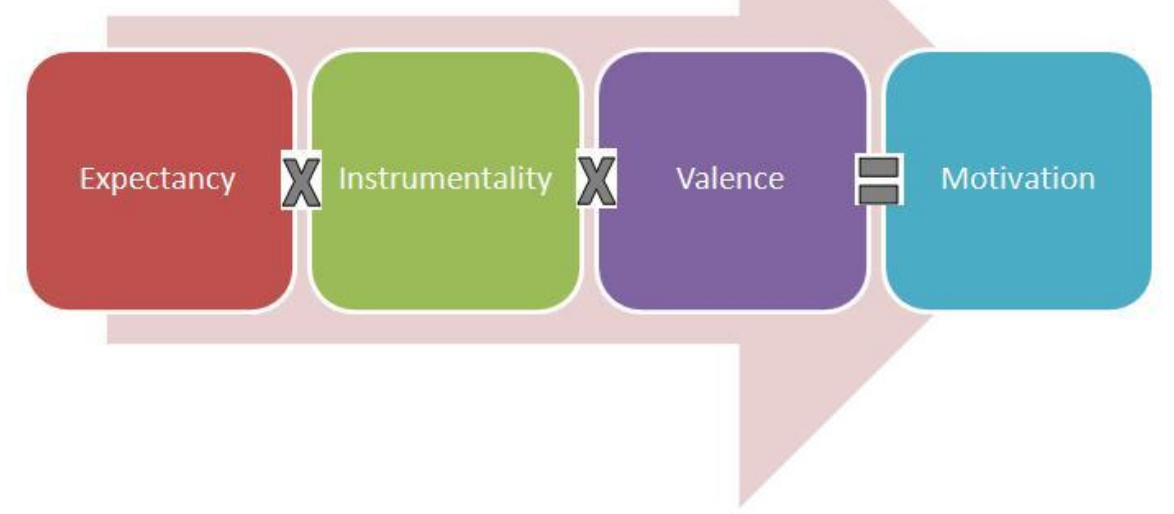

Figure 3.3: Expectancy theory by Victor Vroom (1964).

Source: Human Resource Management. Retrieved from https://wikispaces.psu.edu/display/PSYCH484/Spring+2013+Expectancy

\section{Nursing Studies Utilising Herzberg's Theory}

Herzberg's theory continues to be used to determine and identify the level of job satisfaction in research in a variety of international settings. Numerous studies in nursing populations have used Herzberg's theory when researching job satisfaction, and several have also used it as a conceptual framework (i.e., Jones, 2011; Kacel et al., 2005; Lephalala, 2006; Mitchell, 2009; Russell \& Gelder, 2008).

Kacel and colleagues (2005) employed Herzberg's theory as a framework in their study of job satisfaction among 147 nurse practitioners in a Midwestern area of the United States. This quantitative descriptive study found that both hygiene and 
motivation factors contributed to job satisfaction. Further, the authors mentioned that improving hygiene factors, especially salaries and compensation, improved job satisfaction.

Another study was conducted by Lephalala (2006). She studied the factors influencing nursing turnover in selected private hospitals in England for 136 nurses, using Herzberg's theory as a framework for the variables. The quantitative descriptive study used questionnaires and found that intrinsic (motivation) factors influenced nursing turnover and dissatisfaction. Further, extrinsic (hygiene) factors influenced nurses' dissatisfaction with salary and administration policies.

A third study using the motivation-hygiene theory as a framework was conducted by Mitchell (2009). She studied job satisfaction and burnout among 453 foreign-trained nurses in Saudi Arabia. This mixed study used a three-instrument survey and focus group discussions. Herzberg's theory served as the framework for the study, which found that job satisfaction is influenced by both motivation and hygiene factors. These factors were recognition, the work itself, salary, work conditions, achievement, company policy and administration, relationships with supervisors and relationships with peers. However, they attributed job dissatisfaction to hygiene factors, such company policy and administration, work conditions, status, relationships with supervisors, security and personal life.

Russell and Gelder (2008) studied job design and job satisfaction in 331 members of the International Transplant Nurses Society (ITNS), using Herzberg's theory of motivation. This descriptive, correlation design study used an electronic version of the job design and job satisfaction survey that was mailed to all members of the ITNS. The authors mentioned that the results of the study support Herzberg's theory 
that motivation factors, including achievement, recognition, the work itself and responsibility and advancement, lead to job satisfaction.

Jones (2011) studied the effects of motivation and hygiene factors on job satisfaction for 135 school nurses. A quantitative, cross-sectional survey design was utilised. The study results revealed that nurses were satisfied with organisational policies and pay. However, they were dissatisfied with their jobs. Autonomy had the most influence on job satisfaction and task requirements and professional status negatively affected overall job dissatisfaction.

Herzberg's theory is utilised as a framework in this Saudi Arabian job satisfaction study for many reasons. The hygiene and motivation factors correlated with the NWI-R questionnaire, which was used in the quantitative phase to explore the factors that influence job satisfaction and to identify the level of job satisfaction in Saudi nurses working in public hospitals in the Makkah region. The second reason to use Herzberg's theory was to assess the effects of leadership style, work itself, the possibility for growth, policy and administration and the influence of salary in Saudi nursing and to identify the motivating factors for nurses working in public hospitals. Finally, the literature review revealed that this is the first study that will utilise Herzberg's theory in Saudi nurses working in public hospitals in Saudi Arabia.

\section{Chapter Summary}

This chapter provided a brief introduction and presented the theoretical framework of this study of job satisfaction. The framework is based on Herzberg's twofactor theory, also known as the motivation-hygiene theory. Herzberg's theory is one of the most significant theories related to job satisfaction (Dion, 2006). The main concept of Herzberg's theory is the difference between the two factors: motivation and hygiene. Motivation factors include achievement, recognition, the work itself, responsibility, 
advancement and the possibility for growth (Herzberg, 1966; Herzberg, 2003). Hygiene factors also include company policies and administration, relationship with supervisors, interpersonal relations, working conditions and salary (Herzberg, 1966; Herzberg, 2003). Motivation factors lead to positive attitudes towards the job and hygiene factors surround the 'doing' of the job (Stello, 2011; Herzberg et al., 1959). This chapter also identified theories of job satisfaction and discussed numerous studies on nursing that have used Herzberg's two-factor theory as a conceptual framework in researching job satisfaction.

The next chapter will describe and discuss the research methods used for gathering the data needed to identify the job satisfaction levels of Saudi nurses working in public hospitals. It describes the methodology, research design, settings and sampling strategy of the study. It also describes the two phases of the study. The first phase involved a quantitative design, while the second phase used a qualitative design. Further, it explores and discusses pilot testing and ethical issues relevant to the techniques used with the study participants. 


\section{Chapter 4: Methodology}

\section{Introduction}

The focus of this chapter is to describe the research design, setting, and sampling methods of this study. It describes the quantitative research instrument used for data collection, the validity and reliability of the research instrument and the process of the quantitative data collection and analysis. It also describes the semi-structured face-toface interviews and the process of the qualitative data collection and analysis. Issues related to the study's ethical considerations are also discussed.

To date no studies have been undertaken to determine job satisfaction among Saudi nurses working in public hospitals. Previous Saudi and international research into job satisfaction has identified factors related to job satisfaction of both expatriate and Saudi nurses. This research aims to describe and explore the level of job satisfaction of Saudi nurses working in public hospitals and their perceptions of nurses' intentions to leave. This study aimed to determine which demographic factors, motivation factors and hygiene factors predict job satisfaction among Saudi nurses.

\section{Research Design}

Burns and Grove (2005) define a research design as the 'blueprint for the conduct of a study that maximises control over factors that could interfere with the study's desired outcome' (p. 40). The design used in this study was a mixed methods approach. There are many definitions of the mixed methods approach; one of these definitions, by Gall, Gall and Borg (2010), identified the mixed methods approach as a study that uses both quantitative and qualitative designs for data collection and analysis, either concurrently or sequentially. The purpose of this mixed methods study was to validate the result and bring together the strengths of both quantitative and qualitative designs. According to Johnson and Onwuegbuzie (2004), the goal of mixed methods 
research is not to replace either of these qualitative and quantitative approaches but rather to draw from the strengths and minimise the weaknesses of both in a single research study' (pp. 14-15). Mixed methods research is common in healthcare studies. Healthcare researchers may use this approach to determine and explore complex and multi-faceted problems, especially in healthcare systems with large population samples (Doyle, Brady, \& Byrne, 2009; O’Cathain, Murphy, \& Nicholl, 2007). A mixed methods study design using quantitative and qualitative techniques was appropriate for gathering the data necessary for this study. There are three main advantages of using a mixed methods approach in this study of job satisfaction of Saudi nurses. Firstly, this method can answer research questions that cannot be answered by using a single method alone, and thus can better explain the phenomena. Secondly, it provides a richer, more representative, and fuller picture of the factors that influence the level of job satisfaction (Mertens, 2005). The final advantage of this study design is that it provides hard data that may assist decision-makers to determine and improve Saudi health-care policy (Doyle, Brady, \& Byrne, 2009). The quantitative method was used to examine and identify relationships between the independent variables and the dependent variable, the satisfaction of Saudi nurses with their jobs. A questionnaire was distributed to collect the demographic data of the registered Saudi nurses and to elicit information to identify the factors that lead to satisfaction with their jobs. The qualitative approach utilised face-to-face interviews with Saudi nurses. The interviews provided an opportunity to the participants to reflect on their profession and explore what they thought were the factors that made them satisfied with their jobs. Figure 4.1 illustrates the mixed methods design used in this study, which is a convergent parallel design adapted from Creswell and Plano Clark (2011, p. 118). 


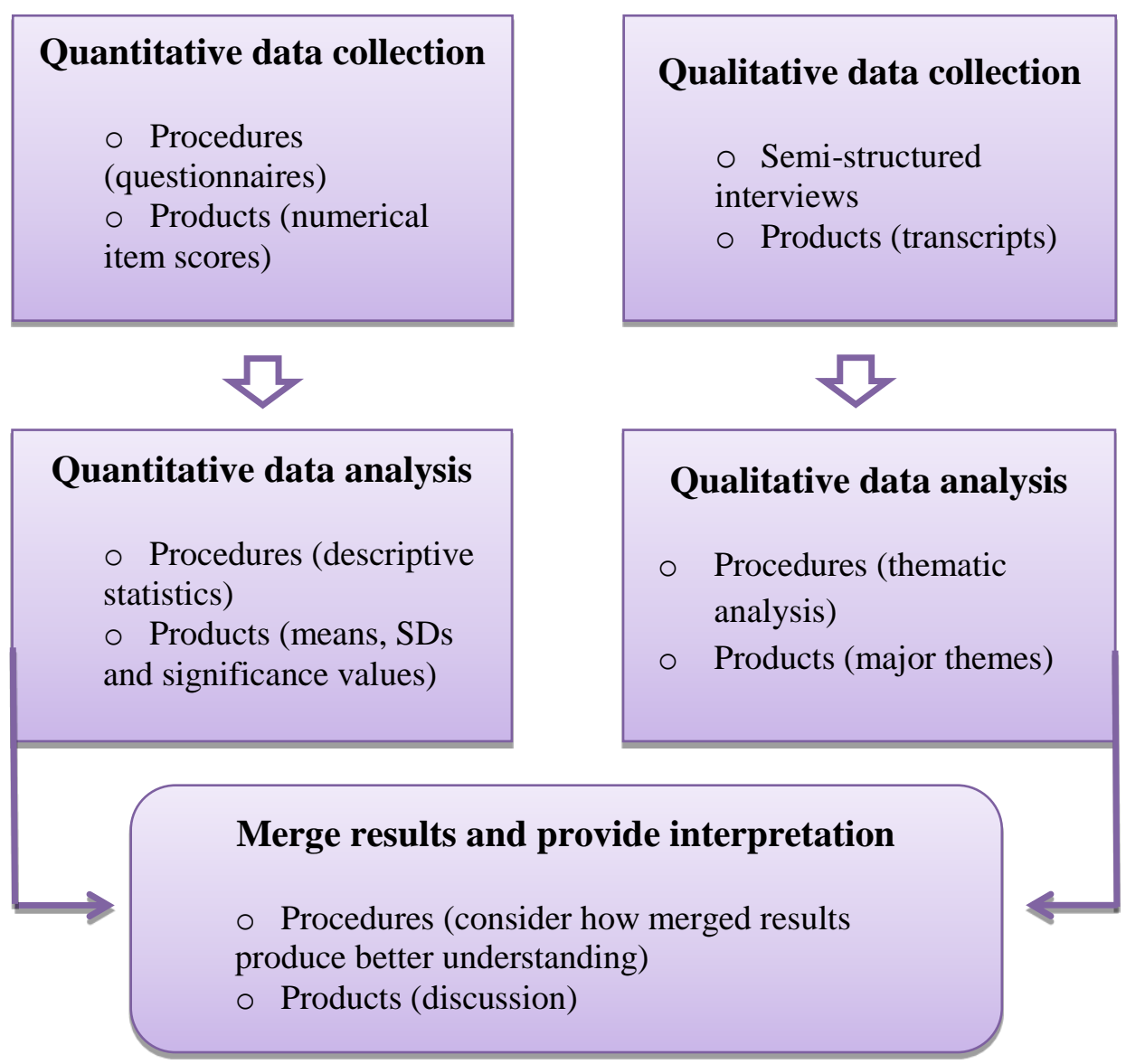

Figure 4.1: The mixed methods approach used in this study.

Based on Creswell and Plano Clark (2011, p. 118).

\section{Setting.}

The study was conducted in the three largest general public hospitals in the three cities in the Makkah region of Saudi Arabia: Jeddah, Makkah and Taif. The study required this setting to obtain as large a sample as possible of Saudi nurses.

The first hospital was King Fahd General Hospital, the largest hospital in Jeddah and, in fact, in the entire Makkah region. The second was King Abdul Aziz General Hospital in the city of Makkah. Finally, the third hospital was King Faisal General Hospital in the city of Taif; all of these hospitals are under MoH direction and have government-supported budgets. The three hospitals provide free medical care for all 
Saudi and non-Saudi patients and comprehensive care for both inpatients and outpatients $(\mathrm{MoH}, 2011)$.

The healthcare system, health policies, and policy development are centralised in Saudi Arabia; hence, they are similar for the three hospitals. However, the bed capacity, organisational structures, employment, and number of Saudi nurse are different in each of these hospitals. Table 4.1 shows statistics for each of the three hospitals in 2010, including the total number of staff nurses (expatriates and Saudis combined), the total number of Saudi nurses and the percentage of Saudi nurses relative to the total.

Table 4.1

The Total Number of Nurses, and the Number of Saudi Nurses, by each Hospital

\begin{tabular}{lccc}
\hline Hospital & Total Nurses & Saudi Nurses & Per Cent \\
\hline King Fahd General Hospital, Jeddah & 1,337 & 413 & 31 \\
King Abdul Alziz Hospital, Makkah & 483 & 240 & 50 \\
King Faisal General Hospital, Taif & 298 & 138 & 49 \\
Total & 2,118 & 791 & 37 \\
\hline
\end{tabular}

\section{Sampling strategy.}

Sampling is defined by Johnson and Christensen (2008) as the process of drawing a sample from the population. The target participants for this research were registered female and male Saudi nurses working full-time in the three public hospitals located in the Makkah region. This study used a convenience non-probability sampling strategy, and all registered Saudi nurses participated voluntarily. A convenience sampling strategy was utilised since it was inexpensive and provided easy accessibility and availability as well as the ability to meet the criteria for inclusion of subjects (Ary, Jacobs, Sorenson, \& Razavieh, 2009). Participation in this study was divided into two concurrent phases. The study was advertised through letters sent by the researcher to all 
the nursing wards of the three hospitals (see Appendix A). The nursing office also publicised this study in general nursing meetings at each of the three hospitals.

Envelopes containing plain language statements explaining the importance of this study, the questionnaire, an invitation letter to participate in a face-to-face interview, a card with the researcher's contact details, consent forms for the face-to-face interviews and a return envelope were given to the nursing office of each hospital to distribute to the internal mail boxes of all Saudi nurses in the three hospitals (see Appendices B and C). The participants were required to complete the anonymous questionnaire, place it in the envelope provided and return it to a box clearly labelled 'Job Satisfaction Survey' which was placed in the main nursing office of each of the three hospitals. The labelled boxes were identified by numbers 1, 2 and 3 in order to identify the return of questionnaires from each of the hospitals. All Saudi nurses who were willing to be interviewed by the researcher were requested to contact the researcher in order to organise for a time for the face-to-face interview. The participants who undertook the survey and responded to the invitation for the interview were all assured that they would not be identified and their responses would be reported in group data only. The following sections explain the two phases of the study. The first phase involved the quantitative design, and the second phase employed the qualitative design.

\section{Phase One: Quantitative design.}

\section{Quantitative sample.}

Seven hundred and ninety-one envelopes were distributed across the three hospitals. Four hundred and thirteen envelopes were provided to the nursing administration office of the King Fahd General Hospital in Jeddah, 240 envelopes to the King Abdul Alziz Hospital in Makkah and 138 envelopes to the King Faisal General Hospital in Taif. A total of 272 registered Saudi nurses completed and returned the 
questionnaires via the return boxes (see Table 4.1). The response rate to the survey was 34 per cent.

The inclusion criteria for participants in this study included all Saudi registered nurses who were working in the public hospital. This study excluded non-Saudi registered nurses.

\section{Research instrument.}

The instrument used in this study was the Nursing Work Index (NWI-R) questionnaire (2000).

\section{The questionnaire.}

Questionnaires are the most common instruments used by researchers to collect data. Questionnaires can be used to obtain a wealth of data and information from research participants, they can be inexpensive for the researcher to manage, and it is relatively easy to compare and analyse the responses to questionnaires (Mertens, 2010). The questionnaire had demographic data added to, and combined with, the NWI-R questionnaire (2000). The questionnaire was translated into the Arabic language by a certified translator in Melbourne, and each translated question was written under each English question for all the survey items to increase the clarity of the questions and to make sure that all nurses understood the survey. All participants were informed that they should answer the survey in the English language and use the Arabic just to improve their understanding of the question.

The NWI-R questionnaire was preceded by questions that elicited information about the participants' demographic data and socioeconomic characteristics, including the following: gender, age, marital status, number of dependent children, number of dependent adults, educational qualifications, and monthly salary. It also included job characteristics and practical experience, such as employing hospital, position, duration 
of employment at the hospital, number of weekly working hours and overall experience in nursing (see Appendix D).

The NWI was originally developed by Kramer and Hafner (1989). It consisted of 65 items that were designed to measure the organisational characteristics that aid nurses' job satisfaction, their ability to provide quality care, and their perceived productivity in hospitals (Kramer \& Hafner, 1989). This instrument was improved by Aiken et al. (2001) to measure the organisational climate that best contributed to nurses' feelings of satisfaction in hospital settings. The revised instrument (the NWI-R) consists of 57 items that are measured with a four-point Likert scale: $1=$ strongly agree, $2=$ agree, $3=$ disagree, $4=$ strongly disagree, so that the participants are not able to select a neutral 'middle' response. Many researchers have used this instrument to study and identify nurses’ job satisfaction, hospital environment, organisational climate and burnout (Aiken \& Patrician, 2000; Jackson-Malik, 2005; Kramer \& Hafner, 1989; Mitchell, 2009).This instrument was also used to measure nurses' job satisfaction in relation to their hospital environments, the work itself, their autonomy, the practice settings, nurse-physician relationships, and organisational support (Aiken \& Patrician, 2000). Permission was not required to use the NWI-R in this study as it is available in the public domain. The authors of the NWI-R have authorised the non-commercial use of their instrument for research purposes (see Appendix E). The NWI-R was used in this study because it is based on Herzberg's motivation-hygiene theory. The main concept of this theory is the distinction between two groups of factors called motivation (or intrinsic factors) and hygiene (or extrinsic factors). Motivation factors included items such as advancement in the job or career, the work itself, the possibility for growth and development, the responsibility given to the worker, feeling recognised and having a sense of achievement. 
The hygiene factors included items that covered satisfaction with interpersonal relations, salary, company policies and administration, supervision and working conditions (Herzberg, 1966) (see Chapter 3). In line with this framework, the NWI-R was used to measure Saudi nurses' job satisfaction based on the intrinsic and extrinsic factors. Table 4.2 below shows the distribution of the NWI-R items as they relate to Herzberg's motivation-hygiene theory.

Table 4.2

Distribution of the NWI-R Questions in Relation to Herzberg's Motivation and Hygiene Theory

\begin{tabular}{ccc}
\hline NWI-R Subscales & Number of Items & NWI-R Question Numbers \\
\hline Motivation & 24 & $7,8,10,11,12,13,17,18,19,20,21,24,28$, \\
& & $29,30,32,33,35,38,42,43,48,50,56$ \\
Hygiene & 33 & $1,2,3,4,5,6,9,14,15,16,22,23,25,26,27$, \\
& & $31,34,36,37,39,40,41,44,45,46,47,49$, \\
& & $51,52,53,54,55,57$ \\
\hline
\end{tabular}

The NWI-R survey was divided into two main parts applying Herzberg's twofactor theory. The first part, as shown in Table 4.3, was related to the motivation factors and included 24 items (such as level of satisfaction with advancement, the work itself, the possibility for growth, responsibility, recognition, and personal achievement). 
Table 4.3

Distribution of the NWI-R Questions in Relation to Herzberg's Motivation Factors

\begin{tabular}{llcc}
\hline Theory & Factors & Number of Items & NWI-R Question Numbers \\
\hline & Advancement & 2 & 29,42 \\
& Work itself & 8 & $12,20,19,21,50,33,38,56$ \\
Herzberg's & Possibility for growth & 2 & 7,8 \\
motivation & Responsibility & 6 & $13,17,24,28,32,48$ \\
factors & Recognition & 4 & $10,18,30,43$ \\
& Achievement & 2 & 11,35 \\
\hline
\end{tabular}

The second part focused on the hygiene factors and consisted of 33 items that were related to satisfaction with interpersonal relations, salary, company policies and administration, supervision, and working conditions, as shown in Table 4.4.

Table 4.4

Distribution of the NWI-R Questions in Relation to Herzberg's Hygiene Factors

\begin{tabular}{llcc}
\hline Theory & Factors & $\begin{array}{c}\text { Number of } \\
\text { Items }\end{array}$ & NWI-R Question Numbers \\
\hline & Interpersonal relations & 4 & $2,23,27,39$ \\
& Salary & 1 & 5 \\
Herzberg'shygiene & $\begin{array}{l}\text { Company policies and } \\
\text { administration }\end{array}$ & 19 & $\begin{array}{c}3,9,15,22,25,26,31,34, \\
\text { factors }\end{array}$ \\
& $\begin{array}{l}\text { Supervision } \\
\text { relationship }\end{array}$ & 2 & $51,52,54,54,57,49$, \\
& Working conditions & 7 & $1,6,16,45,46,53,55$ \\
\hline
\end{tabular}

\section{Pilot test of the questionnaire.}

According to Burns and Grove (2009), some of the reasons for doing a pilot test include the following: to determine whether the proposed study is feasible, to identify potential problems with the research design, to examine the validity and reliability of 
the data collection and research instruments, to give the researcher more experience with the research method and subject and to determine the representativeness of the sample. The purpose of piloting was to examine the instrument for timing, clarity and accuracy. The questionnaire was translated into the Arabic language, and the Arabic questions were written under the English questions for all survey items to increase clarity and to make sure that all participants understood the survey easily. Five Saudi nurses who had experience working in Saudi public hospitals were recruited from the Saudi students' association in Melbourne to respond to the NWI-R survey. These students had a Diploma in Nursing and were enrolled in undergraduate Bachelor of Nursing programmes in Melbourne. They were requested to respond on how long it would take to complete the questionnaire, whether all items were understood and whether the translation of each item into the Arabic language helped clarify the question. The responses of the Saudi nurses were not included in the study sample. The results of this pilot test showed that it took around 20-25 minutes to respond to the survey and there was no difficulty in understanding the questions. The respondents agreed that the Arabic translations clarified the questions being asked. Hence, the content of the questionnaire was not changed, but was modified by the addition of the Arabic translation under each item.

\section{Validity and reliability of the instruments.}

Validity and reliability are important in data collection research instruments (Bryman, 2008; Johnson \& Christensen, 2008). Validity is an essential criterion to evaluate the quality of research (Cohen, Manion, \& Morrison, 2010). According to Cone and Foster (2003), validity is 'the extent to which scores on a measure relate to scores on other measures' (p. 156). Polit and Beck (2004) state that content validity is 'the degree to which the items in an instrument adequately represent the universe of 
content for the concept being measured' (p. 714). Validation is required as evidence that the instrument actually reflects what it is intended to measure (Burns \& Grove 2009). Reliability is also a crucial criterion to evaluate the quality of research (Cohen et al., 2010). According to Creswell (2002), reliability means that 'individual scores from an instrument should be nearly the same or stable on repeated administrations of the instrument, they should be free from sources of measurement error, and they should be consistent' (p. 180).

\section{Validity of the questionnaire.}

The validity of the NWI-R questionnaire has been tested in many studies and the results showed that this instrument can measure job satisfaction, hospital environment, organisational climate and burnout (Aiken \& Patrician, 2000; Kramer \& Hafner, 1989; Joyce \& Crookes, 2007; Mitchell, 2009). It has been established that the NWI-R questionnaire describes the characteristics of Magnet hospitals and measures nursing values in relation to job satisfaction and productivity (Joyce \& Crookes, 2007; Mitchell, 2009).The Magnet hospital researchers tested the content validity of the NWI and they found that the original questionnaires included the characteristics of the Magnet organisations, showing support for the content validity of the tool (Kramer \& Hafner, 1989). Thus, Kramer and Hafner (1989) state that three methods have developed the content validity of the NWI, including development from the Magnet hospital characteristics, extensive research over a 25 -year period on job satisfaction and work value instruments, and the use of three of the four original Magnet hospitals by researchers to analyse the instrument (p. 173). Aiken and Patrician (2000) discussed the validity of the instrument, stating that its validity was indicated by 'the origin of the instrument, its ability to differentiate nurses who worked within a professional practice environment from those who did not, and its ability to explain differences in nurse 
burnout' (p. 4). To ensure the content validity of the NWI-R for Saudi nurses and to identify the level of job satisfaction of Saudi nurses, the questionnaire's validity was tested for the current study through a pilot study.

\section{Reliability of the questionnaire.}

Cronbach's alpha was used to measure the reliability of the questionnaire. Aiken and Patrician (2000) mentioned that the NWI-R had strong reliability scores, and overall, Cronbach's alpha was 0.96. Moreover, after gathering data individually for each subscale, Chronbach's alpha was noted as 0.76 for relationships with physicians, 0.75 for autonomy, and 0.79 for controls (Aiken \& Patrician, 2000). The NWI-R has been used in many studies and most have shown that the reliability of these studies is high (Aiken \& Patrician, 2000; Jackson-Malik, 2005; Kramer \& Hafner, 1989; Mitchell, 2009).

In this study, the Cronbach's alpha value for motivating factors was 0.92 and for hygiene factors it was 0.93 . The total reliability statistic for the current study was 0.96 . Table 4.5 shows the reliability statistics for the total study, as well as the motivation and hygiene factors.

Table 4.5

Reliability Statistics

\begin{tabular}{lcc}
\hline \multicolumn{3}{c}{ Reliability Statistics (Cronbach's alpha) } \\
\hline Factor & $\alpha$ & Number of Items \\
\hline Motivation & .92 & 24 \\
Hygiene & .93 & 33 \\
Total & .96 & 57 \\
\hline
\end{tabular}




\section{Quantitative data collection.}

In this study, the data collection commenced after ethics approval was granted from the RMIT Ethics Committee and the Saudi MoH Medical Research Committee. The researcher contacted the Director of Health Affairs in each of the three cities in the Makkah region. Further, the researcher asked the directors of the three public hospitals to assist in advertising the study through the nursing office at each hospital, via the nursing education office and at the general nursing meetings. The study was also advertised through letters posted on all the nursing boards and main nursing office on the wards of the three hospitals (see Appendix A).

The researcher visited each hospital in the Makkah region and met the Directors of Nursing to give a brief explanation about the purpose of the study and informed them about the nature of the research and the contributions that were expected from them to implement the project. Two weeks after the study was advertised (in May 2011), the envelopes were distributed to Saudi staff nurses, along with information about the study. The participants were required to complete the anonymous NWI-R questionnaire and demographic questions, place it in the envelope, and return it to a sealed box that was placed in the main nursing office at each of the three hospitals and was clearly numbered and labelled 'Job Satisfaction Survey'. The questionnaires did not request, or provide any space to record, the participants' names to ensure anonymity. The information from each participant was assigned a code and no participant was named in the research documentation. Only group data were reported and no individual participant was identified. The researcher collected all of the completed questionnaires from all the boxes in the nursing office of the hospitals and stored them in a secure area for data entry and analysis. According to the RMIT University protocol these data were kept in locked compartments during transcription to a password-protected file. 
Participants who were willing to be interviewed by the researcher were asked to contact the researcher by e-mail in order to organise a face-to-face interview.

\section{Quantitative data analysis.}

The analysis of data is considered the most meaningful step in research. It is the process of converting the raw data into meaningful information to answer the research questions (Creswell, 2009). According to Minichiello, Aroni, and Hays (2008), data analysis is a 'process of systematically arranging and presenting information in order to search for ideas' (p. 258).

The quantitative data collected in this study were entered and analysed using the SPSS Version 18.0 software. Quality control was completed at this stage of data reduction, which involved coding the responses of the questionnaire items, choosing the procedure to be taken regarding missing data and entering completed data to the programme for analysis. There was a low number of missing values in the completed survey, and to avoid errors in statistical analysis, missing data was statistically excluded by pairwise exclusion (Pallant, 2011). Data were presented using descriptive statistics in the form of frequencies and percentages and means and standard deviations for quantitative variables. Quantitative continuous data were compared using Student's ttest for comparisons between two groups and analysis of variance (ANOVA) for comparisons between more than two groups. The data analysis conducted included descriptive analysis, inferential techniques and multiple regression. Descriptive analysis was used to describe the demographic data and explore the current levels of job satisfaction of Saudi nurses. ANOVA tests were used to identify and explore the factors that influence job satisfaction among the Saudi nurses. To examine mean group differences in the study, ANOVA was used. Inferential statistical analyses were conducted to examine which demographic or independent variables of the study 
(gender, age, marital status, number of dependent children, number of dependent adults, qualifications, salary, hospital, position, number of weekly working hours, duration of employment at the hospital and overall experience) predicted the outcome variable. Multivariate analyses were used in two multiple regression analyses to identify job satisfaction among Saudi nurses and to assess the relationships between scores of satisfaction as a dependent factor, and the various independent factors as predictors. The statistical test of significance, or p-value, in this study was set at $<0.05$. Chapter 5 describes the findings and results of the quantitative method.

\section{Phase Two: Qualitative study.}

\section{Qualitative sample.}

The face-to-face interviews were designed to gain an in-depth understanding of what the concept of job satisfaction means to Saudi nurses. According to Tashakkori and Teddlie (1998), using interviews for data collection can be a powerful tool to further explain and confirm the research findings. Creswell (2008) argued that interviews 'permit participants to describe detailed personal information' (p. 226). The face-to-face interview is commonly used as a data collection tool in health sciences research to gather information from interviewees (Ryan, Coughlan \& Cronin, 2009). Interviews help researchers gather enough information and they offer the opportunity for explanation, investigation, modification and clarification of the data in the interaction between the researcher and the interviewees (Gillham, 2005). There are many advantages to interviews, including the generation of important and rich data that cannot be produced by other methods, and allowing an opportunity to follow up incomplete or unclear data responses by asking further questions for clarification, modification, and to gain more in-depth data from participants (Gay \& Airasian, 2000). 
The semi-structured interviews in this study were based on six open-ended questions designed to elicit information about the respondents' perceptions of their profession, reflection on how they joined nursing and what influenced them to become nurses. The purpose of the semi-structured interviews was also to gain an in-depth understanding of the factors positively influence Saudi nurses' job satisfaction in their working environment. Face-to-face interviews were held with 17 Saudi nurses who had different lengths of experience in nursing. The interviews were conducted by a single interviewer (the researcher) and followed the same format, with each lasting up to 35 minutes.

The six open-ended questions broadly followed the research sub-questions. The interview questions included the following (see Appendix F):

Q1: Who influenced your decision to study nursing?

Q2: What factors motivate nurses to continue working as a nurse?

Q3: What are the reasons that would stop you from working as a nurse?

Q4: What do you see as your future goals in your nursing career?

Q5: What factors do you believe could improve the public image of nurses in Saudi Arabia?

Q6: What suggestions do you have to increase the recruitment and retention of Saudi Arabian nurses?

Validity of the interviews.

According to Minichiello, Aroni, and Hays (2008), the validity of interview data depends on the techniques for gathering qualitative data and the design of the interview instrument. In this study, the validation process involved many parts. Firstly, the interview questions were translated into Arabic. Interviews were then recorded using two digital voice-recorder devices. The data from the interviews was transcribed into 
Arabic to ensure that no data was missing and then all of this data was translated back into English by a professional translation office in Melbourne (see Appendix G). The data was back translated, from English to Arabic, in order to verify that all data was translated correctly and that no meaning was lost in the translation process.

Furthermore, validation of the raw data was undertaken through peer debriefing. Creswell (2008) and Brenner (2006) state that research method peer debriefing is one of the processes that enhances the credibility and validity of qualitative research. The senior supervisor and the assistant supervisor regularly undertook the role of peer debriefing. Both were aware of what their subjectively brought to the research and this awareness assisted in ensuring that the reporting was valid and accurate.

\section{Qualitative data collection.}

Participants attended the face-to-face semi-structured interviews voluntarily and they could have chosen to withdraw at any time during the interview. All interviewees $(\mathrm{N}=17)$ were given a choice of interview language and all of them preferred to be interviewed in Arabic. The participants were representatives from the three hospitals. Interview data were transcribed verbatim in Arabic then translated into the English language by a professional certified translation office in Melbourne (see Appendix G). All interviews were held in the nursing education department classrooms, which were very quiet areas. Each interview as recorded using two digital voice recording devices; an Olympus digital voice recorder with new batteries was used to record the interviews and was tested before use in order to check its settings; this was used for back-up. The second digital voice device used was the 'Livescribe Smartpen'. This pen was used to record the interviews along with handwritten comments in a Livescribe notebook during the face-to-face interviews. All data, both audio and written, were automatically synchronised to align the page numbers, date, and time of interview in the notebook. 
The overall quantitative and qualitative data collection period was approximately 24 weeks; it began in May 2011 and ended in October 2011. Approximately 12 weeks were spent collecting data in all hospitals and about 12 weeks were dedicated to data entry and transcription.

\section{Qualitative data analysis.}

After transcribing the recordings in the Arabic language, the researcher carefully revised each interview to ensure that the transcription was accurate and had no missing points. All interviews were translated into the English language by a professional translation office in Melbourne. Then the researcher and his supervisor carefully revised and compared the translation with the original interview transcriptions to ensure that the translations were correct and that meaning had not been lost or altered in the translation.

According to Minichiello et al. (2008), thematic analysis procedures are a suitable technique to analyse quantitative data and to identify themes emerging from analysis of interview transcripts. Data analyses were conducted using a content analysis technique to identify relevant responses and commonality in responses between the different interviews. Through the analysis process, the researcher identified, coded and categorised the patterns that emerged from the data (Krippendorf, 1980; Patton, 1990). Statements made by participants, which are essential to the participants' experience and perceptions (Moustakas, 1994) and are considered relevant for the study were tracked and compared through a process of coding and analysis (Creswell, 2009). The common statements were used to generate themes that represented the perceptions with the group. The coded statements were grouped, or clustered, into thematic categories. These thematic categories are presented as part of the findings. To support theme generation and an in-depth understanding of the experiences and perceptions of the participants, textual data in the form of verbatim examples from the interview discussions were 
included in the report to highlight the key common responses (themes). Relevant data were coded throughout the document following an inductive process, which allowed for emergent categories. NVivo 9 qualitative analysis software was used during the process of coding and the development of themes. NVivo software provides an organised workspace to conduct the classification and sorting of data and the tracking of the frequency of occurrences across the data sources. Finally, a comprehensive review and interpretation of the data provided the conclusions of the analyses, which were revealed in the form of several overarching themes representing the perceptions of the nurses as a whole (Moustakas, 1994).

\section{Ethical considerations.}

According to Burns and Grove (2005), ethical research is important to generate sound knowledge for practice. This study was conducted according to fundamental ethical and human rights principles that were protected during the entire research process. These principles included self-determination, privacy, anonymity and confidentiality, and protection from discomfort and harm.

An ethics application was submitted to the RMIT University and was approved by the College Human Ethics Advisory Network (CHEAN) Ethics Committee. Data collection commenced following ethics approval (see Appendix H). Additionally, permission to conduct the study was granted by the Saudi MoH through the Health and Medical Research Committee of Saudi Arabia, and by the High Authority of the Nursing Department in the Saudi MoH (see Appendix I). In Saudi Arabia, each health organisation and hospital comes under the umbrella of the MoH.

\section{Confidentiality and anonymity of the subjects.}

Participation in this study was voluntary. Anonymity and confidentiality of all the participants was assured. According to RMIT and the National Health and Medical 
Research Council of Australia (NHMRC) guidelines, there were some points that needed to be addressed, and the researcher used the prescribed RMIT template to obtain the informed consent of participants (see Appendix J). Informed consent was obtained in writing from each study participant who offered data in the qualitative phase of the study.

\section{Security of research data.}

The data collected during the study were stored in a secure area and later transferred onto a computer. All questionnaires and transcripts of interviews were placed in a locked filing cabinet throughout the period of the research process. During the research process, all computers were password-protected and only authorised individuals had the ability to access the research data. Moreover, upon completion of the research, data the records were labelled and stored in the research and data storage area at the university, where they will be stored for a period of 5 years before they are destroyed (RMIT University protocol and guidelines; NHMRC, 2011).

\section{Chapter Summary}

This chapter has presented a comprehensive picture of the research methodology employed in order to identify the factors that influence Saudi nurses' job satisfaction working in public hospitals in Makkah region, Saudi Arabia. A concurrent mixed methods design was utilised to answer the research questions and to guide this research. Quantitative and qualitative data were collected to determine the factors that influence the job satisfaction of Saudi nurses. Data were collected in two phases. The first phase involved a questionnaire that elicited information on demographic data and identified factors that led to job satisfaction among Saudi nurses. Face-to-face interviews provided in-depth information on job satisfaction and barriers to job satisfaction. In addition, this 
chapter described the study setting, including the three cities and hospitals where it took place, the sampling strategy of the study, the instruments used for data collection and face-to-face interviews, validity and reliability and the ethical considerations during the study and in the storage of the data and the dissemination of findings.

The findings from the analysis of the quantitative data will be presented in the Chapter 5, and then the analyses of the qualitative data will be presented in Chapter 6 . 


\section{Chapter 5: Descriptive and Inferential Analyses}

\section{Introduction}

This chapter will describe the statistical analyses of the survey data completed by the convenience sample of Saudi nurses working in the three public hospitals in three cities in the Makkah region. Seven hundred and ninety one questionnaires were distributed within the three hospitals and 272 were returned with a response rate of 34 per cent. The research instrument utilised in this study was the NWI-R. The data was analysed using the SPSS, Version 18.0.

The statistical analyses of the study were divided into two main processes. Descriptive and inferential statistical analyses were conducted. The descriptive statistics involved measures of frequency, mean, and standard deviation for each item of the questionnaire and the overall satisfaction scores of the subjects. The inferential statistical included the analysis of variance and t-tests were utilised to identify differences in job satisfaction, motivation, and hygiene factors between participants. Multiple linear regression analysis and correlation test were also utilised to identify the highest predictor variables that affect participants level of job satisfaction at each hospital.

\section{Descriptive Statistics}

Job satisfaction was examined across sets of independent variables. The first set included the demographic characteristics of the participants: gender, age, marital status, number of dependent children, number of dependent adults, qualifications and salary. The second set included job characteristics and practical experience, such as the employing hospital, the position held at the hospital, duration of work experience at the hospital, number of weekly working hours and overall experience. 


\section{Demographic and personal characteristics.}

This section details the demographic and personal characteristics of the Saudi nurses participating in the study and provides the response to the first seven items of the question's demographic section. Table 5.1 shows that 61 per cent of the nurses were female and 39 per cent were male. Thirty-one per cent of the nurses were less than 25 years of age, 54 per cent were 25-35 years and 15 per cent were aged 36 years and over. More than half (53 per cent) of the nurses were single, 43 per cent were married and 4 per cent were divorced or widowed. More than one-third (38 per cent) of the nurses were responsible for dependent children, while 62 per cent were not responsible for dependent children. Also it was noted that 40 per cent of the participants were responsible for dependent adults and 60 per cent were not responsible for dependent adults.

The majority ( 80 per cent) of the Saudi nurses had a diploma and 20 per cent of them held a BSN or postgraduate degrees in nursing science. Participants's salaries ranged according to their qualifications and seniority. The ranges were as follows: 8 per cent received a monthly salary of 1,500-5,000 SR (400-1,333 US\$); 64 per cent receive 5,001-10,000 SR (1,334-2,666 US\$); and 28 per cent receive over 10,000 SR (2,667 US\$) (see Table 5.1). 
Table 5.1

Demographic and Personal Characteristics of the Study Group $(N=272)$

\begin{tabular}{|c|c|c|}
\hline Characteristics & $n$ & Per Cent \\
\hline \multicolumn{3}{|l|}{ Gender: } \\
\hline Male & 107 & 39 \\
\hline Female & 165 & 61 \\
\hline \multicolumn{3}{|l|}{ Age groups: } \\
\hline Less than 25 years & 85 & 31 \\
\hline $25-35$ years & 147 & 54 \\
\hline 36 years and over & 40 & 15 \\
\hline \multicolumn{3}{|l|}{ Marital status: } \\
\hline Single & 144 & 53 \\
\hline Married & 117 & 43 \\
\hline Divorced or widowed & 11 & 4 \\
\hline \multicolumn{3}{|l|}{ Number of dependent children: } \\
\hline None & 170 & 62 \\
\hline Have dependent children & 102 & 38 \\
\hline \multicolumn{3}{|l|}{ Number of dependent adults: } \\
\hline None & 163 & 60 \\
\hline Have dependent adults & 109 & 40 \\
\hline \multicolumn{3}{|l|}{ Qualifications: } \\
\hline Diploma & 219 & 80 \\
\hline Bachelor's degree or postgraduate qualification & 53 & 20 \\
\hline \multicolumn{3}{|l|}{ Salary: } \\
\hline $1,500-5,000 \mathrm{SR} *(400-1,333 \mathrm{US} \$)$ & 21 & 8 \\
\hline $5,001-10,000 \mathrm{SR} *(1,334-2,666 \mathrm{US} \$)$ & 174 & 64 \\
\hline $10,001-15,000 \mathrm{SR} *(2,667-4,000 \mathrm{US} \$)$ & 59 & 22 \\
\hline More than $15,001 \mathrm{SR}^{*}(4,001 \mathrm{US} \$)$ & 18 & 6 \\
\hline
\end{tabular}

* Note: the conversion was as of March 2011.

\section{Job characteristics and practical experience.}

The responses to the final five items of the demographic section of the question are provided in Table 5.2. The employing hospital for 39 per cent of the nurses was Hospital A in Jeddah; 37 per cent were from Hospital B in Makkah and 24 per cent 
were from Hospital C in Taif. The respondents were registered Saudi nurses in various nursing positions. The majority ( 73 per cent) of them were working as staff nurses; 8 per cent were head nurses; another 8 per cent were nurse managers (including supervisor, deputy or chief nursing officer) and 11 per cent were in other nursing positions (such as nursing education and quality control). Approximately 87 per cent of the participants were working less than 50 hours per week and 13 per cent of them were working more than 50 hours a week.

Almost all (63 per cent) of the participants indicated that they had been working in their hospital for less than 5 years, 20 per cent of them had been working there for between 5 and 10 years and 17 per cent of them had been working in the hospital for more than 10 years. Over 46 per cent of the sample reported that they had less than 4 years of experience in nursing; 38 per cent had between 4 and 10 years of nursing experience; and only 16 per cent of the participants indicated that they had more than 10 years of nursing experience. 
Table 5.2

Job Characteristics and Practical Experience of the Study Group $(N=272)$

\begin{tabular}{lcc}
\hline \multicolumn{1}{c}{ Characteristics } & $n$ & $\begin{array}{c}\text { Per } \\
\text { Cent }\end{array}$ \\
\hline Employing hospital: & 107 & 39 \\
Hospital A in Jeddah & 100 & 37 \\
Hospital B in Makkah & 65 & 24 \\
Hospital C in Taif & & \\
\hline Position: & 198 & 73 \\
Staff nurse & 22 & 8 \\
Head nurse & 23 & 8 \\
Nursing manager (Supervisor, Deputy or Chief of Nursing) & 29 & 11 \\
Other (nursing education and quality control nurses) & & \\
\hline Number of weekly working hours: & 238 & 87 \\
50 hours or less & 34 & 13 \\
More than 50 hours & & \\
\hline Less than 5 years & 172 & 63 \\
5-10 years & 55 & 20 \\
More than 10 years & 45 & 17 \\
\hline Less than 4 years & 103 & 38 \\
4-10 years & 43 & 16 \\
\hline More than 10 years & &
\end{tabular}

\section{Responses Reflecting Level of Job Satisfaction}

To facilitate the interpretation and comparisons of the nurses' responses to the different items reflecting their level of job satisfaction according to their characteristics, scoring that ranged between 1 and 4 was applied. A score of 1 indicated 'strongly disagree' and a score of 4 indicated 'strongly agree'. For each item, the total sum of scores for sub-items was divided by the number of sub-items to estimate the item's mean score. The maximum mean score for any item was 4 . 
The first part of the survey was related to the motivating factors and consisted of 24 items related to the level of satisfaction. These items reflected the level of satisfaction with advancement in position (Questions 29 and 42), the nature of the work itself (Questions 12, 19, 20, 21, 33, 38, 50 and 56), the possibility for growth and development in their nursing career (Questions 7 and 8), level of responsibility (Questions 13, 17, 24, 28, 32 and 48), level of recognition by the hospital (Questions 10, 18, 30 and 43) and feeling of personal achievement (Questions 11 and 35).

The second part related to the hygiene factors and consisted of 33 items that were related to the level of satisfaction. These included interpersonal relations at work (Questions 2, 23, 27 and 39), salary scale (Question 5), hospital policies and administration (Questions 3, 9, 15, 22, 25, 26, 31, 34, 36, 37, 40, 41, 44, 47, 49, 51, 52, 54 and 57), supervision (Questions 4 and 14) and the working conditions in general (Questions 1, 6, 16, 45, 46, 53 and 55). Table 5.3 describes the distribution of the NWI$\mathrm{R}$ items as they relate to Herzberg's motivation-hygiene theory.

Table 5.3

Distribution of the NWI-R Questions

\begin{tabular}{lccc}
\hline \multicolumn{1}{c}{ NWI-R Subscales } & $\begin{array}{c}\text { Number } \\
\text { of Items }\end{array}$ & NWI-R Question Numbers \\
\hline & Motivation & 24 & $\begin{array}{c}7,8,10,11,12,13,17,18,19,20,21,24,28, \\
29,30,32,33,35,38,42,43,48,50,56\end{array}$ \\
$\begin{array}{l}\text { Herzberg's } \\
\text { theory }\end{array}$ & & & $1,2,3,4,5,6,9,14,15,16,22,23,25,26,27$, \\
& Hygiene & 33 & $\begin{array}{c}31,34,36,37,39,40,41,44,45,46,47,49,51, \\
\end{array}$ \\
\end{tabular}

\section{Responses to the Factors Reflecting Motivation}

Table 5.4 provides a summary of the descriptive statistics for motivating factors, including advancement at work, the work itself, possibility of growth, responsibility, 
recognition and personal achievement. It was found that the overall mean satisfaction score for the motivating factors was $\mathrm{M}=2.61, \mathrm{SD}=0.52$; with the highest mean score reported for advancement $(\mathrm{M}=2.74, \mathrm{SD}=0.71)$; and the lowest score was for achievement $(\mathrm{M}=2.40, \mathrm{SD}=0.73)$.

Table 5.4

Summary of Motivating Factors

\begin{tabular}{lcc}
\hline Motivating Factors & $\mathrm{M}$ & $\mathrm{SD}$ \\
\hline Advancement & 2.74 & 0.71 \\
Work itself & 2.70 & 0.51 \\
Possibility of growth & 2.70 & 0.67 \\
Responsibility & 2.58 & 0.54 \\
Recognition & 2.55 & 0.73 \\
Achievement & 2.40 & 0.73 \\
Overall satisfaction for motivation & 2.61 & 0.52 \\
\hline
\end{tabular}

\section{Advancement.}

Two items reflected advancement: 71.8 per cent of the nurses stated that staff nurses have the opportunity to serve on hospital and nursing committees and 60.3 per cent of them indicated that there were opportunities in general for advancement (see Table 5.5 below). 
Table 5.5

Responses Reflecting Nurses' Opinions on Advancement

\begin{tabular}{lcrrrrrr}
\hline \multirow{2}{*}{ Items Reflecting Advancement } & \multicolumn{7}{c}{ Percentage } \\
\cline { 2 - 8 } & $\mathrm{SD}$ & $\mathrm{D}$ & $\mathrm{A}$ & $\mathrm{SA}$ & $\mathrm{TA}$ & $\mathrm{M}$ & $\mathrm{Std}$ dev \\
\hline $\begin{array}{l}\text { 42. Staff nurses have the opportunity } \\
\text { to serve on hospital and nursing } \\
\text { committees }\end{array}$ & 7.4 & 20.8 & 53.7 & 18.1 & 71.8 & 2.83 & 0.81 \\
$\begin{array}{l}\text { 29. Opportunities for advancement } \\
\text { 9. }\end{array}$ & 11.8 & 27.9 & 43.9 & 16.4 & 60.3 & 2.65 & 0.89 \\
\hline
\end{tabular}

$\mathrm{SD}$, strongly disagree; $\mathrm{D}$, disagree; A, agree; SA, strongly agree; TA, total agreement. $\mathrm{M}$, mean; Std dev, standard deviation.

\section{The work itself.}

Eight items reflected the effect of work itself on the nurses' satisfaction. The majority (87.5 per cent) of the nurses expressed satisfaction in working with experienced nurses who had good knowledge and were more familiar with the hospital and 73 per cent expressed satisfaction in working with nurses who were clinically competent and professional. In addition, almost three-quarters (74.5 per cent) of the nurses showed agreement with using team nursing for the delivery of nursing care and 77.2 per cent of them showed satisfaction with total patient care. Two-thirds (67.1 per cent) of the nurses indicated that staff nurses have the opportunity to actively participate in their work schedules, such as the days they work and days off. However, less than half (46.9 per cent) of the nurses agreed that there were enough registered nurses to provide quality patient care (see Table 5.6 below). 
Table 5.6

Responses of Nurses to the Work Itself

\begin{tabular}{lcccccccc}
\hline \multirow{2}{*}{ Items Reflecting the Work Itself } & \multicolumn{7}{c}{ Percentage } \\
\cline { 2 - 8 } & SD & D & A & SA & TA & M & Std dev \\
\hline $\begin{array}{l}\text { 56. Working with experienced } \\
\text { nurses who 'know' the hospital }\end{array}$ & 2.2 & 10.3 & 64.7 & 22.8 & 87.5 & 3.08 & 0.64 \\
$\begin{array}{l}\text { 21. Total patient care as the } \\
\text { nursing delivery system }\end{array}$ & 6.0 & 16.8 & 66.3 & 10.9 & 77.2 & 2.82 & 0.70 \\
$\begin{array}{l}\text { 20. Team nursing as the nursing } \\
\text { delivery system }\end{array}$ & 7.4 & 18.1 & 63.1 & 11.4 & 74.5 & 2.79 & 0.74 \\
$\begin{array}{l}\text { 33. Working with nurses who are } \\
\text { clinically competent }\end{array}$ & 8.5 & 18.5 & 60.0 & 13.0 & 73.0 & 2.77 & 0.78 \\
$\begin{array}{l}\text { 50. Staff nurses actively participate } \\
\text { in developing their work schedules } \\
\text { (i.e., which days they work, days } \\
\text { off, etc.) }\end{array}$ & 10.7 & 22.1 & 49.4 & 17.7 & 67.1 & 2.74 & 0.87 \\
$\begin{array}{l}\text { 19. Clinical nurse specialists who } \\
\text { provide patient care consultation }\end{array}$ & 14.5 & 27.8 & 46.5 & 11.2 & 57.7 & 2.54 & 0.87 \\
$\begin{array}{l}\text { 38. Staff nurses are involved in the } \\
\text { internal governance of the hospital } \\
\text { (e.g., practice and policy }\end{array}$ & 17.7 & 26.8 & 43.0 & 12.5 & 55.5 & 2.50 & 0.93 \\
committees) & & & & & & & \\
$\begin{array}{l}\text { 12. Enough registered nurses on } \\
\text { staff to provide quality patient care }\end{array}$ & 21.0 & 32.1 & 38.0 & 8.9 & 46.9 & 2.35 & 0.91 \\
\hline
\end{tabular}

$\mathrm{SD}$, strongly disagree; $\mathrm{D}$, disagree; A, agree; SA, strongly agree; TA, total agreement. $\mathrm{M}$, mean; Std dev, standard deviation.

\section{Possibility of growth.}

Two items reflected the possibility of growth and development in their careers and an almost equal percentage of nurses (62.1 per cent and 67 per cent, respectively) indicated that there were active continuing education programmes for nurses, as well as clear career development paths and opportunities to climb the clinical ladder (see Table 5.7 below). 
Table 5.7

Responses Reflecting Nurses' Opinions of the Possibility of Growth

\begin{tabular}{lccccccc}
\hline \multirow{2}{*}{$\begin{array}{l}\text { Items Reflecting the Possibility of } \\
\text { Growth }\end{array}$} & \multicolumn{8}{c}{ Percentage } \\
\cline { 2 - 8 } & $\mathrm{SD}$ & $\mathrm{D}$ & $\mathrm{A}$ & $\mathrm{SA}$ & $\mathrm{TA}$ & $\mathrm{M}$ & Std dev \\
\hline $\begin{array}{l}\text { 8. Career development/clinical } \\
\text { ladder opportunity }\end{array}$ & 7.2 & 25.8 & 52.4 & 14.6 & 67.0 & 2.75 & 0.79 \\
$\begin{array}{l}\text { 7. Active in-service/continuing } \\
\text { education programmes for nurses }\end{array}$ & 8.5 & 29.4 & 50.2 & 11.9 & 62.1 & 2.65 & 0.80 \\
\hline
\end{tabular}

$\mathrm{SD}$, strongly disagree; $\mathrm{D}$, disagree; $\mathrm{A}$, agree; $\mathrm{SA}$, strongly agree; TA, total agreement. $\mathrm{M}$, mean; Std dev, standard deviation.

\section{Responsibilities.}

Six items reflected responsibilities and more than two-thirds (68.3 per cent) of the respondents indicated out that they agreed with the idea that patient assignments foster continuity of care. Further, 58.5 per cent of the nurses considered that physicians were giving high quality medical care. Meanwhile, it was observed that only around half (53.5 per cent) of the respondents felt free to make important decisions regarding patient care and more than half (55 per cent) agreed that their nursing manager was a good manager and leader (see Table 5.8 below). 
Table 5.8

Responses of the Nurses to Items Reflecting Responsibilities

\begin{tabular}{|c|c|c|c|c|c|c|c|}
\hline \multirow{2}{*}{ Items Reflecting Responsibilities } & \multicolumn{7}{|c|}{ Percentage } \\
\hline & SD & $\mathrm{D}$ & A & SA & TA & M & Std dev \\
\hline $\begin{array}{l}\text { 48. Patient assignments foster } \\
\text { continuity of care (i.e., the same } \\
\text { nurse cares for the patient from one } \\
\text { day to the next) }\end{array}$ & 7.1 & 24.6 & 52.6 & 15.7 & 68.3 & 2.77 & 0.80 \\
\hline $\begin{array}{l}\text { 32. Nurses actively participate in } \\
\text { efforts to control costs }\end{array}$ & 10.4 & 33.2 & 46.6 & 9.7 & 56.3 & 2.56 & 0.81 \\
\hline $\begin{array}{l}\text { 17. Freedom to make important } \\
\text { patient care and work decisions }\end{array}$ & 11.7 & 34.8 & 40.8 & 12.7 & 53.5 & 2.55 & 0.86 \\
\hline $\begin{array}{l}\text { 13. A nurse manager who is a good } \\
\text { manager and leader }\end{array}$ & 19.2 & 25.8 & 37.3 & 17.7 & 55.0 & 2.54 & 1.00 \\
\hline $\begin{array}{l}\text { 28. Physicians give high quality } \\
\text { medical care }\end{array}$ & 10.6 & 30.9 & 52.6 & 5.9 & 58.5 & 2.54 & 0.76 \\
\hline $\begin{array}{l}\text { 24. Not being placed in a position of } \\
\text { having to do things that are against } \\
\text { my nursing judgment }\end{array}$ & 16.7 & 27.5 & 42.0 & 13.8 & 55.8 & 2.53 & 0.93 \\
\hline
\end{tabular}

SD, strongly disagree; D, disagree; A, agree; SA, strongly agree; TA, total agreement. M, mean; Std dev, standard deviation.

\section{Recognition.}

Four items reflected recognition. It was evident that two-thirds (65.9 per cent) of the nurses agreed that their contribution to patient care was publicly acknowledged, whereas only half (50.7 per cent) of the sample perceived that nursing staff are supported in pursuing degrees in nursing. Slightly more than half (53.3 per cent) of the nurses agreed that they received recognition for a job well done and two-thirds (62.6 per cent) of them agreed that there was support for new ideas about patient care (see Table 5.9). 
Table 5.9

Responses of the Nurses to Items Reflecting Recognition

\begin{tabular}{|c|c|c|c|c|c|c|c|}
\hline \multirow{2}{*}{ Items Reflecting Recognition } & \multicolumn{7}{|c|}{ Percentage } \\
\hline & $\mathrm{SD}$ & $\mathrm{D}$ & A & SA & TA & M & Std dev \\
\hline $\begin{array}{l}\text { 43. The contributions that nurses } \\
\text { make to patient care are publicly } \\
\text { acknowledged }\end{array}$ & 11.1 & 23.0 & 49.6 & 16.3 & 65.9 & 2.71 & .87 \\
\hline $\begin{array}{l}\text { 10. Support for new and innovative } \\
\text { ideas about patient care }\end{array}$ & 12.0 & 25.4 & 47.2 & 15.4 & 62.6 & 2.66 & .88 \\
\hline $\begin{array}{l}\text { 18. Praise and recognition for a job } \\
\text { well done }\end{array}$ & 26.1 & 20.6 & 37.9 & 15.4 & 53.3 & 2.43 & 1.04 \\
\hline $\begin{array}{l}\text { 30. Nursing staff are supported in } \\
\text { pursuing a degree in nursing }\end{array}$ & 25.4 & 23.9 & 33.8 & 16.9 & 50.7 & 2.42 & 1.05 \\
\hline
\end{tabular}

Achievements.

Two items reflected achievement. Around half (49.3 per cent) of the nurses agreed that they had enough time and opportunity to discuss patient care with their colleagues. Similarly, around half (49.2 per cent) of the nurses believed that they received back-up from the nurse managers when making decisions even when this conflicted with the physician's opinion (see Table 5.10 below). 
Table 5.10

Responses of the Nurses Reflecting Feelings of Achievement

\begin{tabular}{llllllll}
\hline \multirow{2}{*}{ Items Reflecting Achievement } & \multicolumn{7}{c}{ Percentage } \\
\cline { 2 - 8 } & SD & D & A & SA & TA & M & Std dev \\
\hline $\begin{array}{l}\text { 11. Enough time and opportunity } \\
\text { to discuss patient care problems }\end{array}$ & 15.1 & 35.6 & 38.6 & 10.7 & 49.3 & 2.45 & .88 \\
$\begin{array}{l}\text { with other nurses } \\
\begin{array}{l}\text { 35. A nurse manager backs up the } \\
\text { nursing staff in decision-making, } \\
\text { even if there is conflict with a } \\
\text { physician }\end{array}\end{array}$ & 22.1 & 28.7 & 40.4 & 8.8 & 49.2 & 2.36 & .92 \\
\hline
\end{tabular}

SD, strongly disagree; $\mathrm{D}$, disagree; A, agree; SA, strongly agree; TA, total agreement. M, mean; Std dev, standard deviation.

\section{Responses to the Factors Reflecting Hygiene}

This section provides descriptive statistics for the hygiene factors, including interpersonal relationships in the hospital, salary, hospital policies and administration, supervision and working conditions. The overall mean satisfaction score for the hygiene factors was $\mathrm{M}=2.66, \mathrm{SD}=0.50$, and the highest recorded mean score for a single subitem was for interpersonal relations $(\mathrm{M}=2.83, \mathrm{SD}=0.58)$, while the lowest score was detected for working conditions $(\mathrm{M}=2.51, \mathrm{SD}=0.56)$ (see Table 5.11).

Table 5.11

Summary of All Hygiene Factors

\begin{tabular}{lcc}
\hline \multicolumn{1}{c}{ Hygiene Factors } & $\mathrm{M}$ & $\mathrm{SD}$ \\
\hline Interpersonal relations & 2.83 & 0.58 \\
Salary & 2.70 & 0.84 \\
Policies and administration & 2.67 & 0.49 \\
Supervision & 2.63 & 0.78 \\
Working conditions & 2.51 & 0.56 \\
Overall satisfaction for hygiene & 2.66 & 0.50 \\
\hline
\end{tabular}




\section{Interpersonal relationships in the hospital.}

Four items reflected interpersonal relationships in the hospital. The majority (81.3 per cent) of the nurses considered the relationships between physicians and nurses as being good and 72.6 per cent of them were positive regarding joint practice and collaboration among nurses and physicians. Moreover, 72.4 per cent of the participants indicated good relationships existed with other departments and 67.5 per cent agreed that teamwork was evident between nurses and doctors (see Table 5.12).

Table 5.12

Responses to Items Reflecting Interpersonal Relationships in the Hospital

\begin{tabular}{lccccccc}
\hline \multirow{2}{*}{\begin{tabular}{l} 
Items Reflecting Interpersonal Work \\
\multicolumn{1}{c}{ Relationships }
\end{tabular}} & \multicolumn{7}{c}{ Percentage } \\
\cline { 2 - 8 } & SD & D & A & SA & TA & M & Std dev \\
\hline $\begin{array}{l}\text { 2. Physicians and nurses have good } \\
\text { working relationships }\end{array}$ & 4.5 & 14.2 & 61.2 & 20.1 & 81.3 & 2.97 & 0.72 \\
$\begin{array}{l}\text { 23. Good relationships with other } \\
\text { departments, such as housekeeping } \\
\text { and dietary }\end{array}$ & 6.6 & 21.0 & 55.5 & 16.9 & 72.4 & 2.83 & 0.79 \\
$\begin{array}{l}\text { 39. Collaboration (joint practice) } \\
\text { between nurses and physicians }\end{array}$ & 7.0 & 20.4 & 59.6 & 13.0 & 72.6 & 2.79 & 0.76 \\
$\begin{array}{l}\text { 27. Much teamwork between nurses } \\
\text { and doctors }\end{array}$ & 9.2 & 23.3 & 50.2 & 17.3 & 67.5 & 2.76 & 0.85 \\
\hline
\end{tabular}

$\mathrm{SD}$, strongly disagree; $\mathrm{D}$, disagree; A, agree; SA, strongly agree; TA, total agreement. M, mean; Std dev, standard deviation.

Salary.

Two-thirds (65.2 per cent) of the respondents indicated that they were satisfied with their monthly salary and 14.6 per cent reported that they were highly satisfied with their current salary (see Table 5.13). 
Table 5.13

Response to Item Reflection Nurses' Opinions on Salary

\begin{tabular}{cccccccc}
\hline & \multicolumn{7}{c}{ Percentage } \\
\cline { 2 - 8 } Item Reflecting Salary & SD & D & A & SA & TA & M & Std dev \\
5. A satisfactory salary & 10.1 & 24.7 & 50.6 & 14.6 & 65.2 & 2.70 & 0.84 \\
\hline
\end{tabular}

$\mathrm{SD}$, strongly disagree; $\mathrm{D}$, disagree; A, agree; SA, strongly agree; TA, total agreement. M, mean; Std dev, standard deviation.

\section{Policies and administration.}

Nineteen items explored the nurses' satisfaction with hospital policies and administration. The majority (79 per cent) of the nurses agreed that there was a preceptor programme for newly recruited nurses, three-quarters (75.6 per cent) agreed that the description of policies and procedures governing work in the hospital was standardised and 74.2 per cent replied that each nursing unit had the opportunity to determine its own policies and strategies. More than three-quarters (77.4 per cent) of the respondents pointed out that primary nursing was the nursing delivery system in the hospital and 74.1 per cent believed that nursing care was based on a nursing model rather than a medical model. Further, 71.4 per cent agreed that the administration listens and responds to employee concerns. Nearly two-thirds (65.9 per cent) of the nurses agreed that the nursing care plans are verbally transmitted from nurse to nurse, about the same number (66.3 per cent) agreed that there was a good orientation programme for newly employed nurses and 68.3 per cent showed agreed that there were active quality assurance programmes in their hospitals. More than half (55.6 per cent) of the respondents agreed that administration expected a high standard of nursing care and 55.4 per cent agreed that a clear philosophy of nursing pervaded the patient care environment. Further, 60.2 per cent agreed that the nurse managers consulted with staff on daily problems and procedures. Only around half (53.2 per cent) of the respondents 
perceived that staff nurses had the opportunity to participate in policy decisions and just under half (48.7 per cent) had participated in selecting new equipment. Moreover, it was observed that slightly less than half (46.5 per cent) of the nurses stated that their director of nursing had power and authority equal to that of other top-level executives in the hospital (see Table 5.14 below).

Table 5.14

Responses to Items Reflecting Nurses' Opinion of Policies and Administration

\begin{tabular}{|c|c|c|c|c|c|c|c|}
\hline \multirow{2}{*}{$\begin{array}{c}\text { Items Reflecting Policies and } \\
\text { Administration }\end{array}$} & \multicolumn{7}{|c|}{ Percentage } \\
\hline & SD & $\mathrm{D}$ & $\mathrm{A}$ & SA & TA & M & Std dev \\
\hline $\begin{array}{l}\text { 36. An administration that listens } \\
\text { and responds to employee concerns }\end{array}$ & 10.6 & 18.0 & 35.7 & 35.7 & 71.4 & 2.96 & 0.98 \\
\hline $\begin{array}{l}\text { 40. A preceptor programme for } \\
\text { newly hired registered nurses }\end{array}$ & 9.2 & 11.8 & 54.4 & 24.6 & 79.0 & 2.94 & 0.87 \\
\hline $\begin{array}{l}\text { 22. Primary nursing as the nursing } \\
\text { delivery system }\end{array}$ & 6.3 & 16.3 & 63.7 & 13.7 & 77.4 & 2.85 & 0.73 \\
\hline $\begin{array}{l}\text { 41. Nursing care is based on a } \\
\text { nursing rather than a medical model }\end{array}$ & 4.8 & 21.1 & 59.0 & 15.1 & 74.1 & 2.85 & .073 \\
\hline $\begin{array}{l}\text { 51. Standardised policies, } \\
\text { procedures and ways of doing things }\end{array}$ & 7.0 & 17.4 & 61.6 & 14.0 & 75.6 & 2.83 & 0.75 \\
\hline $\begin{array}{l}\text { 54. Each nursing unit determines its } \\
\text { own policies and procedure }\end{array}$ & 6.6 & 19.2 & 58.3 & 15.9 & 74.2 & 2.83 & 0.77 \\
\hline $\begin{array}{l}\text { 37. An active quality assurance } \\
\text { programme }\end{array}$ & 7.4 & 24.3 & 50.0 & 18.3 & 68.3 & 2.79 & 0.83 \\
\hline $\begin{array}{l}\text { 47. Written, up-to-date nursing care } \\
\text { plans for all patients }\end{array}$ & 9.3 & 24.9 & 51.7 & 14.1 & 65.8 & 2.71 & 0.82 \\
\hline $\begin{array}{l}\text { 3. A good orientation programme } \\
\text { for newly employed nurses }\end{array}$ & 11.0 & 22.7 & 52.3 & 14.0 & 66.3 & 2.69 & 0.85 \\
\hline $\begin{array}{l}\text { 57. Nursing care plans are verbally } \\
\text { transmitted from nurse to nurse }\end{array}$ & 13.0 & 21.1 & 50.0 & 15.9 & 65.9 & 2.69 & 0.89 \\
\hline $\begin{array}{l}\text { 15. Flexible or modified work } \\
\text { schedules are available }\end{array}$ & 12.6 & 25.7 & 43.9 & 17.8 & 61.7 & 2.67 & 0.91 \\
\hline 52. Use of nursing diagnoses & 10.3 & 27.7 & 48.0 & 14.0 & 62.0 & 2.66 & 0.85 \\
\hline $\begin{array}{l}\text { 44. Nurse managers consult with } \\
\text { staff on daily problems and } \\
\text { procedures }\end{array}$ & 12.5 & 27.3 & 48.0 & 12.2 & 60.2 & 2.60 & 0.86 \\
\hline $\begin{array}{l}\text { 49. Regular, permanently assigned } \\
\text { staff nurses never have to float to }\end{array}$ & 11.0 & 33.0 & 42.4 & 13.6 & 56.0 & 2.59 & 0.86 \\
\hline
\end{tabular}


another unit

31. A clear philosophy of nursing pervades the patient care

$\begin{array}{lllllll}11.5 & 33.1 & 46.5 & 8.9 & 55.4 & 2.53 & 0.81\end{array}$

environment

9. Opportunity for staff nurses to participate in policy decisions

$\begin{array}{lllllll}14.3 & 32.5 & 40.0 & 13.2 & 53.2 & 2.52 & 0.90\end{array}$

25. High standards of nursing care are expected by the administration

$\begin{array}{lllllll}19.0 & 25.4 & 43.8 & 11.8 & 55.6 & 2.48 & 0.93\end{array}$

34. The nursing staff participates in selecting new equipment

$\begin{array}{lllllll}20.8 & 30.5 & 39.0 & 9.7 & 48.7 & 2.38 & 0.92\end{array}$

26. A chief nursing executive is equal in power and authority to other top-level executives

$\begin{array}{lllllll}22.1 & 31.4 & 38.4 & 8.1 & 46.5 & 2.32 & 0.91\end{array}$

SD, strongly disagree; D, disagree; A, agree; SA, strongly agree; TA, total agreement. $\mathrm{M}$, mean; Std dev, standard deviation.

\section{Supervision.}

Two items reflected supervision. Almost two-thirds (60.2 per cent) of the nurses indicated that the supervisory staff nurses were supportive and 59.5 per cent suggested that the chief nursing officers were highly visible and accessible to the staff nurses (see Table 5.15).

Table 5.15

Responses to Items Reflecting Nurses' Opinions on Supervision

\begin{tabular}{lccccccc}
\hline \multirow{2}{*}{\begin{tabular}{l} 
Items Reflecting Opinions \\
\multicolumn{1}{c}{ On Supervision }
\end{tabular}} & SD & D & A & SA & TA & M & Std dev \\
\cline { 2 - 8 } & 4. A supervisory staff that \\
$\begin{array}{l}\text { is supportive of nurses } \\
\begin{array}{l}\text { 14. A chief nursing officer } \\
\text { is highly visible and } \\
\text { accessible to staff }\end{array}\end{array}$ & 13.3 & 26.6 & 41.7 & 18.5 & 60.2 & 2.65 & 0.93 \\
\hline
\end{tabular}

$\mathrm{SD}$, strongly disagree; $\mathrm{D}$, disagree; $\mathrm{A}$, agree; SA, strongly agree; TA, total agreement. $\mathrm{M}$, mean; Std dev, standard deviation. 


\section{Working conditions.}

Seven items reflected the working conditions. Three-quarters (74.4 per cent) of the nurses reported that they agreed with the use of problem-oriented medical records and almost two-thirds (62.8 per cent) indicated that they control their own practice. Further, 58.8 per cent agreed that they had the opportunity to work in a highly specialised unit. Also, 41 per cent of the nurses remarked that there was enough staff to get the work done and 40.2 per cent perceived that the work environment was pleasant, attractive and comfortable (see Table 5.16).

Table 5.16

Nurses' Responses to the Items Reflecting Hospital Working Conditions

\begin{tabular}{|c|c|c|c|c|c|c|c|}
\hline \multirow{2}{*}{$\begin{array}{l}\text { Items Reflecting Working } \\
\text { Conditions }\end{array}$} & \multicolumn{7}{|c|}{ Percentage } \\
\hline & SD & $\mathrm{D}$ & $\mathrm{A}$ & SA & TA & M & Std dev \\
\hline $\begin{array}{l}55 . \text { Use of a problem- } \\
\text { oriented medical record }\end{array}$ & 7.5 & 18.1 & 60.0 & 14.4 & 74.4 & 2.81 & 0.77 \\
\hline $\begin{array}{l}\text { 6. Nurses control their } \\
\text { own practice }\end{array}$ & 8.6 & 28.6 & 53.4 & 9.4 & 62.8 & 2.64 & 0.77 \\
\hline $\begin{array}{l}\text { 53. Floating, so that } \\
\text { staffing is equalised } \\
\text { among units }\end{array}$ & 11.3 & 29.1 & 48.7 & 10.9 & 59.6 & 2.59 & 0.83 \\
\hline $\begin{array}{l}\text { 46. Opportunity to work in } \\
\text { a highly specialised unit }\end{array}$ & 12.3 & 28.9 & 48.1 & 10.7 & 58.8 & 2.57 & 0.84 \\
\hline $\begin{array}{l}\text { 1. Adequate support } \\
\text { services allow me to spend } \\
\text { time with my patients }\end{array}$ & 10.4 & 37.0 & 39.6 & 13.0 & 52.6 & 2.55 & 0.85 \\
\hline $\begin{array}{l}\text { 16. Enough staff to get the } \\
\text { work done }\end{array}$ & 26.2 & 32.8 & 29.2 & 11.8 & 41.0 & 2.27 & 0.98 \\
\hline $\begin{array}{l}\text { 45. The work environment } \\
\text { is pleasant, attractive and } \\
\text { comfortable }\end{array}$ & 33.2 & 26.6 & 33.9 & 6.3 & 40.2 & 2.13 & 0.95 \\
\hline
\end{tabular}

$\mathrm{SD}$, strongly disagree; $\mathrm{D}$, disagree; $\mathrm{A}$, agree; SA, strongly agree; TA, total agreement. $\mathrm{M}$, mean; Std dev, standard deviation. 


\section{Inferential Statistics}

This section presents the study results associated with each of the four research questions. Inferential statistical analyses were conducted to examine which demographic or independent variables of the study (gender, age, marital status, number of dependent children, number of dependent adults, qualifications, salary, hospital, position, number of weekly working hours, duration of employment at the hospital and overall experience) predicted the dependent variable, job satisfaction, which was divided into two parts: motivation and hygiene. ANOVA and t-tests were utilised to identify the differences in job satisfaction, motivation and hygiene scores among Saudi nurses. Multiple linear regression analysis was utilised to identify the strongest predictor variables that affect the participants' level of job satisfaction (motivation and hygiene).

\section{Research Question 1: Motivation factors affecting job satisfaction.}

The first research question asks: How do demographic factors affect motivation job satisfaction? The results demonstrated that the mean satisfaction scores in relation to motivating factors - including job advancement, the work itself, possibility for growth, responsibility, recognition and personal achievement—were significantly higher among males $(\mathrm{M}=2.71, \mathrm{SD}=0.50)$ than females $(\mathrm{M}=2.55, \mathrm{SD}=0.53),(\mathrm{p}<0.05)$. The results indicated that nurses who have no dependent adults to care for were significantly more satisfied with the motivating factors $(\mathrm{M}=2.69, \mathrm{SD}=0.50)$ compared to nurses who had dependent adults in their care $(\mathrm{M}=2.51, \mathrm{SD}=0.53),(\mathrm{p}<0.05)$. It also was found that age, marital status, number of dependent children, qualifications and monthly income were not significantly associated with variations in the mean scores for motivating factors (p>0.05; refer to Table 5.17). 
Table 5.17

Satisfaction with Motivating Factors According to the Demographic Characteristics of the Study Group (N=272)

\begin{tabular}{|c|c|c|c|}
\hline Characteristics & $\mathrm{M}$ & $\mathrm{SD}$ & Significance \\
\hline \multicolumn{4}{|l|}{ Gender: } \\
\hline Male nurses & 2.71 & 0.50 & \multirow{2}{*}{$\begin{array}{c}t(235)=2.36 \\
\mathbf{p}=\mathbf{0 . 0 1 9}\end{array}$} \\
\hline Female nurses & 2.55 & 0.53 & \\
\hline \multicolumn{4}{|l|}{ Age groups: } \\
\hline Less than 25 years & 2.62 & 0.59 & \multirow{3}{*}{$\begin{array}{c}F(2,234)=1.85 \\
p=0.159\end{array}$} \\
\hline $26-35$ years & 2.57 & 0.48 & \\
\hline More than 36 years & 2.75 & 0.50 & \\
\hline \multicolumn{4}{|l|}{ Marital status: } \\
\hline Single & 2.61 & 0.52 & \multirow{3}{*}{$\begin{array}{c}\mathrm{F}(2,234)=0.005 \\
\mathrm{p}=0.995\end{array}$} \\
\hline Married & 2.61 & 0.53 & \\
\hline Divorced & 2.59 & 0.36 & \\
\hline \multicolumn{4}{|l|}{ Number of dependent children: } \\
\hline None & 2.62 & 0.52 & \multirow{2}{*}{$\begin{array}{c}\mathrm{t}(235)=0.43 \\
\mathrm{p}=0.666\end{array}$} \\
\hline Have dependent children & 2.59 & 0.53 & \\
\hline \multicolumn{4}{|l|}{ Number of dependent adults: } \\
\hline None & 2.69 & 0.50 & \multirow{2}{*}{$\begin{array}{c}t(235)=2.64 \\
\mathbf{p}=\mathbf{0 . 0 0 9}\end{array}$} \\
\hline Have dependent adults & 2.51 & 0.53 & \\
\hline \multicolumn{4}{|l|}{ Qualifications: } \\
\hline Diploma & 2.62 & 0.52 & \multirow{2}{*}{$\begin{array}{c}\mathrm{t}(235)=0.663 \\
\mathrm{p}=0.508\end{array}$} \\
\hline $\begin{array}{l}\text { Bachelor's degree or postgraduate } \\
\text { qualification }\end{array}$ & 2.57 & 0.55 & \\
\hline \multicolumn{4}{|l|}{ Monthly salary: } \\
\hline $1,500-5,000$ SR $(400-1,333$ US\$) & 2.67 & 0.44 & \multirow{4}{*}{$\begin{array}{c}\mathrm{F}(3,233)=0.570 \\
\mathrm{p}=0.635\end{array}$} \\
\hline $\begin{array}{l}5,001-10,000 \text { SR }(1,334-2,666 \\
\text { US\$) }\end{array}$ & 2.62 & 0.54 & \\
\hline $\begin{array}{l}\text { 10,001-15,000 SR (2,667-4,000 } \\
\text { US\$) }\end{array}$ & 2.54 & 0.47 & \\
\hline More than 15,000 SR $(4,000$ US $\$)$ & 2.71 & 0.64 & \\
\hline
\end{tabular}

There were no significant differences among participants from the three hospitals regarding variations among nurses' satisfaction scores for motivating factors according to job characteristics and practical experience. However, the mean satisfaction scores were higher among the nursing managers who were working more 
than 50 hours per week. However, these differences were not statistically significant (p>0.05; see Table 5.18).

In relation to the length of time working in the hospital, the ANOVA revealed a significant overall effect. Follow-up tests using the Tukey post-hoc procedure $(\alpha=0.05)$ indicated that nurses who had worked for a period of 5-10 years were significantly less satisfied with the motivating factors than nurses who had worked in the hospital for less than 5 years $(\mathrm{p}=0.023)$.

In connection with duration of nursing experience in the hospital, the ANOVA test showed a significant overall effect. Follow-up tests using the Tukey post-hoc procedure $(\alpha=0.05)$ indicated that nurses who had overall experience of $4-10$ years were significantly less satisfied with motivating factors than nurses who had more than 10 years of experience $(\mathrm{p}=0.005)$ and less than 4 years of experience $(\mathrm{p}=0.024)$ (see Table 5.18). 
Table 5.18

Satisfaction with Motivating Factors According to the Job Characteristics and Practical Experience of the Study Group $(N=272)$

\begin{tabular}{lccc}
\hline \multicolumn{1}{c}{ Characteristics } & M & SD & Significance \\
\hline Employing hospital: & & & \\
$\quad$ Hospital A in Jeddah & 2.60 & 0.55 & \\
Hospital B in Makkah & 2.62 & 0.52 & $\mathrm{~F}(2,234)=0.061$ \\
Hospital C in Taif & 2.61 & 0.45 & \\
\hline Position: & & & \\
$\quad$ Staff nurses & 2.59 & 0.54 & \\
$\quad$ Head nurses & 2.60 & 0.49 & $\mathrm{~F}(3,233)=0.634$ \\
$\quad$ Nursing managers & 2.76 & 0.40 & $\mathrm{p}=0.594$ \\
$\quad$ Others (nursing education and quality & 2.61 & 0.53 & \\
$\quad$ control nurses) & & & \\
\hline Number of weekly working hours: & 2.60 & 0.51 & $\mathrm{t}(235)=-0.466$ \\
$\quad$ Less than 50 hours & 2.65 & 0.61 & $\mathrm{p}=0.642$ \\
$\quad$ More than 50 hours & & & \\
\hline Duration of employment in the hospital: & 2.66 & 0.52 & $\mathrm{~F}(2,234)=3.54$ \\
$\quad$ Less than 5 years & 2.43 & 0.49 & $\mathbf{p = 0 . 0 3 0}$ \\
$\quad$ 5-10 years & 2.63 & 0.53 & \\
$\quad$ More than 10 years & & & \\
\hline Lverall experience: & 2.66 & 0.52 & $\mathrm{~F}(2,234)=6.075$ \\
$\quad$ 4-10 years & 2.47 & 0.49 & $\mathbf{p}=\mathbf{0 . 0 0 3}$ \\
$\quad$ More than 10 years & 2.78 & 0.52 & \\
\hline
\end{tabular}

\section{Research Question 2: Hygiene factors affecting job satisfaction.}

The second research question asks: How do the demographic factors affect hygiene job satisfaction? The estimated mean satisfaction scores for hygiene factors (including interpersonal relationships in the hospital, salary, hospital policies and administration, supervision and working conditions) were higher among males. Participants who were in the age group of 36 years and over and participants who were divorced or widowed also indicated higher satisfaction scores. Higher satisfaction scores were also indicated for nurses who have dependent children, but not for those with dependent adults and among participants who have a Diploma in Nursing and 
nurses who have a monthly income of 15,000 SR or more. However, these differences were not statistically significant $(\mathrm{p}>0.05)$ (see Table 5.19).

Table 5.19

Satisfaction with Hygiene Factors According to the Demographic Characteristics of the Study Group $(N=272)$

\begin{tabular}{|c|c|c|c|}
\hline Characteristics & $\mathrm{M}$ & SD & Significance \\
\hline \multicolumn{4}{|l|}{ Gender: } \\
\hline Male nurses & 2.70 & 0.48 & \multirow{2}{*}{$\begin{array}{c}\mathrm{t}(214)=0.957 \\
\mathrm{p}=0.340\end{array}$} \\
\hline Female nurses & 2.64 & 0.52 & \\
\hline \multicolumn{4}{|l|}{ Age groups: } \\
\hline Less than 25 years & 2.72 & 0.54 & \multirow{3}{*}{$\begin{array}{c}\mathrm{F}(2,213)=3.030 \\
\mathrm{p}=0.0503\end{array}$} \\
\hline $26-35$ years & 2.59 & 0.47 & \\
\hline More than 36 years & 2.80 & 0.48 & \\
\hline \multicolumn{4}{|l|}{ Marital status: } \\
\hline Single & 2.65 & 0.49 & \multirow{3}{*}{$\begin{array}{c}\mathrm{F}(2,213)=0.184 \\
\mathrm{p}=0.832\end{array}$} \\
\hline Married & 2.68 & 0.53 & \\
\hline Divorced/widowed & 2.73 & 0.38 & \\
\hline \multicolumn{4}{|l|}{ Number of dependent children: } \\
\hline None & 2.66 & 0.49 & \multirow{2}{*}{$\begin{array}{c}t(214)=-0.108 \\
p=0.914\end{array}$} \\
\hline Have dependent children & 2.67 & 0.52 & \\
\hline \multicolumn{4}{|l|}{ Number of dependent adults: } \\
\hline None & 2.70 & 0.49 & \multirow{2}{*}{$\begin{array}{l}\mathrm{t}(214)=1.261 \\
\mathrm{p}=0.209\end{array}$} \\
\hline Have dependent adults & 2.61 & 0.52 & \\
\hline \multicolumn{4}{|l|}{ Qualifications: } \\
\hline Diploma & 2.68 & 0.49 & \multirow{2}{*}{$\begin{array}{c}\mathrm{t}(214)=0.897 \\
\mathrm{p}=0.371\end{array}$} \\
\hline $\begin{array}{l}\text { Bachelor's degree or postgraduate } \\
\text { qualifications }\end{array}$ & 2.60 & 0.55 & \\
\hline \multicolumn{4}{|l|}{ Monthly salary: } \\
\hline $1,500-5,000$ SR $(400-1,333$ US\$) & 2.82 & 0.39 & \multirow{4}{*}{$\begin{array}{c}\mathrm{F}(3,212)=1.337 \\
\mathrm{p}=0.263\end{array}$} \\
\hline 5,001-10,000 SR (1,334-2,666 US\$) & 2.65 & 0.51 & \\
\hline $10,001-15,000$ SR $(2,667-4,000$ US\$) & 2.60 & 0.47 & \\
\hline More than 15,000 SR (4,000 US\$) & 2.83 & 0.56 & \\
\hline
\end{tabular}

With respect to the participants' perception of the hygiene factors' effects on job characteristics, it was found that there were no statistically significant differences among nurses at the three hospitals. It was also found that the mean satisfaction score was higher among head nurses $(M=2.76, S D=0.41)$ and nursing managers $(M=2.75$, 
$\mathrm{SD}=0.46$ ), those who worked less than 50 hours per week and nurses who had been working in the hospital for more than 10 years, but these differences were not statistically significant $(\mathrm{p}>0.05)$.

In relation to length of total nursing experience, the ANOVA tests revealed a significant impact overall. Follow-up tests using the Tukey post-hoc procedure $(\alpha=0.05)$ indicated that nurses who had overall experience of 4-10 years were significantly less satisfied with the hygiene factors than nurses who had an overall experience of more than 10 years $(p=0.004)$ and those who had less than 4 years experince $(p=0.016)$ (see Table 5.20). 
Table 5.20

Satisfaction with Hygiene Factors According to Job Characteristics and Practical Experience of the Study Group $(N=272)$

\begin{tabular}{lccc}
\hline Characteristics & M & SD & Significance \\
\hline $\begin{array}{l}\text { Employing hospital: } \\
\quad \text { Hospital A in Jeddah }\end{array}$ & 2.67 & 0.52 & \\
$\quad$ Hospital B in Makkah & 2.66 & 0.52 & $\mathrm{~F}(2,213)=0.15$ \\
$\quad$ & 2.66 & 0.41 & $\mathrm{p}=0.985$ \\
$\quad$ Hospital C in Taif & & & \\
\hline Position: & 2.65 & 0.52 & \\
$\quad$ Staff nurse & 2.76 & 0.41 & $\mathrm{~F}(3,212)=0.772$ \\
$\quad$ Head nurse & 2.75 & 0.46 & $\mathrm{p}=0.511$ \\
$\quad$ Nursing manager & 2.57 & 0.49 & \\
$\quad$ Other (nursing education and quality & & & \\
$\quad$ control nurses) & 2.67 & 0.48 & $\mathrm{t}(214)=0.569$ \\
Number of weekly working hours: & 2.61 & 0.64 & $\mathrm{p}=0.573$ \\
$\quad$ Less than 50 hours & & & \\
$\quad$ More than 50 hours & 2.70 & 0.51 & $\mathrm{~F}(2,213)=2.993$ \\
\hline Duration of employment in the hospital: & 2.50 & 0.43 & $\mathrm{p}=0.052$ \\
$\quad$ Less than 5 years & 2.72 & 0.52 & \\
$\quad$ 5-10 years & & & \\
$\quad$ More than 10 years & 2.72 & 0.51 & $\mathrm{~F}(2,213)=6.595$ \\
$\mathbf{p}=\mathbf{0 . 0 0 2}$ \\
$\quad$ Less than 4 years & 2.52 & 0.46 & \\
4-10 years & 2.84 & 0.49 & \\
$\quad$ More than 10 years & & & \\
\hline Overall experience: & & & \\
\hline
\end{tabular}

\section{Research Question 3: Factors that predict job satisfaction.}

Statistical analysis was conducted to explore variables concerning the third research question: What are the factors that predict job satisfaction among Saudi nurses in public hospitals? A multiple linear regression analysis was run to test the strongest predictor for the independent factors, which included personal and job characteristics of Saudi nurses identified to have a significant association with the level of satisfaction for motivation. The results revealed that the significant predictors for satisfaction with motivation were gender $(B=-.170, p=.017)$ and number of dependent adults $(B=-.190$, $\mathrm{p}=.008$ ). Beta values reveal the relationship between the independent and dependent 
variables. The negative beta coefficients indicate a negative relationship between the predictor and the outcome, thereby showing that having fewer dependent adults was predictive of higher satisfaction and being a female nurse was predictive of higher satisfaction. Table 5.21 provides the coefficient results for the multiple linear regression analysis models.

Table 5.21

Predictors for Level of Satisfaction Reflecting Motivating Factors

\begin{tabular}{|c|c|c|c|c|c|}
\hline \multirow[t]{2}{*}{ Items } & \multicolumn{2}{|c|}{$\begin{array}{l}\text { Unstandardised } \\
\text { Coefficients }\end{array}$} & \multirow{2}{*}{$\begin{array}{c}\text { Standardised } \\
\text { Coefficients } \\
\text { Beta }\end{array}$} & \multirow[t]{2}{*}{$\mathrm{t}$} & \multirow{2}{*}{$\mathrm{p}$} \\
\hline & $\mathrm{B}$ & Std. Error & & & \\
\hline (Constant) & 3.133 & .282 & & 11.100 & .000 \\
\hline Gender & -.170 & .071 & -.160 & -2.413 & .017 \\
\hline Age groups & .146 & .077 & .184 & 1.895 & .059 \\
\hline Marital status & -.011 & .081 & -.012 & -.137 & .891 \\
\hline Number of d. children & -.009 & .095 & -.009 & -.099 & .921 \\
\hline Number of d. adults & -.190 & .071 & -.179 & -2.686 & .008 \\
\hline Qualifications & -.065 & .092 & -.050 & -.705 & .482 \\
\hline Monthly salary & -.005 & .068 & -.006 & -.068 & .946 \\
\hline Employing hospital & -.005 & .047 & -.007 & -.097 & .923 \\
\hline Position & .030 & .036 & .058 & .809 & .419 \\
\hline Number of working hours & .005 & .107 & .003 & .051 & .960 \\
\hline
\end{tabular}

The overall R square for this model was 8.0 per cent. Table 5.22 shows the model summary.

Table 5.22

Model Summary

\begin{tabular}{ccccc}
\hline Model & $\mathrm{R}$ & $\mathrm{R}$ Square & Adjusted R Square & Std. Error of the Estimate \\
\hline 1 & .283 & .080 & .031 & .51285 \\
\hline
\end{tabular}


A second multiple linear regression analysis was conducted to examine the prediction ability of the independent factors, which included personal characteristics, job characteristics and the experience level of Saudi nurses identified to have a significant association with the level of satisfaction regarding hygiene. The results revealed no significant predictor for satisfaction with hygiene. Table 5.23 provides the coefficient results for the linear regression analysis model.

Table 5.23

Predictors for Level of Satisfaction Reflecting Hygiene Factors

\begin{tabular}{|c|c|c|c|c|c|}
\hline \multirow[t]{2}{*}{ Items } & \multicolumn{2}{|c|}{$\begin{array}{l}\text { Unstandardised } \\
\text { Coefficients }\end{array}$} & \multirow{2}{*}{$\begin{array}{c}\text { Standardised } \\
\text { Coefficients } \\
\text { Beta }\end{array}$} & \multirow[t]{2}{*}{$\mathrm{t}$} & \multirow{2}{*}{$\mathrm{p}$} \\
\hline & B & Std. Error & & & \\
\hline (Constant) & 3.100 & .294 & & 10.548 & .000 \\
\hline Gender & -.068 & .074 & -.066 & -.926 & .356 \\
\hline Age groups & .045 & .080 & .059 & .564 & .574 \\
\hline Marital status & .044 & .084 & .050 & .521 & .603 \\
\hline Number of d. children & -.003 & .099 & -.003 & -.028 & .978 \\
\hline Number of d. adults & -.095 & .074 & -.093 & -1.290 & .199 \\
\hline Qualifications & -.086 & .096 & -.068 & -.893 & .373 \\
\hline Monthly salary & .006 & .071 & .008 & .085 & .932 \\
\hline Employing hospital & -.027 & .049 & -.042 & -.560 & .576 \\
\hline Position & .001 & .038 & .002 & .019 & .985 \\
\hline Number of working hours & -.112 & .112 & -.074 & -1.007 & .315 \\
\hline $\begin{array}{l}\text { Duration of work in } \\
\text { hospital }\end{array}$ & -.047 & .070 & -.072 & -.677 & .499 \\
\hline Overall experience & -.001 & .077 & -.001 & -.011 & .991 \\
\hline
\end{tabular}

The overall R square for this model was 2.5 per cent. Table 5.24 shows the model summary. 
Table 5.24

Model Summary

\begin{tabular}{ccccc}
\hline Model & $\mathrm{R}$ & R Square & Adjusted R Square & Std. Error of the Estimate \\
\hline 1 & .159 & .025 & -.032 & .50971 \\
\hline
\end{tabular}

\section{Gender.}

To investigate the gender and the level of satisfaction, the relationship between female and male Saudi nurses and independent factors (which included personal and job characteristics and level of job satisfaction) were considered. Personal demographic characteristics included age, marital status, number of dependent children, number of dependent adults, qualifications and salary. Job characteristics and practical experience included the employing hospital, position at the hospital, duration of work experience at the hospital, number of weekly working hours and overall experience.

\section{Female Saudi nurses.}

Multiple linear regression analysis was conducted to measure the predictor variables that substantially contribute for female Saudi nurses and independent factors identified to have a significant association with the level of satisfaction for motivation, and this was found to be the number of dependent adults $(B=-.185, \mathrm{p}=.049)$. The negative beta coefficients show a negative relationship between the predictor and the outcome; having fewer dependent adults was predictive of higher female satisfaction. The results of the multiple linear regression analysis are shown in Table 5.25. 
Table 5.25

Predictors for Female Level of Satisfaction Reflecting Motivating Factors

\begin{tabular}{lccccc}
\hline \multicolumn{1}{c}{ Model } & \multicolumn{2}{c}{ Unstandardised } & Standardised & & \\
& Coefficients & Coefficients & $\mathrm{t}$ & $\mathrm{p}$ \\
& $\mathrm{B}$ & $\begin{array}{c}\text { Std. } \\
\text { Error }\end{array}$ & Beta & & \\
\hline (Constant) & 2.554 & .334 & & 7.639 & .000 \\
Age group & .191 & .101 & .256 & 1.899 & .060 \\
Marital status & .014 & .105 & .016 & .135 & .893 \\
Number of d. children & .117 & .127 & .106 & .926 & .356 \\
Number of d. adults & -.185 &. $\mathbf{0 9 3}$ & -.170 & $-\mathbf{1 . 9 9 1}$ & $\mathbf{. 0 4 9}$ \\
Qualifications & -.082 & .116 & -.066 & -.708 & .480 \\
Monthly salary & -.073 & .083 & -.103 & -.880 & .380 \\
Employing hospital & .064 & .064 & .089 & 1.000 & .319 \\
Position & .008 & .050 & .016 & .162 & .872 \\
Number of working hours & -.042 & .149 & -.025 & -.284 & .777 \\
Duration of work in & -.134 & .090 & -.203 & -1.488 & .139 \\
hospital & & & & & \\
Overall experience & .065 & .091 & .092 & .706 & .481 \\
\hline
\end{tabular}

The overall R square for this model was 10.6 per cent. Table 5.26 shows the model summary.

Table 5.26

Model Summary

\begin{tabular}{ccccc}
\hline Model & $\mathrm{R}$ & R Square & Adjusted R Square & Std. Error of the Estimate \\
\hline 1 & .325 & .106 & .031 & .51989 \\
\hline
\end{tabular}

A multiple linear regression analysis was run to measure the predictor variables that substantially contribute for female Saudi nurses and independent factors identified to have a significant association with the level of satisfaction regarding hygiene. The results showed that there is no significant predictor for female nurses and job 
satisfaction with hygiene. A p-value that was borderline in terms of significance $(p=.05)$ was observed regarding the age group. The results of the multiple linear regression analysis are summarised in Table 5.27.

Table 5.27

Predictors for Female Level of Satisfaction Reflecting Hygiene Factors

\begin{tabular}{lccccc}
\hline \multicolumn{1}{c}{ Model } & \multicolumn{2}{c}{ Unstandardised } & \multicolumn{2}{c}{ Standardised } & \\
& \multicolumn{2}{c}{ Coefficients } & Coefficients & $\mathrm{t}$ & $\mathrm{p}$ \\
& $\mathrm{B}$ & Std. Error & Beta & & \\
\hline (Constant) & 2.473 & .348 & & 7.113 & .000 \\
Age group & .207 & .105 & .283 & 1.978 & .050 \\
Marital status & -.004 & .109 & -.004 & -.035 & .972 \\
Number of d. children & .230 & .132 & .213 & 1.748 & .083 \\
Number of d. adults & -.131 & .097 & -.123 & -1.357 & .178 \\
Qualifications & -.136 & .121 & -.111 & -1.126 & .262 \\
Monthly salary & -.047 & .086 & -.069 & -.551 & .583 \\
Employing hospital & .116 & .067 & .164 & 1.728 & .087 \\
Position & -.043 & .052 & -.085 & -.826 & .410 \\
Number of working hours & -.033 & .154 & -.020 & -.211 & .833 \\
Duration of employment in & -.081 & .094 & -.124 & -.859 & .392 \\
hospital & & & & & \\
Overall experience & -.032 & .095 & -.046 & -.332 & .741 \\
\hline
\end{tabular}

The overall R square for this model was 13.4 per cent. Table 5.28 shows the model summary.

Table 5.28

Model Summary

\begin{tabular}{ccccc}
\hline Model & R & R Square & Adjusted R Square & Std. Error of the Estimate \\
\hline 1 & .366 & .134 & .049 & .50508 \\
\hline
\end{tabular}




\section{Male Saudi nurses.}

A second multiple linear regression analysis was conducted to measure the predictor variables that substantially contribute for male Saudi nurses and independent factors identified to have a significant association with the level of satisfaction for motivation. These were number of dependent children $(B=-.366, p=.012)$, monthly salary $(B=.327, p=.008)$, position $(B=.129, p=.016)$ and overall experience $(B=-.291$, $\mathrm{p}=.035$ ). The negative beta coefficients indicate a negative relationship between the predictor and the outcome; having fewer dependent children and less overall experience were predictive of higher male satisfaction. Table 5.29 summarises the coefficient results for the multiple linear regression analysis models.

Table 5.29

Predictors for Male Level of Satisfaction Reflecting Motivating Factors

\begin{tabular}{|c|c|c|c|c|c|}
\hline \multirow[t]{2}{*}{ Model } & \multicolumn{2}{|c|}{$\begin{array}{l}\text { Unstandardised } \\
\text { Coefficients }\end{array}$} & \multirow{2}{*}{$\begin{array}{c}\text { Standardised } \\
\text { Coefficients } \\
\text { Beta }\end{array}$} & \multirow{2}{*}{$\mathrm{t}$} & \multirow{2}{*}{$\mathrm{p}$} \\
\hline & $\mathrm{B}$ & $\begin{array}{l}\text { Std. } \\
\text { Error }\end{array}$ & & & \\
\hline (Constant) & 2.972 & .369 & & 8.054 & .000 \\
\hline Age group & .045 & .117 & .052 & .385 & .701 \\
\hline Marital status & .041 & .123 & .046 & .329 & .743 \\
\hline Number of $d$. children & -.366 & .142 & -.364 & -2.581 & .012 \\
\hline Number of d. adults & -.208 & .106 & -.209 & -1.967 & .053 \\
\hline Qualifications & -.067 & .159 & -.047 & -.426 & .672 \\
\hline Monthly salary & .327 & .120 & .400 & 2.716 & .008 \\
\hline Employing hospital & -.044 & .065 & -.076 & -.684 & .496 \\
\hline Position & .129 & .052 & .268 & 2.462 & .016 \\
\hline Number of working hours & .084 & .149 & .060 & .561 & .576 \\
\hline $\begin{array}{l}\text { Duration of employment in } \\
\text { the hospital }\end{array}$ & .029 & .100 & .041 & .288 & .774 \\
\hline Overall experience & -.291 & .136 & -.401 & -2.144 & .035 \\
\hline
\end{tabular}


The overall $\mathrm{R}$ square for this model was 25.7 per cent. Table 5.30 shows the model summary.

Table 5.30

Model Summary

\begin{tabular}{ccccc}
\hline Model & $\mathrm{R}$ & R Square & Adjusted R Square & Std. Error of the Estimate \\
\hline 1 & .507 & .257 & .157 & .45607 \\
\hline
\end{tabular}

Multiple linear regression analysis was conducted to measure the predictor variables that substantially contribute for male Saudi nurses and independent factors identified to have a significant association with the level of satisfaction regarding hygiene. These were number of dependent children $(B=-.466, p=.001)$, monthly salary $(\mathrm{B}=.341, \mathrm{p}=.004)$ and employing hospital $(\mathrm{B}=-.167, \mathrm{p}=.009)$. The negative beta coefficients indicate a negative relationship between the predictor and the outcome; having fewer dependent children and the three public hospitals were predictive of higher male satisfaction. The results of the multiple linear regression analysis for male Saudi nurses are shown in Table 5.31. 
Table 5.31

Predictors for Male Level of Satisfaction Reflecting Hygiene Factors

\begin{tabular}{|c|c|c|c|c|c|}
\hline \multirow[t]{2}{*}{ Model } & \multicolumn{2}{|c|}{$\begin{array}{l}\text { Unstandardised } \\
\text { Coefficients }\end{array}$} & \multirow{2}{*}{$\begin{array}{c}\text { Standardised } \\
\text { Coefficients } \\
\text { Beta }\end{array}$} & \multirow[t]{2}{*}{$\mathrm{t}$} & \multirow[t]{2}{*}{$\mathrm{p}$} \\
\hline & B & Std. Error & & & \\
\hline (Constant) & 3.416 & .356 & & 9.604 & .000 \\
\hline Age group & -.213 & .113 & -.258 & -1.893 & .062 \\
\hline Marital status & .160 & .119 & .190 & 1.348 & .181 \\
\hline Number of $d$. children & -.466 & .137 & -.481 & -3.411 & .001 \\
\hline Number of d. adults & -.044 & .102 & -.046 & -.430 & .669 \\
\hline Qualifications & -.176 & .153 & -.128 & -1.153 & .253 \\
\hline Monthly salary & .341 & .116 & .433 & 2.937 & .004 \\
\hline Employing hospital & -.167 & .063 & -.299 & -2.677 & .009 \\
\hline Position & .093 & .050 & .200 & 1.839 & .070 \\
\hline $\begin{array}{l}\text { Number of working } \\
\text { hours }\end{array}$ & -.146 & .144 & -.109 & -1.016 & .313 \\
\hline $\begin{array}{l}\text { Duration of employment } \\
\text { in the hospital }\end{array}$ & .032 & .096 & .047 & .333 & .740 \\
\hline
\end{tabular}

The overall $\mathrm{R}$ square for this model was 28.3 per cent. Table 5.32 shows the model summary.

Table 5.32

Model Summary

\begin{tabular}{ccccc}
\hline Model & $\mathrm{R}$ & R Square & Adjusted R Square & Std. Error of the Estimate \\
\hline 1 & .532 & .283 & .183 & .43246 \\
\hline
\end{tabular}

Age group.

Age group was explored by identifying the relationship between the three age groups and independent factors, which included personal and job characteristics and level of job satisfaction. Participants were divided to three age groups, the first being 
nurses aged less than 25 years, the second being nurses aged between 26 and 35 years and the third nurses aged 36 years old and above.

First age group (less than 25 years).

Multiple linear regression analysis was conducted to measure the prediction for the first age group and independent factors, and it was found that gender $(B=-.346$, $\mathrm{p}=.021)$ and number of dependent adults $(\mathrm{B}=-.293, \mathrm{p}=049)$ contributed substantially to job satisfaction with motivation. The negative beta coefficients indicate a negative relationship between the predictor and the outcome; having a lower score of gender (i.e., males) and fewer dependent adults were predictive of higher motivation. The results of the multiple linear regression analysis are provided in Table 5.33.

Table 5.33

Predictors for Level of Satisfaction in the First Age Group Reflecting Motivating Factors

\begin{tabular}{|c|c|c|c|c|c|}
\hline \multirow[t]{2}{*}{ Model } & \multicolumn{2}{|c|}{$\begin{array}{l}\text { Unstandardised } \\
\text { Coefficients }\end{array}$} & \multirow{2}{*}{$\begin{array}{c}\text { Standardised } \\
\text { Coefficients } \\
\text { Beta }\end{array}$} & \multirow[t]{2}{*}{$\mathrm{t}$} & \multirow[t]{2}{*}{$\mathrm{p}$} \\
\hline & $\mathrm{B}$ & Std. Error & & & \\
\hline (Constant) & 3.365 & .731 & & 4.605 & .000 \\
\hline Gender & -.346 & .146 & -.282 & -2.373 & .021 \\
\hline Marital status & -.098 & .213 & -.075 & -.461 & .646 \\
\hline Number of d. children & .125 & .255 & .079 & .490 & .626 \\
\hline Number of d. adults & -.293 & .146 & -.233 & -2.005 & .049 \\
\hline Qualifications & .519 & .285 & .225 & 1.821 & .074 \\
\hline Salary monthly & -.002 & .237 & -.001 & -.007 & .994 \\
\hline Employing hospital & -.043 & .094 & -.059 & -.458 & .648 \\
\hline Position & -.217 & .168 & -.156 & -1.291 & .201 \\
\hline $\begin{array}{l}\text { Number of working } \\
\text { hours }\end{array}$ & .151 & .227 & .086 & .666 & .508 \\
\hline $\begin{array}{l}\text { Duration of } \\
\text { employment in the } \\
\text { hospital }\end{array}$ & .100 & .254 & .054 & .395 & .694 \\
\hline Overall experience & -.307 & .267 & -.163 & -1.150 & .255 \\
\hline
\end{tabular}


The overall R square for this model was 23.1 per cent. Table 5.34 shows the model summary.

Table 5.34

Model Summary

\begin{tabular}{ccccc}
\hline Model & $\mathrm{R}$ & R Square & Adjusted R Square & Std. Error of the Estimate \\
\hline 1 & .480 & .231 & .092 & .56694 \\
\hline
\end{tabular}

A multiple linear regression analysis was run to examine the prediction for the first age group and independent factors, and it was found that gender $(B=-.328, p=.024)$ and qualifications $(\mathrm{B}=.596, \mathrm{p}=.035)$ contributed substantially to job satisfaction with hygiene. The negative beta coefficients indicate a negative relationship between the predictor and the outcome; being male was predictive of higher nurses' hygiene. The results of the multiple linear regression analysis are summarised in Table 5.35. 
Table 5.35

Predictors for Level of Satisfaction of the First Age Group Reflecting Hygiene Factors

\begin{tabular}{|c|c|c|c|c|c|}
\hline \multirow[t]{2}{*}{ Model } & \multicolumn{2}{|c|}{$\begin{array}{l}\text { Unstandardised } \\
\text { Coefficients }\end{array}$} & \multirow{2}{*}{$\begin{array}{c}\text { Standardised } \\
\text { Coefficients } \\
\text { Beta }\end{array}$} & \multirow[t]{2}{*}{$\mathrm{t}$} & \multirow{2}{*}{$\mathrm{p}$} \\
\hline & B & Std. Error & & & \\
\hline (Constant) & 3.062 & .708 & & 4.323 & .000 \\
\hline Gender & -.328 & .141 & -.292 & -2.322 & .024 \\
\hline Marital status & -.173 & .207 & -.144 & -.835 & .407 \\
\hline Number of d. children & .256 & .247 & .175 & 1.035 & .305 \\
\hline Number of d. adults & -.177 & .142 & -.153 & -1.248 & .217 \\
\hline Qualifications & .596 & .276 & .282 & 2.159 & .035 \\
\hline Monthly salary & .066 & .230 & .036 & .287 & .775 \\
\hline Employing hospital & -.030 & .091 & -.045 & -.327 & .745 \\
\hline Position & -.194 & .163 & -.152 & -1.188 & .240 \\
\hline Number of working hours & .117 & .220 & .072 & .531 & .598 \\
\hline $\begin{array}{l}\text { Duration of employment } \\
\text { in the hospital }\end{array}$ & -.289 & .247 & -.171 & -1.174 & .246 \\
\hline Overall experience & .018 & .259 & .011 & .070 & .944 \\
\hline
\end{tabular}

The overall R square for this model was 25.1 per cent. Table 5.36 shows the model summary.

Table 5.36

Model Summary

\begin{tabular}{ccccc}
\hline Model & $\mathrm{R}$ & R Square & Adjusted R Square & Std. Error of the Estimate \\
\hline 1 & .501 & .251 & .096 & .51819 \\
\hline
\end{tabular}

Second age group (26-35 years).

A second multiple linear regression analysis was conducted to measure the strongest predictor for the second age group and independent factors identified to have a significant association with the level of satisfaction for motivation, and it was found that position $(\mathrm{B}=.081, \mathrm{p}=.039)$ and the duration of employment at the hospital $(\mathrm{B}=-.216$, 
$\mathrm{p}=.008)$ contributed substantially to job satisfaction with motivation. The negative beta coefficients indicate a negative relationship between the predictor and the outcome; having a shorter duration of employment in the hospital was predictive of higher nurses' motivation. Table 5.37 summarises the coefficient results for the multiple linear regression analysis models.

Table 5.37

Predictors for Level of Satisfaction of the Second Age Group Reflecting Motivating Factors

\begin{tabular}{|c|c|c|c|c|c|}
\hline \multirow[t]{2}{*}{ Model } & \multicolumn{2}{|c|}{$\begin{array}{l}\text { Unstandardised } \\
\text { Coefficients }\end{array}$} & \multirow{2}{*}{$\begin{array}{c}\text { Standardised } \\
\text { Coefficients } \\
\text { Beta }\end{array}$} & \multirow[t]{2}{*}{$\mathrm{t}$} & \multirow[t]{2}{*}{$\mathrm{p}$} \\
\hline & B & Std. Error & & & \\
\hline (Constant) & 3.305 & .373 & & 8.872 & .000 \\
\hline Gender & -.095 & .086 & -.100 & -1.109 & .270 \\
\hline Marital status & .034 & .098 & .039 & .345 & .731 \\
\hline Number of d. children & -.040 & .107 & -.041 & -.371 & .712 \\
\hline Number of d. adults & -.131 & .085 & -.136 & -1.532 & .128 \\
\hline Qualifications & -.132 & .104 & -.119 & -1.274 & .205 \\
\hline Monthly salary & -.034 & .086 & -.041 & -.396 & .693 \\
\hline Employing hospital & .060 & .057 & .098 & 1.064 & .289 \\
\hline Position & .081 & .039 & .190 & 2.086 & .039 \\
\hline Number of working hours & -.088 & .126 & -.063 & -.693 & .490 \\
\hline $\begin{array}{l}\text { Duration of employment } \\
\text { in the hospital }\end{array}$ & -.216 & .080 &.- .301 & -2.679 & .008 \\
\hline Overall experience & .003 & .082 & .004 & .034 & .973 \\
\hline
\end{tabular}

The overall $\mathrm{R}$ square for this model was 17.5 per cent. Table 5.38 shows the model summary. 
Table 5.38

Model Summary

\begin{tabular}{ccccc}
\hline Model & $\mathrm{R}$ & $\mathrm{R}$ Square & Adjusted R Square & Std. Error of the Estimate \\
\hline 1 & .418 & .175 & .097 & .45286 \\
\hline
\end{tabular}

A multiple linear regression analysis was conducted to measure the prediction for the second age group and independent factors identified to have a significant association with the level of satisfaction regarding hygiene and it was found that the number of working hours $(\mathrm{B}=-.278, \mathrm{p}=.040)$ had a significant association. The negative beta coefficients indicate a negative relationship between the predictor and the outcome; having less working hours was predictive of higher nurses' hygiene. The results of the multiple linear regression analysis for the second age group are shown in Table 5.39. 
Table 5.39

Predictors for Level of Satisfaction of the Second Age Group Reflecting Hygiene Factors

\begin{tabular}{|c|c|c|c|c|c|}
\hline \multirow[t]{2}{*}{ Model } & \multicolumn{2}{|c|}{$\begin{array}{l}\text { Unstandardised } \\
\text { Coefficients }\end{array}$} & \multirow{2}{*}{$\begin{array}{c}\text { Standardised } \\
\text { Coefficients } \\
\text { Beta }\end{array}$} & \multirow[t]{2}{*}{$\mathrm{t}$} & \multirow[t]{2}{*}{$\mathrm{p}$} \\
\hline & $\mathrm{B}$ & Std. Error & & & \\
\hline (Constant) & 3.180 & .394 & & 8.072 & .000 \\
\hline Gender & .099 & .091 & .104 & 1.089 & .279 \\
\hline Marital status & .174 & .104 & .202 & 1.676 & .097 \\
\hline Number of d. children & -.077 & .113 & -.081 & -.685 & .495 \\
\hline Number of d. adults & -.060 & .090 & -.063 & -.667 & .506 \\
\hline Qualifications & -.187 & .110 & -.169 & -1.708 & .091 \\
\hline Monthly salary & -.168 & .091 & -.204 & -1.849 & .067 \\
\hline Employing hospital & .038 & .060 & .062 & .634 & .527 \\
\hline Position & .068 & .041 & .161 & 1.666 & .099 \\
\hline $\begin{array}{l}\text { Number of working } \\
\text { hours }\end{array}$ & -.278 & .134 & -.202 & -2.080 & .040 \\
\hline $\begin{array}{l}\text { Duration of employment } \\
\text { in the hospital }\end{array}$ & -.044 & .085 & -.061 & -.512 & .609 \\
\hline Overall experience & -.015 & .087 & -.019 & -.172 & .863 \\
\hline
\end{tabular}

The overall R square for this model was 16.0 per cent. Table 5.40 shows the model summary.

Table 5.40

Model Summary

\begin{tabular}{ccccc}
\hline Model & $\mathrm{R}$ & R Square & Adjusted R Square & Std. Error of the Estimate \\
\hline 1 & .400 & .160 & .072 & .45582 \\
\hline
\end{tabular}

Third age group (36 years old and above).

A third multiple linear regression analysis was run to examine the prediction for the third age group and independent factors identified to have a significant association 
with the level of satisfaction regarding motivation and hygiene. The results of this linear regression revealed no significant predictor for satisfaction with both motivation and hygiene. Tables 5.41 and 5.43 show the coefficient results for the linear regression analysis of this age group.

Table 5.41

Predictors for Level of Satisfaction of the Third Age Group Reflecting Motivating Factors

\begin{tabular}{|c|c|c|c|c|c|}
\hline \multirow{2}{*}{ Model } & \multicolumn{2}{|c|}{$\begin{array}{l}\text { Unstandardised } \\
\text { Coefficients }\end{array}$} & \multirow{2}{*}{$\begin{array}{c}\text { Standardised } \\
\text { Coefficients } \\
\text { Beta }\end{array}$} & \multirow{2}{*}{$\mathrm{t}$} & \multirow{2}{*}{$\mathrm{p}$} \\
\hline & $\mathrm{B}$ & $\begin{array}{l}\text { Std. } \\
\text { Error }\end{array}$ & & & \\
\hline (Constant) & 3.370 & 1.226 & & 2.749 & .011 \\
\hline Gender & -.249 & .263 & -.211 & -.948 & .353 \\
\hline Marital status & -.004 & .180 & -.005 & -.020 & .984 \\
\hline Number of d. children & -.092 & .262 & -.087 & -.350 & .730 \\
\hline Number of $d$. adults & -.098 & .263 & -.099 & -.371 & .714 \\
\hline Qualifications & -.193 & .287 & -.179 & -.671 & .509 \\
\hline Monthly salary & -.151 & .190 & -.190 & -.793 & .436 \\
\hline Employing hospital & .101 & .190 & .135 & .532 & .600 \\
\hline Position & .055 & .100 & .132 & .552 & .586 \\
\hline $\begin{array}{l}\text { Number of working } \\
\text { hours }\end{array}$ & .543 & .388 & .290 & 1.402 & .174 \\
\hline $\begin{array}{l}\text { Duration of work in } \\
\text { hospital }\end{array}$ & -.061 & .141 & -.091 & -.433 & .669 \\
\hline Overall experience & .071 & .186 & .090 & .383 & .705 \\
\hline
\end{tabular}

The overall R square for this model was 17.6 per cent. Table 5.42 shows the model summary. 
Table 5.42

Model Summary

\begin{tabular}{ccccc}
\hline Model & $\mathrm{R}$ & $\mathrm{R}$ Square & Adjusted R Square & Std. Error of the Estimate \\
\hline 1 & .420 & .176 & -.217 & .55105 \\
\hline
\end{tabular}

Table 5.43

Predictors for Level of Satisfaction of the Third Age Group Reflecting Hygiene Factors

\begin{tabular}{|c|c|c|c|c|c|}
\hline \multirow[t]{2}{*}{ Model } & \multicolumn{2}{|c|}{$\begin{array}{l}\text { Unstandardised } \\
\text { Coefficients }\end{array}$} & \multirow{2}{*}{$\begin{array}{c}\text { Standardised } \\
\text { Coefficients } \\
\text { Beta }\end{array}$} & \multirow[t]{2}{*}{$\mathrm{t}$} & \multirow{2}{*}{$\mathrm{p}$} \\
\hline & $\mathrm{B}$ & Std. Error & & & \\
\hline (Constant) & 2.998 & 1.203 & & 2.493 & .021 \\
\hline Gender & -.168 & .258 & -.148 & -.652 & .521 \\
\hline Marital status & -.042 & .177 & -.055 & -.236 & .815 \\
\hline Number of d. children & -.138 & .257 & -.136 & -.537 & .597 \\
\hline Number of d. adults & .182 & .258 & .191 & .704 & .489 \\
\hline Qualifications & -.288 & .282 & -.278 & -1.022 & .318 \\
\hline Monthly salary & .141 & .187 & .184 & .756 & .458 \\
\hline Employing hospital & -.099 & .187 & -.137 & -.527 & .603 \\
\hline Position & -.047 & .098 & -.116 & -.473 & .641 \\
\hline $\begin{array}{l}\text { Number of working } \\
\text { hours }\end{array}$ & .383 & .380 & .213 & 1.009 & .324 \\
\hline $\begin{array}{l}\text { Duration of employment } \\
\text { in the hospital }\end{array}$ & -.061 & .138 & -.095 & -.445 & .661 \\
\hline Overall experience & .019 & .182 & .025 & .104 & .918 \\
\hline
\end{tabular}

The overall $\mathrm{R}$ square for this model was 18.3 per cent. Table 5.44 shows the model summary.

Table 5.44

Model Summary

\begin{tabular}{ccccc}
\hline Model & $\mathrm{R}$ & $\mathrm{R}$ Square & Adjusted R Square & Std. Error of the Estimate \\
\hline 1 & .428 & .183 & -.225 & .53264 \\
\hline
\end{tabular}




\section{Research Question 4: Factors that predict job satisfaction in each hospital.}

The last research question asked was what are the factors that predict job satisfaction among Saudi nurses in each of the hospitals? To answer this question, the relationship between the three general public hospitals and the independent factors (personal and job characteristics of Saudi nurses and level of job satisfaction) were considered. Demographic and personal characteristics included gender, age group, marital status, number of dependent children, number of dependent adults, qualifications and monthly salary. Job characteristics and practical experience included the employing hospital, position at the hospital, duration of work experience at the hospital, number of weekly working hours and overall experience.

\section{Hospital A in Jeddah.}

Linear regression analysis was run to test the prediction for Saudi nurses working at Hospital A and the independent factors identified to have a significant association with the level of satisfaction for motivation. The results of this linear regression revealed that the significant predictor for independent factors in this hospital and satisfaction with motivation was gender $(\mathrm{B}=-.347, \mathrm{p}=.003)$. The negative beta coefficients indicate a negative relationship between the predictor and the outcome; having a low score for gender (i.e., males) was predictive of higher nurses' motivation. Table 5.45 demonstrates the coefficient results for the linear regression analysis model. 
Table 5.45

Predictors for Level of Satisfaction at Hospital A in Jeddah Reflecting Motivating

Factors

\begin{tabular}{lccccc}
\hline \multicolumn{1}{c}{ Model } & \multicolumn{2}{c}{ Unstandardised } & Standardised & & \\
& $\mathrm{B}$ & Std. Error & Beta & & \\
& 3.437 & .388 & & 8.866 & .000 \\
\hline Gonstant) & -.347 &. $\mathbf{1 1 3}$ & $\mathbf{- . 3 1 0}$ & $\mathbf{- 3 . 0 8 8}$ & $\mathbf{. 0 0 3}$ \\
Age group & .106 & .126 & .140 & .845 & .400 \\
Marital status & -.056 & .115 & -.062 & -.486 & .628 \\
Number of d. children & .109 & .151 & .096 & .723 & .471 \\
Number of d. adults & -.131 & .110 & -.118 & -1.191 & .237 \\
Qualifications & .000 & .138 & .000 & -.001 & .999 \\
Monthly salary & .043 & .124 & .050 & .349 & .728 \\
Position & .025 & .060 & .047 & .416 & .678 \\
Number of working & -.083 & .135 & -.063 & -.621 & .536 \\
hours & & & & & \\
Duration of & & .106 & -.118 & -.845 & .400 \\
employment in hospital & -.090 & .127 & -.194 & -1.307 & .194 \\
Overall experience & -.165 & & &
\end{tabular}

The overall $\mathrm{R}$ square for this model was 13.7 per cent. Table 5.46 shows the model summary.

Table 5.46

Model Summary

\begin{tabular}{ccccc}
\hline Model & $\mathrm{R}$ & R Square & Adjusted R Square & Std. Error of the Estimate \\
\hline 1 & .370 & .137 & .034 & .54522 \\
\hline
\end{tabular}

A multiple linear regression analysis was run to test the prediction for Saudi nurses working at Hospital A and the independent factors identified to have a significant association with the level of satisfaction for hygiene. 
The results of this test showed that the significant predictor for independent factors in this hospital and satisfaction with hygiene was gender $(B=-.301, p=.006)$. The negative beta coefficients indicate a negative relationship between the predictor and the outcome; having a low score for gender (i.e., males) was predictive of higher nurses' hygiene. The results of the multiple linear regression analysis are summarised in Table 5.47.

Table 5.47

Predictors for Level of Satisfaction at Hospital A in Jeddah Reflecting Hygiene Factors

\begin{tabular}{lccccc}
\hline \multicolumn{1}{c}{ Model } & \multicolumn{2}{c}{ Unstandardised } & Standardised & & \\
& $\mathrm{B}$ & Std. Error & Beta & & $\mathrm{p}$ \\
\hline Constant) & 3.295 & .370 & & 8.908 & .000 \\
Gender & -.301 &. $\mathbf{1 0 7}$ & $\mathbf{- . 2 8 3}$ & $\mathbf{- 2 . 7 9 9}$ & $\mathbf{. 0 0 6}$ \\
Age group & .092 & .120 & .128 & .763 & .447 \\
Marital status & -.031 & .110 & -.037 & -.284 & .777 \\
Number of d. children & .157 & .144 & .146 & 1.090 & .279 \\
Number of d. adults & -.059 & .105 & -.056 & -.565 & .573 \\
Qualifications & -.011 & .132 & -.009 & -.085 & .933 \\
Monthly salary & .064 & .118 & .077 & .537 & .592 \\
Position & -.015 & .057 & -.030 & -.261 & .795 \\
Number of working & -.091 & .128 & -.073 & -.710 & .479 \\
hours & & & & & \\
Duration of employment & -.070 & .101 & -.097 & -.691 & .492 \\
in the hospital & & .121 & -.231 & -1.547 & .125 \\
Overall experience & -.187 & & & & \\
\hline
\end{tabular}

The overall $\mathrm{R}$ square for this model was 12.2 per cent. Table 5.48 shows the model summary. 
Table 5.48

Model Summary

\begin{tabular}{ccccc}
\hline Model & R & R Square & Adjusted R Square & Std. Error of the Estimate \\
\hline 1 & .349 & .122 & .017 & .52027 \\
\hline
\end{tabular}

Hospital B in Makkah.

A second multiple linear regression analysis was used to examine the prediction for independent factors identified to have a significant association with the level of satisfaction for motivation in Saudi nurses working at Hospital B. The results of the multiple linear regression indicated that the significant predictor for independent factors in this hospital and satisfaction with motivation was the number of dependent adults $(B=-.328, p=.017)$. The negative beta coefficients indicate a negative relationship between the predictor and the outcome; having fewer dependent adults was predictive of higher nurses' motivation. Table 5.49 summarises the coefficient results for the multiple linear regression analysis models. 
Table 5.49

Predictors for Level of Satisfaction at Hospital B in Makkah Reflecting Motivating

Factors

\begin{tabular}{|c|c|c|c|c|c|}
\hline \multirow[t]{2}{*}{ Model } & \multicolumn{2}{|c|}{$\begin{array}{l}\text { Unstandardised } \\
\text { Coefficients }\end{array}$} & \multirow{2}{*}{$\begin{array}{c}\text { Standardised } \\
\text { Coefficients } \\
\text { Beta }\end{array}$} & \multirow[t]{2}{*}{$\mathrm{t}$} & \multirow[t]{2}{*}{$\mathrm{p}$} \\
\hline & B & Std. Error & & & \\
\hline (Constant) & 2.778 & .429 & & 6.469 & .000 \\
\hline Gender & .035 & .131 & .031 & .270 & .788 \\
\hline Age group & .162 & .135 & .196 & 1.201 & .234 \\
\hline Marital status & .075 & .143 & .078 & .527 & .600 \\
\hline Number of d. Children & -.010 & .161 & -.009 & -.059 & .953 \\
\hline Number of d. adults & -.328 & .135 & -.298 & -2.438 & .017 \\
\hline Qualifications & -.230 & .151 & -.184 & -1.520 & .133 \\
\hline Monthly salary & -.084 & .103 & -.134 & -.808 & .422 \\
\hline Position & .000 & .063 & .000 & .002 & .999 \\
\hline Number of working hours & .167 & .194 & .096 & .861 & .392 \\
\hline $\begin{array}{l}\text { Duration of employment in } \\
\text { the hospital }\end{array}$ & -.097 & .113 & -.154 & -.859 & .393 \\
\hline Overall experience & .135 & .117 & .202 & 1.154 & .253 \\
\hline
\end{tabular}

The overall $\mathrm{R}$ square for this model was 20.3 per cent. Table 5.50 shows the model summary.

Table 5.50

Model Summary

\begin{tabular}{ccccc}
\hline Model & $\mathrm{R}$ & R Square & Adjusted R Square & Std. Error of the Estimate \\
\hline 1 & .451 & .203 & .078 & .50090 \\
\hline
\end{tabular}

A multiple linear regression analysis was used to examine the prediction for female and male Saudi nurses working at Hospital B and the independent factors that were identified to have a significant association with the level of satisfaction for hygiene. The results of the multiple linear regression examination showed that the 
significant predictor for independent factors in this hospital and satisfaction with hygiene was qualifications $(B=-.369, \mathrm{p}=.034)$. The negative beta coefficients indicate a negative relationship between the predictor and the outcome; having fewer qualifications is predictive of higher nurses' hygiene. The results of the multiple linear regression analysis are summarised in Table 5.51.

Table 5.51

Predictors for Level of Satisfaction at Hospital B in Makkah Reflecting Hygiene Factors

\begin{tabular}{|c|c|c|c|c|c|}
\hline \multirow[t]{2}{*}{ Model } & \multicolumn{2}{|c|}{$\begin{array}{l}\text { Unstandardised } \\
\text { Coefficients }\end{array}$} & \multirow{2}{*}{$\begin{array}{c}\text { Standardised } \\
\text { Coefficients } \\
\text { Beta }\end{array}$} & \multirow[t]{2}{*}{$\mathrm{t}$} & \multirow[t]{2}{*}{$\mathrm{p}$} \\
\hline & $\mathrm{B}$ & Std. Error & & & \\
\hline (Constant) & 2.937 & .480 & & 6.114 & .000 \\
\hline Gender & .174 & .147 & .151 & 1.184 & .241 \\
\hline Age group & .056 & .150 & .067 & .369 & .713 \\
\hline Marital status & .075 & .160 & .077 & .468 & .642 \\
\hline Number of d. children & .033 & .180 & .031 & .183 & .855 \\
\hline Number of d. adults & -.178 & .151 & -.161 & -1.180 & .243 \\
\hline Qualifications & -.369 & .169 & -.293 & -2.179 & .034 \\
\hline Monthly salary & -.111 & .116 & -.177 & -.957 & .343 \\
\hline Position & .017 & .071 & .031 & .237 & .814 \\
\hline Number of working hours & -.229 & .216 & -.132 & -1.056 & .296 \\
\hline $\begin{array}{l}\text { Duration of employment in } \\
\text { the hospital }\end{array}$ & -.089 & .126 & -.142 & -.708 & .482 \\
\hline Overall experience & .252 & .130 & .377 & 1.933 & .058 \\
\hline
\end{tabular}

The overall R square for this model was 19.4 per cent. Table 5.52 shows the model summary. 
Table 5.52

Model Summary

\begin{tabular}{lllll}
\hline Model & $\mathrm{R}$ & R Square & Adjusted R Square & Std. Error of the Estimate \\
\hline 1 & .441 & .194 & .039 & .51331 \\
\hline
\end{tabular}

\section{Hospital C in Taif.}

Data analysis for Hospital $\mathrm{C}$ was tested through bivariate correlations between each of the independent and dependent variables, including motivation and hygiene. The independent variables were gender, age group, marital status, number of dependent children, number of dependent adults, qualifications, monthly salary, position at the hospital, duration of employment at the hospital, number of weekly working hours and overall experience. The correlations between these variables for Hospital C were not significant. Given the result of the correlation test, a multiple linear regression analysis was not conducted to assess the prediction for independent factors and Saudi nurses working at Hospital $\mathrm{C}$ with the level of satisfaction for motivation and hygiene. Table 5.53 summarises the correlation results for this hospital. 
Table 5.53

Correlation between the Independent Variables for Saudi Nurses Working at Hospital C Reflecting Motivating and Hygiene Factors

\begin{tabular}{|c|c|c|c|}
\hline \multicolumn{2}{|c|}{ Correlations } & Motivation & Hygiene \\
\hline \multirow{3}{*}{ Gender } & Pearson Correlation & -.121 & .230 \\
\hline & Sig. (2-tailed) & .396 & .139 \\
\hline & $\mathrm{N}$ & 51 & 43 \\
\hline \multirow{3}{*}{ Age group } & Pearson Correlation & .199 & .084 \\
\hline & Sig. (2-tailed) & .161 & .591 \\
\hline & $\mathrm{N}$ & 51 & 43 \\
\hline \multirow{3}{*}{ Marital status } & Pearson Correlation & -.022 & .069 \\
\hline & Sig. (2-tailed) & .879 & .660 \\
\hline & $\mathrm{N}$ & 51 & 43 \\
\hline \multirow{3}{*}{$\begin{array}{l}\text { Number of } \\
\text { dependent children }\end{array}$} & Pearson Correlation & .001 & -.100 \\
\hline & Sig. (2-tailed) & .993 & .523 \\
\hline & $\mathrm{N}$ & 51 & 43 \\
\hline \multirow{3}{*}{$\begin{array}{l}\text { Number of } \\
\text { dependent adults }\end{array}$} & Pearson Correlation & -.082 & -.077 \\
\hline & Sig. (2-tailed) & .569 & .622 \\
\hline & $\mathrm{N}$ & 51 & 43 \\
\hline \multirow{3}{*}{ Qualifications } & Pearson Correlation & -.027 & .084 \\
\hline & Sig. (2-tailed) & .852 & .593 \\
\hline & $\mathrm{N}$ & 51 & 43 \\
\hline \multirow{3}{*}{ Monthly salary } & Pearson Correlation & .087 & .103 \\
\hline & Sig. (2-tailed) & .542 & .513 \\
\hline & $\mathrm{N}$ & 51 & 43 \\
\hline \multirow{3}{*}{ Position } & Pearson Correlation & .194 & .081 \\
\hline & Sig. (2-tailed) & .173 & .604 \\
\hline & $\mathrm{N}$ & 51 & 43 \\
\hline \multirow{3}{*}{$\begin{array}{l}\text { Number of working } \\
\text { hours }\end{array}$} & Pearson Correlation & $\mathrm{a}$ & $\mathrm{a}$ \\
\hline & Sig. (2-tailed) & & \\
\hline & $\mathrm{N}$ & 51 & 43 \\
\hline \multirow{3}{*}{$\begin{array}{l}\text { Duration of } \\
\text { employment in the } \\
\text { hospital }\end{array}$} & Pearson Correlation & -.097 & -.010 \\
\hline & Sig. (2-tailed) & .500 & .949 \\
\hline & $\mathrm{N}$ & 51 & 43 \\
\hline \multirow{3}{*}{ Overall experience } & Pearson Correlation & .035 & -.035 \\
\hline & Sig. (2-tailed) & .805 & .824 \\
\hline & $\mathrm{N}$ & 51 & 43 \\
\hline
\end{tabular}




\section{Chapter Summary}

This chapter presented the statistical descriptive and inferential results of a study concerning the job satisfaction of Saudi nurses working in three general public hospitals in Saudi Arabia. The independent variables in this study were gender, age, marital status, number of dependent children, number of dependent adults, qualifications, salary, hospital, position, number of weekly working hours, duration of employment at the hospital and overall experience. The dependent factor used for this study was nurse job satisfaction (motivation and hygiene).

This analysis section was divided into two main parts: the first part presented the descriptive statistics (such as measures of frequency, means and standard deviations for each item of the questionnaire and the overall satisfaction scores of the subjects). The second part of the analysis included inferential statistics, whereby ANOVA and t-tests were utilised to identify differences in job satisfaction and the motivation and hygiene factors among participants. Multiple linear regression analysis was also utilised to identify the highest predictor variables that affect participants' level of job satisfaction. The results indicated that the mean satisfaction scores in relation to motivating factors were significantly higher among male nurses $(M=2.71)$ than female nurses $(p<0.05)$. This was also the case for nurses who do not have dependent adults at home $(\mathrm{M}=2.69)$ compared to nurses who have dependent adults $(\mathrm{p}<0.05)$. Further, nurses who had worked in the hospitals for less than 5 years were significantly more satisfied with the motivating factors than nurses who had worked for $5-10$ years $(\mathrm{p}=0.023)$. Nurses who had overall experience of less than 4 years $(\mathrm{p}=0.024)$ or more than 10 years $(\mathrm{p}=0.005)$ were significantly more satisfied with the motivating factors. However, nurses who had an overall experience of more than 10 years $(\mathrm{p}=0.004)$ or less than 4 years $(\mathrm{p}=0.016)$ were significantly more satisfied with the hygiene factors. A multiple linear regression 
analysis showed that the significant predictors for satisfaction with motivation were gender $(B=-.170, p=.017)$ and number of dependent adults at home $(B=-.190, p=.008)$.

A multiple linear regression analysis was run to assess the prediction for satisfaction with motivation factors and gender. The results showed that the significant predictor was being female, and that for satisfaction with motivation was the number of dependent adults $(B=-.185, p=.049)$. However, there is no significant predictor for females and job satisfaction with hygiene. Further, the results revealed that the significant predictors for male satisfaction with motivation were number of dependent children $(B=-.366, p=.012)$, monthly salary $(B=.327, p=.008)$, position $(B=.129$, $\mathrm{p}=.016)$ and overall experience $(\mathrm{B}=-.291, \mathrm{p}=.035)$. In addition, male nurses with dependent children $(\mathrm{B}=-.466, \mathrm{p}=.001)$, monthly salary $(\mathrm{B}=.341, \mathrm{p}=.004)$ and the employing hospital $(\mathrm{B}=-.167, \mathrm{p}=.009)$ were significantly more satisfied with the hygiene factors.

Multiple linear regression analysis was conducted to measure the prediction for Saudi nurses' age group and independent factors. It was found that the prediction for the first age group and independent factors was gender $(B=-.346, p=.021)$ and number of dependent adults $(B=-.293, p=.049)$ contributed substantially to job satisfaction with motivation. Gender $(\mathrm{B}=-.328, \mathrm{p}=.024)$ and qualifications $(\mathrm{B}=.596, \mathrm{p}=.035)$ contributed substantially to job satisfaction with hygiene. After analysis of the independent factors shown to have a significant association with the level of satisfaction for motivation for second age group of Saudi nurses it was found that position $(\mathrm{B}=.081, \mathrm{p}=.039)$ and duration of employment in the hospital $(B=-.216, p=.008)$ were substantial contributors. The number of working hours $(B=-.278, \mathrm{p}=.040)$ contributed substantially for hygiene. In the third age group of Saudi nurses analysis of the independent factors identified to 
have a significant association with the level of satisfaction regarding motivation and hygiene revealed significant predictors for satisfaction for both motivation and hygiene.

The results of a multiple linear regression analysis found that the significant predictor for Saudi nurses in Hospital A concerning satisfaction with motivation was gender $(B=-.347, p=.003)$, and gender $(B=-.301, p=.006)$ was also significant when hygiene factors were analysed. Further, the results for nurses working at Hospital B and satisfaction with motivation was the number of dependent adults $(B=-.328, p=.017)$, and of the hygiene factors qualifications was significant $(B=-.369, p=.034)$. Hospital $C$ was tested through bivariate correlations and the results showed that there were no significant correlations between the variables.

Chapter 6 will present the findings from semi-structured interviews with Saudi nurses. 


\section{Chapter 6: Qualitative Data Findings}

\section{Introduction}

This chapter reports on the findings of the qualitative data arising from the semistructured interviews with 17 Saudi nurses. The purpose of the semi-structured interviews was to gain a deeper understanding concerning the concept of job satisfaction of Saudi nurses working in public hospitals in Makkah region. Qualitative data arising from interviews helps researchers gather sufficient information regarding the subject, and interviews allow the interviewees to explain their views, feelings and thoughts freely, as well as reflect on the words and sentences they use to describe a phenomenon (Gillham, 2005; Tashakkori \& Teddlie, 1998). According to Creswell (2008), the interview can 'provide useful information when you cannot directly observe participants and they permit participants to describe detailed personal information' (p. 226). This chapter has six main sections arising from the six open-ended research questions that were asked of the interviewees. These questions were:

1. Who influenced your decision to study nursing?

2. What factors motivate nurses to continue working as a nurse?

3. What are the reasons that would stop you from working as a nurse?

4. What do you perceive your future goals to be in your nursing career?

5. What factors do you perceive will improve the public image of nurses in Saudi Arabia?

6. What suggestions do you have to increase the recruitment and retention of Saudi Arabian nurses?

These questions arose from the factors that were postulated to influence the levels of job satisfaction of Saudi nurses working in three main public hospitals in the Makkah region (Jeddah, Makkah and Taif). This chapter explores the themes that 
emerged from the data and will provide deep and meaningful insights into the 17 interviewees' perceptions of the factors that affect Saudi nurses' job satisfaction. NVivo 9 qualitative analysis software was used to assist with the coding, store all data and the development of themes. The demographic characteristics of the participants will be presented first.

\section{Demographic and Personal Characteristics}

Seventeen Saudi nurses, nine females and eight males, volunteered and were interviewed. The nurses came from the three public hospitals in the Makkah region. All interviewees were registered nurses and had previously completed the questionnaire to collect the quantitative data for this study. The interviewees had various qualifications; the majority had a Diploma of Nursing and only four had higher qualifications, such as a BSN or a postgraduate degree in nursing science. They all had different lengths of experience in nursing. Six of the participants had more than 10 years of experience, while five of them had less than 5 years of experience. The duration each interview was up to 35 minutes. Table 6.1 provides the demographic information for the 17 interviewees, including their qualifications, gender, experience and marital status. 
Table 6.1

Demographics Information for the Interviewees

\begin{tabular}{lllcl}
\hline Interviewee & Qualifications & Gender & $\begin{array}{c}\text { Experience } \\
\text { (years) }\end{array}$ & Marital status \\
\hline Nurse 1 & Diploma of Nursing & male & 5 & single \\
Nurse 2 & Diploma of Nursing & female & 13 & married \\
Nurse 3 & Diploma of Nursing & female & 35 & married \\
Nurse 4 & Diploma of Nursing & female & 6 & single \\
Nurse 5 & Diploma of Nursing & male & 7 & married \\
Nurse 6 & Diploma of Nursing & male & 3 & single \\
Nurse 7 & Bachelor of Nursing & male & 7 & married \\
Nurse 8 & Diploma of Nursing & female & 7 & married \\
Nurse 9 & Diploma of Nursing & female & 1 & single \\
Nurse 10 & Diploma of Nursing & male & 1 & single \\
Nurse 11 & Master of Nursing & male & 12 & single \\
Nurse 12 & Diploma of Nursing & female & 9 & married \\
Nurse 13 & Diploma of Nursing & female & 4 & married \\
Nurse 14 & Bachelor of Nursing & male & 20 & married \\
Nurse 15 & Diploma of Nursing & female & 10 & married \\
Nurse 16 & Diploma of Nursing & female & 2 & single \\
Nurse 17 & Master of Nursing & male & 10 & married \\
\hline
\end{tabular}

\section{Interview Findings}

The qualitative data analysis sought to identify the main themes and sub-themes regarding the factors that affect the job satisfaction of Saudi nurses working in the three public hospitals in the Makkah region. All of the interview participants preferred to be interviewed in the Arabic language and further agreed to the use of two digital audio recorders. The interviews were transcribed on the day of each interview and then later translated into the English language by a professional translation office in Melbourne. Table 6.2 summarises the questions, rationale for the questions, the six themes and the sub-themes that were extracted from the data. 
Table 6.2

Overview of Job Satisfaction by the Participants in Face-to-Face Interviews

\begin{tabular}{|c|c|c|c|}
\hline $\begin{array}{l}\text { Interview } \\
\text { Question }\end{array}$ & Rationale & Themes & Sub-Themes \\
\hline $\begin{array}{l}\text { Who } \\
\text { influenced } \\
\text { your decision } \\
\text { to study } \\
\text { nursing? }\end{array}$ & $\begin{array}{l}\text { Investigating who } \\
\text { encouraged and } \\
\text { affected own } \\
\text { decision to become } \\
\text { a nurse }\end{array}$ & $\begin{array}{l}\text { Influences on the } \\
\text { decision to study } \\
\text { nursing }\end{array}$ & $\begin{array}{l}\text { Family } \\
\text { Friends } \\
\text { Personal decision }\end{array}$ \\
\hline $\begin{array}{l}\text { What factors } \\
\text { motivate } \\
\text { nurses to } \\
\text { continue } \\
\text { working as a } \\
\text { nurse? }\end{array}$ & $\begin{array}{l}\text { Investigating } \\
\text { factors motivating } \\
\text { the nurses to stay in } \\
\text { the profession }\end{array}$ & $\begin{array}{l}\text { Factors that } \\
\text { motivate nurses to } \\
\text { continue working } \\
\text { as a nurse }\end{array}$ & $\begin{array}{ll}\checkmark & \text { Religious factors } \\
\checkmark & \text { Moral factors } \\
\checkmark & \text { Financial factors } \\
\checkmark & \text { Social and community } \\
\text { service factors }\end{array}$ \\
\hline $\begin{array}{l}\text { What are the } \\
\text { reasons that } \\
\text { would stop } \\
\text { you from } \\
\text { working as a } \\
\text { nurse? }\end{array}$ & $\begin{array}{l}\text { Investigating the } \\
\text { reasons that make } \\
\text { Saudi nurses leave } \\
\text { the profession }\end{array}$ & $\begin{array}{l}\text { Reasons to } \\
\text { potentially cease } \\
\text { nursing }\end{array}$ & \begin{tabular}{ll}
$\checkmark$ & Society’s view \\
$\checkmark$ & Recognition \\
$\checkmark$ & Leadership style \\
$\checkmark$ & Shortage of nurses \\
\multicolumn{2}{l}{ with long working hours }
\end{tabular} \\
\hline $\begin{array}{l}\text { What do you } \\
\text { perceive your } \\
\text { future goals } \\
\text { to be in your } \\
\text { nursing } \\
\text { career? }\end{array}$ & $\begin{array}{l}\text { Identifying the } \\
\text { future goals of } \\
\text { nurses to be in the } \\
\text { profession }\end{array}$ & $\begin{array}{l}\text { Future goals in } \\
\text { nursing career }\end{array}$ & $\begin{array}{l}\checkmark \quad \text { Continuance of } \\
\text { nursing education } \\
\checkmark \quad \text { Improving the } \\
\text { community's view of nurses } \\
\checkmark \quad \text { Saudization }\end{array}$ \\
\hline $\begin{array}{l}\text { What factors } \\
\text { do you } \\
\text { perceive will } \\
\text { improve the } \\
\text { public image } \\
\text { of nurses in } \\
\text { Saudi } \\
\text { Arabia? }\end{array}$ & $\begin{array}{l}\text { Identifying factors } \\
\text { that could improve } \\
\text { the view of nursing } \\
\text { in Saudi society }\end{array}$ & $\begin{array}{l}\text { Factors perceived } \\
\text { to improve the } \\
\text { public image of } \\
\text { nurses in Saudi } \\
\text { Arabia }\end{array}$ & $\begin{array}{l}\checkmark \quad \text { Educating the } \\
\text { community } \\
\checkmark \quad \text { Increasing the number } \\
\text { of Saudi nurses }\end{array}$ \\
\hline $\begin{array}{l}\text { What } \\
\text { suggestions } \\
\text { do you have } \\
\text { to increase } \\
\text { recruitment } \\
\text { and retention } \\
\text { of Saudi } \\
\text { Arabian } \\
\text { nurses? }\end{array}$ & $\begin{array}{l}\text { Exploring } \\
\text { suggestions to } \\
\text { maintain and } \\
\text { increase Saudi } \\
\text { nurses working in } \\
\text { public hospitals }\end{array}$ & $\begin{array}{l}\text { Suggestions to } \\
\text { increase } \\
\text { recruitment and } \\
\text { retention of Saudi } \\
\text { Arabian nurses }\end{array}$ & $\begin{array}{l}\checkmark \quad \text { Developing nursing } \\
\text { colleges } \\
\checkmark \quad \text { Provide rewards } \\
\checkmark \quad \text { Improving the hospital } \\
\text { environment }\end{array}$ \\
\hline
\end{tabular}

The following six themes and sub-themes are provided as the findings of the qualitative interviews: 


\section{Influences on the decision to study nursing.}

Participants were asked who influenced their decision to study nursing. Many reasons influenced their career choices; Saudi nurses were encouraged to study nursing by family and friends, and also by their own experience and positive beliefs about providing care. The interviewees in this study stated that family and friends influenced their decision to study nursing; however, many of them made a purely personal decision to study nursing.

\section{Role of the family in making educational decisions.}

Family plays an important role in influencing and encouraging young adults to study nursing. This is particularly the case if the family has had good experiences with the nursing profession and the healthcare environment, or if another family member works in the healthcare system as a nurse or in another healthcare field, such as medical doctors, pharmacists and health workers. Families may have strong motives to encourage their young people to study nursing. More than half of the interviewees spoke of their family's influence in their decision. For example, Nurses 6 and 9, both of whom have Diploma in Nursing, said they found strong support and encouragement from family members because they also worked as nurses. They said: 'Those who influenced my decision to study nursing were my family, particularly my uncle and aunt who were working in the nursing field' (Nurse 6); and 'Influence came from my aunt who worked as a nurse, I liked the way she worked and it was she who encouraged me to study nursing' (Nurse 9).

Nurse 12, who has 9 years of experience in nursing and who holds a Diploma, says she was encouraged by her sister, who works as a nurse, and also by her father to study nursing: 'My older sister is a nurse. She encouraged me to work as a nurse. However, my father was my main supporter in studying nursing' (Nurse 12). 
Nurse 13 has 4 years of experience in nursing and holds a Diploma in Nursing. Her uncles, who are medical doctors, supported her to study nursing and then work as a nurse. Moreover, she gained much encouragement to study nursing from her father. She stated: 'Influence came from myself and my family. I found encouragement from my father, as well as there are doctors in the family, my uncles, who encouraged me a lot to study nursing' (Nurse 13).

Nurses 2, 8 and 16 all have different lengths of experience in nursing and all have Diploma in Nursing. All of these participants were encouraged by family members who influenced their decision to study nursing and then work as nurses. Further, Nurse 8 added that she could find a job very quickly, and that this was due to the shortage of Saudi nurses in public hospitals. For example, Nurses 2, 8 and 16 mentioned: 'What influenced my decision to study nursing came from my family brothers and particularly my parents...' (Nurse 2); 'Influence came from my father and family, as well as the availability of nursing positions which helps nurses to be employed faster' (Nurse 8) and 'Influence came from my family, particularly my sister and mother' (Nurse 16).

Other participants, Nurses 10 and 15, confirmed this, saying: 'Influence came from my family and particularly my brothers' (Nurse 10), and 'Influence for my decision to study nursing came from my family, particularly my father. Through them, I found strong encouragement and support to work as a nurse' (Nurse 15).

\section{Role of friends in making educational decisions.}

Participants mentioned that their friends greatly influenced their decisions to study nursing and played a significant role in encouragement, especially if the friends worked as nurses or as other health professionals. For example, Nurse 3 has 35 years of experience and holds a Diploma in Nursing. She said: 
Influence came from my friend who works as a nurse. This happened after she nursed me at home, using devices such as a sphygmomanometer and a thermometer and she had a very nice way with me. After that, I wished to have her career and follow her style in dealing with patients (Nurse 3).

Other participants who were encouraged by friends to study nursing were Nurses 5, 17 and 1. They said: '[The] influence came from myself, I could not find other options, but as I studied, I loved the job. Further, I had great encouragement from my friends in the department to continue my study' (Nurse 5); 'Influence came from my friend who works as a nurse with long years of experience, as well as the availability of nursing positions which helps nurses to be employed faster' (Nurses 17) and '[My] influence came from my colleagues who studied nursing' (Nurse 1).

\section{Personal educational decision-making.}

Some participants said that nobody influenced their decisions to study nursing and that they attended nursing school as a result of their own convictions and their love of the nursing profession. For example, Nurse 11, who has a Master's degree in nursing said:

My decision came after my admission into hospital and what I saw of the nursing job during that time. It was then that I liked the nurses' performance; thus, my love to this profession began first, then I wanted to study in this field (Nurse 11).

Nurses 4 and 7 both made personal decisions to study nursing without the influence of others. Nurse 4 has a Diploma in Nursing. Nurse 7 has a Bachelor's Degree in nursing. They made similar comments regarding their influences: 'No one influenced my decision to study nursing. I made my decision with full conviction. I was looking for a 
nice career and I chose nursing' (Nurse 4) and 'No one influenced my decision. It was the lack of other options' (Nurse 7).

Nurse 14 made a personal decision to study nursing and he attended nursing school after he found an announcement in the newspaper from a nursing school. He stated: 'No one influenced my decision. I simply found an advertisement in the newspaper and applied at the institute to study nursing' (Nurse 14).

\section{Factors that motivate nurses to continue working as nurses.}

Interviewees were asked to consider the factors that motivate nurses to continue working in nursing. Participants indicated that there are many factors that motivate Saudi nurses to continue work in the sector. The sub-themes that emerged from the interviewees were related to factors such as religious motives, moral motives, financial incentives and social and community motives.

\section{Religious factors.}

All participants in this study were Muslim, and they believe that the supplication 'Dua' from patients to God (Allah) is the praise that they find most important. For example, Nurses 1, 4 and 6 all have more than 3 years of experience. These nurses commented, 'What motivates me to continue working as a nurse is the prayers and praise that I receive from the patients' (Nurse 1); 'What encourages and motivates me to continue working in the nursing sector is the prayers and praise that I receive from the patients' (Nurse 4) and 'What encourages me to continue working as a nurse is the prayers and praise that I receive from the patients and their families' (Nurse 6). Other interviewees thought that they were obtaining rewards from God (Allah) for helping and caring for sick people. Nurses 5 and 15, who have Diploma in Nursing, made similar comments on this subject: 'What motivates me to continue working as a nurse is getting God's (Allah's) reward' (Nurse 5) and 'What motivates me to continue working as a nurse and 
the most important is Allah's reward...Helping the sick and so the internal satisfaction all makes me happy and satisfied' (Nurse 15).

Nurse 16 wished to follow in the footsteps of the lady companions of the Prophet Mohammed (peace be upon him) and his friends, who helped and cared for the sick people during the Islamic war of the fourteenth century, such as Rufaida AlAsalmiya. Nurse 16 has 2 years of experience. She said:

What motivates me to continue working as a nurse are religious motives, like following the example of the great lady companions of the Prophet of Allah during Islamic war with the Prophet Mohammed and his friends, my love of helping people, particularly the sick, and confidence and knowledge (Nurse 16).

\section{Moral and financial factors.}

Moral and financial incentives are important motivators for Saudi nurses to continue working in nursing. Moral motivation comes from various people, including family, parents, friends, patients and colleagues. It also comes from nurses feeling happy and comfortable when they are helping patients and providing nursing services to them. For example, Nurses 3, 6, 8, 9 and 15 all have a Diploma in Nursing; Nurses 8 and 9 said: 'What motivates me to continue working as a nurse is the moral motive from family, nursing being enjoyable, feeling comfortable' (Nurse 8), and 'What motivates me to continue working as a nurse is moral and comes from my family and the work environment' (Nurse 9).

Nurse 3, who has 35 years in the nursing sector, reported gaining strong support and moral motivation from her father and friends to continue working as a nurse. She stated:

My motives are moral and come from my father and my work colleagues. My father used to drive me to my work, an area 80 kilometres away and 
approximately two hours from home, and then wait for me, almost 12 hours, until I finished my work to drive me back home. Also, support from the work environment (Nurse 3).

Nurse 6 received encouragement and moral motivation from patients and their families and relatives. He said: 'What encourages me is the sense of gratitude and appreciation I receive from the patients and their relatives and the self-satisfaction I get when helping patients' (Nurse 6).

Financial motivation is vital for many people and it has become a good incentive to keep nurses working in the profession. Generally, the income for Saudi nurses who work under the MoH umbrella is good, and is satisfactory for most nurses. For instance, Nurses 4, 11, and 17, who have differing qualifications, said: 'What motivates me to continue working as a nurse is the good financial incentive' (Nurses 11 and 17) and '...Income is good' (Nurse 4). Nurse 5 confirmed this point of view about the financial incentives by saying, 'What motivates me to continue working as a nurse is..., Further, the financial incentive is good and satisfactory' (Nurse 5). However, not all interviewees were happy with their pay and entitlements. Nurse 6 mentioned that the financial motivation is not sufficient for encouragement. He said, 'What encourages me is the sense of gratitude; however, the financial motivation itself does not encourage us in this profession' (Nurse 6).

\section{Social and community service factors.}

Participants were also motivated by social and community service factors. They enjoyed being able to provide a humanitarian service and they tried to improve how Saudi society in general views the nursing profession. Further, they wished to decrease the number of expatriate nurses and replace them with Saudi nurses whose language, culture and religion are similar to those of the patients. Despite Nurses 2, 5, 9, 11, 13 
and 14 having different qualification levels and different lengths of experience in the hospital system, they all agreed, stating: 'What motivates me to continue working as a nurse is educating the society and delivering a message that Saudi nurses are able to care for patients' (Nurse 2); 'What motivates me to continue working as a nurse is...the self-fulfilment, the caring for the sick. It's being a community service...Further, nursing is considered a rare speciality in Saudi Arabia, because of the shortage of Saudis working in this area' (Nurse 11); 'Nursing is a humanitarian and enjoyable profession. Society's view of nursing has changed. Nursing has proven that it is an honourable and enjoyable profession, not as the society visualises it, particularly to the Saudi girl' (Nurse 13) and 'What motivates me to continue working as a nurse is...humanitarian service, the need of the country and elevation of nursing as the profession...' (Nurse 14).

Other nurses stated that they were motivated to study nursing in order to replace the foreign nurses in Saudi Arabia: 'What motivates me to continue working as a nurse is a humanitarian service that cares for the community. Add to that the benefit of replacement of the expatriate nurses by Saudi nurses' (Nurse 5), and 'Motives come from...helping the patients and their acceptance of us as Saudis. Saudi patients need Saudi nurses rather than foreign nurses to care for them; nurses who share their beliefs, language, culture and religion. This was a great incentive to me to continue working in the nursing profession' (Nurse 9).

\section{Reasons to potentially cease nursing.}

Participants were asked to state the reasons that would stop them from working as a nurse. The interviewees gave many reasons, and their responses were categorised into four sub-themes: society's view of nurses, lack of recognition, leadership style and shortage of nurses, with the resulting long working hours. 


\section{Society's view of nurses.}

The public view of nurses and the profession of nursing plays a vital role in the shortage of Saudi nurses and this was reflected in the overall job satisfaction of Saudi nurses. In Saudi society, the profession of nursing has a poor image and is not considered respectable. Further, society's view contributes to the shortage of both female and male enrolments in nursing schools and universities. For instance, Nurse 12 reported that society's view was one of the reasons that influenced her to almost stop working as a nurse. Moreover, her parents were worried about her status as an unmarried woman working in a mixed-gender profession because the Saudi Arabian culture does not support the notion of Saudi women working with men in mixed environments. She said:

The reasons are...society's view of nursing almost made me leave the profession. For example, my aunt completely ignores me and broke away from me, because I am a nurse. And, my parents were greatly concerned about me being not married and working in a mixed-gender environment (Nurse 12).

Nurse 11 agreed, but said it was more than just society's views: 'My reasons are related to the officials view from policymakers, work employees and some managers from other department rather than the society's one' (Nurse 11).

Nurse 3 mentioned the image of nursing in Saudi society as a reason and suggested how this can be improved through the excellent work of Saudi nurses. She said:

A nurse who is distinguished in her work can improve the nursing image in a community which accepts the distinguished person in general. And, if she has joined the profession out of love and conviction, she will definitely be able to improve the image. However, what happens now is that people do not find 
available job opportunities except in nursing, so they join the profession without conviction - the thing that later reflects negatively on their performance, thus worsening the nursing image. Personal interviews must be held for the prospective students of any nursing educational institute, choosing only the fully convinced lovers of the profession (Nurse 3).

Nurse 7 thought that nursing was mostly seen as a female job and that the view of others is mostly negative:

Reasons are it is a woman's job more than a man's; the negative view of the society towards nurses...perception of other departments' employees of you as a male nurse...When someone asks me about my job, I do not say, 'I work as a male nurse!', but I say, 'I work in health!' I feel ashamed to say that I am a nurse, because of the negative view of the society. It often happened when I said that I was a nurse, that I got a strange look, non-appreciation and a change in the way others treated me. The concept of society about nursing is that it is just a job that you get by experience, not a science or profession. I regret joining this profession because of the way the society views it, the way the hospital treat us and the nature of work unfortunately, I did not know that about nursing beforehand. All these reasons make me think of leaving the profession (Nurse 7).

Nurse1 stated that the general public's negative view concerns him. He said: 'The reasons are: the negative view of society to nurses; the general idea that foreign nurses are better than the Saudi nurses' (Nurse 1).

\section{Lack of recognition.}

Lack of recognition is one of the many reasons that push Saudi nurses out of the profession. It is important to keep nurses working and encourage them to continue 
working in the nursing sector. Nurses 1, 4 and 7 reported that lack of recognition and encouragement were issues for them. For example, Nurse 7 said: 'The reasons are...lack of support and encouragement for Saudi nurses in the work environment; lack of appreciation and commending' (Nurses 7). Nurse 3 also mentioned that lack of recognition is one of the important reasons that lead to the failure of the nursing role's development. She argued: 'Nurses suffer also from material, moral and administrative injustice and lack of appreciation, which is the most important reason that leads to failure of profession development' (Nurse 3).

Nurse 5 reported that there are many reasons that nurses leave the profession and that lack of recognition is one of them: 'There is no reason that makes me leave the profession. However, there are reasons that make me hate it. Among such reasons are...now, they employ incompetent nurses. Let alone not offering encouraging moral or material incentives' (Nurse 5).

\section{Leadership style.}

Interviewees indicated that the administration style and treatment of nurses are at the top of the list of reasons that would make them leave nursing and try to find other employment. For example, Nurse 1 argued: 'The reasons are...not feeling comfortable in the work environment - that's why I always think of leaving work or changing department or work environment' (Nurse 1).

Nurse 3 said that the nurses in Saudi Arabia do not have as much independence as personnel in other departments, such as pharmacy and laboratories, and that the nursing administrators are mostly non-nurses. Other reasons she mentioned were working longer hours and diminished monetary bonuses for good performance. She revealed: 
My reasons are related to nursing not having the administrative independence enjoyed by other departments such as the pharmacy and laboratory department, which advocate for their own rights and support. On the contrary, nursing falls under the administration of other non-nursing departments - meaning that nursing is less important than other departments are. And nurses' rights are not that clear, though they have more responsibilities and work longer hours. For example, look at the financial advantages enjoyed by other departments, where they get allowances up to 40-70 per cent, while nurses get only 20 per cent (Nurse 3).

Nurse 17 confirmed that nurses in Saudi Arabia do not have much independence and that the administrators of nurses are mostly non-nurses. He said: 'My reasons are related to nursing does not have administrative independence and nurses' rights are not that clear the nursing administration is more centralisation of order and non-cooperation with the staff' (Nurse 17).

Nurses 5, 6, 7, 15 and 16 confirmed that nursing management communication and management style is one of the many reasons that could stop them from working as nurses; in particular, the treatment of staff nurses by nursing managers. Nurse 5 asserted:

There are reasons that make me hate it. Among such reasons are the administration...that always sees the negativities and does not appreciate the positive things. Nurses' rights are marginalised. For example, a problem happened between a nurse and a consultant and though the doctor was in error, the nurse was the one who got punished by the administration - these are things that make you frustrated, hate the profession and the administration (Nurse 5). 
Nurse 6 confirmed that by saying: 'My reasons are: the severe treatment we receive from the nursing office, like punishment for any error and no reward for a good job done' (Nurse 6). Another interviewee shared his experiences of this concept by saying:

Let alone the way the nursing office treats us - they treat us badly. No way can you see the nursing director of the hospital. I wish he would sit with the nurses, listen to them and know their problems — such thing would have its positive impact on nurses. All these reasons make me think of leaving the profession (Nurse 7).

Nurses 15 and 16 argued this point similarly; for example, Nurse 16 said: 'My reasons are non-cooperation of the administration and lack of a means of communication between nurses and the nursing office in the MoH' (Nurses 16).

\section{Shortage of nurses and the associated long working hours.}

Shortage of nurses is a critical issue in all healthcare organisations and this can affect the satisfaction of nursing staff. The interviewees indicated that the shortage of nurses and their long working hours are one of the many reasons that might push Saudi nurses out of the profession. For example, Nurses 9 and 10 said: 'My reasons are...long working hours; shortage of nurses, especially Saudi nurses' (Nurse 9) and 'My reasons are...shortage of nurses' (Nurse 10). Nurses 14 confirmed this by saying, 'Reasons are...shortage of nurses, particularly experienced ones; and the grave shortage of Saudi nurses' (Nurse 14).

Nurses 6, 7, 15 and 16 also said that the long working hours reported would stop nurses from working in public hospitals: 'My reasons are...long working hours, particularly for the married, up to 45 hours per week, with no overtime allowance' (Nurse 6) and 'My reasons are...long working hours and the nature of the work in the hospital' (Nurse 
7). Nurses 15 and 16 agreed, saying: 'My reasons are...besides the work pressure and long working hours' (Nurse 15) and 'Reasons are...long working hours' (Nurse 16).

Not all interviewees reported reasons to potentially cease their nursing jobs.

Nurses 2 and 13, both staff nurses, mentioned that there were no reasons to make them leave nursing. They said: 'No reasons make me stop working as a staff nurse' (Nurses 2 and 13). Nurses 8 stated that she like the nursing job and she had no reason to cease the profession. She asserted: ' ... I like this profession. There is nothing in my work or its environment that makes me leave it' (Nurse 8).

\section{Future goals in nursing careers.}

Participants were then asked what they perceived their future goals to be in their nursing careers. The interviewees indicated many future goals. The following subthemes are discussed: continuance of nursing education, improving community views and Saudization.

\section{Continuing education.}

More than half of the participants reported that their goals in the future were to continue their study of nursing, such as by gaining postgraduate certificate and improving their nursing education, skills and training. In the Saudi Arabian education system not all universities have a postgraduate degree for male nurses, and only two universities offer a postgraduate degree, such as a Master's degree, for females. Most female and male Saudi nurses have diploma degree and many have dreams to continue their studies to win a higher certificate in the nursing sector. For instance, Nurses 1, 4, 5, 6, 7, 9, 12,15 and 16 revealed that their goals for the future included continuing their study of nursing science at a postgraduate level in developed countries such as Australia, the United Kingdom, Canada and the United States. The following are some examples of their comments: 'My goals are...providing more opportunities for nurses, particularly the 
young, to continue their studies and improve their educational level and vocational status' (Nurse 1); 'My goals are...more opportunities for postgraduate studies' (Nurse 4); 'My goals are creating higher postgraduate degrees in nursing at universities and establishing specialised university colleges for nursing sciences; supporting nursing researchers, working to implement their results and appreciating the researchers and appreciating higher degrees by vocational qualification' (Nurse 11) and 'My goals are...opportunities for postgraduate studies, particularly for men' (Nurse 14).

Further, Nurse 2 said that improving nursing studies, particularly in English language competence, was important: 'My goals are...improving nursing curricula and education for the private sector, especially in the English language' (Nurse 2).

Nurse 5 said that the level of nursing standards for those working in the public hospitals had recently declined and he compared this situation with the past, when there were highly qualified nurses. Further, he asserted that qualified nurses can improve Saudi nursing education, skills and training, and that his main future goal is to have opportunities for postgraduate studies. He said:

Nursing standards are very low because of the lack of competent nurses who can train and educate the new ones. In the past, nursing standards were very good and we learned much from them. My goals are...opportunities for postgraduate studies; employing highly qualified nurses; and improving nursing education in institutes and universities (Nurse 5).

In addition, Nurses 8 and 17 reported that promoting engagement with nursing education, nursing training and nursing research are future goals as well. They said, 'My goals are...intensifying nurse's education, training and engaging them in lectures, seminars and scientific research and knowing what is new in nursing through continuous education' (Nurses 8 and17). Nurses 2, 9 and 15 confirmed that continuing 
nursing education was also a future goal: 'My goals are providing nurses with intensive courses and training...' (Nurses 2) and ‘ My goals are...training and engaging [nurses] in lectures, seminars and scientific research' (Nurses 9 and 15).

Nurse 3 reported that nurses need to specialise and become highly qualified through further education and training. Further, she mentioned that more specialisation in the nursing system needs to develop to complement the medical system. She said:

My goals are to have qualified nurses at the highest educational and training levels, similar to the doctors' system, in different fields such as medicine, surgery, etc.; to promote our nursing standard to a par with international nursing in skills and capabilities (Nurses 3).

Nurse 17 confirmed that specialisation and becoming highly qualified through further education and training was also a future goal: 'My goals are to have qualified nurses at the highest educational and training levels and more specialised in nursing fields such as emergency nursing and intensive care nursing...' (Nurse 17).

\section{Improving the community's view of nurses.}

Improving the community's view of nurses was a significant concept and future goal for the participants. Nurses 1, 7, 15 and 16 indicated that is one of their future goals. For example, Nurses 15 and 16 stated: 'My goals are...improved community perceptions of the nursing profession and nurses' (Nurse 15) and 'My goals are...to see community and Ministry appreciation of nurses through the media; ...; improve the community perception of the nursing profession and nurses' (Nurse 16). Further, Nurse 1 confirmed that the community's perception of nursing is an issue, but said that he thought the community view regarding nursing is noticeably improving, stating, 'My goals are to improve the community perception of the nursing profession and nurses, 
knowing that there is already a noticeable improvement; more respect to nurses and their job' (Nurse 1).

\section{Saudization.}

Saudization is one of the $\mathrm{MoH}$ programmes designed to increase the number of Saudi nurses and to replace foreign nurses. It was one of the future goals of the $\mathrm{MoH}$ policymakers as well as some of the interviewees. For example, Nurse 6 indicated that increasing the number of Saudi nursing aides would help, and would decrease the work load for nurses. He said: 'My goals are...more nurses and nurses' aides to reduce the work load on nurses, whom I wish to be Saudis' (Nurse 6). Nurses 9, 13 and 16 confirmed that their future goals for the nursing profession included increasing the number of Saudi nurses and increasing the chances for Saudi young people to become nurses. For instance, Nurses 13, 9 and 16 revealed: 'My goals are...more Saudi nurses' (Nurse 13) and 'My goals are...more opportunities for Saudi[s] to become a nurse' (Nurses 9 and 16).

Nurse 8 indicated that developing nurses with an excellent quality of nursing education and training was one of her future goals: 'My goals are giving more attention to this profession; more Saudi nurses; employment of highly competent nurses...' (Nurse 8).

Nurse 14 reported that he wished that the Saudi nurses' administration started at a higher level: 'My goal...I wish a Saudi nursing administration to be established on a ministerial level' (Nurse 14).

In contrast, Nurses 7 and 13 have different goals, not like those of most of the nurses participating in this study. Nurse 7 indicated that Saudi nurses work without clear job descriptions and that they do everything in hospitals; one of his goals for the future was to see clear job descriptions established for nurses working in public 
hospitals. He said, 'My goals are... a defined job description for nurses, who currently do every kind of work, like a cleaner, an administrator, a doctor...etc.' (Nurse 7).

Nurse 13 indicated that one of her future goals is improving nursing policy and more chances for nurses to share in decision-making. She asserted, 'My goals are...showing professionalism at work; opportunities for nurses to share in decisionmaking and [for decisions] not to be made totally by nursing administration; and setting better work policies by nursing administration' (Nurse 13).

Factors perceived to improve the public image of nurses in Saudi Arabia.

Participants were asked what factors they considered would improve the public image of nurses in Saudi Arabia. The interviewees' responses to the factors that would improve the public image of nursing in Saudi Arabia were categorised into two main sub-themes: education of the community and increasing the number of Saudi nurses.

\section{Education of the community.}

The majority of the interviewees asserted that education of the community regarding the nursing profession is one of the most important factors that would improve the public image of nursing in Saudi Arabia. For example, 15 of the nurses indicted that public perception could be improved by educating the Saudi community through media such as TV, radio, the internet and the press, and also through educational programmes about the profession for students at schools, people in markets, public gatherings, publications, seminars, lectures, conferences and interviews. For example, Nurse 1 said: 'Media like TV, radio, the internet and the press, have a key role in improving nursing's public image. It can contribute to educating the community about the nursing profession, thus improving its image' (Nurse 1). Other participants indicated: 'Factors are media support, thus educating the community about the nursing profession through intensive campaigns to secondary schools, encouraging students to 
join the nursing profession, people in markets, home visits and public gatherings'

(Nurses 11 and 12); '... The best way to improve the public image of nurses is educating the community about their role through publications and documentaries; a role to be undertaken by the media' (Nurse 7); ‘...You can change community’s perception of nursing through educational seminars, lectures and explanatory publications about the profession, its concept and goals; this is the media's role' (Nurse 8), and 'The media, particularly Arabic movies and TV series, has a key role in the development of this look' (Nurse 14).

Nurse 3 indicated that the media have played a major role in the overall negative public image of nursing in the Saudi community; stating:

The media has an important role to play. In the past, it was the media which visualised nurses as immoral and the nursing profession as not respectable and ugly, particularly in Arabic movies. Now, this image has improved because the media have started to focus on the nurse's role, work and efforts; no doubt, people from nursing backgrounds who have joined the media have contributed to this change (Nurse 3).

The Saudi community still does not have enough information regarding the nursing profession and the role of nurses. For instance, Nurse 6 told this anecdote: 'Once a relative of mine asked me what my job was. "I am a nurse", I replied. "So, you clean patients!' But, after I explained to him the nurse's role, he appreciated the profession' (Nurse 6).

A story from Nurse 5 illustrated the community's negative perception of the nursing profession. He said:

I was attending a course in Riyadh with a group of people. In the beginning, everyone stood to introduce themselves: doctors, pilots, engineers, etc. When I 
mentioned that I was a (male) nurse, I felt the contempt in some people's eyes due to their ignorance of the profession. However, when I explained to them about nursing, their look changed this time it was respect that I felt. This is what we ask the media to do. The negative perception is something related to the past; when my grandfather knew that I was working as a nurse, he said to me, 'Nursing is a woman's job; why do you take a woman's job?' (Nurse 5). Another story from Nurse 11, who has a Master's degree in nursing, related the community's negative view of the nursing profession in Saudi Arabia. He said: I hold a Master's degree. When my family and friends ask me about the field of this degree and I say “...in nursing”, I get a look of surprise mixed with contempt. That is why I say “... in health sciences”, but not in nursing - this is to avoid the community's negative perception of it. And, I think this kind of perception is still there, even with the attainment of higher nursing educational degrees, such as the doctorate (Nurse 11).

Nurse 13 told a story from her experiences with female Saudi patients regarding female nurses who work in a mixed-gender environment and she mentioned how nursing job roles are viewed in Saudi community. She said:

Most patient female companions wonder why a Saudi girl works as a nurse; they believe this profession is not appropriate for Saudi girls due to gender mixing in the work environment - it is a job for foreigners. However, this does not frustrate me or change my mind about nursing. Improving nursing's image depends on the way nurses treat patients - if they treat them nicely, this will help in improving the image. The looking down on nurses came, I believe, from their behaviour and the way they treated others (Nurse 13). 
Further, Nurse 14 also mentioned the story of one of his colleagues, who was refused marriage by a girl because he is a nurse. He said: 'A colleague went to ask a girl's hand in marriage, but he was refused, being a nurse' (Nurse 14).

However, some interviewees mentioned other reasons why the Saudi community has this negative view of the nursing profession. For example, Nurse 5 indicated that the nature of healthcare organisations as a mixed-gender environment is one of the reasons. He said: 'There are no educational programmes that explain the nurse's job and introduce it to the community. This is because most of the community have a negative perception of the profession due to the mixed-gender nature of its environment' (Nurse 5). Nurse 11 confirmed this by saying: 'It is the education of the community. The cause of the inferior regard for Saudi nurses is the mixed-gender environment at work. Add to that, people's ignorance of the nature of the nurse's work and role in the hospital' (Nurse 11).

\section{Increasing the numbers of Saudi nurses.}

The interviewees indicated that one factor that would improve the public image of nursing in Saudi Arabian communities would be to increase the number of Saudiborn nursing staff. For example, Nurses 2, 12 and 16 believed that increasing the number of Saudi nurses nationally would improve the community image of nursing, 'Increasing the Saudi-born nursing workforce would improve the public image' (Nurses 2, $12 \& 16)$. Nurse 2 told this story:

It happened that a cancer patient received the best nursing care. So, her family wished the future in all hospitals to be for the Saudi people to take up nursing. In the past, patients used to refuse the Saudi nurse and ask for the foreign one; but patients now encourage and ask for the Saudi nurse rather than the foreign one. This happened because of the elevated trust in Saudi nursing, the better 
community perception of nursing and also, because of the easy communication between Saudi patients and nurses (Nurse 2).

However, Nurses 8 and 10 thought this was not accurate and that the public view of the nursing profession is improving. They asserted: 'Nowadays, the nursing image has improved with the increase of Saudi nurses' (Nurse 8) and 'Nowadays, the nursing image has improved and the community is accepting the idea of nursing, particularly men' (Nurse 10).

\section{Suggestions to increase the recruitment and retention of Saudi Arabian} nurses.

Participants were asked for their suggestions on how to increase the recruitment and retention of Saudi Arabian nurses. The interviewees offered many suggestions, which were categorised into the three sub-themes that emerged from their responses: developing nursing colleges, increasing rewards and improving the hospital environment.

\section{Developing nursing colleges.}

The majority of the interviewees, including Nurses 1, 2, 4, 6, 7, 8, 9, 10, 11 and 16 , suggested developing more and better nursing schools and colleges to increase the recruitment of female and male Saudi nurses. For example, Nurse 2 said: 'My suggestions to keep and increase Saudi nurses are...opening more educational opportunities for nursing students in institutes, universities and health colleges Kingdom-wide' (Nurse 2). Nurse 11 stated: 'My suggestions to keep and increase Saudi nurses are increasing the nursing colleges' capacity for students' (Nurse 11).

Other interviewees, Nurses 4, 6 and 10 said that more chances are needed for postgraduate nursing study, either locally or overseas. For example: 'My suggestions to keep and increase Saudi nurses are more opportunities for higher studies' (Nurse 4) and 
'My suggestions are more international scholarship opportunities for postgraduate nursing studies' (Nurse 10).

Another nurse mentioned starting a bachelor's degree for male nurses, like those for female nurses, at university: 'My suggestions to keep and increase Saudi nurses are establishing nursing colleges at a university level for male nurses and equalising them with female nurses who hold Bachelor's and Master's degrees in nursing' (Nurse 6). Further, Nurse 6 stated his wish for the profession as: 'I wish to have more high efficiency Saudi nurses that will able to transform the profession' (Nurse 6).

Nurse 7 asserted that more opportunities are needed for nurses to attend conferences by saying: 'My suggestions to keep and increase Saudi nurses are...opportunities for study and attending courses and conferences' (Nurse 7). Another nurse said that developing short education programmes would help: 'My suggestions are developing nursing through courses, seminars and lectures; sweetening the profession for prospective employees' (Nurse 8).

\section{Increasing rewards.}

The majority of the participants, including Nurses 1, 2, 4, 5, 6, 7, 8, 9, 12, 13, 15, 16 and 17 asserted that financial and moral rewards would help to encourage nurses to stay in the profession. For example: 'My suggestions to keep and increase Saudi nurses are more financial and moral incentives; moral incentives are far more important than the financial, for their positive impact on morale and performance' (Nurses 8, 2, 5, 6 and 9); 'Most nurses who withdraw from nursing do that seeking moral and financial incentives' (Nurse 1) and 'A thankyou letter from the administration is better than a salary increase, it encourages me and makes me satisfied with my work' (Nurse 7). 
Nurse 12 confirmed the idea that moral and financial rewards could encourage nurses to remain working in hospitals. She told a story regarding a hospital that recognised it best nurse:

To keep nurses more moral and financial incentives from nursing administration and better communication between the head of nursing and nurses is needed. I have never had any moral stimulus or encouragement at my current job. I remember one day the hospital's 'Best Nurse' was being honoured. Amazingly, she was not allowed to appear on the stage to receive her award herself; instead, the head of department was chosen to do that (Nurse 12).

Nurse 13 outlined her own experience regarding financial and moral incentives by revealing her story:

I have never received a thankyou letter from my hospital, but I officially received one from a patient. I had a patient who was giving birth and the patient did not have relatives. But, I remained always with her supporting, motivating and serving, till she overcame her psychological condition and left the hospital. Later, she sent me a formal thankyou letter which I received through the administration what a strong moral incentive it was to me (Nurse 13). In addition, Nurse 16 confirmed this by saying, 'I received a thankyou letter from the nursing administration and how clear was its impact on me and my selfdevelopment' (Nurse 16).

Nurse 15 indicated that being rewarded is effective at keeping nurses in the profession, especially the moral reward. She said:

My suggestions to keep and increase Saudi nurses are moral incentives such as thankyou and praising letters and also financial incentives. As for me, I find that 
moral incentives are a very strong incentive which contributes a great deal to staying in the profession; I think it's what made me stay until now (Nurse 15). Improving hospital environments.

Improving hospital environments was one of the suggestions of the participants to keep existing nurses and to increase the number of Saudi-born nurses. Nurses 1, 3, 4, 5, 6, 8 and 14 indicated that comfortable work environments would maintain and raise the numbers of Saudi staff. For example, Nurses 4 and 8 stated: 'My suggestions to keep and increase Saudi nurses are improving work environments' (Nurse 4) and 'My suggestions to increase employment are...providing a comfortable work environment' (Nurse 8). Nurse 6 confirmed that improving the work environment and adding nurses' advantages was important; he asserted his view as follows:

My suggestions to keep and increase Saudi nurses are...improving the work environment which has a great impact; better environment, more staying, less withdrawal...more nurses' advantages to sweeten the profession for prospective employees; for example, it was found that nurse frustration happens after the third year of employment at a hospital. In the first year, the nurse is active. Then their activity goes downhill over the first 3 years. By the third year, the nurse seeks a transfer due to lack of work incentives and advantages (Nurse 6).

Further, Nurse 14 agreed and provided his own concept and example: 'My suggestions to keep and increase Saudi nurses are providing for all the needs of the nursing staff working in hospitals; improving the work environment (example: no place for nurses at hospitals to sit and have a coffee break)' (Nurse 14).

\section{Other suggestions.}

Nurse 13 indicated that one of her suggestions to keep Saudi nurses in the profession is to provide nurses with the same rights as employees in the other health 
professions. She asserted: 'Suggestions are giving nurses the same rights and advantages enjoyed by their colleagues in other departments...If nurses are given their full rights, there will be no withdrawal from the profession' (Nurse 14).

Nurse 11 made the suggestion of identifying the factors that create job satisfaction by research on all Saudi nurses in Saudi Arabia and then, based on the results of the study, create a plan to improve job satisfaction. He said:

Suggestions to keep nurses are improving job satisfaction through a central study done at a kingdom level on all Saudi nurses to measure job satisfaction annually, and according to the results an action plan should be developed to improve quality; less work pressure on nurses through employing enough of them; equal and just treatment of nursing administration to all nurses. Though moral incentives have a stronger impact on our satisfaction, we do not get any moral support from nursing administrators because they, themselves, are lacking the same (Nurse 11).

\section{Chapter Summary}

Semi-structured interviews were conducted to gain an in-depth understanding of the concept of job satisfaction in Saudi nurses. Seventeen female and male Saudi nurses from the three main public hospitals in the Makkah region participated in these face-toface interviews. Findings from these qualitative interviews were gained from the interviewees responses to the six open-ended questions of the study. This thematic analysis provided the major themes and the sub-themes of the participants in this study.

The Saudi nurses in the three main hospitals revealed six major themes in this study. The first theme was the influences in their decision to study nursing. They said that family and friends influenced their decision to study nursing. However, many of them made personal decisions to study nursing. The second theme was the factors that 
motivate nurses to continue working as a nurse. The participants indicated that there are many factors that motivate Saudi nurses to continue work in the nursing sector. The sub-themes that emerged regarding the factors that motivated them included religious motives, moral and financial incentives, and social and community service.

The third theme was the reasons to potentially cease nursing. The interviewees offered many reasons that would make them leave the nursing profession. Their responses were categorised into four sub-themes: society's view of nurses, the lack of recognition, leadership style and the long working hours cause by the shortage of nurses.

The fourth theme was their future goals in their nursing careers. This theme, in particular, reflects the participants' future goals as nursing professional in Saudi Arabia. Three sub-themes are discussed: continuing nursing education, improving community views of nursing and Saudization.

The next theme was the factors that were perceived to be able to improve the public image of nurses in Saudi Arabia. Many people in the Saudi community are not interested in the nursing profession due to the negative perception of the profession. Further, they do not understand the role of nurses, either in the hospitals or the community. The interviewees' responses to the factors that would improve the public image of nursing in Saudi Arabia were categorised into two main sub-themes; educating the community and increasing the number of Saudi nurses.

The final theme in this study was the question of increasing the levels of recruitment and retention of Saudi Arabian nurses. The nurses' responses were categorised into three sub-themes: developing nursing colleges, increasing rewards and improving the hospital environment. 
The following chapter will present a discussion of these findings and provide recommendations for future study. 


\section{Chapter 7: Discussion}

\section{Introduction}

This study has explored the factors that influence the level of job satisfaction of Saudi nurses working in the three main public hospitals in three cities in the Makkah region of Saudi Arabia. The study employed a mixed-method research approach that included a quantitative questionnaire and face-to-face interviews to enhance the data collection and analysis in order to answer the research questions (Creswell, 2009; Doyle et al., 2009). This study was based on Herzberg's two-factor theory (the motivationhygiene theory). The main concept of this theory is the difference between the two factors: motivation (intrinsic) and hygiene (extrinsic) and their effect on job satisfaction or job dissatisfaction.

This chapter discusses the findings of this research and explores the ramifications of the study's outcomes. This chapter will be presented in four sections. The first section discusses how demographic factors affect the motivation-related job satisfaction factors. The second section discusses how the demographic factors affect the hygiene-related job satisfaction factors. The third section discusses the general factors that predict job satisfaction among Saudi nurses working in public hospitals and the last section discusses the factors that predict job satisfaction among Saudi nurses working in each of the public hospitals included in this study (Jeddah, Makkah and Taif).

\section{Demographic Factors Affecting Motivation Job Satisfaction}

The demographic factors in this study were divided into two categories: personal characteristics and job characteristics and nursing experience. The personal characteristics included gender, age, marital status, number of dependent children, number of dependent adults, educational qualifications and monthly salary. The job 
characteristics and nursing experience included the employing hospital, position, duration of employment at the hospital, number of weekly working hours and overall experience in nursing.

This section discusses the significant demographic factors that affect nurses' motivation-related job satisfaction. According to Herzberg's theory (1966), motivation factors are those that contribute to satisfaction, while motivation encompasses the following six factors: advancement in the job or career, the work itself, the possibility for growth and development, the responsibility given to the worker, feeling recognised and a sense of achievement The analysis of the quantitative data in this study showed that the primary factors influencing Saudi nurses' job satisfaction are gender, the number of dependent adults that they are responsible for, their duration of employment in the hospital and their overall nursing experience (see Tables 5.17 and 5.18).

\section{Effects of gender on job satisfaction.}

In this study, 61 per cent of the subjects were female nurses. The quantitative data analysis showed that the female nurses at the public hospitals in the Makkah region were significantly less satisfied in their jobs than the male nurses $(\mathrm{p}=0.019)$. This result is not surprising in view of the Saudi culture and the public image Saudi society holds of the nursing profession (refer to Table 5.17), in that Saudi nurses are still subject to a negative public image. Surprisingly, this negative regard for nursing as a profession is also seen in developed societies such as Australia (Takase, Maude, \& Manias, 2006). Takase et al. (2006) studied the impact of the perceived negative public image on nursing in Australia and found that it negatively affects nurses' work behaviour, job satisfaction, turnover intentions and performance.

This result aligned with Al-Ahmadi's (2009) study in the Riyadh region of Saudi Arabia, which investigated the factors affecting the performance of both Saudi and non- 
Saudi nurses in 15 hospitals, and found that job satisfaction was significantly lower among female nurses compared to male nurses. Similarly, in the United States Sochalski (2002) found that the level of job satisfaction among female nurses was lower than that of male nurses. In contrast to the findings of the present study and those of Sochalski and Al-Ahmadi showing greater satisfaction among male nurses compared to female nurses, Tourangeau and Cranley (2006) found that the female nurses are more satisfied in their jobs than are male nurses in Ontario, Canada, demonstrating some contradictions in global results. The findings of this study with regard to gender further contradict several Western studies, which have found that gender did not affect nursing job satisfaction (Cahill, 2011; Curtis, 2008). These studies were conducted in the United States (Cahill, 2011) and Ireland (Curtis, 2008).

Despite these previous findings of higher job satisfaction among male nurses, they may be at higher risk for turnover. Ragapaksa and Rothsteim (2009), who examined the factors that affect the decisions of female and male nurses to leave their jobs in the United States, found that male nurses leave at a higher rate than female nurses. Further, they found that three reasons for leaving nursing included more convenient working hours, better salaries and more rewarding professions.

Among the most important factors affecting nurses in Saudi Arabia are the norms and values of the Islamic way of life, which are characterised by honour, strong family bonds and the protection of females. Although there is a prevailing social agreement that women may work, little agreement exists about the circumstances and type of work in which women can engage (Tumulty, 2001). Occupations that are seen as appropriate for women include teaching, social work, banking and marketing and other occupations in which the woman is working in an environment with other women. Nursing is considered a less desirable job option for Saudi women, and Saudi female 
nurses experience less job satisfaction for several reasons, which may include the way that their culture and society views nursing in terms of the widespread lack of respect for nurses by the public and the mixed-gender environment in which nurses work.

\section{Culture and societal views.}

Saudi Arabia has an Islamic, Arabic culture, which affects most aspects of Saudi society, including education, health and lifestyle. Many studies have discussed Saudi Arabian perceptions of nurses and the nursing profession (El-Gilany \& Al-Wehady, 2001; Lovering, 2008). The literature has affirmed that cultural, familial and religious factors strongly influence the educational and professional options of young Saudis (Miller-Rosser et al., 2006). Because Saudi Arabian society views nurses as having a low social status, people who choose the nursing profession face disapproval from their family, friends and society. For example, interviewee Nurse 12 confirmed disapproval from her family, especially her aunt, who reportedly ignores her and has disowned her because she is working as a nurse.

The moral aspect underlying this negative perception of the nursing profession is related to the Saudi culture, which disapproves of the mixing of genders in hospital environments and other health organisations (Lovering, 2008). Therefore, in mixed environments, such as health organisations and hospitals, gender factors could influence nurses' sense of job satisfaction, especially in Saudi Arabia, where there is a strong religious influence in society. Further, the Arab media has played a major role in this negative view of the public with regard to the nursing profession; where old television programmes and old movies depicted nurses as unintelligent and flirtatious with doctors (Mebrouk, 2008). This result was strongly supported by interviewees Nurse 3 and Nurse 14 , who discussed the role of the media in the overall negative perception of nursing in 
Saudi society, stating that it showed the nursing profession as immoral and disreputable, especially in older Arabic movies.

Thus, from the results of prior research, most Western studies found no significant difference between job satisfaction and gender (Cahill, 2011; Curtis, 2008); however, research conducted in different cultures has shown that there is a significant difference in the level of job satisfaction between the genders (Al-Ahmadi, 2009; Petterson et al., 1995; Ragapaksa \& Rothsteim, 2009; Sochalski, 2002). Specific to Saudi Arabia, female nurses suffer from a poor public image within Saudi society, where nursing is considered a lower-class occupation and is not viewed as a respectable profession.

According to Al-Omar (2003), women in Saudi Arabia are not choosing nursing as a profession because this occupation has a low status within their community. This negative view of nursing has prevented female nurses from working and being satisfied with their profession. This concept was strongly supported by the interview results in this study. Interviewee Nurse 12 reported that Saudi society's low regard for nursing was one of the important reasons that influenced her to almost quit working as a nurse. Further, Nurse 11 asserted that the negative view came from policymakers and hospital workers more than from society. The public view of nurses strongly deters people from joining the nursing profession; thus nursing has not been a favourable choice for many Saudi Arabian females and it is considered even less favourable for Saudi Arabian males (Al-Omer, 2003). This negative attitude of the public towards nursing could affect female nurses' prospects for marriage, and any issue that interferes with marriage, especially in a historically more traditional culture like Saudi Arabia (Miller-Rosser et al., 2006), is opposed by the family. 
Saudi high school female and male students' perceptions and choice of nursing as a profession have been shown to be influenced by the public image of nursing, family disagreement, cultural and communal values and the worry of not being a 'marriageable' prospect (Al-Omer, 2003). This may explain the high percentage of single nurses (53 per cent) in this study within a traditional Islamic community like Saudi Arabia, where females are married at a young age. These results are consistent with other studies. For example, Abualrub and Alghamdi (2012) found that 53 per cent of the 308 nurses in their study of nurse satisfaction and retention were single. This was strongly supported by the interview results of this study. For example, Nurse 12 stated that her parents were greatly worried about her ending up as an unmarried woman and working as a nurse in a mixed-gender profession and environment. However, for Nurses 1, 7, 15 and 16, one of the perceived future goals for nursing was improving Saudi society's view of the nursing profession.

\section{Lack of respect.}

Lack of respect is the primary reason why nurses are less satisfied with their jobs. Lack of respect for nurses has also been reported in the United States. According to Barney (2002), 'A career in nursing, historically, was not respected' (p. 154). Young people, especially females, study and enrol in nursing because of the limited career options available to them. It has been reported that women in the United States who have chosen nursing as a career often steer their daughters away from the nursing profession and encourage them to pursue careers in other areas, such as medicine or biotechnology (Barney, 2002). Similarly, Saudi nurses suffer from a lack of professional respect from their relatives, patients, allied health colleagues, doctors and the community at large. 
Within Saudi society, professions such as nursing are not considered to be respectable, in contrast to other professions in the same hospital, such as laboratory workers, pharmacists and social workers. However, in the ancient history of nursing in Islam and during the times of the Prophet Mohammed (peace be upon him), nursing was a respectable career for Muslim women due to the support and appreciation from the Prophet, Mohammed (peace be upon him) and the Muslim army (Miller-Rosser et al., 2006). Further, as appreciation for female nurses' efforts, the Prophet assigned a share of the wealth from his victory in battle to the team of nurses that was equivalent to that of the soldiers (Al-Osaimi, 2004). According to Lu et al. (2005), nursing job dissatisfaction is often high for many reasons, and one of these reasons is a lack of respect. Interviewee Nurse 1 highlighted that a future goal for the discipline of nursing is to raise the profile of the nursing profession, so that Saudi nurses earn more respect from the Saudi population.

\section{Mixed-gender environment.}

In the Saudi community, the mixed-gender environment in hospitals could influence female nurses' job satisfaction. Gender segregation, which is common in Saudi society and is a part of a culture based on religion, has been adopted as a custom respected by all healthcare institutions. In all Saudi public hospitals, there are segregated male and female wards, and male nurses take care of male patients and female nurses take care of female patients. Nevertheless, in some instances when there are insufficient male nurses or a shortage of male staff, female nurses are called upon to work and cover for the lack of male nurses by providing care to male patients.

The care for patients of the opposite sex has been discussed in research concerned with modesty in the healthcare systems of Muslim communities, showing that healthcare professionals, in general, should avoid touching opposite sex Muslim 
patients, except when giving direct nursing care (Lawrence \& Rozmus, 2001). Such hesitation is not as necessary with a patient who is of the same gender (Lawrence \& Rozmus, 2001). Saudi families do not accept females working in mixed environments such as hospitals. According to Arab Islamic society, Saudi women should only work with females to be compatible with Islamic and Saudi cultures. There are few jobs that fit with these restrictions, such as needlework and teaching in girls' schools (MillerRosser et al., 2006). Nurse 13 mentioned her experience with Saudi female patients who shared their beliefs, stating that the nursing profession is not appropriate for Saudi females due to the mixed-gender environment in the hospitals and that they considered the profession appropriate only for foreign nurses.

This perception was also described in research by Alawri and Ghazi (1982, cited in El-Sanabary, 2003), who contended that many Saudi families consider that the nursing profession is not an honourable profession for females. The authors asserted, 'This attitude rests on the belief that nursing forces a girl to mix with men, to stay long hours away from home and work night shifts: a job condition that is socially unacceptable and runs contrary to deep rooted beliefs of what is permissible for a girl to do...' (1982, cited in El-Sanabary, 2003, p. 268). Moreover, research undertaken on the effect of shifts on the psychological status of the nurses revealed a significant relationship between the frequency of night shifts and stress among nurses (AlHammad, Raheel, Al-Baiz, \& Al-Otaibi, 2009).

Saudi Arabian law still does not allow females to drive a car and this is a barrier preventing female nurses from travelling easily to work. Saudi female nurses suffer from the issue of transportation to work, especially on different shifts, as they rely heavily on male family members to drive them to work. The public transportation system is almost non-existent in Saudi Arabia. This was a point also raised by Nurse 3, 
who said that her father supported and motivated her to continue working as a nurse and he drove her to work every day, a distance of approximately 80 kilometres away from their home. This was encouraging to her, and more fathers like him are required in Saudi society in order to assist in changing the poor image of the nursing profession.

\section{Number of dependent adults.}

Another factor that affected job satisfaction among the participants of this study was the number of dependent adults that they were responsible for. The t-test results indicated that the relationship between level of job satisfaction and number of dependent adults was statistically significant $(\mathrm{p}=0.009)$. It was found that nurses who had no dependent adults at home were significantly more satisfied with the motivation factors than nurses who had dependent adults at home. In Saudi Arabia, within the Islamic context and according to the local culture, offspring have clear responsibilities to care for their parents and extended family members, particularly the elderly. The literature discussed the influence of dependent adults on the job satisfaction of employees (Brooks \& Anderson, 2004; Khani et al., 2008). This finding was also mirrored in a study by Almalki et al. (2012), who studied the quality of work life among primary healthcare nurses in the Jazan region of Saudi Arabia and found a significant difference in job satisfaction between nurses with dependent adults and those without dependent adults. Saudi nurses who are responsible for dependent adults were significantly less satisfied with their jobs due to the pressures put on them by their society, culture and the lack of support they receive for providing care to their elderly relatives.

Saudi society, culture and lack of support.

As reported in the previous section, the findings of this study indicated very clearly that nurses who have dependent adults were less satisfied with their work than 
nurses who do not have dependent adults, and that this was mainly caused by the lack of support and the pressures placed on them by their society, religion and culture. Family relationships are very important in the Saudi community, and they are influenced by Islamic cultural values. According to Mebrouk (2008), family is essential in the life of Muslims and Saudis. Hence, Islamic ethical principles play a significant role in the family's life, including standards of behaviour and attitudes that influence personal relationships between family members, such as honesty, mercy, sympathy, respect and kindness.

Islam has a very strong position in strengthening Saudi culture and shapes most of the cultural norms and practices. It encourages Muslims to take care of dependent adults, especially parents, and to place them in the highest esteem. Priority is always given to the parent's needs over the individual's own needs. All Muslims must care for and treat their direct and extended elderly family members kindly, and provide them with the support needed for them to maintain as healthy a lifestyle as possible. Saudis are required to be patient and have a good relationship with their parents, especially when they get older and need more help. This is deeply rooted in their beliefs as Muslims following the commandments of the holy Qu'ran. Allah said:

Your Lord has commanded that you worship none but Him and that you be kind to your parents. Whether one or both of them attain old age in your life, say not to them a word of contempt (Fie), nor shout at them, but address them in terms of fine, correct and honourable words (the holy Qu'ran: 1-isrā, Verses 17-23). Further, the Prophet Mohammed (peace be upon him) affirmed: 'I refer to the man who finds his parents old in age — both of them or one of them—and yet did not earn entitlement to Paradise by rendering good service to them' [Muslim]. Moreover, Abdullah Ibn Mas'ood said: 'I asked the Prophet (peace be upon him) which deed is 
most liked by Allah?' He (peace be upon him) said: 'Prayer offered on time.' I asked him: 'Then what?' He (peace be upon him) said: 'Kindness and respect towards parents.'...' [Al-Bukhaari and Muslim].

Nurses who have dependent adults have more responsibility, stress and work at home than nurses who do not have dependent adults. Generally, employees in Saudi Arabia do not receive any monetary support or health and social services to assist in the care of their dependent adults. Lack of support for the nurses' ailing family members was found to be a source of dissatisfaction among nurses (Almalki et al., 2012). Other sources of job dissatisfaction among nurses were the inadequate vacations, long working hours and lack of time with their parents and relatives. Increasing pressure put upon caregivers due to impacts such as the personalisation schedule and the increasing social, financial and psychological constraints experienced in the workplace and daily life will possibly take their toll and add to the factors leading to more stress on the carer (Mathews, 2009).

\section{Duration of employment.}

The third factor that affected job satisfaction among the nurses in this study was the duration of employment. A one-way ANOVA test was performed to examine the relationship between the duration of employment and job satisfaction. The results revealed that the Saudi nurses who had worked for 5-10 years in public hospitals were less satisfied $(\mathrm{p}=0.030)$ than other nurses. These findings are consistent with the research findings on nurses working in public hospitals elsewhere around the world. The results of a study by Mrayyan (2005) revealed that nurses who worked in public hospitals reported lower levels of job satisfaction than nurses working in private hospitals, and that fewer of them had the intention to stay in their jobs. 
Public hospitals in Saudi Arabia are different to other Saudi health sectors such as private hospitals, National Guard Health Affairs, Army Forces Medical Services, ARAMCO private hospitals and university teaching hospitals. All public hospitals in Saudi Arabia provide free healthcare to all patients, Saudi and non-Saudi. However, the private hospitals only cover Saudi patients who have been specially authorised to be provided with treatment, or those who have private health coverage or employees working in the organisation. Thus, public hospitals are always overcrowded and working to full capacity, because most patients only come to the public hospitals when they are extremely ill. According to Brown (2005), patients in Saudi Arabia usually do not visit physicians in clinics or hospitals unless they are very ill. Thus, the patients who are admitted to the public hospitals need high intensity care, which also affects the stress levels of the nurses employed in public hospitals.

Nurses in the 5-10 year employment group were comparatively less satisfied than nurses who have been employed for less than 5 years and those who have been employed for longer than 10 years. There are many factors that influence the job satisfaction of nurses working in public hospitals. These factors include work stress, long working hours and the hospital environment.

\section{Work stress.}

Nurses employed in public hospitals may experience more work stress than those nurses employed in other health sectors. Stress can influence employee satisfaction at work. The role of stress in nurses' work and careers has been found to result in job dissatisfaction among registered nurses (Hoffman \& Scott, 2003). According to Unruh (2005), the stress of hospital work or the hospital environment has long been mentioned as a key factor influencing job satisfaction among employees. Stress can affect nurses and play a vital role in their decision to quit and leave the 
hospital (Chan et al., 2013). Yau et al. (2012) mentioned that the high level of occupational stress is linked to time, responsibility and workload. Al-Omar (2003) found that the level of job stress among MoH public hospital staff was high due to the absence of appreciation, insufficient technical facilities, short breaks and long working hours. The current study showed that nurses who have been working more than 10 years in public hospitals have less stress and are more satisfied with their job. These results concur with a study by Al-Omar (2003), who found that the level of stress of the five MoH hospitals' staff is high, but the older and more experienced staff members had less work stress. This may be due to them being more familiar with the job and their hospital environment and culture.

\section{Long working hours.}

The results of this study showed that nurses who have worked in public hospitals for 5-10 years have more responsibility than nurses who have worked less than 5 years, and that they have more work stress than nurses who have worked for more than 10 years. Many nursing studies have mentioned that nurses' working hours are linked with and influence their job satisfaction (Almalki et al., 2012; Hegney et al., 2006). A study in Queensland, Australia, revealed that nurses in the public sector were more likely to perceive their working hours as unsatisfactory compared to nurses in the private sector (Hegney et al., 2006). In Saudi Arabia, a study by Almalki and colleagues (2012) found that the majority of Saudi nurses were dissatisfied with many factors, including their long working hours. Al Hosis (2009) confirmed that male and female Saudis do not chose the nursing profession as a career due to several reasons, and that one important reason was the long working hours required.

Generally, Saudi nurses in all public hospitals have the same working hours as other professionals such as pharmacists and physicians; however, nurses receive less 
pay than the other health professionals. According to the Ministry of Civil Services (MoCS, 2010), in Saudi Arabia the standard working hours for all health professionals, including nurses, is 176 hours per month. Nurses in Saudi Arabia work approximately 48 hours per week, compared to 35 hours for other employees in all other public sector occupations (MoCS, 2010). Nevertheless, in recognition of these additional hours, nurses only receive 20 per cent extra in their salary, compared to the bonuses other health professionals receive, such as pharmacists, who receive 45 per cent of their salary if they work extra hours, and physicians, who receive 70 per cent of their salary for the extra hours worked (Abu-Zinadah, 2004). This was discussed with Nurse 3, who highlighted that Saudi nurses do not receive as many bonuses as do other health professionals, who receive monetary bonuses of between 40-70 per cent, whereas nurses only receive 20 per cent of their salary for all their extra work.

Saudi female nurses find that shift work with long working hours is not compatible with their families' expectations. This notion was stated by Al-Otaibi, Makhdom and Ibrahim (2012), who found that among the factors causing less satisfaction among female Saudi nurses were the unmet familial and social demands as a resutl of the limited free time remaining after their long working hours. Further, Ashy (2004) mentioned that many Saudi nurses spend a long time at work, making it difficult to balance family life and work, especially among female nurses. This was strongly supported by the interview results. Nurse 3 asserted that her reasons for wanting to leave her employment in nursing were the heavy duties and responsibilities, as well as the long working hours. Further, Nurses 6, 7, 9, 15 and 16 confirmed that there are many reasons to quit nursing, with one of them being the long working hours, especially for married nurses. According to Al-Omer (2003), there are many reasons why Saudi females do not choose nursing as a career and feel less satisfied with the profession. 
Among these reasons were the long working hours and shift work. The long working hours and sometimes the schedule of extended overnight working hours is culturally sensitive and sometimes unacceptable to Saudi families.

\section{Hospital environment.}

This study found that nurses who have worked for 5 years in the public hospitals suffered from their hospital's environment. According to Nurse 1, the uncomfortable environment was a reason for her wanting to leave her job as a nurse in the public hospital. Nurse 6 stated that improving the hospital environment could increase nursing job satisfaction and have a positive impact on the profession. The work environment is important for all workers, so that they feel safe, comfortable and satisfied. A good hospital environment can help nurses to provide quality care. The level of job satisfaction is influenced by the environment, as shown in several previous nursing studies (Bahalkani et al., 2011; Shaver \& Lacey, 2003).

Bahalkani et al. (2011) studied the job satisfaction of nurses working in a tertiary-level healthcare in Islamabad, Pakistan, and found that one of the reasons for job dissatisfaction was the poor working environment. The work environment has been emphasised as a highly important factor for healthcare systems to consider in order to enhance the retention of nursing staff and decrease the shortage of nurses (El-Jardali, Dimassi, Dumit, Jamal, \& Mouro, 2009; Zurn, Dal Poz, Stillwell, \& Adams, 2004). Shaver and Lacey (2003) asserted that environment variables and the job setting could influence nurses' job satisfaction. The majority of the interviewees in the present study confirmed that one way of increasing the recruitment of Saudi nurses would be to improve the hospital environment.

A comfortable hospital environment could help maintain Saudi nurses in their jobs, increase the number of nurses and reduce the shortage of nursing staff. For 
example, Nurse 1 stated that an uncomfortable environment was a reason for quitting working as a nurse in a public hospital. Moreover, many Saudi hospitals do not have good facilities for workers to enjoy during their breaks. Sims (2003) indicated that the lack of a supportive work environment increased nurses' job dissatisfaction. Similarly, Nurse 14 suggested that one factor that could help in maintaining and increasing Saudi nursing staff was to provide for the nurses' needs within the hospital environment; for example, a place for nurses to sit and have a coffee break. Further, Nurse 6 mentioned improving the work setting in his suggestions for retaining Saudi nurses in public hospitals. He claimed a better environment could have a strong impact on increasing the number of nurses staying in the profession and reducing nurse turnover.

Many factors influence nurses' dissatisfaction with working in public hospitals. These factors can include work stress, long working hours and the hospital environment. Reducing the work stress and the working hours of nursing shifts, as well as providing a good hospital environment could enhance nursing care, increase job satisfaction and decrease job turnover among nurses in Saudi Arabia.

\section{Overall experience.}

In this study, Saudi nurses who had 4-10 years of work experience were less satisfied than other nurses working in Saudi public hospitals. The demographic factor that affected motivation and job satisfaction among the Saudi nurses in this study was their overall nursing experience (refer to Table 5.18). A one-way ANOVA test was performed to examine the relationship between the Saudi nurses' overall years of experience and job satisfaction. It was revealed that the Saudi nurses who had 4-10 years of experience were significantly less satisfied in relation to motivational factors than those nurses who had either more than 10 years of nursing experience or less than 4 years of experience $(\mathrm{p}=0.003)$. This finding aligned with those of Kavanaugh et al. 
(2006), who found that the number of years of professional experience was commonly linked to healthcare professionals' job satisfaction. In Saudi Arabia, Al-Ahmadi (2002) also demonstrated that nurses' job satisfaction was positively associated with the number of years of experience.

The current result is consistent with many other studies. For example, Kacel et al. (2005), who studied nurse practitioner job satisfaction in a Midwestern state of the United States, found that nurses who were new graduates and had less practical experience were more satisfied with nursing than other nurses. The authors stated that 'NPs with 0-1 year practice experience were the most satisfied with their jobs, but satisfaction scores fell steadily with each additional year of experience, reaching a plateau between the eighth and eleventh years of practice' (p. 27). Ma, Samuels and Alexander (2003) showed that nurses who had less than 2 years of work experience had a higher level of job satisfaction than those who had more than 2 years of work experience. In contrast, Almalki et al. (2012) showed that nurses who have more experience in nursing were more satisfied than nurses with less experience. Further, AlAameri (2000) found that older nurses and more experienced nurses were more satisfied and committed to their hospitals than younger nurses. These findings from Almaliki and Al-Aameri are more consistent with the findings of this study and this may be attributed to the fact that Saudi nurses who have more experience in nursing were more satisfied with their jobs. Older nurses may have good personal relationships with other staff and friends. However, young nurses who have a working experience of 4-10 years are less satisfied, perhaps due to the lack of recognition from their leaders and managers.

\section{Lack of recognition.}

The findings of this study revealed that new nurses and those who have less than 4 years of nursing experience were satisfied with their jobs. These nurses were more 
motivated and challenged by nursing. They were excited to explore the nursing profession and hospital environment and put their education and training into practice. Further, this increased satisfaction among younger and less experienced nurses may be due to the fact that they have obtained their degrees and diplomas and job positions as nurses after years of study and practice (Ma et al., 2003). Thus, these nurses may be more satisfied as they are focusing on a new job after long years of study. They may be happy to have a salary and work in a hospital community. They also receive more recognition than other nurses from managers and senior nurses, as they are new and need a lot of support and encouragement. Older Saudi nurses and those who have more than 10 years of experience were also more satisfied with nursing in this study. This group of nurses have considerable experience at work and they knew how to improve and develop in their profession and how to achieve job satisfaction. Thus, some of these nurses who have more than 10 years of experience at the job have leadership positions and receive recognition from hospital managers and the community. This could be the main reason for them being satisfied with their jobs.

Recognition is important to employees and can influence job satisfaction. Many researchers have reported that recognition of performance is positively linked with job satisfaction (Abualrub \& Al-Zaru, 2008; Al-Ahmadi, 2002; Khowaja, Merchant \& Hirani, 2005). Al-Ahmadi (2002) reported that there are many factors that determine job satisfaction, and that one of these is recognition. Not only is this finding consistent with these studies, but it is also consistent with Herzberg's theory. According to Herzberg (1966), recognition and job advancement can influence employee satisfaction, such that 'strong determiners of job satisfaction—achievement, recognition, work itself, responsibility and advancement' (pp. 72-73). Nurses who had more experience in and were committed to the hospitals they worked in expected greater recognition (Ma et al., 
2003), and they obtained it. Recognition of the performance of nurses has a strong influence on job satisfaction and intention to stay in the profession; however, lack of recognition and appreciation can have a negative effect on intention to stay in the profession (Abualrub \& Al-Zaru, 2008). Older and experienced nurses receive more respect and greater recognition from their co-workers, managers and most other people. Therefore, this leads them to be more comfortable and satisfied with nursing and the hospital environment.

Finally, Saudi nurses who had between 4 and 10 years of experience in nursing were less satisfied with their jobs and reported a lack of recognition from the nursing manager and hospital leadership. This was strongly supported by the interview results. Nurses 1, 4 and 7, who all had between 4 and 10 years of overall nursing experience, stated that the main reason that could stop them from working in nursing is the lack of recognition and appreciation. At public hospitals, nurses are suffering a lack of appreciation and encouragement. Further, Nurse 5, who had 7 years of experience in nursing, mentioned that lack of recognition and lack of encouragement would make him leave the nursing profession. According to Herzberg's (1966) theory, recognition is one of the factors that determine job satisfaction. The group of nurses with experience of between 4 and 10 years seemed to be disillusioned with nursing and had low motivation, more family responsibilities, fewer opportunities to advance into leadership roles and limited possibilities for professional growth. All of these factors contributed to them being less satisfied with their jobs.

Some Saudi nurses receive recognition from their patients, who encourage them to continue working as nurses in public hospitals. This statement was strongly supported by the interview results. For example, Nurse 6 asserted that his motivation comes from the recognition and appreciation he receives from his patients and their relatives. 
Further, Nurse 13 reported that she had received a formal thankyou letter from a patient after delivering nursing care; however, she had never received any thankyou letters from the hospital.

In brief, Saudi nurses who have between 4 and 10 years of experience in nursing were less satisfied with their jobs than nurses who have either less than 4 or more than 10 years of experience, and this lower level of job satisfaction stems from lack of job recognition. Overall, this result shows that the level of satisfaction with motivation factors for Saudi nurses working in public hospitals was affected by their gender, the number of dependent adults in their care, their duration of employment at the hospital and their overall experience.

\section{Demographic Factors Affecting Hygiene Job Satisfaction}

Two sets of demographic factors were used in this study: personal characteristics and job characteristics and nursing experience. Personal characteristics included gender, age, marital status, number of dependent children, number of dependent adults, educational qualifications and monthly salary. The job characteristics and practical experience included the employing hospital, position, duration of employment at the hospital, number of weekly working hours and overall experience in nursing. The following section discusses the significant demographic factors that affect nurses' hygiene-related job satisfaction in the current study. According to Herzberg's (1966) theory, hygiene factors contribute to dissatisfaction. Hygiene entails the following five factors: company policies and administration, supervision, interpersonal relationships, working conditions and salary. Overall experience was the most significant factor influencing Saudi nurses' job satisfaction (refer to Table 5.20). 


\section{Overall experience.}

Only one of the demographic factors was found to affect job satisfaction among the Saudi nurses in this study: overall nursing experience. A one-way ANOVA test was performed to look at the relationship between the Saudi nurses' overall years of experience and job satisfaction. The results revealed that the Saudi nurses who have 4 10 years overall experience were more dissatisfied in relation to the hygiene factors than other nurses with either less than 4 or more than 10 years of experience $(p=0.020)$. Similarly, Mrayyan (2005) showed a significant positive link between nursing job satisfaction and years of experience. Older nurses have been reported to be more satisfied with their job than nurses who were younger and had less experience in many studies, and they also reported a lower rate of intention to leave their job (Letvak \& Buck, 2008; Rambur et al., 2003).

\section{Leadership style.}

Leadership style is one of the important factors that could negatively influence employees' job satisfaction. Nursing research has shown that there is a link between the leadership style of a hospital's nursing managers and the level of nurses' job satisfaction. According to Al-Hussami (2008), leadership style in a hospital setting can affect the level of nurses' job satisfaction. Further, Lu and colleagues (2005) found that the leadership issue was one of many factors that influenced dissatisfaction and turnover among nurses. In this research study, the findings indicated that leadership style is a factor that plays an essential role in improving and supporting the level of job satisfaction among Saudi nurses working in public hospitals.

Nurses working in public hospitals who have between 4 and 10 years of experience tend to be dissatisfied with their jobs. These nurses play multiple roles in their hospitals, which contribute to making their rights and job descriptions 
indeterminate. Seven of the interviewees indicated that Saudi nurses work without clear job descriptions and are performing more than nursing jobs in public hospitals, such as working in roles that cleaners, administrators or doctors would normally perform. The face-to-face interviews highlighted the reasons for the nurses' intentions to leave nursing. The primary reasons reported were the lack of clarity about nurses' rights and the lack of cooperation of nursing leadership with the nursing staff. For example, Nurse 7 mentioned his goals for the future, and one of his goals was to have clear job descriptions for nurses working in public hospitals. Saudi nurses described unclear job descriptions and poor leadership style at public hospitals. The other interviewees stated that their leaders and managers focused on their mistakes and on the occasional staff errors without showing appreciation or offering rewards for the continual good nursing care provided by the nurses on a daily basis. The nursing departments in Saudi public hospitals are very dependent on, and controlled by, non-nursing professions, such as the head of the medical department and the deputy medical director of the hospital. However, other allied health departments, such as the pharmacy and laboratories, are independent departments. The interviewees, particularly Nurses 3 and 17 were concerned that nurses in public hospitals do not have administrative independence, unlike the other allied health departments. Kleinman (2004) studied the relationship between leadership behaviours and the retention of staff nurses. The results of their study showed a positive relationship between effective manager/leader behaviours and increased staff retention. This was strongly supported by the interview results in this study as well. For example, Nurses 5, 6, 7, 15 and 16 highlighted the fact that communication with nursing management communication and the treatment of staff nurses by the nurse managers could lead them to walk away from their jobs as nurses. 
It is clearly evident from the results of this study that the leadership style of the managers in Saudi public hospitals could negatively or positively influence Saudi nurses' intention to stay or leave their jobs.

\section{Factors That Most Predict Job Satisfaction Among Saudi Nurses}

Multiple regression analysis was utilised to predict the factors that influence Saudi nurses' job satisfaction in all of the three public hospitals. This analysis was conducted to examine which of the independent variables of the study (gender, age, marital status, number of dependent children, number of dependent adults, qualifications, salary, hospital, position, number of weekly working hours, duration of employment at the hospital and overall experience) predicted the outcome variables of motivation and hygiene. The analysis revealed that the significant predictors for satisfaction with motivation were gender and number of dependent adults (refer to Table 5.21). The beta coefficients indicated a negative relationship between the predictor and the outcome variable. Thus, it was evident that female nurses were much less satisfied in their jobs and that nurses who were responsible for dependent adults were also less satisfied with their jobs.

A second multiple regression analysis was used to predict the hygiene factors that influence Saudi nurses' job satisfaction. The results revealed that there were no significant predictor for satisfaction with hygiene (refer to Table 5.23). This result supported Herzberg's theory that hygiene factors are less important for job satisfaction than motivation factors (Herzberg, 1966).

Other multiple regression analyses were used to measure the predictor variables that substantially contributed for gender. The results revealed that the significant predictor for female satisfaction with motivation was the number of dependent adults, with no significant predictor linked to hygiene job satisfaction (refer to Tables 5.25 and 
5.27). Further, the results showed that the significant predictors for male nurses to be satisfied with their jobs were the number of dependent children, monthly salary, position and overall experience, while the employing hospital was a significant predictor for satisfaction with hygiene (see Tables 5.29 and 5.31).

\section{Monthly salary.}

Salary is defined as payment, fringe benefits and wages; it is the regular income that employees receive for their work (Chen et al., 2008). Salary may be the first concern for new nurses and it is high priority for nurses who migrate to find job opportunities with enough income to improve their standard of living and allow them to save. All the participants in this study were Saudi nurses and all of them were working under the MoH umbrella, which means that their salaries and job benefits came from the MoH. Many researchers have found that salary can influence job satisfaction and turnover; for example, Yin and Yang (2002), who studied nursing turnover in Taiwan, reported results that highlighted monthly salaries and payments as the significant factors influencing nursing turnover. Similarly, in this present study, Nurses 11 and 17 reported that good income motivates them to continue working in the nursing field, and Nurse 5 said that the financial incentives in nursing are satisfactory and that this is a good motivation for him to continue working as a nurse.

However, according to Herzberg's (1966) theory, salary is not a motivator; rather, it is a hygiene factor and does not necessarily directly support job satisfaction. Nurses $2,5,6,8$, and 9 were strong supporters of the idea that salary is not a motivator and suggested that more incentives are needed to retain, let alone increase the Saudi nursing workforce. These participants indicated that salaries may be important, but positive encouragement and appreciation of the work rendered by nurses can be far more important than financial incentives, due to their positive impact on the morale and 
performance of staff. Nurse 7 mentioned that a formal thankyou letter from a nursing manager has a much stronger effect on performance than a salary increase. Herzberg's (1966) theory emphasised this point, and indicated that recognition is one of the motivators that does indeed determine job satisfaction.

\section{Factors That Predict Job Satisfaction Among Saudi Nurses in Each of}

\section{the Hospitals}

Data in relation to the factors that influence Saudi nurses' job satisfaction in each of the three public hospitals (Hospital A in Jeddah, Hospital B in Makkah and Hospital C in Taif) were analysed. While all of these hospitals are run by the $\mathrm{MoH}$, and hence all have the same policies, objectives and procedures, analyses of data to identify the factors that influence each public hospital were conducted separately.

\section{Hospital A in Jeddah.}

Hospital A is the largest hospital in Jeddah and in the entire Makkah region. In total, 39 per cent of the nurses participating in this study were from this hospital. Multiple regression analysis was used to predict the factors that influence Saudi nurses' job satisfaction. The analysis revealed that the only significant predictor for satisfaction with motivation and hygiene was gender (refer to Tables 5.45 and 5.47). The beta coefficients indicated a negative relationship between the predictor and the outcome, with the most significant factor influencing Saudi nurses' job satisfaction in Hospital A being gender.

\section{Gender.}

Job satisfaction is a comprehensive issue influenced by various factors, such as gender (Borkowski et al., 2007). In hospital A, the mixed-gender environment may affect the job satisfaction of Saudi nurses. Studies have found a significant correlation between job satisfaction and gender (Al-Ahmadi, 2009; Ragapaksa \& Rothsteim, 2009; 
Sochalski, 2002). In a mixed-gender environment, as in Saudi public hospitals such as Hospital A, gender factors may influence the nurses' job satisfaction, especially in Saudi society. In Saudi Arabia, female and male nurses are viewed as having low status and are perceived negatively as a result of general public image of the nursing profession (Lovering, 2008). This is reflected in the fact that most Saudi nurses become dissatisfied with their job and they feel ashamed to identify their profession to other people, friends and sometimes even family.

This was strongly apparent in the face-to-face interviews in this study. Nurse 7 asserted that the negative view of nursing in Saudi society was one of the important reasons that caused nurses to quit their jobs. Moreover, he said that when someone asks him about his job, he does not say that he works as a male nurse. Instead, he says he is a health worker, as he feels ashamed to say that he is a nurse because of the negative views of society about nursing. Nurse 5 confirmed that when he tells his family members or friends that he works as a nurse, they are surprised and thus he always says he works in health sciences. Nursing has traditionally been an unacceptable profession for both male and female Saudi nationals, but especially for females. This is due to the low status of nurses, based on cultural, traditional and social values. This result in Hospital A confirmed the main finding of this study, as discussed earlier. The job satisfaction of nurses working in Hospital A in Jeddah was more strongly influenced by gender factors than it was for nurses working in hospitals B and C.

\section{Hospital B in Makkah.}

Thirty-seven per cent of the Saudi nurses who participated in this study were from Hospital B in Makkah. The multiple linear regression analysis revealed that the only significant predictor of satisfaction with motivation was the number of dependent adults (refer to Table 5.49) and the only significant predictor for satisfaction with 
hygiene was the nurses' qualifications (refer to Table 5.51). The beta coefficients for both results indicated a negative relationship between the predictors and the outcomes.

\section{Number of dependent adults.}

Being responsible for dependent adults may affect job satisfaction. Nurses working in Hospital B without dependent adults in their care were more satisfied with their jobs compared to nurses who were responsible for dependent adults. In the Saudi community, family relationships are very important and they are influenced by Islamic and cultural values (Mebrouk, 2008). The Islamic context and the local culture encourages all Muslims to take care of their parents and treat them kindly, offer them unlimited support and provide them with a healthy and safe life. This result in Hospital B confirmed the main finding of this study, as discussed earlier. The job satisfaction of nurses working in Hospital B in Makkah was more strongly influenced by the number of dependent adults they had in their care than was the case for nurses working in Hospitals A and C.

\section{Qualifications.}

Nurses working in Hospital B had varying qualifications and levels of education, such as a Diploma in Nursing, a BSN or a MSN. The majority of the nurses in this hospital held a Diploma of Nursing; 80 per cent of all participants in this study have a diploma. Qualification levels are related to job satisfaction worldwide and numerous studies have shown a significant relationship between these two variables (Al-Enezi et al., 2009; Rambur et al., 2003; Yin \& Yang, 2002). Shah, Al-Enezi, Chowdhury and Otaibi, (2004) studied factors that determine job satisfaction among nurses in Kuwait and found that nurses' educational level is a significant predictor of job satisfaction. However, other nursing studies have reported that nurses with a lower level of education are more satisfied with their jobs and less likely to quit (Betkus \& MacLeod, 
2004; Yin \& Yang, 2002). Rambur et al. (2003) studied the intention of registered nurses to leave their position and showed that job satisfaction was lower for nurses with a higher level of education.

However, Saudi nurses lack opportunities to continue their nursing studies, such as by obtaining a bachelor's degree or a postgraduate qualification. Nurses with a bachelor's degree or higher degrees rated the wage and an advanced nursing position as factors that positively influence their job satisfaction compared to nurses with a diploma. According to Cabigao (2009), limited or entirely lacking opportunities for professional development is a major reason for job dissatisfaction. Further, the lack of support for continuing education for nurses in public hospitals is a critical issue; particularly in Hospital B. Nurses who had the opportunity to enrol in an education programme to continue their study were more satisfied and more likely to stay in their profession than those who did not (Hart, 2005).

Opportunities for professional improvement or development are very important, and this was strongly supported by the participants in the face-to-face interviews. For example, one of the future goals for the nursing profession reported by most of the interviewees was continuing nursing education. Nurse 1 reported that Saudi nurses need more opportunities to continue their studies and improve their knowledge. Nurse 11 asserted that a future goal for the nursing profession was more support for nursing research, and developing postgraduate degree programmes in nursing education in Saudi Arabia. Nurses 5 and 14 confirmed that their future goals were continuing their postgraduate studies in nursing. Further, Nurse 2 asserted that her suggestion to maintain and increase Saudi nurses' recruitment and retention would be to boost educational opportunities for nurses. Similarly, Nurse 10 highlighted the need for international scholarships for nurses to pursue higher education overseas. 
Overall, the job satisfaction of nurses working in Hospital B was highly influenced by the number of dependent adults in their care and qualification factors; more so than was the case for the nurses working in Hospitals A and C. More opportunities for Saudi nurses to continue their studies and gain higher qualifications in nursing could enhance the nursing profession, increase job satisfaction and decrease job turnover.

\section{Hospital C in Taif.}

Hospital C in Taif is located in the south-western area of Saudi Arabia and 24 per cent of the total Saudi nurses participating in this study were from Hospital C. For the analysis of variables in this hospital, a bivariate correlation analysis was used between each of the independent variables and the dependent variables. The independent variables included gender, age group, marital status, number of dependent children, number of dependent adults, qualifications, monthly salary, position at the hospital, duration of employment at the hospital, number of weekly working hours and overall experience. The dependent variables were motivation- and hygiene-related job satisfaction. The results revealed that there was no significant relationship between motivation and hygiene factors and the demographic factors for Saudi nurses working in this hospital (refer to Table 5.53). A multiple linear regression analysis was not conducted to assess the prediction for independent factors and Saudi nurses working at Hospital C with the level of satisfaction for these factors because the sample was too small to give results. Therefore, the only analysis performed was the bivariate correlations test.

\section{Chapter Summary}

This chapter addressed the essential issues that arose from the findings of the questionnaire and face-to-face interviews in this study. In summary, the above 
discussion offers insights into the factors that may influence the level of job satisfaction among Saudi nurses working in the three main public hospitals in three cities-Jeddah, Makkah and Taif — in the Makkah region of Saudi Arabia. According to the findings, the factors that influenced motivation job satisfaction were gender, number of dependent adults, duration of employment in the hospital and overall nursing experience. The second section discussed how demographic factors affected hygiene job satisfaction factors. The only factor that affected hygiene job satisfaction was overall experience. The third section discussed the factors that predicted job satisfaction among Saudi nurses working in the three public hospitals. The factors that predicted job satisfaction with motivation were gender and number of dependent adults.

The last section discussed the factors that affected Saudi nurses working in each of the public hospitals in relation to the motivation and hygiene job satisfaction factors. The findings indicated that gender influenced Saudi nurses working in Hospital A in Jeddah, while in Hospital B in Makkah, the number of dependent adults and level of qualification influenced Saudi nurses' job satisfaction. No significant factors were found to influence Saudi nurses working in Hospital C in Taif. Job satisfaction was positively influenced in Saudi nurses working in public hospitals in the Makkah region and the finding of this study showed that Saudi nurses generally were not satisfied with their jobs. The next chapter provides the research conclusions and key implications derived from the results of this study and offers context-appropriate recommendations. 


\section{Chapter 8: Conclusion}

\section{Introduction}

This chapter concludes the thesis by examining the strengths and limitations of this study. It also discusses the implications of the findings of this research and makes recommendations for the $\mathrm{MoH}$ in Saudi Arabia for policy changes. Recommendations for nursing education, nursing practice and nursing leadership are also made. An appeal is made for the Saudi community to support the nursing profession so that successful recruitment of students to study and work as nurses increases in order to maintain and sustain a national nursing workforce. This chapter makes recommendations for future research in this important area that will assist in the achievement of the aims and goals of Saudization, and then concludes this thesis.

\section{Strengths of the Study}

Based on the current published research, this study was the first to identify and explore the factors that influence job satisfaction in Saudi-born nurses working in public hospitals in the Makkah region. Previous studies have explored Saudi and non-Saudi nurses' job satisfaction in a mixture of public and private hospitals. This is a major addition and a significant contribution to the body of nursing knowledge in general, and more specifically, for the Saudi MoH. The results of this study are important because they provide baseline data on the job satisfaction of Saudi nurses working in public hospitals and can be used as a point of reference for future similar studies in the same region, as well as across the Kingdom. The aim of this study is to assist in identifying what the Saudi healthcare institutions and systems can do to retain Saudi nurses in their jobs.

The results of this study identified why Saudi nurses are attracted to nursing as a career and what factors were important in assisting them to make decisions to join the 
nursing workforce. These issues and factors will assist the $\mathrm{MoH}$, as well as the universities, to develop recruiting strategies that will attract a greater number of Saudis to the nursing profession.

Job satisfaction has become even more important for the nursing workforce due to the worldwide shortage of nurses (Hansen, 2007; Peterson, 2009). Job satisfaction is a key factor in increasing and stabilising the nursing workforce in Saudi Arabia, and a crucial factor in improving the overall quality of patient care provided. This study investigated factors that influence Saudi nurses working in public hospitals in three major cities in the Makkah region: Jeddah, Makkah and Taif. A further strength of this research is the exploration of the nurses' workplace environments, their attitudes towards their patients and health team members and their individual characteristics. All of these add to the Ministry's knowledge of the factors that positively influence job satisfaction among Saudi nurses. The findings of this study may contribute to enhancing the job satisfaction of nurses in the Makkah region through the implementation of the suggestions made by the nurses in the face-to-face interviews. MoH policymakers must assess and consider the needs expressed by the Saudi nurses in order to have a clear understanding of what actions are required to assist in maintaining and retaining a Saudi nursing workforce. One of the participants in the face-to-face interviews suggested that following this study, assessment of the job satisfaction of Saudi nurses should be conducted annually in all the regions of Saudi Arabia. The responses and suggestions provided by the nurses should be taken into consideration. An action plan should be developed by policymakers to implement the suggestions made by Saudi nurses in order to increase their level of satisfaction in their jobs.

The next strength of this study is the use of a mixed methods design. Johnson and Christensen (2008) consider that research results are stronger when based on a 
variety of methods. This mixed methods approach is common in healthcare research, and healthcare researchers use this approach to determine and explore complex and multi-faceted problems, such as job satisfaction, shortage, retention and staff turnover in the healthcare system (Doyle et al., 2009). The use of both quantitative and qualitative approaches assisted in establishing a wider understanding and obtaining rich responses via the interviews, in which nurses were able to reflect on their careers and explain what made them choose this career, what really matters to keep them in their career and the factors that might lead them to consider leaving nursing.

This research applied a concurrent mixed methods design, with a combination of quantitative and qualitative data collection and analysis. This approach of using a variety of methods was used to enhance the research validity and to provide greater confidence in the findings. Another strength of this study is the use the MotivationHygiene Theory as a conceptual framework. The results of this study supported the theory that motivation and hygiene factors affect job satisfaction, recruitment and retention of the Saudi nursing workforce. The final strength of this study is that it has identified factors that influence job satisfaction among Saudi nurses working in public hospitals and thus is important to support and enhance the $\mathrm{MoH}$ in its efforts increase and maintain the stability of the Saudi nursing workforce through the Saudization plan. According to Omer (2005), under the Saudization programme, the Saudi Arabian government and $\mathrm{MoH}$ have placed a high priority for the recruitment and education of Saudis to nursing programmes to satisfy the growing need for nurses in the healthcare system.

\section{Limitations of the Study}

One limitation of this study was that only Saudi nurses working in public hospitals in the Makkah region participated in the study. Hence, the findings might not 
be applicable to nurses working in other public health sectors, such as primary healthcare centres. The results may also be unique to the Makkah region and nurses working in public hospitals in other Saudi regions may have differing views. Therefore, the findings of this study may not be applicable to all registered nurses working in public hospitals in Saudi Arabia.

A second limitation was that there was insufficient literature available on the factors that influence job satisfaction among Saudi nurses working in public hospitals in Saudi Arabia, as well as in other health sectors, so the results could not be compared to any past trends. This deficiency can be attributed to the fact that there has been little research among Saudi nurses in Saudi public hospitals. Thus, it is not possible to critically compare the results of this study with comparable research in Saudi Arabia to check for differences in opinion.

The last limitation was that it was very difficult to collect qualitative data for the study, especially when seeking to conduct face-to-face interviews with Saudi nurses in a closed area in each of the hospitals. This was challenging due to social, religious and cultural concerns. The interviews with female nurses were conducted in a culturally respectful way, in a quiet but open area in the nursing education department.

Nonetheless, potential participants were reluctant to meet and speak with the researcher. As a result, the number of female participants in the face-to-face interviews was reduced. These limitations were understood through the interpretation of the results and implications in the current study. Importantly, they should be taken into consideration for further nursing research.

\section{Implications and Recommendations}

The nursing shortage has become a serious issue within the healthcare systems in many countries worldwide and has a negative impact on the quality of healthcare 
delivery. There is an urgent need for concerted efforts to improve the shortage of Saudi nurses and to reduce the high turnover within the nursing workforce, which is affected by the lack of job satisfaction among nurses working in Saudi Arabia. With the continual shortage of Saudi nurses in public hospitals, Saudi nurses' level of job dissatisfaction is expected to increase, supporting increased turnover as well. Further, a continued shortage of Saudi national nurses could result in an increase in the recruitment of expatriate nurses to cover these shortages within Saudi public hospitals and Saudi healthcare organisations, thereby undermining the Saudization policy. Hence, it is in the best interest of all stakeholders that the $\mathrm{MoH}$ understands and recognises what contributes to the job satisfaction of Saudi nurses. The MoH should appreciate the impact of dissatisfaction on the health organisations and the overall healthcare system and, most importantly, on the quality of care provided to Saudi patients. Based on the findings of this study, implications and recommendations are made for health policy, nursing education, nursing leadership and for the Saudi community to ensure improvements in the level of job satisfaction among Saudi nurses working in public hospitals in the Makkah region.

\section{Recommendations for the MoH.}

Based on the findings of this study, the recommendations for the Saudi MoH are as follows:

- The Saudi MoH should formulate a national database for all health sectors indicating the number of national and expatriate nurses in each healthcare agency (private and public). The healthcare agencies must have bi-annual reviews of their workforce and report this data directly to the national database. Hence, the MoH can more effectively monitor the supply and demand for 
nurses, conduct audits and publish regular and comparable healthcare workforce statistics.

- The MoH needs to adopt a new strategic plan based on the findings of this research project and previous job satisfaction studies in order to increase and sustain the national nursing workforce.

- Policymakers should focus on the needs of Saudi nurses to enhance job satisfaction and decrease turnover. This study has revealed factors important to Saudi nurses, such as childcare facilities, flexible working conditions, including part-time work to allow nurses to share family care responsibilities for children and dependent adults, the provision of rewards and an improved hospital transportation system to facilitate the transport of female nurses to work without the need to rely on a male family member.

- The MoH needs to conduct advertising campaigns to improve the image of the nursing profession to increase its adoption as a professional career by the public. These campaigns should utilise the internet and the media to reach out to the public.

- The MoH. along with the MoE, should work hand-in-hand to assist in promoting the nursing profession in all high schools throughout the Kingdom. These two ministries should consult with specialised companies to conduct career fairs as well as workplace introductions for high school students.

- It is necessary that the MoH develops policies to reduce nursing attrition. Hospital administrations can develop an award and reward system for nurses that will support retention of the nurses in their jobs. For example, nurses who perform well should be encouraged by rewards in the form of formal recognition at work, MoH awards, job promotion and higher duty opportunities, as well as 
educational and financial incentives. According to Herzberg's (1966) theory, such incentives and recognition will assist in increasing the retention rate and job satisfaction of the nursing staff.

- The MoH should establish a professional Saudi Nursing Council that will assess the registration of local nurses and the qualifications of foreign nurses who work in Saudi Arabian hospitals. This Council should be promoted and supported by the $\mathrm{MoH}$. Once this Council is formed, then nursing as a profession will become independent, like other allied healthcare professions. This will also support coordination between the various sectors in the nursing profession, health ministries and the private sector in order to contribute solutions aimed at improving nursing workforce problems such as shortages, developing nursing education and practice, and, in particular, reducing nursing job dissatisfaction.

- It is recommended that research into job satisfaction of Saudi nurses continue in order to improve job satisfaction, decrease nursing turnover and shortages.

\section{Recommendations for education.}

Based on the findings of this study, the recommendations for education for

Saudi nurses who work in the public hospitals are as follows:

- It is recommended that the MoH and MoHE should continue to provide opportunities for nurses to upgrade their qualifications from a diploma to a bachelor's degree. In addition, opportunities should be provided for nurses to purse postgraduate education to promote research and enhance the academic status of the profession.

- It is recommended that the $\mathrm{MoH}$ establish a comprehensive education plan for all Saudi nurses working in public hospitals through in-service education and training. Further, educational facilities such as libraries, and learning resources 
such as computers and internet access, should be provided for nurses so that they can update and refresh their practical skills and knowledge as well as write, publish and share international nursing research output and conference programme materials.

- It is recommended that the MoH cooperates with the MoHE to increase the number of university-qualified nurses.

- It is also recommended that the MoE should collaborate with the Saudi universities and consider introducing Master's and $\mathrm{PhD}$ programmes in nursing for nurses who are not able to travel abroad due to family commitments.

\section{Recommendations for leadership.}

Based on the findings of this study, the recommendations for Saudi nurse managers who work in the public hospitals are:

- MoH managers must provide a highly supportive leadership role to all nurses. Effective management and supervisory skills are very important in supporting and motivating nurses and enhancing their skills and performance on the job.

- The nursing discipline should be supported to function independently from other allied health professions. The nursing profession should be able to plan and develop an Order of Nurses or a Nursing Council similar to all other professions. Job descriptions should be drawn, defining the hierarchal roles in both the nursing practice and nursing education fields, clearly outlining the expectations for each position. This would provide clear promotional pathways and opportunities for nurses.

- Hospital nursing managers should scout the wards and have a close relationship with the nurses on the wards. Meetings should be organised with each nurse at least once a year in order to have open discussions between nursing management 
and staff. Nurse managers should be able to deduce from such discussions the intentions of the nurses to stay or leave and should explore with the nurse the reasons behind such intentions. Discussions between nursing management and staff nurses should identify the factors that could contribute to increased nurse job satisfaction and should explore potential solutions to these problems, supporting enhanced job satisfaction.

- Nurses need regular contact with senior management through formal and informal meetings to discuss their issues and feel that they are being heard and understood.

\section{Recommendations for practice.}

Based on the findings of this study, the recommendations for Saudi staff nurses who work in the public hospitals are as follows:

- Saudi nurses should have clear job descriptions to avoid the need to assume multiple roles in the hospital, which contributes to job overload and staff stress and burnout.

- Saudi nurses should be provided with follow-up training on new technical and technological advances that are brought into their practice areas.

- A preceptorship programme should be established at each hospital so that experienced nurses who are satisfied with their jobs can preceptor new graduates and assist them to settle into their jobs. This will have a positive effect on new graduates and will provide excellent role models and mentors for them.

- Hospitals should incorporate an orientation programme for new staff nurses, providing them with the necessary information about their jobs, increasing the nurses' understanding of their hospital's policies and procedures and informing them of specific details about their workplace. 


\section{Recommendations for the Saudi community.}

Based on the findings of this study, the recommendations for the Saudi community are:

- It is recommended that the image of the nursing profession in the Saudi community be improved through explaining the roles nurses play in society. The role of nursing in the healthcare profession, the health community and the prevention of disease must be identified and understood.

- It is essential to educate Saudi society about the nursing profession and the roles of female and male nurses working in mixed-gender environment settings to improve the public image of nurses. This will contribute to improving job performance and reducing nursing turnover. This image should be improved by informational programmes and educational opportunities such as TV programmes, radio talk shows, the internet, the press and intensive recruitment campaigns in girls' and boys' schools.

- The governement, the leaders in the nursing profession and the media have to cooperate in providing a positive image of the nursing profession by highlighting at every opportunity the important role of nursing to the Saudi public. This will encourage the Saudi community to study and work as nurses and will solve the shortage of nurses' issue and will allow national nurses to provide culturally specific and appropriate nursing care to the people of Saudi Arabia.

- It is necessary to shift the social perceptions of the nursing profession in Saudi Arabia from a negative to a positive view, which will support the $\mathrm{MoH}$ programme of Saudization for the retention of Saudi nurses, thereby decreasing the number of expatriate nurses and replacing them with Saudi nurses. This will 
be achieved if nurses are satisfied, able to provide quality care and are given more incentives (to all nurses) by the MoH.

- The Saudi community should respect and support Saudi nurses in general, and particularly nurses working in public hospitals, like other professions in the same hospitals. This can only be achieved through the support of other health professionals and through collaborative work that will improve the roles of nurses as well as intensive a positive media campaign be implemented to improve the community respect and appreciation of nursing as a profession.

- Saudi females have limited career options available to them and nursing is a viable career option for Saudi women. However, female nurses need more respect and encouragement to continue working and helping female patients, since it is culturally inappropriate for male nurses to provide nursing care to female patients.

\section{Recommendations for future research.}

This research has contributed new knowledge regarding Saudi nurses' job satisfaction. It could be used to guide policymakers in making decisions for future directions, and recommendations for this are:

- The first recommendation is to investigate and explore the concept of job satisfaction among female and male Saudi nurses in the 12 other regions of Saudi Arabia. It would be advisable to replicate this study in order to be able to make comparisons between Saudi nurses working in public hospitals in different regions of Saudi Arabia.

- It is also recommended to replicate this study and examine the job satisfaction of Saudi nurses working in community centres, private hospitals, military hospitals and educational hospitals and compare the findings to this study. Exploring the 
differences and similarities in responses will establish whether there are different protocols that promote job satisfaction in these different health sectors that could be implemented across all healthcare agencies in order to promote nurses' job satisfaction and retention.

- It is recommended to conduct job satisfaction studies based on different theories such as Maslow's hierarchy of needs and using different research instruments or measures, such as the MMSS. It would be helpful to examine the various findings and compare them to this study to assess differences and similarities and whether other novel findings are uncovered.

- The focus of this study was on Saudi nurses, but it is also important to conduct similar studies on a mixed sample of Saudi and expatriate nurses working in the public hospitals to compare and gain a comprehensive view of the factors that positively influence job satisfaction among nurses in Saudi public hospitals.

- It is also recommended to conduct a study comparing nurses' job satisfaction with the job satisfaction levels of other healthcare professionals working in Saudi public hospitals.

\section{Implications of the conceptual framework.}

The conceptual framework utilised in the current study is the motivationhygiene theory, also known as Herzberg's two-factor theory or Herzberg's dual-factor theory (1959). The main concept of this theory is the difference between motivation factors and hygiene factors. Hygiene factors are considered less important to job satisfaction than are motivation factors. Motivation factors lead to job satisfaction because of the need of the individual for self-growth and self-actualisation. This theory is one of the most commonly used theories in job satisfaction research (Dion, 2006). As seen in the literature review, many studies in nursing research have used this theory as a 
theoretical framework in testing job satisfaction of nurses (Jones, 2011; Kacel et al., 2005; Lephalala, 2006; Mitchell, 2009; Russell \& Gelder, 2008). This study was based on Herzberg's theory because the motivating and hygiene factors are correlated in the research instrument, the NWI-R, utilised in the quantitative phase of this study to explore and identify the factors that affect job satisfaction.

\section{Motivation factors.}

According to Herzberg (1966), motivation factors are intrinsic and linked to the job itself and produce job satisfaction. Their absence leads to a lack of job satisfaction. The six motivation factors noted by Herzberg include advancement in the job or career, the work itself, the possibility for growth and development, the responsibility given to the worker, feeling recognised and the sense of achievement (Herzberg, 1966). The results of this study indicated that the mean job satisfaction scores in relation to motivating factors were significantly lower among female nurses than male nurses and among nurses who do not have dependent adults at home compared to nurses who have dependent adults in their care. Nurses who had worked in the hospitals for 5-10 years were significantly less satisfied with the motivating factors than other nurses. Nurses who had overall experience of more than 4 years and less than 10 years were significantly less satisfied with the motivating factors than other nurses groups.

\section{Hygiene factors.}

According to Herzberg (1966), hygiene factors are extrinsic to the job and poor hygiene factors can cause job dissatisfaction. However, improved hygiene factors can decrease job dissatisfaction. Hygiene factors include company policies and administration, supervision, interpersonal relations, working conditions and salary (Herzberg, 1966). The results of this study indicated that the mean satisfaction scores in relation to hygiene factors were significantly lower only among nurses who had an 
overall experience of more than 4 years and less than 10 years. The hygiene factors were less important to job satisfaction among the participants.

In summary, the results of this study support Herzberg's motivation-hygiene theory, which asserts that the hygiene factors are less important to job satisfaction; however, the motivation factors are most important and can lead to job satisfaction. This theory seemed to identify and explain the phenomena of job satisfaction among Saudi nurses working in public hospitals in Makkah region of Saudi Arabia.

\section{Conclusion}

The widespread nursing shortage and the high turnover rate of nurses have become a significant problem and phenomenon in most healthcare organisations of both developed and developing countries around the globe. In the Saudi Arabian healthcare system, the shortage of Saudi nurses working in the public hospitals is a major concern, as it greatly affects the efficiency and productivity of the healthcare sector (Al-Aameri, 2000). The shortage of Saudi nurses is mainly attributed to various social, cultural and educational factors. Over many decades, the Saudi Arabian MoH has relied exclusively on the recruitment of expatriate nurses from 40 countries, such as the United Kingdom, Ireland, United States of America, Philippines, South Africa, Malaysia and India, to service its public hospitals. The stability of the Saudi national nursing workforce is important to maintain the efficient functioning of the Saudi Arabian healthcare system. Identifying and improving the factors that affect job satisfaction among Saudi nurses could help to maintain the stability of Saudi nurses working in public hospitals and increase the number of Saudi students enrolling in nursing programmes in the future.

This study provided insights into specific components of the factors that influence Saudi nurses' job satisfaction. This study benefits the nursing profession by adding knowledge with regard to Saudi nurses' job satisfaction in Saudi Arabian public 
hospitals. Thus, this study fills a gap in the Saudi literature and has allowed recommendations to be made for future nursing workforce directions. One of the most important interventions should be the ability to recruit and retain Saudi national nurses into the Saudi public healthcare system. The Saudi Arabian MoH should support and encouraging the recruitment and development of Saudi nurses, who will be able to deliver high quality care and who share the Arabic language and Saudi culture with their patients.

This study has identified the factors that affect job satisfaction among female and male Saudi nurses working in public hospitals in three cities in the Makkah region, Saudi Arabia. Overall, this study found that Saudi nurses working in public hospitals in the Makkah region were not satisfied with their jobs. The findings in this study identified the factors that affected Saudi national nurses' job satisfaction and the results indicated that female Saudi nurses in particular were not satisfied with their jobs in public hospitals. Nurses who had dependent adults in their care, and those who had been employed for 5-10 years in public hospitals were the least satisfied with their jobs. In addition, nurses who had an overall experience of 4-10 years were dissatisfied with their jobs in public hospitals. It is imperative that the Saudi Arabian MoH consider these results and work to improve job satisfaction among Saudi nurses. This will assist in the recruitment and retention of Saudi nurses in Saudi public hospitals. 


\section{References}

Abu-Zinadah, S. (2004). The situation of Saudi nursing. Health Forum, 52, 42-43.

Abu-Zinadah, S. (2006). Nursing situation in Saudi Arabia. Riyadh, Saudi Arabia:

Saudi Council for Health Specialties. Retrieved from

http://www.nurse.scfhs.org.

Abualrub, R. F., \& Al-Zaru, I. M. (2008). Job stress, recognition, job performance and intention to stay at work among Jordanian hospital nurses. Journal of Nursing Management, 16(3), 227-236.

Abualrub, R. F., \& Alghamdi, M. G. (2012). The impact of leadership styles on nurses' satisfaction and intention to stay among Saudi nurses. Journal of Nursing Management, 20(5), 668-678.

Abu Raddaha, A. H., Alasad, J., Albikawi, Z. F., Batarseh, K. S., Realat, E. A., Saleh, A. A., \& Froelicher, E. S. (2012). Jordanian nurses’ job satisfaction and intention to quit. Leadership in Health Services, 25(3), 216-231.

Abo-Znadh, S. H. (1999). An exploration of selected staff and job characteristics, and their relationship to quality of work life, among staff nurses in medical/surgical units in two tertiary care hospitals in Saudi Arabia. $\mathrm{PhD}$ thesis, George Mason University, Fairfax, VA.

Adair, John. (2006). Part 2. Maslow and Herzberg, Chapter 6. Herzberg's motivationhygiene theory. Leadership and motivation. London and Philadelphia: Kogan Page.

Adams, A., \& Bond, S. (2000). Hospital nurses' job satisfaction, individual and organizational characteristics. Journal of Advanced Nursing 32(3), 536-543.

Aiken, L. H., Clarke, S. P., Sloane, D. M., Sochalski, J. A., Busse, R., Clarke, H., Giovanetti, P., Hunt, J., Rafferty, A. M., \& Shamian, J. (2001). Nurses’ reports 
on hospital care in five countries: The ways in which nurses' work is structured have left nurses among the least satisfied workers, and the problem is getting worse. Health Affairs, 20(3), 43-53.

Aiken, L. H., Clarke, S. P., Sloane, D. M., Sochalski, J., \& Silber J. H. (2002). Hospital nurse staffing and patient mortality, nurse burnout, and job dissatisfaction. Journal of the American Medical Association, 288, 1987-1993.

Aiken, L. H., \& Patrician, P. A. (2000). Measuring organizational traits of hospitals: The revised Nursing Work Index. Nursing Research, 49(3), 146-153.

Alhusaini, H.A. (2006). Obstacles to the efficiency and performance of Saudi nurses at the Ministry of Health, Riyadh Region: Analytical field study. Riyadh, Saudi Arabia: Ministry of Health [in Arabic].

Al-Aameri, A. S. (2000). Job satisfaction and organizational commitment for nurses. Saudi Medical Journal, 21(6), 531-535.

Al-Aameri, A. S. (2003). Source of job stress for nurses in public hospitals. Saudi Medical Journal, 24(11), 1183-1187.

Al-Ahmadi, H. (2002). Job satisfaction of nurses in Ministry of Health hospitals in Riyadh, Saudi Arabia. Saudi Medical Journal 23, 645-650.

Al-Ahmadi, H. (2009). Factors affecting performance of hospital nurses in Riyadh Region, Saudi Arabia. International Journal of Healthcare Quality Assurance, $22(1), 40-54$.

Al-Dossary, R., Vail, J., \& Macfarlane, F. (2012). Job satisfaction of nurses in a Saudi Arabian university teaching hospital: A cross-sectional study. International Nursing Review, 59(3), 424-430.

Al-Dossary, A., While, A., \& Barriball, L. (2008). Healthcare and nursing in Saudi Arabia. International Nursing Review, 55(1), 125-128. 
Al-Enezi, N., Chowdhury, R. I., Shah, M. A., \& Al-Otabi, M. (2009). Job satisfaction of nurses with multicultural backgrounds: A questionnaire survey in Kuwait. Applied Nursing Research, 22(2), 94-100.

Al-Hammad, F. A., Raheel, H., Al-Baiz, L. E., \& Al-Otaibi, A. M. (2009). The effect of shift work on psychological stress, sleep pattern and health of nurses working at a tertiary hospital, Riyadh. Middle East Journal, 6(6), 14-20.

Al-Hussami, M. (2008). A study of nurses' job satisfaction: The relationship to organizational commitment, perceived organizational support, transactional leadership, transformational leadership, and level of education. European Journal of Scientific Research, 22(2), 286-295.

Al Hosis, K. F., Mersal, F. A., \& Keshk, L. I. (2013). Effects of job stress on health of Saudi nurses working in Ministry of Health hospitals in Qassim region in KSA. Life Science Journal, 10(1), 1036-1044.

Almalki, M., Fitzgerald, G., \& Clark, M. (2011a). Healthcare system in Saudi Arabia: An overview. Eastern Mediterranean Health Journal, 17(10), 784-793.

Almalki, M., FitzGerald, G., \& Clark, M. (2011b). The nursing profession in Saudi Arabia: An overview. International Nursing Review, 58(3), 304-311.

Almalki, M. J., Fitzgerald, G., \& Clark, M. (2012). Quality of work life among primary healthcare nurses in the Jazan region, Saudi Arabia: A cross-sectional study. Human Resources for Health, 10(1), 30.

Al-Mahmoud, S. (2013). The commitment of Saudi nursing students to nursing as a profession and as a career. Life Science Journal, 10(2), 591-603.

Al-Momani, M. M. (2008). Improving nurse retention in Jordanian public hospitals. Topics in Advanced Practice Nursing, 8(4), 9.

Al-Osaimi, M. H. (2004). The first nurse. Jeddah, Saudi Arabia: King Fahd Hospital 
Press.

Al-Omar, B. A. (2003). Sources of work stress among hospital staff at the Saudi Ministry of Health. JKAU: Economy \& Administration, 17(1), 3-16.

Al-Omar, B.A. (2004). Knowledge, attitudes and intention of high school students towards the nursing profession in Riyadh city, Saudi Arabia. Saudi Medical Journal, 25(2), 150-155.

Al-Otaibi, M., Makhdom, Y., \& Ibrahim, A. (2012). Sources of work stress and productivity among female healthcare workers in the emergency departments of general hospitals in Jeddah, K.S.A. Journal of Applied Medical Sciences, 1(2), 69-79.

Al-Sadan, I. A. (2000). Educational assessment in Saudi Arabian schools. Assessment in Education, I, 142-155.

Al-Zayyer, W. (2003). The effectiveness of recruitment and retention strategies and the severity of recruitment and retention barriers of staff nurses in selected tertiary care hospitals in Saudi Arabia. PhD thesis, George Mason University, Fairfax, VA.

Arab News. (2011). King Abdullah grants women the vote. Retrieved from http://arabnews.com/saudiarabia/article506568.ece?comments=all

Ary, D., Jacobs, L., Sorenson, C., \& Razavieh, A. (2009). Introduction to research in education ( $8^{\text {th }}$ ed.). Belmont, CA: Wadsworth.

Ashy, M. A. (2004). Saudi Arabia. In K. Malley-Morrison (Ed.), International perspectives on family violence and abuse: A cognitive ecological approach (pp. 167-186). New Jersey: Lawrence Erlbaum Associates.

Bahalkani, H. A., Kumar, R., Lakho, A. R., Mahar, B., Mazhar, S. B., \& Majeed, A. (2011). Job satisfaction in nurses working in tertiary level healthcare settings of 
Islamabad, Pakistan. Journal of Ayub Medical College, Abbottabad, 23(3), 130133.

Barney, S. M. (2002). The nursing shortage: Why is it happening? Journal of Healthcare Management, 47(3), 153-155.

Best, M. F., \& Thurston, N. E. (2004). Measuring nurse job satisfaction. Journal of Nursing Administration, 34(6), 283-290.

Betkus, M. H., \& MacLeod, M. L. P. (2004). Retaining public health nurses in rural British Columbia: The influence of job and community satisfaction. Canadian Journal of Public Health, 95(1), 54-58.

Borkowski, N., Amman, R., Song, S., \& Weiss, C. (2007). Nurses' intent to leave the profession: Issues related to gender, ethnicity and educational level. Healthcare Management Review, 32, 160-167.

Brenner, M. E. (2006). Interviewing in educational research. In J. Green, G. Camilli \& P. Elmore (Eds), Handbook of complementary methods in education research. Hillsdale, NJ: Lawrence Erlbaum.

Brewer, J., \& Hunter, A. (1989). Multimethod research: A synthesis of styles. Newbury Park, CA: Sage.

Brooks, B. A., \& Anderson, M. A. (2004). Nursing work life in acute care. Journal of Nursing Care Quality, 19(3), 269-275.

Brown, G. (2005). International Nursing Department: An up close and personal look at Saudi Arabia (Jeddah and Riyadh): History, culture, and healthcare. ABNF Journal, 16(4), 83-86.

Bryman, A. (2008). Social research methods ( $3^{\text {rd }}$ ed.). Oxford: Oxford University Press. Burns, N., \& Grove, S. (2005). The practice of nursing research: Conduct, critique and utilization $\left(5^{\text {th }}\right.$ ed.). Philadelphia: Saunders. 
Burns, N., \& Grove, S. K. (2009). The practice of nursing research $\left(6^{\text {th }}\right.$ ed.). Linn, MO: Saunders Elsevier.

Cabigao, E. (2009). Predictors of intention to quit and satisfaction among nurses who work in nursing homes. PhD thesis, College of Health Sciences, Trident University International, Cypress, CA.

Cahill, B. A. (2011). Impact of the state practice environment on nurse practitioner job satisfaction. $\mathrm{PhD}$ thesis, Health Sciences Center, University of Illinois at Chicago, IL.

CDSI. (2013). Saudi Statistics. Retrieved from http://www.cdsi.gov.sa/english/index.php

Chan, Z. C. Y., Tam, W. S., Lung, M. K. Y., Wong, W. Y., \& Chau, C. W. (2013). On nurses moving from public to private hospitals in Hong Kong. Journal of Clinical Nursing, 22(9-10), 1382-1390.

Chen, H.-C., Chu, C.-I., Wang, Y.-H., \& Lin, L.-C. (2008). Turnover factors revisited: A longitudinal study of Taiwan-based staff nurses. International Journal of Nursing Studies, 45(2), 277-285.

Choong, Y.-O., Lau, T.-C., Kuek, T.-Y., \& Lee, E.-K. (2012). Job satisfaction of Malaysian nurses: A causal model. Journal of Economics and Behavioral Studies, 4(12), 723-729.

Central Department of Statistics. (2012). Statistical Yearbook, 2010. Retrieved from http://www.cdsi.gov.sa/yb46/Pages/MixFPage.htm

Cohen, L., Manion, L., \& Morrison, K. (2010). Research methods in education ( $2^{\text {nd }}$ ed.). London: Routledge.

Cone, J. D., \& Foster, S. L. (2003). Dissertations and theses: From start to finish: Psychology and related fields. Washington, DC: American Psychological 
Association.

Coomber, B., \& Barriball, L. K. (2007). Impact of job satisfaction components on intent to leave and turnover for hospital-based nurses: A review of the research literature. International Journal of Nursing Studies, 44(2), 297-314.

Cowin, L. (2002). The effects of nurses' job satisfaction on retention: An Australian perspective. Journal of Nursing Administration, 32(5), 283-291.

Creswell, J. W. (2002). Educational research: Planning, conducting, and evaluating quantitative and qualitative research. Upper Saddle River, NJ: Pearson Education.

Creswell, J. W. (2008). Educational research: Planning, conducting, and evaluating quantitative and qualitative research $\left(3^{\text {rd }}\right.$ ed.). Upper Saddle River, NJ: Pearson Education.

Creswell, J. W. (2009). Research design: Qualitative, quantitative, and mixed methods approaches $\left(3^{\text {rd }}\right.$ ed.). Thousand Oaks, CA: Sage.

Creswell, J. W., \& Plano Clark, V. L. (2011). Designing and conducting mixed methods research $\left(2^{\text {nd }}\right.$ ed.). Thousand Oaks, CA: Sage.

Curtis, E. A. (2008). The effects of biographical variables on job satisfaction among nurses. British Journal of Nursing, 17(3), 174-180.

Dion, M. J. (2006). The impact of workplace incivility and occupational stress on the job satisfaction and turnover intention of acute care nurses. $\mathrm{PhD}$ thesis, University of Connecticut, Storrs, CT.

Doyle, L., Brady, A.-M., \& Byrne, G. (2009). An overview of mixed methods research. Journal of Research in Nursing, 14(2), 175-185.

Energy Information Agency (EIA). (2011). Saudi Arabia. Retrieved from http://www.eia.doe.gov/cabs/Saudi_Arabia/Oil.html 
El-Gilany, A, \& Al-Wehady, A. (2001). Job satisfaction of female Saudi nurses. East Mediterranean Health Journal, 7(1/2), 31-37.

El-Jardali, F., Dimassi, H., Dumit, N., Jamal, D., \& Mouro, G. (2009). A national crosssectional study on nurses' intent to leave and job satisfaction in Lebanon: Implications for policy and practice. BMC Nursing 8,3 .

El-Sanabary, N. (2003). Women and the nursing profession in Saudi Arabia. In N. H. Bryant (Ed.), Women in nursing in Islamic societies (pp. 255-280). Pakistan: Oxford University Press.

Erlin, J. (2004). Wanted—nurses: Ethical issues and the nursing shortage. Orthopedic Nursing, 23(4), 289-292.

Gall, M., Gall, J. \& Borg, W. (2010). Applying educational research: How to read, do, and use research to solve problems of practice (6th ed.). Boston, MA: Pearson.

Gallagher, E. B. (2002). Modernization and health reform in Saudi Arabia. In A. C. Twaddle (Ed), Healthcare reform around the world (pp. 181-197). London: Auburn House.

Gay, L. R., \& Airasian, P. W. (2000). Educational research: Competencies for analysis and application $\left(6^{\text {th }}\right.$ ed.). Upper Saddle River, N.J.: Merrill.

Gill, A.S., Flaschner, A.B., \& Shachar, M. (2006). Mitigating stress and burnout by implementing transformational leadership. International journal of contemporary hospitality management, 18(6), 469-481.

Gillham, B. (2005). Research interviewing: A practical guide. Maidenhead: Open University Press.

Hansen, K. (2007). Nurses' job satisfaction. M.S. thesis, D’Youville College, New York.

Hart, S. A. (2005). Hospital ethical climates and registered nurses' turnover intentions. 
Journal of Nursing Scholarship, 37(2),173-177.

Hayes, B., Bonner, A., \& Pryor, J. (2010). Factors contributing to nurse job satisfaction in the acute hospital setting: A review of recent literature. Journal of Nursing Management, 18(7), 804-814.

Hayes, B., Bonner, A., \& Douglas, C. (2013). The levels of job satisfaction, stress and burnout in Australia and New Zealand haemodialysis nurses. In Renal Society of Australasia Conference, 6-8 June 2013, Hobart, Tasmania, Australia.

Hayes, L. J., O’Brien-Pallas, L., Duffield, C., Shamian, J., Buchan, J., Hughes, F., Spence-Laschinger, H. K., North, N., \& Stone, P. W. (2006). Nurse turnover: A literature review. International Journal of Nursing Studies, 43(2), 237-263.

Herzberg, F. (2003). One more time: How do you motivate employees? Harvard Business Review, 81(1), 86.

Herzberg, F., Mausner, B., \& Snydermann B. (1959). The motivation to work. New York: Wiley.

Herzberg, F. (1966). Work and the nature of man. New York: World Publishing.

Hegney, D., Plank, A., \& Parker, V. (2006). Extrinsic and intrinsic work values: Their impact on job satisfaction in nursing. Journal of Nursing Management, 14(4), 271-281.

Hoffman, A. J., \& Scott, L.D. (2003). Role stress and career satisfaction among registered nurses by work shift patterns. Journal of Nursing Administration, 33(6), 337-342.

Hwang, J., Lou, F., Han, S. S., Cao, F., Kim, W. O., \& Li, P. (2009). Professionalism: The major factor influencing job satisfaction among Korean and Chinese nurses. International Nursing Review, 56(3), 313-318.

International Council of Nurses. (2004). The global shortage of registered nurses: An 
overview of issues and actions. Retrieved from http://www.icn.ch/global/shortage.pdf

Jackson-Malik, P. J. (2005). Organizational climate and hospital nurses' job satisfaction, burnout, and intent to leave. $\mathrm{PhD}$ thesis, University of Pennsylvania, Philadelphia, PA.

James, L. P. (2001). Reflection on the determinants of voluntary turnover. International Journal of Manpower, 22(7/8), 600.

Johnson, B., \& Christensen, L. B. (2008). Educational research: Quantitative, qualitative, and mixed approaches $\left(3^{\text {rd }}\right.$ ed.). Los Angeles: Sage Publications.

Johnson, R. B., \& Onwuegbuzie, A. J. (2004). Mixed methods research: A research paradigm whose time has come. Educational Researcher, 33(7), 14-26.

Jones, T. L. (2011). Effects of motivating and hygiene factors on job satisfaction among school nurses. PhD thesis, Walden University, Minneapolis, MN.

Joyce, J., \& P. Crookes. (2007). Developing a tool to measure 'magnetism' in Australian nursing environments. Australian Journal of Advanced Nursing, 25(1), 17-23.

Jradi, H., Zaidan, A., \& Shehri, A. M. A. (2013). Public health nursing education in Saudi Arabia. Journal of Infection and Public Health, 6(2), 63-68.

Kacel, B., Miller, M., \& Norris, D. (2005). Measurement of nurse practitioner job satisfaction in a Midwestern state. Journal of the American Academy of Nurse Practitioners, 17, 27-32.

Karasek, R. A. (1979). Job demands, job decision latitude and mental strain: Implications for job redesign. Administrative Science Quarterly, 24, 284-306.

Kasule, O. H. (2003). Historical roots of the nursing profession in Islam. Retrieved from www.iiu.edu.my/medic/islmed/Lecmed/rufaid98.nov.html 
Kavanaugh, J., Duffy, J. A., \& Lilly, J. (2006). The relationship between job satisfaction and demographic variables for healthcare professionals. Management Research News, 29, 304-325.

Khani, A., Jaafarpour, M., \& Dyrekvandmogadam, A. (2008). Quality of nursing work life. Journal of Clinical and Diagnostic Research, 2, 1169-1174.

Khowaja, K., Merchant, R., \& Hirani, D. (2005). Registered nurses' perception of work satisfaction at a tertiary care university hospital. Journal of Nursing Management, 13(1), 32-39.

Kleinman, C. (2004). The relationship between managerial leadership behaviours and staff nurse retention. Hospital Topics, 82(4), 2-9.

Kovner, C., Brewer, C., Wu, Y.-W., Cheng, Y., \& Suzuki, M. (2006). Factors associated with work satisfaction of registered nurses. Journal of Nursing Scholarship, 38(1), 71-79.

Kramer, M., \& Hafner, L. P. (1989). Shared values: Impact on staff nurse job satisfaction and perceived productivity. Nursing Research, 38(3), 172-177.

Larrabee, J. H., Janney, M. A., Ostrow, C. L., Withrow, M. L., Hobbs, G. R., Jr., \& Burant, C. (2003). Predicting registered nurse job satisfaction and intent to leave. Journal of Nursing Administration, 33(5), 271-283.

Lawrence, P., \& Rozmus, C. (2001). Culturally sensitive care of the Muslim patient. Journal of Transcultural Nursing, 12(3), 228-233.

Lephalala, R. (2006). Factors influencing nursing turnover in selected private hospitals in England. Master's thesis, University of South Africa, Pretoria, South Africa.

Letvak, S., \& Buck, R. (2008). Factors influencing work productivity and intent to stay in nursing. Nursing Economics, 26(3), 159-165.

Longo, J. (2007). Factors affecting registered nurses’ job satisfaction and intent to 
leave. PhD thesis, Florida Atlantic University, Boca Raton, FL.

Lovering, S. (2008). Arab Muslim nurses' experiences of the meaning of caring. $\mathrm{PhD}$ thesis, University of Sydney, Sydney, Australia.

Lu, H., While, A. E., \& Barriball, L. K. (2005). Job satisfaction among nurses: A literature review. International Journal of Nursing Studies, 42(2), 211-227.

Lu, K. Y., Lin, P. L., Wu, C. M., Hsieh, Y. L., \& Chang, Y. Y. (2002). The relationship among turnover intentions, professional commitment, and job satisfaction of hospital nurses. Journal of Professional Nursing, 18, 214-219.

Lynn, M. R., \& Redman, R. W. (2005). Faces of the nursing shortage: Influences on staff nurses' intentions to leave their positions or nursing. Journal of Nursing Administration, 35(5), 264-270.

Ma, C.-C., Samuels, M. E., \& Alexander, J. W. (2003). Factors that influence nurses' job satisfaction. Journal of Nursing Administration, 33, 293-299.

Ma, C.-C. (2002). Factors that influence job satisfaction of nurses in South Carolina hospitals. PhD thesis, University of South Carolina, Columbia, SC.

Ma, J., Lee, P., Yang, Y., \& Chang, W. (2009). Predicting factors related to nurses' intention to leave, job satisfaction, and perception of quality of care in acute care hospitals. Nursing Economics, 27(3), 178.

Maaet, M. (2011). Health recognises the huge project to develop and expand the powers of departments of nursing in the Kingdom. Alriyadh Newspaper (15578).

Mansfield, P. K., Yu, L. C., McCool, W., Vicary, J. R. \& Packard, J. S. (1989). The job context index: A guide for improving the 'fit' between nurses and their work environment. Journal of Advanced Nursing, 14, 501-508.

Maslow, A. H. (1954). Motivation and personality. New York: Harper \& Row.

Mathews, I. (2009). Social work and spirituality. Exeter, UK: Learning Matters. 
McGlynn, K., Griffin, M. Q., Donahue, M., \& Fitzpatrick, J. J. (2012). Registered nurse job satisfaction and satisfaction with the professional practice model. Journal of Nursing Management, 20(2), 260-265.

Mebrouk, J. (2008). Perception of nursing care: Views of Saudi Arabian female nurses. Contemporary Nurse, 28(1/2), 149.

Mertens, D. M. (2005). Research and evaluation in education and psychology: Integrating diversity with quantitative, qualitative, and mixed methods (2nd ed.). Thousand Oaks, CA: Sage.

Mertens, D. (2010). Research and evaluation in education and psychology: Integrating diversity with quantitative, qualitative and mixed methods $\left(3^{\mathrm{rd}} \mathrm{ed}.\right)$. Thousand Oaks, CA: Sage.

Michal, E. M. B., Jan, A. N., \& Amy, L. (2001). Antecedents to retention and turnover among child welfare, social work, and other human service employees: What can we learn from past research? A review and meta-analysis. The Social Service Review, 75(4), 625.

Miller, P. E. (2007). The relationship between job satisfaction and intention to leave: A study of hospice nurses in a for-profit corporation. $\mathrm{PhD}$ thesis, Capella University, Minneapolis, MN.

Miller-Rosser, K., Chapman, Y., \& Francis, K. (2006). Historical, cultural, and contemporary influences on the status of women in nursing in Saudi Arabia. Online Journal of Issues in Nursing, 11(3).

Miller-Rosser, K., Chapman, Y., \& Francis, K. (2009). The use of oral testimony when reconstructing nursing history. A Saudi Arabian experience. Singapore Nursing Journal, 36(1), 23.

Minichiello, V., Aroni, R., \& Hays, T. (2008). In-depth interviewing: Principles, 
techniques, analysis ( $3^{\text {rd }}$ ed.). Sydney: Pearson Education Australia.

Mitchell, J. (2009). Job satisfaction and burnout among foreign-trained nurses in Saudi Arabia: A mixed-method study. PhD thesis, University of Phoenix, Phoenix, AZ.

Ministry of Civil Services (MoCS). (2010). Health professionals' guide. Retrieved from http://www.mcs.gov.sa/InformationCenter/ArchivingLibrary/Regulations/Regul atio

Ministry of Education. (MoE). (2002). مر اكز مصادر التعلم [Learning resource centres (LRCs) in Saudi Arabia]. Riyadh, Saudi Arabia: The Ministry of Education Press.

Ministry of Health (MoH). (2011). Statistics book of the Ministry of Health, Kingdom of Saudi Arabia. Retrieved from http://www.moh.gov.sa/en/Ministry/Statistics/book/Pages/default.aspx Ministry of Higher Education (MoHE). (2010). Higher education in numbers and figures $\left(2^{\text {nd }}\right.$ ed.). Riyadh: Ministry of Higher Education.

Ministry of Petroleum and Mineral Resources. (2006, May 2009). Saudi oil. Retrieved from http://www.mopm.gov.sa/mopm/detail.do?content=history_oil_and_gas

Mrayyan, M. T. (2005). Nurse job satisfaction and retention: Comparing public to private hospitals in Jordan. Journal of Nursing Management, 13, 40-50.

Mufti, M. H. (2000). Healthcare development strategies in the kingdom of Saudi Arabia. New York: Springer.

Nahm, H. (1940). Job satisfaction in nursing. American Journal of Nursing, 40(12), 1389-1392.

Nissly, J. A. (2004). Prospective and retrospective examinations of factors related to intention to leave and turnover among public child welfare workers. $\mathrm{PhD}$ thesis, 
University of Southern California, Los Angeles, CA.

O’Cathain, A. A., Murphy, E. E., \& Nicholl, J. J. (2007). Why, and how, mixed methods research is undertaken in health services research in England: A mixed methods study. BMC Health Services Research, 7, 85-85.

Omer, T. Y. (2005). Leadership style of nurse managers at the Saudi National Guard hospitals. PhD thesis, George Mason University, Fairfax, VA.

Oulton, J. A. (2006). The global nursing shortage: An overview of issues and actions. Policy, Politics, \& Nursing Practice, 7(3), 34S-39S.

Pallant, J. F. (2011). SPSS survival manual: A step-by-step guide to data analysis using SPSS programme $\left(4^{\text {th }}\right.$ ed). Sydney: Allen \& Unwin.

Peterson, J. (2009). Job stress, job satisfaction and intention to leave among new nurses. $\mathrm{PhD}$ thesis, University of Toronto, Toronto, Canada.

Polit, D. F., \& Beck, C. T. (2004). Nursing research: Principles and methods $\left(7^{\text {th }} \mathrm{ed}\right.$.). Philadelphia: Lippincott Williams \& Wilkins.

Price, M. (2002). Professional issues. Job satisfaction of registered nurses working in an acute hospital. British Journal of Nursing, 11(4), 275-280.

Ramady, M (2010). The Saudi Arabian economy: Policies, achievements, and challenges. New York: Springer.

Rambur, B., Mclntosh, B., Palumbo, M. V., \& Reinier, K. (2005). Education as a determinant of career retention and job satisfaction among registered nurses. Journal of Nursing Scholarship, 37(2), 185-192.

Rambur, B., Palumbo, M. V., McIntosh, B., \& Mongeon, J. (2003). A statewide analysis of RNs' intention to leave their position. Nursing Outlook, 51(4), 182188.

Robbins, S. P., Judge, T. A., Millett, B., \& Waters-Marsh, T. (2008). Organisational 
behaviour $\left(5^{\text {th }}\right.$ ed.). Sydney: Pearson Education Australia.

Royal Embassy of Saudi Arabia (USA). (2013). About Saudi Arabia. Retrieved from http://www.saudiembassy.net/about/countryinformation/map_of_provinces.aspx

Ruggiero, J. S. (2005). Health, work variables, and job satisfaction among nurses. Journal of Nursing Administration, 35(5), 254-263.

Russell, C. R. N. P., \& Gelder, F. R. B. E. (2008). An international perspective: Job satisfaction among transplant nurses. Progress in Transplantation, 18(1), 32.

Ruthankoon, R., \& Ogunlana, S. O. (2003). Testing Herzberg's two-factor theory in the Thai construction industry. Engineering, Construction and Architectural Management, 10(5), 333-341.

Ryan, F., Coughlan, M., \& Cronin, P. (2009). Interviewing in qualitative research: The one-to-one interview. International Journal of Therapy \& Rehabilitation, 16(6), $309-314$.

Seo, Y., Ko, J., \& Price, J. L. (2004). The determinants of job satisfaction among hospital nurses: A model estimation in Korea. International Journal of Nursing Studies, 41(4), 437-446.

Shader, K., Broome, M. E., Broome, C. D., West, M. E., \& Nash, M. (2001). Factors influencing satisfaction and anticipated turnover for nurses in an academic medical centre. Journal of Nursing Administration, 31(4), 210-216.

Shah, M. A., Al-Enezi, N., Chowdhury, R. I., \& Otaibi, M. (2004). Determinant of job satisfaction among nurses in Kuwait. Australian Journal of Advanced Nursing, $21,10-16$.

Shaver, K. H., \& Lacey, L. M. (2003), Job and career satisfaction among staff nurses. Journal of Nursing Administration, 33(3), 166-172. 
Sims, C.E. (2003). Increasing clinical, satisfaction, and financial performance through nurse-driven process improvement. Journal of Nursing Administration, 33 (2), $68-75$.

Skinner, V., Madison, J., \& Humphries, J. H. (2012). Job satisfaction of Australian nurses and midwives: A descriptive research study. Australian Journal of Advanced Nursing (Online), 29(4), 19-27.

Sochalski, J. (2002). Nursing shortage redux: Turning the corner on an enduring problem. Health Affairs, 21(5), 157-164.

Sullivan-Havens, D., \& Johnston, M. A. (2004). Achieving Magnet hospital recognition. Journal of Nursing Administration, 34, 579-588.

Smith, P. C., Kendall, L. M., \& Hulin, C. L. (1969). The measurement of satisfaction in working and retirement. Chicago: Rand McNally.

Stello, C. M. (2011). Herzberg's two-factor theory of job satisfaction: An integrative literature review. Journal of Education and Human Development, 1-32.

Takase, M., Maude, P., \& Manias, E. (2006). Impact of the perceived public image of nursing on nurses' work behaviour. Journal of Advanced Nursing, 53(3), 333343.

Tashakkori, A., \& Teddlie, C. (1998). Mixed methodology: Combining qualitative and quantitative approaches. London: Sage.

Timmreck, T. C. (2001). Managing motivation and developing job satisfaction in the healthcare work environment. Healthcare Manager, 20(1), 42-58.

Tourangeau, A. E., \& Cranley, L. A. (2006). Nurse intention to remain employed: Understanding and strengthening determinants. Journal of Advanced Nursing, 55(4), 497-509.

Tourangeau, A. E., McGillis Hall, L., Doran, D. M., \& Petch, T. (2006). Measurement 
of nurse job satisfaction using the McCloskey/Muller Satisfaction Scale. Nursing Research, 55(2), 129-136.

Tumulty, G. (2001). Professional development of nursing in Saudi Arabia. Journal of Nursing Scholarship, 33(3), 285-290.

Unruh, L. Y. (2005). Employment conditions at the bedside: A cause of and solution to the RN shortage. Journal of Nursing Administration, 35, 11-14.

Vroom, V. H. (1964). Work and motivation. New York: John Wiley \& Sons.

Wagner, C. M., \& Huber, D. L. (2003). Catastrophe and nursing turnover: Nonlinear models. Journal of Nursing Administration, 33(9), 486-492.

Wilson, C. (2006). Why stay in nursing? Nursing Management, 12(9), 24-32.

World Health Organization (WHO). (2002a). The World Health Report 2000. Health systems: Improving performance. Geneva: World Health Organization.

World Health Organization (WHO). (2002b). Strategic directions for strengthening nursing and midwifery services. Retrieved from http://whqlibdoc.who.int/publications/2002/924156217X.pdf

Yau, S., Xiao, X., Lee, L., Tsang, A., Wong, S., Wong, K., (2012). Job stress among nurses in China. Applied Nursing Research 25, 60-64.

Yin, J. T., Yang, K. A., 2002. Nursing turnover in Taiwan: A meta-analysis of related factors. International Journal of Nursing Studies, 39 (6), 573-581.

Zaghloul, A. A., Al-Hussaini, M. F., \& Al-Bassam, N. K. (2008). Intention to stay and nurses' satisfaction dimensions. Multidisciplinary Healthcare, 1, 51-58.

Zangaro, G. A., \& Johantgen, M. (2009). Registered nurses' job satisfaction in navy hospitals. Military Medicine, 174(1), 76.

Zurn, P., Dal Poz, M. R., Stillwell, B., Adams, O. (2004). Imbalance in the health workforce. Human Resources for Health 2, 13. 


\section{Appendix A: The Study Advertisement Letters}

\section{To all Saudi nurses,}

I am a PhD student at the RMIT University, Australia. I am conducting a research study entitled

\section{JOB SATISFACTION OF SAUDI NURSES WORKING IN SAUDI ARABIAN PUBLIC HOSPITALS}

The purpose of this study is to identify and explore the factors that influence the level of job satisfaction of Saudi nurses working in public hospitals in the Makkah region.

Your participation will help me to identify the factors that affect job satisfaction of Saudi nurses. Please respond to the questionnaire and the invitation for a face to face interview placed in your mail boxes. Your participation is greatly appreciated.

Sincerely,

Mohammed Alshmemri 


\section{Appendix B: Plain Language Statement}

• RMIT

\section{School of Health Sciences, Nursing and Midwifery}

GPO Box 71

Bundoora VIC 3083

Australia

Ph: +61399257447

Fax: +61394675286

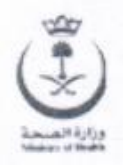

Project Title:

Job Satisfaction of Saudi Nurses Working in Saudi Arabian Public Hospitals.

\section{Investigator:}

Investigator: Sciences, RMIT University, \$3201930@student.rmit.edu.au

\section{Supervisors:}

- Associate Professor Lina Shahwan-Akl PhD, School of Health Sciences, RMIT University, lina.shahwan-akl@rmit,edu.au Phone: 99

- Associate Professor Phillip Maude, PhD, School of Health Sciences, RMIT University, Phillip.Maude@rmit,edu.au Phone: 99

\section{Dear participant,}

You are invited to participate in a research project being conducted by RMIT University. This information sheet describes the project in straightforward lanivers sheet carefully and be confident that you understand its contents before deciding whether to participate or not. If you have any questions about the project, please contact the investigator.

Who is involved in this research project? Why is it being conducted?

This research is being conducted by Mohammed Alshmemri as part of studies for the award of a PhD in the Discipline of Nursing and Midwifery, RMIT University.

Why have you been approached?

You have been invited to respond to a survey questionnaire in order to assist in understanding the factors that highy affect job satisfaction, recruitment and retention of Saudi Arabian nurses. You factors that highly affect jo force interview by personally cont the researcher through email. Your participation in both the survey and the face to face interview is completely voluntary and would be greatly appreciated.

What is the project about? What are the questions being addressed?

The aim of the study is to examine and identify the factors that Saudi nurses perceive to be most in the Saudi nursing workforce. It is envisaged that around 300 Saudi registered nurses will be invited to participate in the questionnaire. From the total population, the first 35 participants who contact to participate in the questionnaire. From the total population,
the researcher and sign the consent form will be interviewed. 
If I agree to participate, what will I be required to do?
After reviewing and understanding this plain language statement you will be asked to complete a survey which will take 15-30 minutes to complete. Completing the survey will imply your consent to participate, you will be requested to return the completed survey to a box labeled "Job Satisfaction" that will be placed in the Nursing Department of your hospital.

If you wish to participate in the face to face interview that will be voice recorded you will be required to sign a consent form. The face to face interview will take around 30-45 minutes.

What are the risks or disadvantages associated with participation?

There are no risks associated with your participation in this research project. All responses will remain confidential, be reported as group data and will have no influence on your employment.

\section{What are the benefits associated with participation?}

It is hoped that this research wili provide further understanding of the factors and issues that influence Saudis to study and work in the Discipline of Nursing. It will identify the most important factors that influence job satisfaction that will assist in the recruitment and retention of Saud nurses in public hospitals.

\section{What will happen to the information I provide?}

All inform All information gathered as part of this research wata can only be accessed by the researcher and supervisors. After 5 years, the data will be destroyed. The data collected will be analysed and the results may be published in academic journals or conferences without including any personal results may be potial to identify either you or your health agency.

\section{What are my rights as a participant?}

participant, you have the right to withdraw your participation at any time; have any unprocessed data withdrawn and destroyed, provided it can be reliably identified, and provided that so doing does not increase your risk; and have any questions answered at any time.

Due to the nature of this data collection process, I am not obtaining written informed consent unless you elect to be interviewed.

Whom should I contact if I have any questions?

please contact the researcher s3201930@ (1) rmit.edu.au and Phillip.Maude@rmit,edu.au.

You may also contact the following person in Saudi Arabia should you have any concerns about this research:

General Directorate of Nursing, Ministry of Health Saudi Arabia

Muneera Bint Hamdan Al-Osaimy (General Director) Phone +96

$+9661$

Email:

tmail.com

Yours Sincerely

Mohammed Alshmemri

PhD candidate

s3201930@student.rmit.edu.au

Any complaints about your participation in this project may be directed to the Executive Officer, RMIT Human

作

Research Ethics Committee, Research \& innovation, RModure will also be available from this

number is 


\section{Appendix C: Semi-Structured Interview Invitation Letter}

Face to Face Interview Invitation دعوة للمقابلة وجها لوجهه

I would like to conduct some follow up interviews.

Please contact me via E-mail if you would like to be included in this interview.

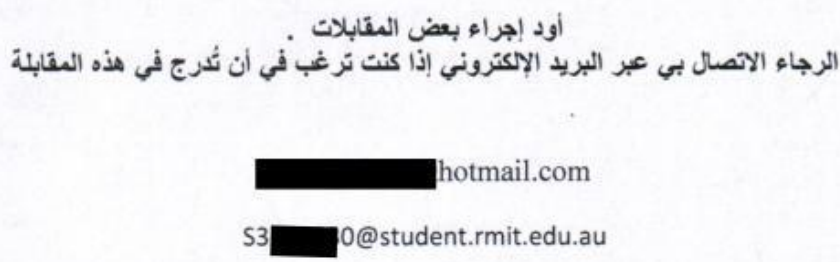

Thank you for your participation in this research project

شكر المثار كتكم في هذا المشروع البحئي 


\title{
Appendix D: Demographic Survey
}

\author{
JOB SATISFACTION \\ RESEARCH SURVEY
}

Please respond to the questions below by ticking one appropriate circle $(\sqrt{ })$

1. What is your gender? (Please $\sqrt{ }$ one)

Male

Female

2. What is your age? (Please $\sqrt{ }$ one)

Less than 25 years

25-35 years

$\bigcirc 3$ years and over

3. Marital status is

Single

Married

Divorced or Widowed

4. Please indicate how many dependent Children do you have

5. Please indicate the number of dependent adults in your care

6. What is your highest nursing education? (please $\sqrt{ }$ one)

Diploma

Bachelor's Degree and Post-graduate degrees 
7. What is your salary range per month? (please $\sqrt{ }$ one)

SR $1,500-5,000(400-1,333$ US \$)

SR $5,001-10,000(1,334-2,666$ US \$)

SR $10,001-15,000(2,667-4,000$ US $\$)$

$\geq$ SR $15,001(4,000$ US \$)

8. Please write the name of the hospital you are working in.

9. What is your current position (please $\sqrt{ }$ one)

Staff nurse

Head nurse

Nursing manger (Supervisor, Deputy and Chief Nursing)

Other, please indicate (Nursing Education and Quality Control nurses)

10. How many hours do you work in a week?

Less than 50 hours

50 hours and more

11. How long have you worked in this hospital?
Less than 5 years
5-10 years
More than 10 years

12. How long have you worked as nurse? (please $\sqrt{ }$ one)

Less than 4 year

4-10 years

More than 10 years. 


\section{Appendix E: NWI Revised Questionnaire (English and}

\section{Arabic)}

Please indicate the extent to which you agree that the following items are present in your current job by circling the number corresponding to your response.

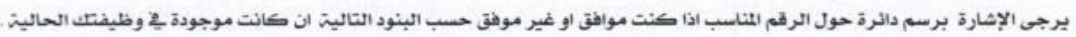

\begin{tabular}{|c|c|c|c|c|c|}
\hline & PRESENT IN CURRENT JOB & 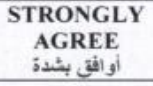 & $\begin{array}{c}\text { AGREE } \\
\text { إli }\end{array}$ & $\begin{array}{c}\text { DISAGREE } \\
\text { لا لأو }\end{array}$ & 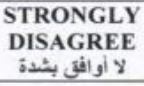 \\
\hline 1 & $\begin{array}{l}\text { Adequate support services allow me to spend time with my } \\
\text { patients. }\end{array}$ & 1 & 2 & 3 & 4 \\
\hline 2 & 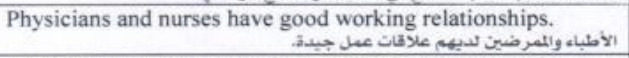 & 1 & 2 & 3 & 4 \\
\hline 3 & 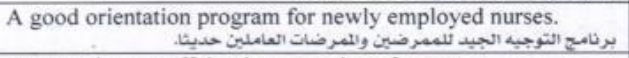 & 1 & 2 & 3 & 4 \\
\hline 4 & 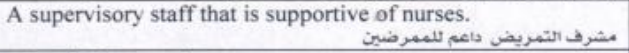 & 1 & 2 & 3 & 4 \\
\hline 5 & A satisfactory salary. & 1 & 2 & 3 & 4 \\
\hline 6 & Nursing control its own practice. مكم التهريض بتدريب خاصن & 1 & 2 & 3 & 4 \\
\hline 7 & Active in service/continuing education programs for nurses. & 1 & 2 & 3 & 4 \\
\hline 8 & التطوير الوطبي / فرصت للقيادة السريريت & 1 & 2 & 3 & 4 \\
\hline 9 & Opportunity for staff nurses to participate in policy decisions. & 1 & 2 & 3 & 4 \\
\hline 10 & 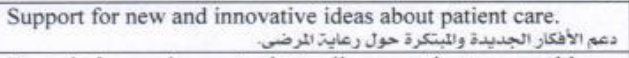 & 1 & 2 & 3 & 4 \\
\hline 11 & 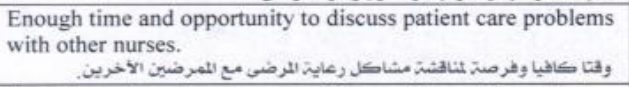 & 1 & 2 & 3 & 4 \\
\hline 12 & 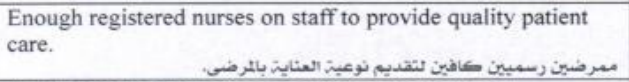 & 1 & 2 & 3 & 4 \\
\hline 13 & 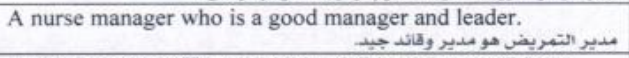 & 1 & 2 & 3 & 4 \\
\hline 14 & $\begin{array}{l}\text { A chief nursing officer is highly visible and accessible to } \\
\text { staff. }\end{array}$ & 1 & 2 & 3 & 4 \\
\hline 15 & 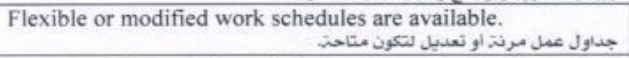 & 1 & 2 & 3 & 4 \\
\hline 16 & Enough staff to get the work done. & 1 & 2 & 3 & 4 \\
\hline 17 & 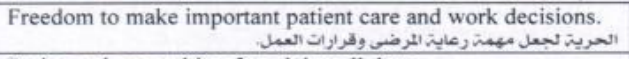 & 1 & 2 & 3 & 4 \\
\hline 18 & 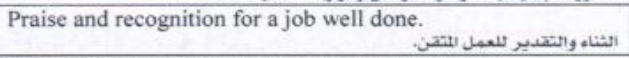 & 1 & 2 & 3 & 4 \\
\hline 19 & 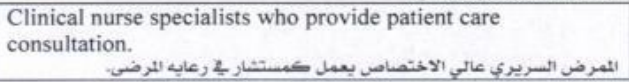 & 1 & 2 & 3 & 4 \\
\hline 20 & 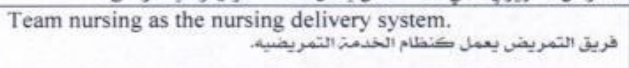 & 1 & 2 & 3 & 4 \\
\hline 21 & 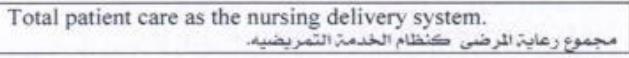 & 1 & 2 & 3 & 4 \\
\hline
\end{tabular}




\begin{tabular}{|c|c|c|c|c|c|}
\hline 43 & $\begin{array}{l}\text { The contributions that nurses make to patient care are } \\
\text { publicly acknowledged. }\end{array}$ & 1 & 2 & 3 & 4 \\
\hline 44 & $\begin{array}{l}\text { Nurse managers consult with staff on daily problems and } \\
\text { procedures. }\end{array}$ & 1 & 2 & 3 & 4 \\
\hline 45 & $\begin{array}{l}\text { The work environment is pleasant, attractive, and } \\
\text { comfortable. }\end{array}$ & 1 & 2 & 3 & 4 \\
\hline 46 & 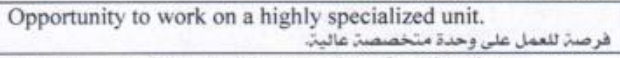 & 1 & 2 & 3 & 4 \\
\hline 47 & 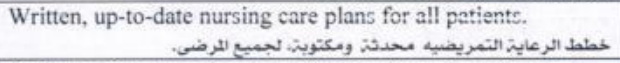 & 1 & 2 & 3 & 4 \\
\hline 48 & 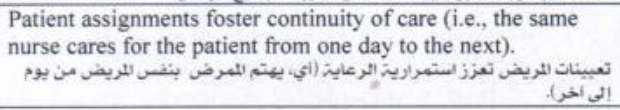 & 1 & 2 & 3 & 4 \\
\hline 49 & $\begin{array}{l}\text { Regular, permanently assigned staff nurses never have to } \\
\text { float to another unit. }\end{array}$ & 1 & 2 & 3 & 4 \\
\hline 50 & 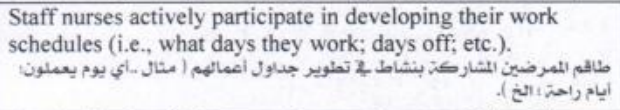 & 1 & 2 & 3 & 4 \\
\hline 51 & 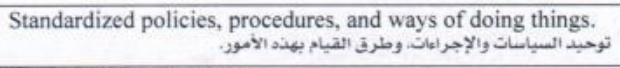 & 1 & 2 & 3 & 4 \\
\hline 52 & Use of nursing diagnoses. & 1 & 2 & 3 & 4 \\
\hline 53 & 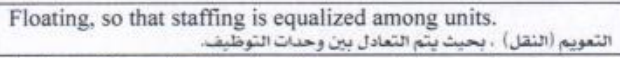 & 1 & 2 & 3 & 4 \\
\hline 54 & 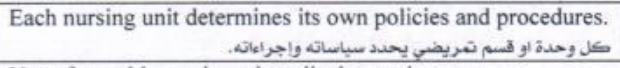 & 1 & 2 & 3 & 4 \\
\hline 55 & 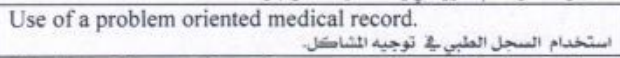 & 1 & 2 & 3 & 4 \\
\hline 56 & Working with experienced nurses who "know" the hospital. & 1 & 2 & 3 & 4 \\
\hline 57 & $\begin{array}{l}\text { Nursing care plans are verbally transmitted from nurse to } \\
\text { nurse. }\end{array}$ & 1 & 2 & 3 & 4 \\
\hline
\end{tabular}

Source: Aiken, L. H., \& Patrician, P. A. (2000). Measuring organizational traits of hospitals: The revised nursing work index. Nursing Research, 49(3), 146-153. 


\section{Appendix F: Questions for Semi-structured Interviews}

\section{FACE TO FACE INTERVIEWS}

مقابلات وجها لوجهه

1. Who influenced your decision and encouraged to study nursing?

من له الثأثير في قرارثك وشجعك لدر اسة التمريض؟

2. What factors motivate you to continue working as a nurse?

ما هي الحوافز التئي دفعتك لمواصلة عملك كمرض؟

3. What are the reasons that would stop you from working as a nurse?

ماهي الأسباب التي تجعلك تحجم عن عملك كمرض؟

4. What do you perceive your future goals to be in your nursing career?

ما تصور أهدافك في المستقبل ليكون في مهنة تصريضك؟

5. What factors do you perceive will improve the public image of nurses in Saudi Arabia?

ما هي العوامل في تصوركم من شأتها تحسين الصورة العامة للممرضين في المملكة العربية السعودية؟

6. What suggestions do you have to increase recruitment and retention of Saudi Arabian nurses?

ماهي الآتر احات التى لديك لزيادة التوظيف وإيقاء ممرضي المملكة العربية السعودية ؟ 


\section{Appendix G: Qualitative Data Translation}

\section{To Whom It May Concern}

I am the undersigned,

Mrs. Naira Riad,

NAATI 3 Professional English <-> Arabic Translator

NAATI No. 56135

of "TransArabica" for Arabic translation

certify that-

I have translated from Arabic into English, documents related to the results' analysis of the qualitative study, and advised on writing style of the interviews' results, of Mr. Mohammed Alshememri's Doctorate research.

If you have any queries, please do not hesitate to contact me using the above mentioned contact details.

Kind regards

Naira Riad

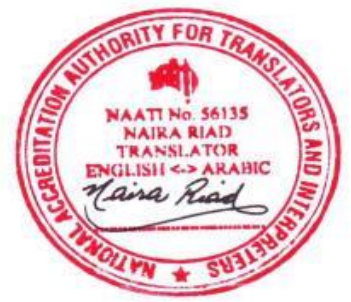




\section{Appendix H: Ethics Approval Letter (RMIT University)}

\section{DRMIT \\ UNIVERSITY}

$20^{\text {th }}$ September 2010

Mohammed Alshmemri

Unit $6 / 180$ Broadway

Reservoir VIC 3073

Dear Mohammed,

BSEHAPP 35 - 10 ALSHMEMRI Job Satisfaction of Saudi Nurses working in Saudi Arabian Public Hospitals

Thank you for submitting your amended application for review.

I am pleased to inform you that the CHEAN has approved your application for a period of 3 Years \& 3 Months to December 2013 and your research may now proceed.

The CHEAN would like to remind you that:

All data should be stored on University Network systems. These systems provide high levels of manageable security and data integrity, can provide secure remote access, are backed up on a regular basis and can provide Disaster Recover processes should a large scale incident occur. The use of portable devices such as CDs and memory sticks is valid for archiving; data transport where necessary and for some works in progress.

The authoritative copy of all current data should reside on appropriate network systems; and the Principal Investigator is responsible for the retention and storage of the original data pertaining to the project for a minimum period of five years.

Annual reports are due during December for all research projects that have been approved by the College Human Ethics Advisory Network (CHEAN).

The necessary form can be found at: http://www.rmit.edu.au/governance/committees/hrec

Yours faithfully,

Diana Donohue

Chair, Science Engineering \& Health

College Human Ethics Advisory Network 'A'

$\mathrm{Cc}$

Chair, CHEAN B:
Other Investigators:

HREC

Indu Singh, School of Medical Science

Lina Shahwan-Akl, School of Health Sciences

Phillip Maude, School of Health Sciences
Peter Burke, Executive Officer
RMIT University

Science En
and Health

College Human Ethic Advisory Network

Plenty Road
Bundoora VIC 3083

PO Box 71

Bundoora VIC 3083

Tel. +61399257096 Fax +61399256506 - www.rmit.edu.au 


\section{Appendix I: Permission letter from MoH and Medical}

\section{Research Committee, Saudi Arabia.}

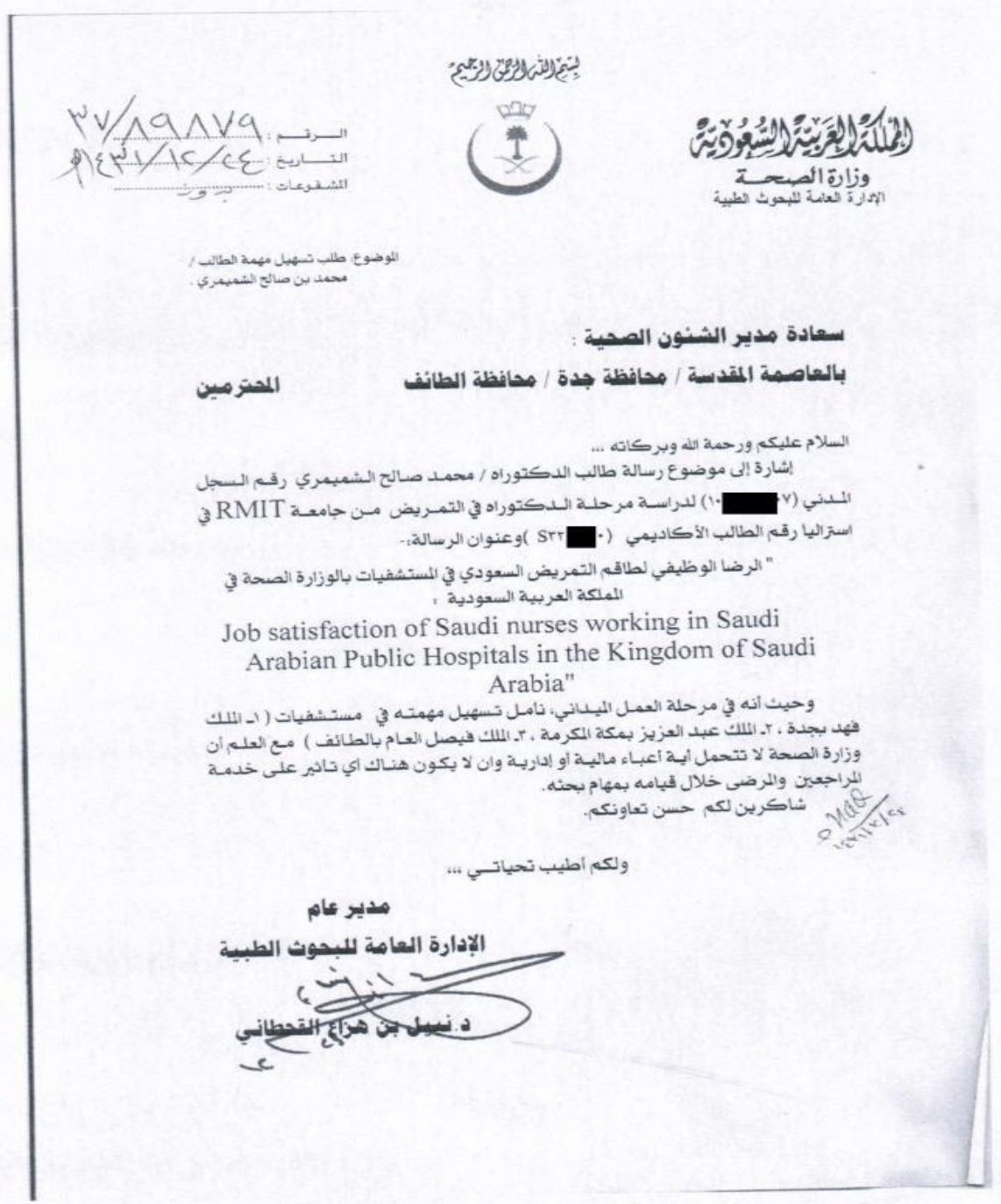




\section{Appendix J: Translation of the MoH and Medical Research}

\section{Committee Letter}

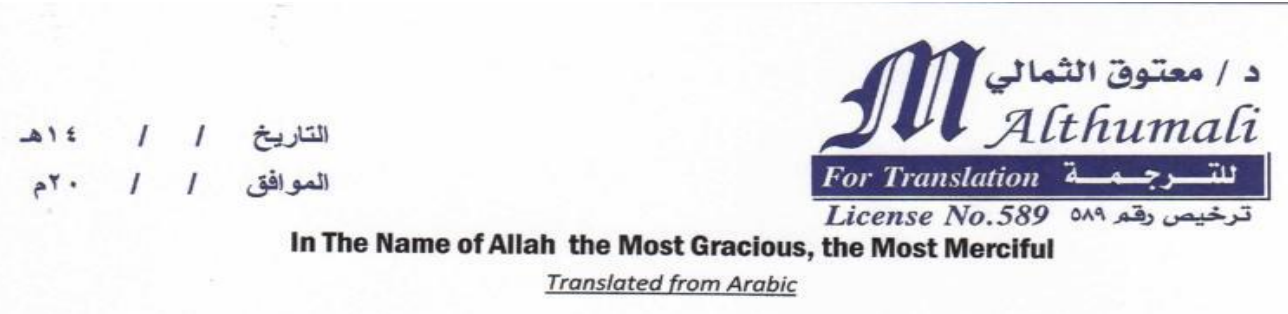

Kingdom of Saudi Arabia

No.: $89879 / 37$

Ministry of Health

Date: $24.12 .1431 H(30.11 .2010)$

General Administration of Medical Research

Attachments : none

Subject: Request to Facilitate the Task of the student Mohammed Saleh AlShmemeri

His Excellency the Director of Health Affairs

in the Holy Capital / Jeddah Governorate / Taif Governorate Respected Reference to the letter from the Doctoral Student: Mohammed Saleh AlShmemeri to study the Doctorate in Nursing at RMIT University in Australia. Student academic No.is : ( 53 O) The title of the thesis is:

Job satisfaction of Saudi nurses working in Saudi Arabian Public Hospital in the Kingdom of Saudi Arabia

Since he is at the stage of field work, we hope to facilitate his mission in Hospitals

1- King Fahd in Jeddah.

2- King Abdul Aziz in Makkah AlMukarramah.

3- King Faisal in Taif.

Note that the Ministry of Health will not tolerate any financial or administrative burdens and there is not any effect on checkers and patients services during his research... My Best Regards.

General Manager of

General Administration of Medical Research signed

Dr. Nabeel H. AlQahtani

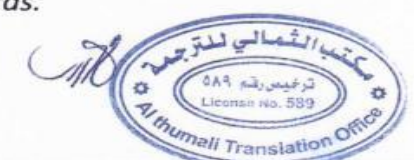

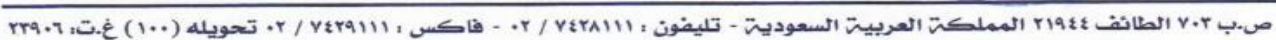
Saudi Arabia - P.O. Box 703 Taif 21944 - Tel: 02/7428111 - Fax: 02/7429111 Ext:(100) 


\section{Appendix K: Consent Form for Interviews}

\section{- RMIT}

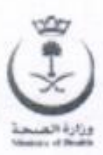

School of Health Sciences,

Nursing and Midwifery

GPO Box 71

Bundoora VIC 3083

Australia

Ph: +61 399257447

Fax: +61394675286

Prescribed Consent Form For Persons Participating In Research Projects Involving Interviews, Questionnaires or Disclosure of Personal Information

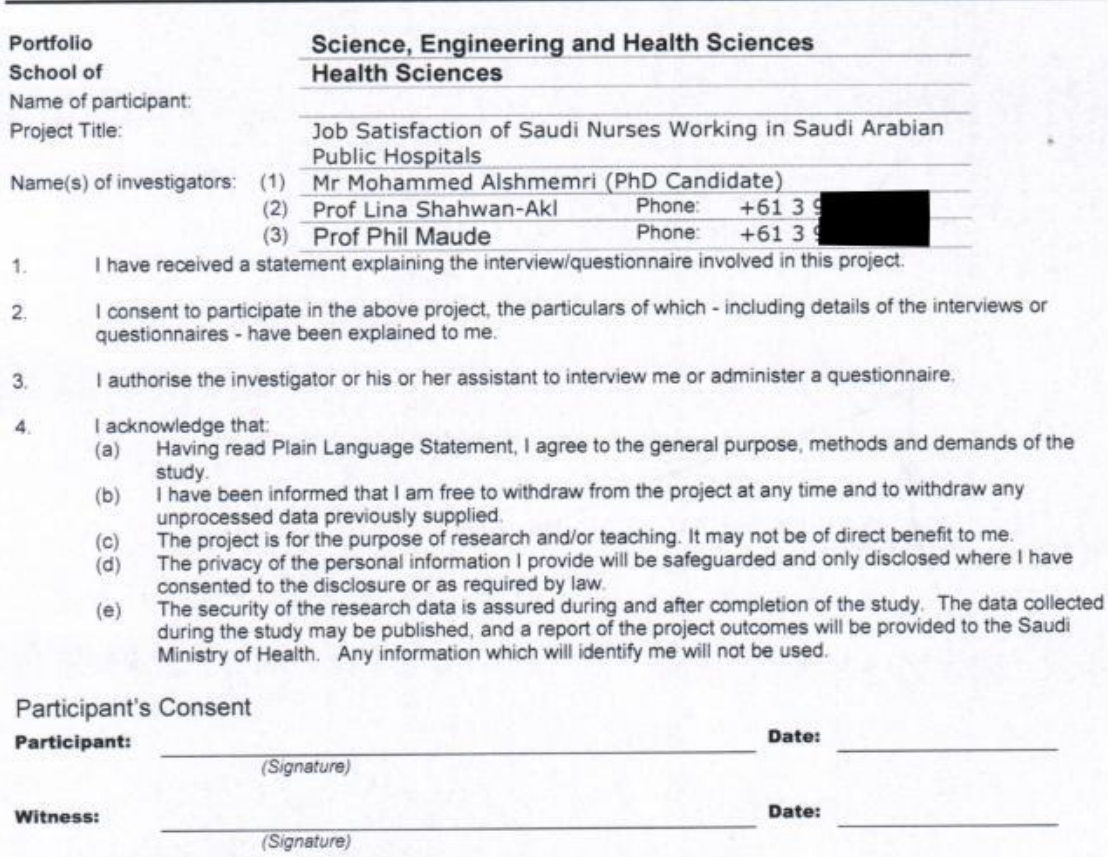

Where participant is under 18 years of age:

I consent to the participation of in the above project.

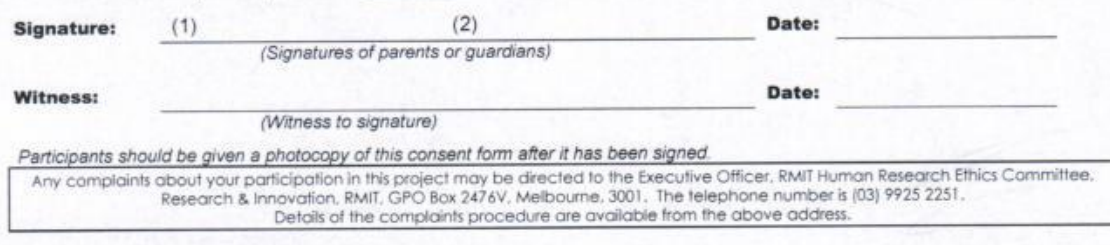

